\title{
Flow Behavior in Multilayer Deposits of Unsaturated Paste Tailings
}

\author{
By \\ Bereket Fisseha, B.Sc. Soil and Water Conservation
}

A thesis submitted to the Faculty of Graduate Studies and Research

in partial fulfillment of the requirements for the degree of

Master of Applied Science

in

Environmental Engineering*

Department of Civil and Environmental Engineering

Carleton University

Ottawa, Ontario

Canada

*The Master of Applied Science in Environmental Engineering Program is a joint program with the University of Ottawa administered by the Ottawa-Carleton Institute for Environmental Engineering 


$\begin{array}{ll}\begin{array}{l}\text { Library and } \\ \text { Archives Canada }\end{array} & \begin{array}{l}\text { Bibliothèque et } \\ \text { Archives Canada }\end{array} \\ \begin{array}{l}\text { Published Heritage } \\ \text { Branch }\end{array} & \begin{array}{l}\text { Direction du } \\ \text { Patrimoine de l'édition }\end{array} \\ \begin{array}{l}\text { 395 Wellington Street } \\ \text { Ottawa ON K1A 0N4 } \\ \text { Canada }\end{array} & \begin{array}{l}\text { 395, rue Wellington } \\ \text { Ottawa ON K1A 0N4 } \\ \text { Canada }\end{array}\end{array}$

Your file Votre référence ISBN: 978-0-494-40638-0

Our file Notre référence

ISBN: 978-0-494-40638-0

NOTICE:

The author has granted a nonexclusive license allowing Library and Archives Canada to reproduce, publish, archive, preserve, conserve, communicate to the public by telecommunication or on the Internet, loan, distribute and sell theses worldwide, for commercial or noncommercial purposes, in microform, paper, electronic and/or any other formats.

The author retains copyright ownership and moral rights in this thesis. Neither the thesis nor substantial extracts from it may be printed or otherwise reproduced without the author's permission.
AVIS:

L'auteur a accordé une licence non exclusive permettant à la Bibliothèque et Archives Canada de reproduire, publier, archiver, sauvegarder, conserver, transmettre au public par télécommunication ou par l'Internet, prêter, distribuer et vendre des thèses partout dans le monde, à des fins commerciales ou autres, sur support microforme, papier, électronique et/ou autres formats.

L'auteur conserve la propriété du droit d'auteur et des droits moraux qui protège cette thèse. $\mathrm{Ni}$ la thèse ni des extraits substantiels de celle-ci ne doivent être imprimés ou autrement reproduits sans son autorisation.
In compliance with the Canadian Privacy Act some supporting forms may have been removed from this thesis.

While these forms may be included in the document page count, their removal does not represent any loss of content from the thesis.
Conformément à la loi canadienne sur la protection de la vie privée, quelques formulaires secondaires ont été enlevés de cette thèse.

Bien que ces formulaires aient inclus dans la pagination, il n'y aura aucun contenu manquant.

\section{Canada}




\section{Abstract}

Understanding the factors affecting the drying process of paste or thickened tailings deposition is important in order to accurately predict the rate of drying and optimize deposition planning. Evaporation from multilayer deposits of tailings from two different mines were studied at the laboratory using small scale and large $(1.5 \mathrm{~m}$ by $1.5 \mathrm{~m}$ in plan) scale experiments, in which wind was simulated using fans. In each case, a $100 \mathrm{~mm}$ deep layer was initially deposited and allowed a period of time to dry, subsequent to placement of another $100 \mathrm{~mm}$ layer. The effect of the earlier dried layer in facilitating the drying rate of the fresh layer, the effect of cracks, and the effect of salt precipitation on the rate of evaporation was studied. The experimental results were compared using a one dimensional unsaturated flow prediction model. The following conclusions were reached: first, the underlying layer enhances the rate of drying by soaking moisture from the fresh layer and the unsaturated flow model was able to simulate the suction profile for the interlayer interaction. Second, there was no significant change in the rate of evaporation due to cracks. Third, in the tailings from one of the mines, the accumulation of salts at the surface eventually progressed to the point where it caused a decrease in the rate of evaporation.

\footnotetext{
Also, included in this thesis are studies on the relation between the soil-water characteristic curve and grain size distribution, and on factors influencing the density achieved by desiccation.
} 


\section{Acknowledgments}

First and foremost, I would like to thank my supervisor Dr. Paul Simms. I am grateful for the opportunity he provided me and for the constant support and mentorship over the course of my project. Without his generous contributions of time, energy, and expertise, even over evenings or weekends, this thesis would never have been possible.

I would like to thank the staff of Civil and Environmental Engineering laboratory Ken McMartin, Stanley Conley, Pierre Trudel and Dr. Marie Tudoret-Chow for their assistance and technical advices.

I would like to thank and recognize my fellow graduate student Ms Rachel Bryan for her assistance and support as a work mate throughout the research. I am also grateful for the assistance I got from Julio Hendrequz, Mahmmod Altarhouni.

I would like to thank Barrick Gold and Golder Associates for funding the research.

Last but not least, I would like to thank my family and friends for their constant support, patience and encouragement. 


\section{Table of Contents}

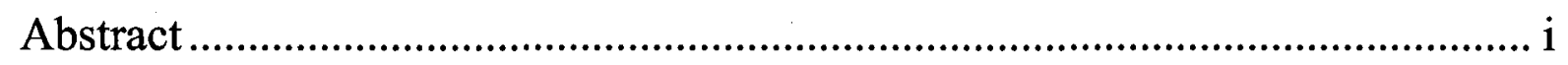

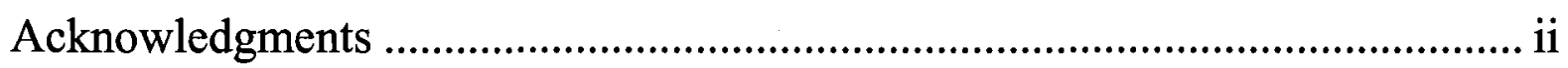

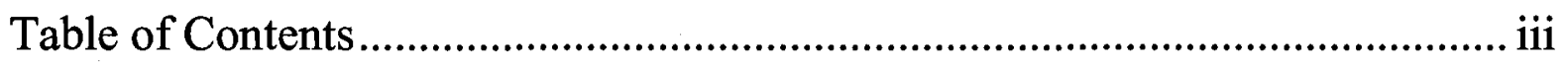

List of Figures ................................................................................. vii

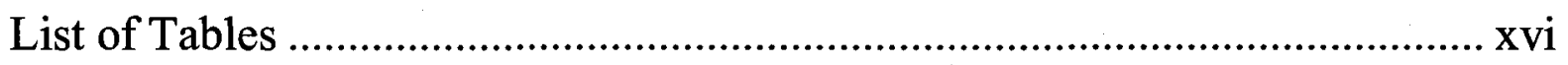

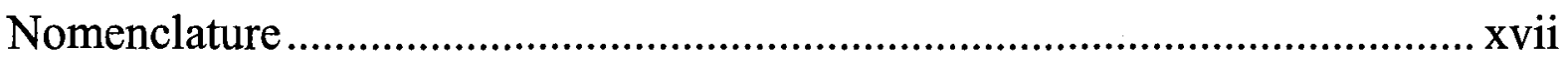

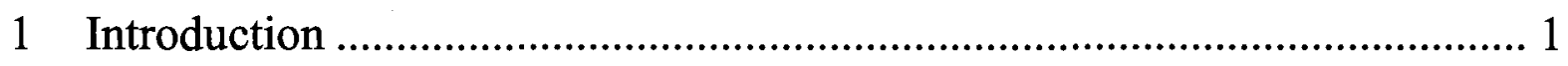

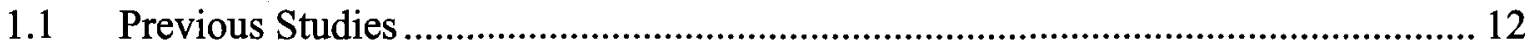

1.2 Objectives and Scope ………………………............................................. 12

1.2.1 Multilayer Unsaturated Flow and Evaporation in Laboratory Experiments.................. 13

1.2.2 Methods to Predict Soil-Water Characteristic Curve (SWCC) from Grain Size

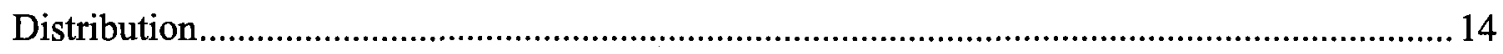

1.2.3 Determine the Factors that Influence the Final Void Ratio Obtained by Desiccation.. 15

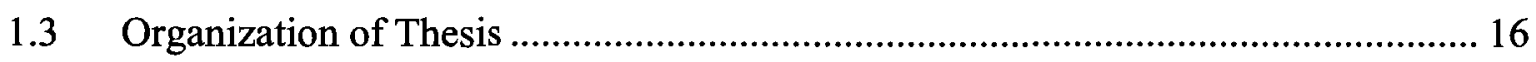

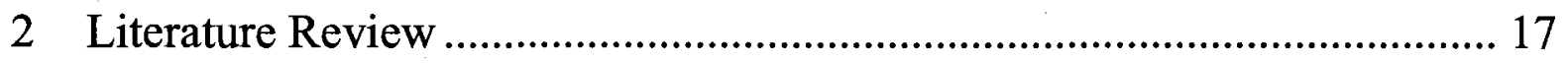

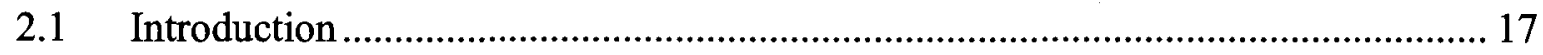

2.2 Phase Relationships........................................................................................ 18

2.3 Hydraulic Head, Soil Suction and Relative Humidity ........................................... 21

2.4 Theory of Soil-Water Characteristic Curve (SWCC) ……..................................... 25

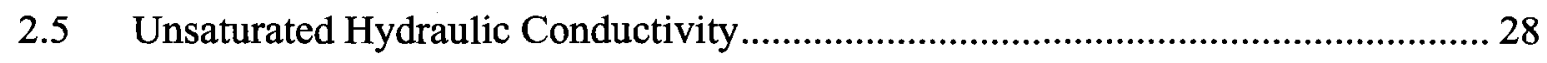

$2.6 \quad$ Liquid Flow in Unsaturated Soils..................................................................... 31

$2.7 \quad$ Vapour and Heat Transfer ............................................................................... 32 
2.8 Evaporation and Coupled Soil-Atmosphere Interaction

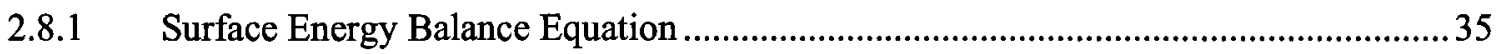

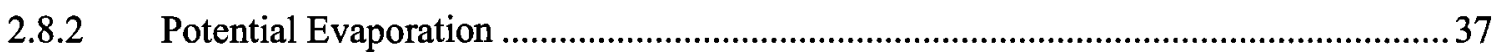

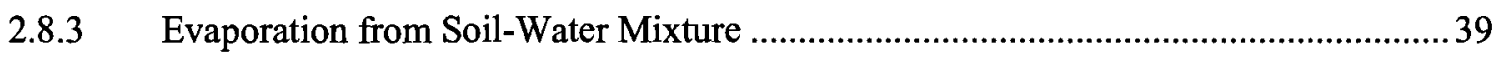

2.8.4 Modelling of Evaporation at the Soil-Water Surface .............................................. 40

2.8.5 Other Factors Affecting Evaporation from a Soil Surface or Tailings Surface............43

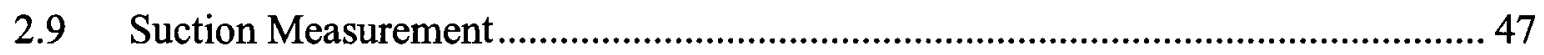

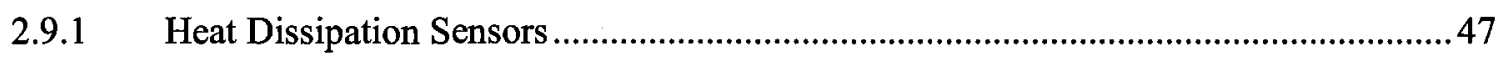

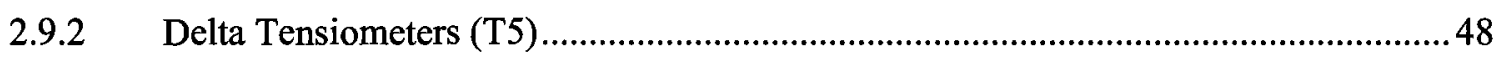

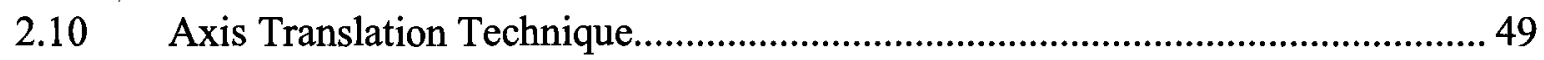

3 Materials and Methods ...........................................................................50

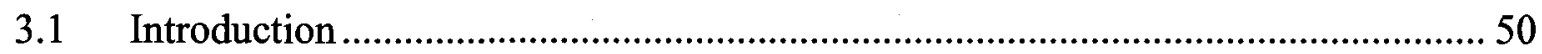

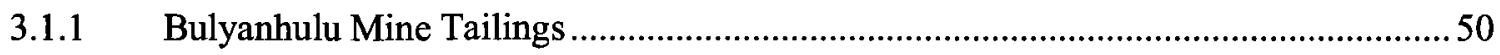

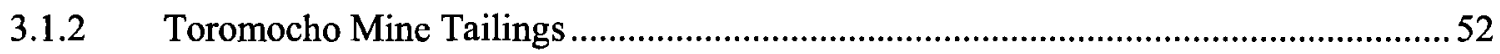

3.2 Large-Scale Experimental Setup for Bulyanhulu Tailings Drying Test ................. 54

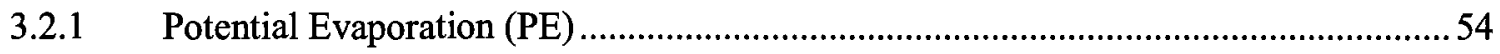

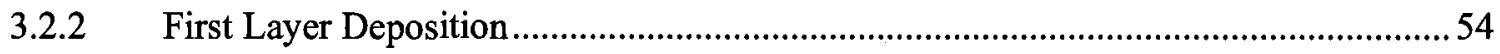

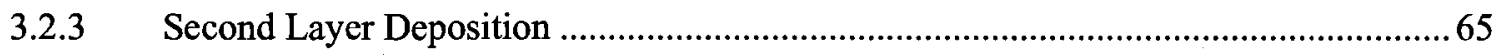

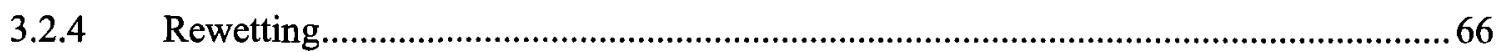

3.3 Small-Scale Experimental Setup for Bulyanhulu Tailings Drying Test ................ 66

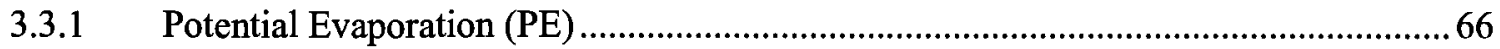

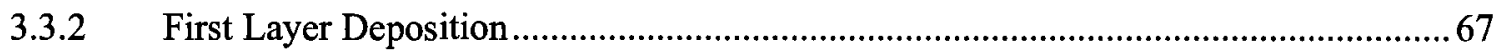

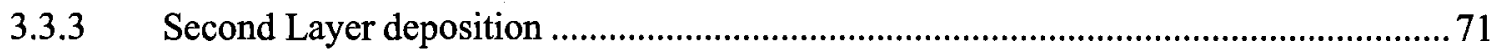

3.4 Small-Scale Experimental Setup for Toromocho Tailings Drying Test ................ 73

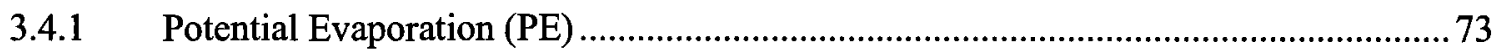




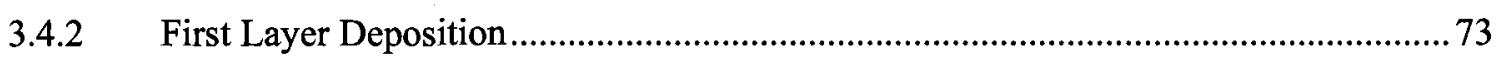

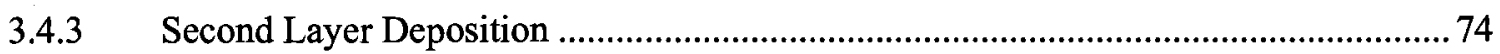

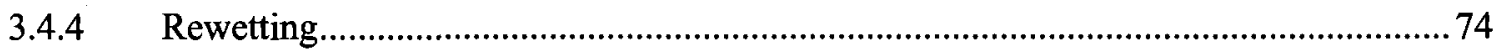

3.5 Laboratory Measurement of Soil Water Characteristics Curve (SWCC) .............. 75

3.5.1 SWCC Experimental Setup for Bulyanhulu Tailings.......................................... 75

3.5.2 SWCC Experimental Setup for Toromocho Tailings ............................................. 77

$4 \quad$ Numerical Simulation................................................................ 78

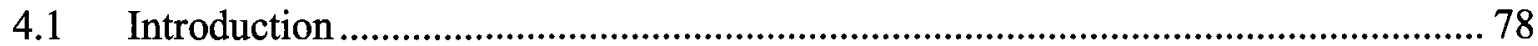

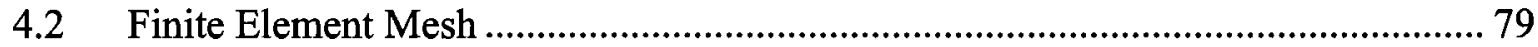

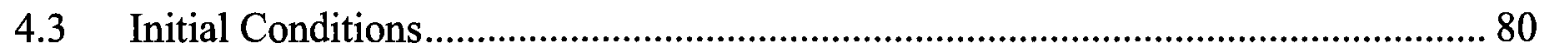

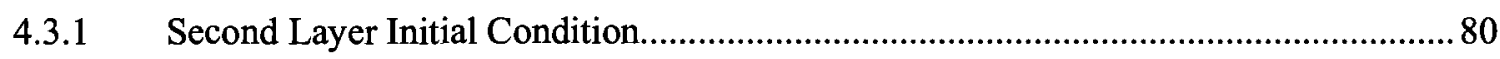

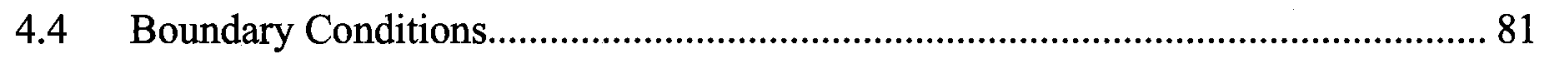

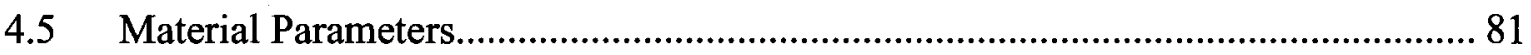

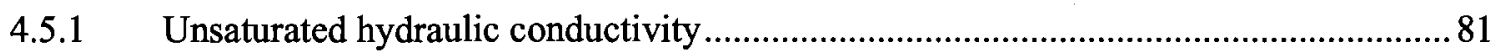

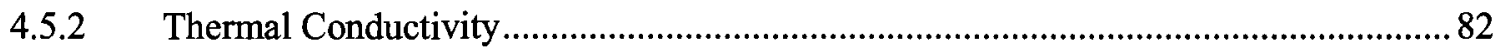

5 Experimental Results and Discussions................................................ 84

5.1 Experimental Results for Soil-Water Characteristic Curve (SWCC) For Tailings.. 84

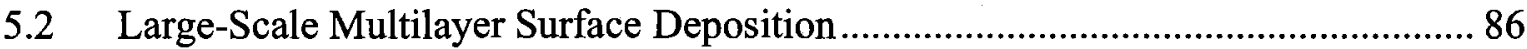

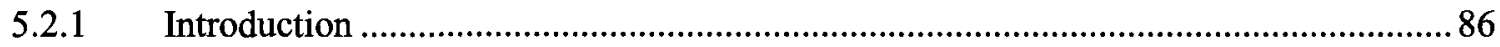

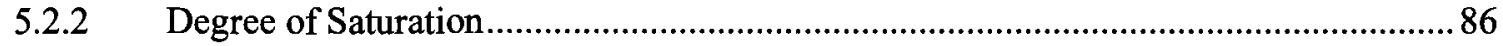

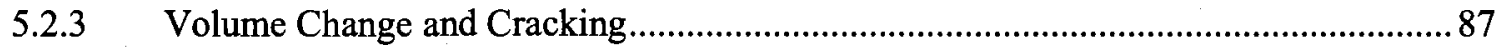

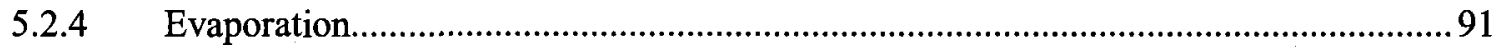

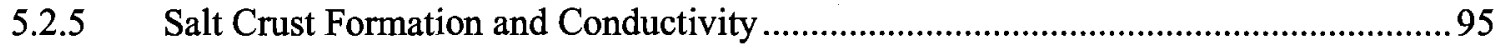

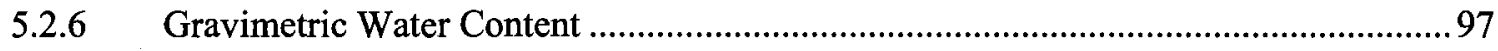

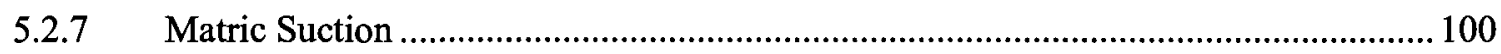


5.2.8 5.2.7 Large-Scale Experimental Pictures

5.3 Small -Scale Multilayer Surface Deposition Bulyanhulu Tailings ..................... 128

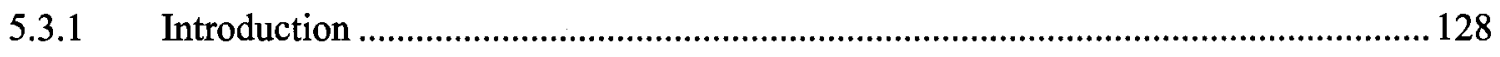

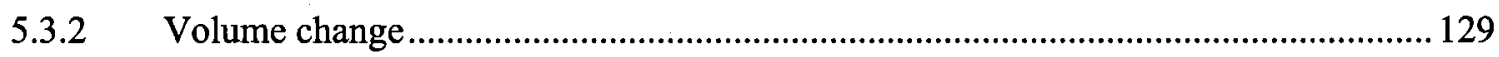

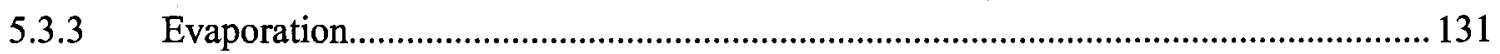

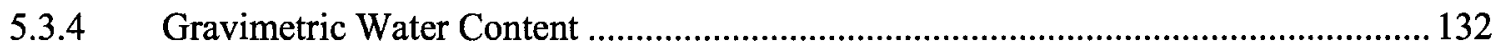

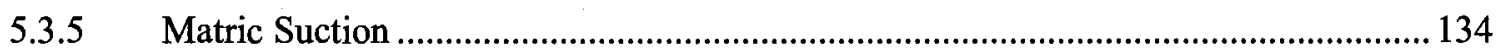

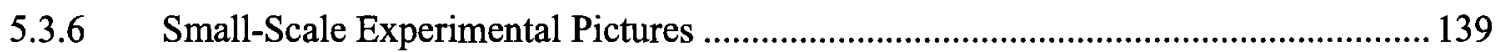

5.4 Toromocho Mine Tailings........................................................................ 146

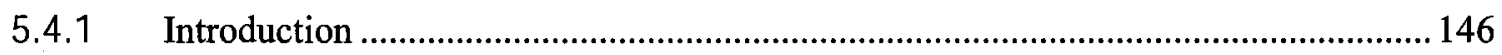

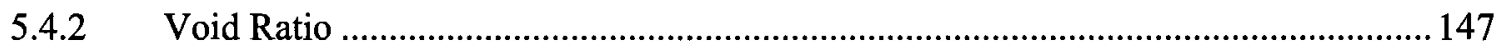

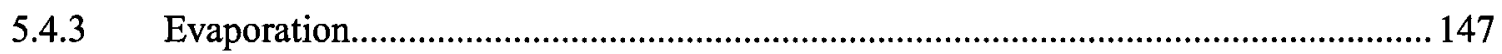

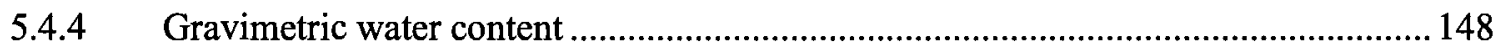

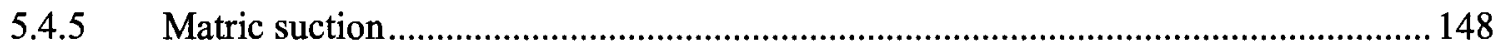

5.4.6 Small-Scale Single Layer Surface Deposition................................................... 151

5.5 Discussion of Major Result for Drying Tests................................................ 154

5.5.1 Effect of the Older Desiccated layer on Drying of the Second Layer ........................ 154

5.5.2 Effect of Cracks on Rate of Evaporation.............................................................. 160

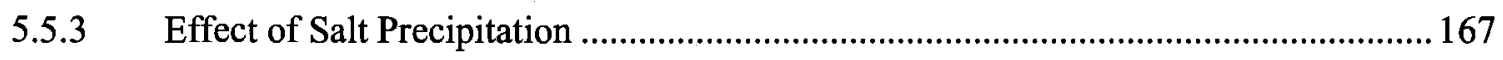

6 Summary, Conclusion and Recommendations................................... 172

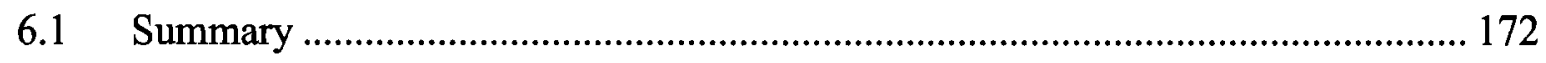

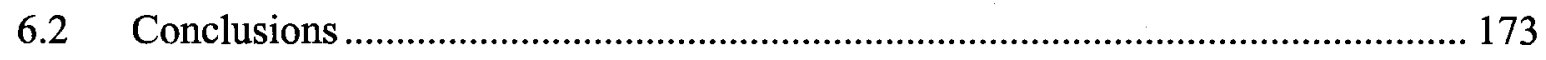

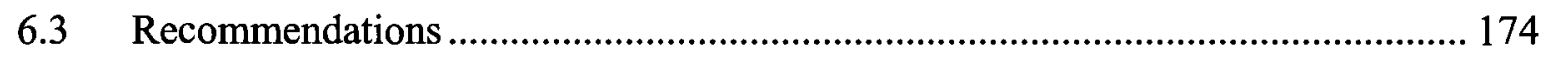

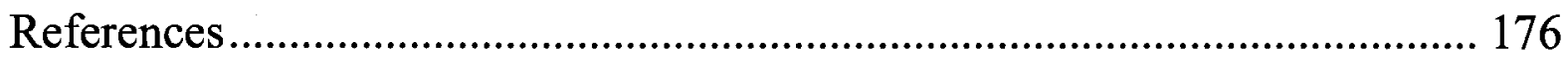


Appendix A: The influence on the initial degree of saturation on the shrinkage curve of silts 186

Appendix B: Methods to predict unsaturated properties of soils from grain size:

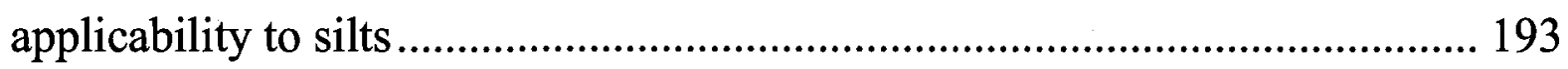

Appendix C: chemical composition of tailings: - Solid Phase ………………... 200

Appendix D: Chemical composition of mine tailings: - Liquid Phase............. 201

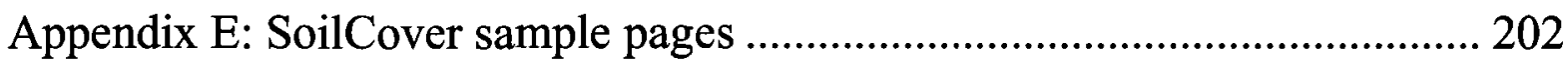

Appendix F: Temperature and Relative Humidity data..................................... 213

Appendix G: Sample of height measurements for large scale drying test ...... 215 


\section{List of Figures}

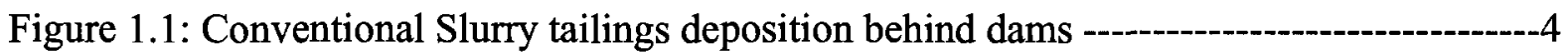

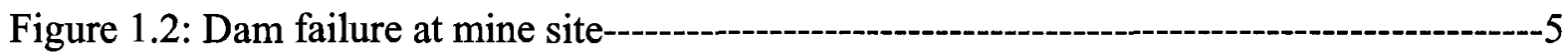

Figure 1.3: Surface deposition of paste tailings at the Bulyanhulu mine in Tanzania-----------6

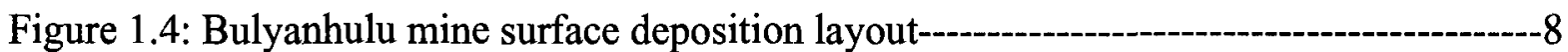

Figure 1.5: Active deposition of a new fresh layer on top of an older desiccated layer---------9

Figure 1.6: Relationship between degree of saturation, void ratio, oxygen diffusion and gravimetric moisture content

Figure 1.7: Factors controlling drying of a freshly deposited layer

Figure 2.8.3: The relationship between rate of actual evaporation and potential evaporation $(\mathrm{AE} / \mathrm{PE})$ and water availability

Figure 2.8.4: Relationship between the total suction and relative humidity $-42$

Figure 3.1.1: Particle size distribution for Bulyanhulu tailings using a hydrometer test------51

Figure 3.1.2: Particle size distribution for Toromocho tailings using hydrometer test--------53

Figure 3.2.1: Top view of a load cell with a capacity of $2272.73 \mathrm{~kg}$ $-55$

Figure 3.2.2: Side view of a load cell with a capacity of $2272.73 \mathrm{~kg}$ $-56$

Figure 3.2.3: Layout of a load cells prior the experimental setup $-57$ 
Figure 3.2.4: Outer view of an empty box on top of the load cell prior the drying test

Figure 3.2.5: Inner view of large scale box prior to surface deposition of mine tailings------59

Figure 3.2.6: Tailings were mixed using paint mixer and by hand before deposition$-60$

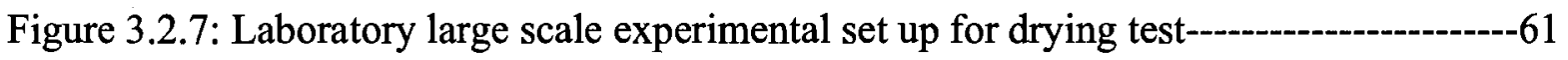

Figure 3.2.8: Computed potential evaporation, daily temperature and relative humidity data for large scale Bulyanhulu drying test-

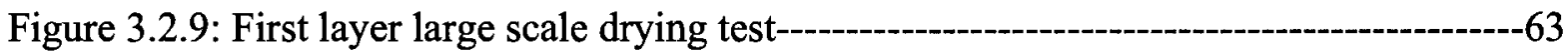

Figure 3.2.10: Crack width and length measurements-------

Figure 3.3.1: Computed PE, daily temperature and relative humidity for small scale

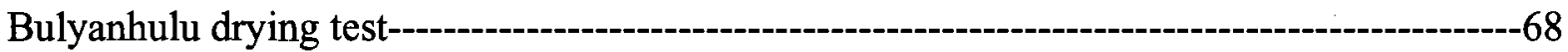

Figure 3.3.2: The bucket was mounted on a scale and weight was measured and recorded--69

Figure 3.3.3: Wind was induced to simulate evaporation using a commercial fan in small

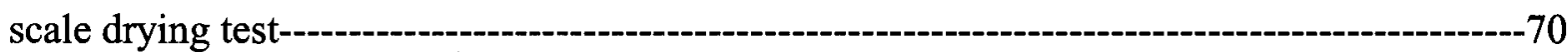

Figure 3.3.4: Datalogger used to record the weight and matric suction measurements from

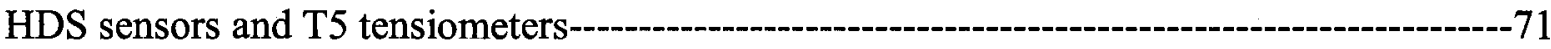

Figure 3.3.5: Dismantling small scale column drying test at the end of the experiment------72

Figure 3.5.1: Soil-water characteristic curve experimental setup using a volumetric pressure

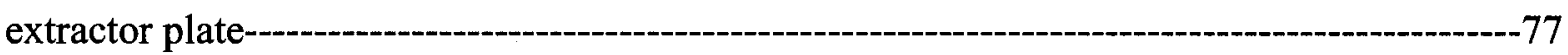

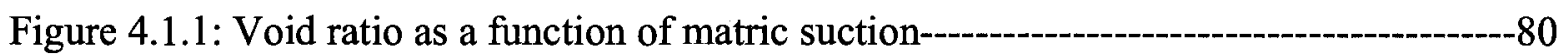


Figure 5.1.1: Soil-water characteristic curve for Bulyanhulu tailings-----------------------------84

Figure 5.1.2: Soil-water characteristic curve for Toromocho tailings---'-

Figure 5.2.1: Cumulative evaporation, degree of saturation, void ratio and average GWC for the large scale Bulyanhulu drying test---_-

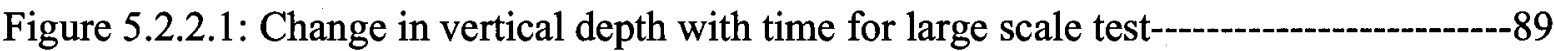

Figure 5.2.2.2: Void ratio calculated using only vertical shrinkage and using for lateral

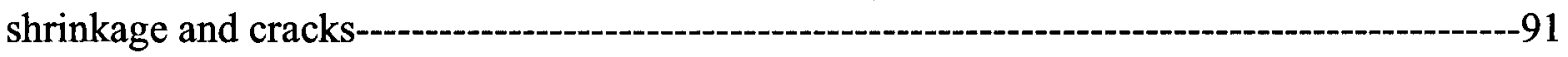

Figure 5.2.3.1: Measured and computed actual evaporation, and computed potential evaporation for large-scale drying test--

Figure 5.2.3.2: Hourly rate of evaporation for the first 4 days of the drying test-_-_-_-_-_-a95

Figure 5.2.4.1: Conductivity and osmotic suction measurements -------------------------------96

Figure 5.2.4.2: Precipitation of salt on surface and on edge of cracks---------------------------97

Figure 5.2.5.1: Average and surface gravimetric water contents--

Figure 5.2.5.2: Measured GWC at middle and near cracks at day 10 ---------------------------99

Figure 5.2.5.3: Measured GWC at middle and near cracks at day -

Figue 5.2.6.1: Schematic representation for the T5 tensiometers during large scale test----102

Figure 5.2.6.2: Matric suction measurement for first layer drying test using T5's. The tensiometers were located $4-5 \mathrm{~cm}$ and $8-9 \mathrm{~cm}$ from the bottom of the tank $-103$ 
Figure 5.2.6.3: Matric suction measurement for second layer drying test using T5's. The tensiometers were located $1-2 \mathrm{~cm}, 1-2 \mathrm{~cm}, 7-8 \mathrm{~cm}$ and $7-8 \mathrm{~cm}$ from the top of dried first layer

Figure 5.2.6.4: Matric suction measurement during rewetting of the large scale using T5's----

Figure 5.2.6.5: Matric suction measurement using T5 and HDS sensors for the first layer of large-scale drying test The tensiometers were located $4-5 \mathrm{~cm}$ and $8-9 \mathrm{~cm}$, and HDS were located $7-8 \mathrm{~cm}$ and $8-9 \mathrm{~cm}$ from the bottom of the tank $-106$

Figure 5.2.6.6: Matric suction measurement using T5 and HDS sensors for the second layer of large-scale drying test The tensiometers were located $1-2 \mathrm{~cm}, 1-2 \mathrm{~cm}, 7-8 \mathrm{~cm}$ and 7-8 cm, and HDS were located first layer at $8.5 \mathrm{~cm}(\mathrm{~F}=8.5 \mathrm{~cm})$ and second layer at $1.5 \mathrm{~cm}(\mathrm{~S}=1.5$ $\mathrm{cm})$

Figure 5.2.6.7: Sensitivity graph for HDS sensors 108

Figure 5.2.6.8: Measured using T5's and HDS sensors and SoilCover predicted matric suctions for the first layer drying test $-109$

Figure 5.2.6.9: Measured using T5's, HDS and SoilCover predicted matric suctions for the second layer drying test-

Figure 5.2.7.1: January 26/2008, Day 0 first layer drying test-

Figure 5.2.7.2: January 28/2008, second day of Bulyanhulu drying test

Figure 5.2.7.3: January 29/2008, day three first layer drying test113 


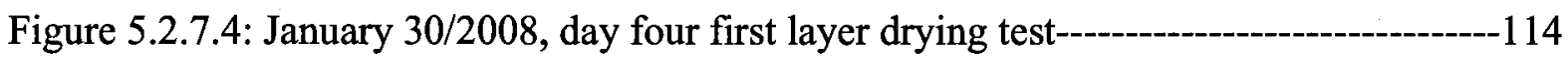

Figure 5.2.7.5: January 31/2007, days five of first layer drying test-----------------------------115

Figure 5.2.7.6: February 1/2008, day six of first layer drying test----

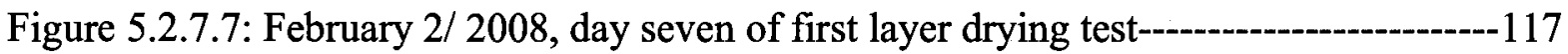

Figure 5.2.7.8: February 3/2008, day eight of first layer drying test---_-_-_-118

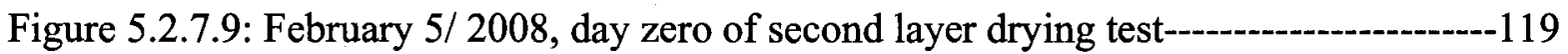

Figure 5.2.7.10: February 6/ 2008, day one of second layer drying test-----------------------120

Figure 5.2.7.11: February 6/ 2008, day one of second layer drying test----------------------121

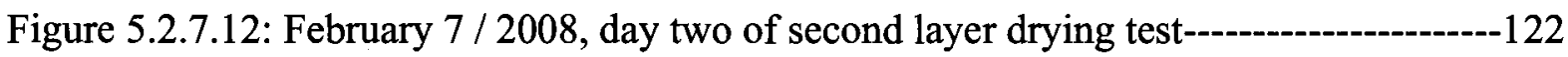

Figure 5.2.7.13: February 8/ 2008, day three of second layer drying test--_-

Figure 5.2.7.14: February 9/ 2008, day four of second layer drying test---_-_-

Figure 5.2.7.15: February 10/ 2008, day zero of rewetting--_-_-_-_-

Figure 5.2.7.16: February 11/2008, day one of rewetting--126

Figure 5.2.7.17: February 12/ 2008, day two of rewetting--127

Figure 5.3.1: Cumulative evaporation, void ratio, saturation, GWC on small-scale multilayer drying test----1--129

Figure 5.3.2: Void ratio with time for small scale drying test---_-_-_-_- 
Figure 5.3.3: Measured, computed actual evaporation (AE) and potential evaporation (PE) from small-scale drying test-

Figure 5.3.4: Gravimetric moisture content of small scale with profile depth

Figure 5.3.5.1: Matric suction measurements using T5 tensiometer for the first layer-

Figure 5.3.5.2: Matric suction measurement using T5's for second layer. the elevation of tensiometers given by letter " $F$ " stands for first layer and letter "S" for second layer-------136

Figure 5.3.5.3: Matric suction measured using T5 and predicted using SoilCover for the first layer small scale drying test $-137$

Figure 5.3.5.4: Matric suction measured and predicted after addition of the second layer in the small scale drying test$-138$

Figure 5.3.6.1: Bulyanhulu small-scale drying test by day 1 $-139$

Figure 5.3.6.2: Bulyanhulu small-scale drying test by day 3 $-140$

Figure 5.3.6.3: Bulyanhulu small-scale drying test, crack measurements by day 6 $-141$

Figure 5.3.6.4: Precipitation of salts during first layer Bulyanhulu drying test, by day 9---142

Figure 5.3.6.5: Precipitation of salts during first layer Bulyanhulu drying test, by day 10--143

Figure 5.3.6.6: Precipitation of salts at the end of second layer Bulyanhulu drying test, by day 25 144

Figure 5.3.6.7: Small-Scale Bulyanhulu drying test during dismantling145 Figure 5.4.1: Cumulative evaporation, average void ratios, and gravimetric moisture contents $-146$ 
Figure 5.4.2: Matric suction measurement using T5 tensiometer from small-scale drying test

Figure 5.4.3: Matric suction measurements using T5 tensiometer after rewetting test-------150

Figure 5.4.4: Matric suction measured and predicted for Toromocho tailings drying test---151

Figure 5.4.5: Cumulative evaporation, void ratio and gravimetric water content for single layer Toromocho drying test

Figure 5.4.6: Matric suction measurements using T5 Tensiometer data from single layer drying test-

Figure 5.5.2: SoilCover prediction and measured matric suction for Toromocho tailings drying test 155

Figure 5.5.3: Interlayer matric suction using measured T5 and predicted SoilCover156 Figure 5.5.4: SoilCover prediction for small-scale drying test at the end of first layer and the first day of second layer

Figure 5.5.5: SoilCover prediction for small-scale drying test at the end of first layer and the first day of second layer and direct measured matric suction measurements using T5 tensiometres

Figure 5.5.6: Matric suction measurement for small-scale drying test after the during the placement of second layer 160

Figure 5.5.7: Effect of cracks on rate of evaporation162 
Figure 5.5.8: Computed actual evaporation, computed potential evaporation and measured actual evaporation-

Figure 5.5.9: Day two of first layer drying test-------164

Figure 5.5.10: Day three of first layer drying test---165

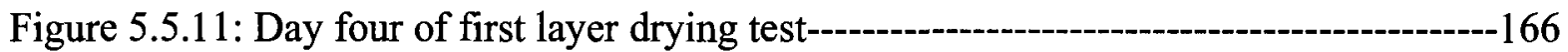

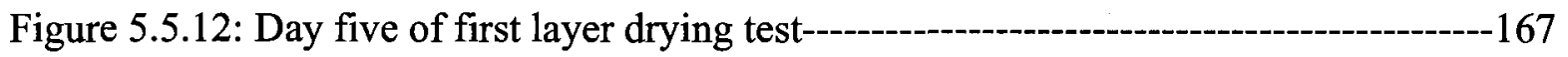

Figure 5.5.13: Osmotic suction versus time for each layer----------------------------------------169

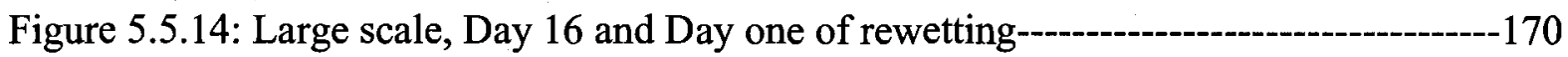

Figure 5.5.15: Large scale, day seventeen for first layer and day two after rewetting-------171 


\section{List of Tables}

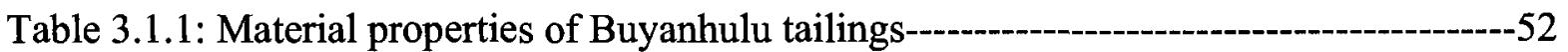

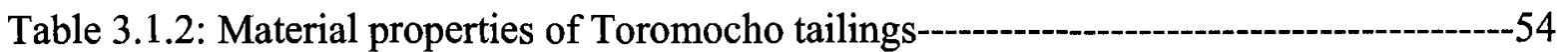

Table 4.5.1: Different $m_{v}$ values used to simulate using SoilCover for different experimentse- 


\section{Nomenclature}

$a_{f}=$ fitting parameter corresponding to soil suction at the inflection point, related to air entry

value

$a_{v g}=$ fitting soil parameter at the inflection point of the curve

$A E=$ actual evaporation flux from soil surface

$C_{h}=$ specific heat

$C_{p m}=$ specific heat of moist air at a constant pressure

$C_{u}=$ coefficient of uniformity

$C_{v}=$ correction factor for vapour flow

$C_{v h}=$ volumetric heat capacity of the soil

$D=$ particle size diameter

$D_{v}=$ diffusion coefficient of water through the soil

$D_{\text {vap }}=$ molecular diffusivity of water vapour in air

$D_{10}=10 \%$ passing of cumulative weight of particle size distribution

$D_{50}=50 \%$ passing of cumulative weight of particle size distribution

$D_{60}=60 \%$ passing of cumulative weight of particle size distribution

$e=$ void ratio

$e_{a}=$ vapour pressure of air above the surface

$e_{s}=$ saturation vapour pressure above the surface

$E=$ evaporation

$E C=$ electrical conductivity of pore water and the reservoir water in the odeometer cell

$f(w)=$ turbulent exchange function 
$g=$ gravitational accelaration

$G=$ conducted heat flux into the subsurface soil

$G_{s}=$ specific gravity of solid particles

$h=$ hydraulic head

$h_{s}=$ specific humidity in air

$h_{r}=$ constant parameter used to represent soil suction at the residual water content

$H=$ convective sensible heat flux

$i=$ Van't Hoff factor

$k_{h}=$ eddy transfer coefficient of heat

$k_{r}=$ relative unsaturated hydraulic conductivity

$k_{r}\left(\psi_{m}\right)=$ relative unsaturated hydraulic conductivity at a particular matric suction

$k_{s}=$ saturated hydraulic conductivity

$k_{v}=$ eddy transfer coefficient of of water vapour

$k_{x}=$ unsaturated hydraulic conductivity in the direction of $\mathrm{x}$

$k_{y}=$ unsaturated hydraulic conductivity in the direction of $y$

$k(\theta)=$ hydraulic conductivity at a given volumetric water content

$L_{v}=$ latent heat of vaporization of water

$m_{l}{ }^{w}=$ rate of change in water content with changes in applied normal stress

$m_{2}{ }^{w}=$ rate of change in water content with matric suction

$m_{f}=$ fitting parameter related to curvature of the function at high suction range

$m_{s}=$ mass of solid particles

$m_{v g}=$ fitting parameter related to the curvature in high suction range

$m_{w}=$ mass of water 
$M=$ molarity of pore solution

$n=$ porosity

$n_{f}=$ fitting parameter related to rate of desaturation of the soil

$n_{v g}=$ fitting parameter related to rate of desaturation of the soil

$p=$ total atmospheric pressure

$p_{v}=$ partial pressure of water vapour

$R=$ universal gas constant

$R_{n}=$ net radiation

$R_{s}=$ radius of curvature for contractile skin

$R H=$ relative humidity

$R H_{a}=$ relative humidity of air

$R H_{s}=$ relative humidity at the soil pores

$S=$ degree of saturation

$t=$ time

$T=$ absolute temperature

$T_{d}=$ dry bulb temperature

$T_{s}=$ surface tension between pores and solid particles

$v_{w o}=$ specific volume of water

$V_{\text {vap }}=$ one dimensional flux of water vapour

$V=$ total volume

$V_{v}=$ volume of voids

$V_{s}=$ volume of solids

$V_{w}=$ volume of water 
$w=$ gravimetric water content

$w_{a}=$ wind speed

$w_{l}=$ liquid limit

$w_{p}=$ plastic limit

$w_{s}=$ saturated gravimetric water content

$w_{s h}=$ shrinkage limit

$w_{\text {rvg }}=$ residual gravimetric water content

$w_{w}=$ gravimetric water content at a given matric suction

$x=$ direction of $\mathrm{x}$

$y=$ direction of $y$

$z=$ direction of $z$ (above surface)

$Z=$ elevation within soil from a given datum

$\alpha=$ contact angle

$\theta=$ volumetric water content

$\rho=$ density of moist air

$\rho_{b}=$ bulk density

$\rho_{d}=$ dry density

$\rho_{s}=$ density of solid particles

$\rho_{v}=$ density of vapour in air

$\rho_{w}=$ density of water

$u_{a}=$ pore-air pressure

$u_{w}=$ pore-water pressure

$v_{\nu}=$ partial pressure of pore water vapour 
$v_{v o}=$ saturation pressure of vapour above pure water

$\omega_{v}=$ molecular mass of water vapour

$\psi_{m}=$ matric suction

$\psi=$ total suction

$\pi=$ osmotic suction

$\beta o=$ bowen ratio

$\sigma=$ applied normal stress

$\varepsilon=$ tortuosity factor

$\delta=$ cross sectional area of soil available for vapour flow

$\lambda=$ thermal conductivity

$\Gamma=$ slope of the saturation vapour pressures and temperature curve at the relevant temperature

$\eta=$ psychrometric constant 


\section{Introduction}

Mine tailings are a stream of waste, produced as a result of mechanical and chemical processes used to extract and separate the desired elements from excavated rock. Tailings consist of crushed rocks and effluents that are generated in the mine processing plant including unrecoverable and uneconomic metals, minerals, man-made additives and process water. Millions of tons of tailings are generated at each site. In Canada, tailings are generated at a rate 20 times that of municipal solid waste (Feasby et al., 1997).

Tailings are conventionally deposited as a slurry in dammed impoundments. These impoundments pose environmental liabilities in a number of ways including generation of seepage and risk of structural failure. In terms of seepage, tailings often contain reactive minerals such as iron sulphides that are geochemically unstable in the near-surface environment. These minerals may react with oxygen and generate acidity in the tailings' pore-water and consequently low $p H$. This acidity in turn promotes dissolution of many other minerals, leading to high levels of heavy metals in the pore-water. This contaminated water is called Acid Drainage. The egress of acid drainage into surface and groundwaters is a major economic liability for the mining industry (Feasby et al., 1997), and has been known to severely impact ecosystems and human health.

Historically, the extent and magnitude of contaminated seepage into surface water and groundwater has not been well-understood until late 1970's in Canada and late 1980's 
elsewhere. However, a number of incidents have been reported on the effect of leachate from historical mine sites on surrounding water sources. For instance in Scandinavia, a number of rivers and lakes have been contaminated from ores. Low $p H$, high metal concentrations and loss of aquatic life was reported on surface waters located downstream of historical tailings impoundments (Robertson, 1987). The Baltic Sea has been noticeably contaminated as a result of acid drainage (Lindahl, 1990).

Structural stability of tailings impoundment is another concern for conventional deposition of slurry tailings. A number of dam failures and subsequent flooding of downstream areas with tailings have occurred throughout the world (ICOLD, 2001). A famous case is Minas de Aznalcóllar, a mine tailings impoundment located in southwestern Spain for a mine that operated from 1956 to1979. Minas de Aznalcóllar failed in April 25, 1998 (Eptisa, 1998), devastating thousands of hectares of arable land, and requiring a cleanup cost of at least $\$ 100$ million (ENS, 2002).

Therefore, the mining industry has been investigating alternative disposal methods. Surface deposition of paste or thickened tailings is an alternative technique to conventional deposition. The term "thickened" denotes dewatering of the tailings below the conventional deposition water content. Paste is a subset of thickened tailings, whereby the tailings gravimetric moisture content is lowered to the point that the tailings exhibit a yield stress, form a gentle slope during stack deposition on the surface, and no segregation of particles 
occurs during deposition. The desired gravimetric moisture content is achieved by dewatering the tailings using methods such as deep cone thickeners or belt press filters.

Paste or thickened tailings disposal have some advantages over conventional tailings disposal. including removing reliance on dams, reducing the potential for leakage or leachate to the surrounding surface water or ground water, increasing water recycling within the operation of the mining facility, and allowing for the progressive closure of mine waste impoundments due to relative rapid strength development at the surface (Robinsky, 1999; Sofra and Boger, 2002; heriault et al., 2003; Shuttleworth et al., 2005; Martin et al., 2006; Simms et al., 2007). This thesis focuses on paste deposition of gold mine tailings.

Figures 1.1-1.4 show deposition of conventional slurry tailings and paste tailings for comparative purposes. Figure 1.1 shows deposition of conventional tailings as slurry behind dams. 


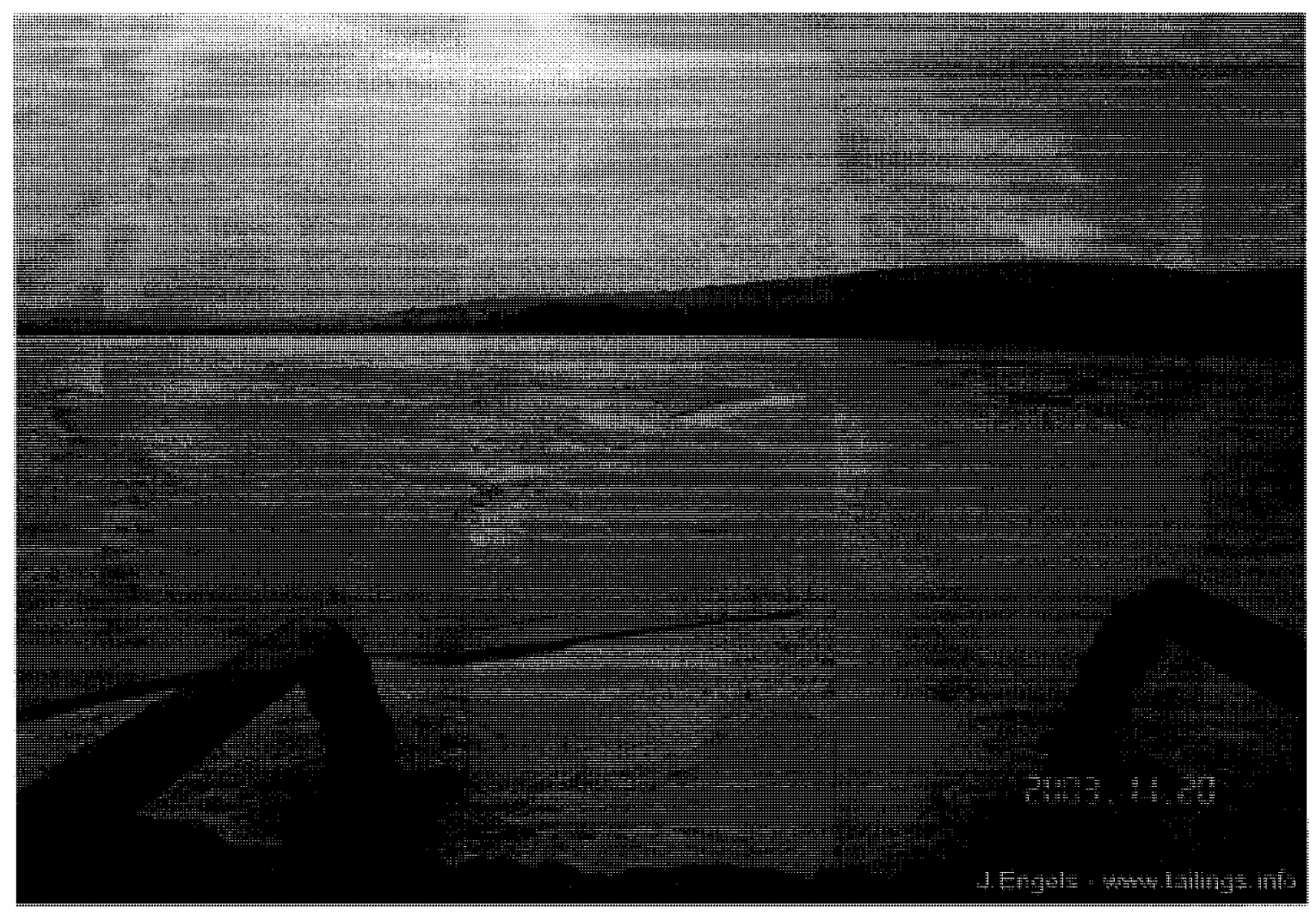

Figure 1.1: Conventional slurry tailings deposition behind dams (from www.tailings.info).

As it can be seen in Figure 1.1, a large volume of water is needed on a daily basis for the mine waste impoundments. This is a huge concern to mine sites located in arid and semi-arid regions or to the sites where there is short periods of rainfall, as the operational cost for the water is much higher. An example of a failure of a tailings dam is shown in Figure 1.2. 


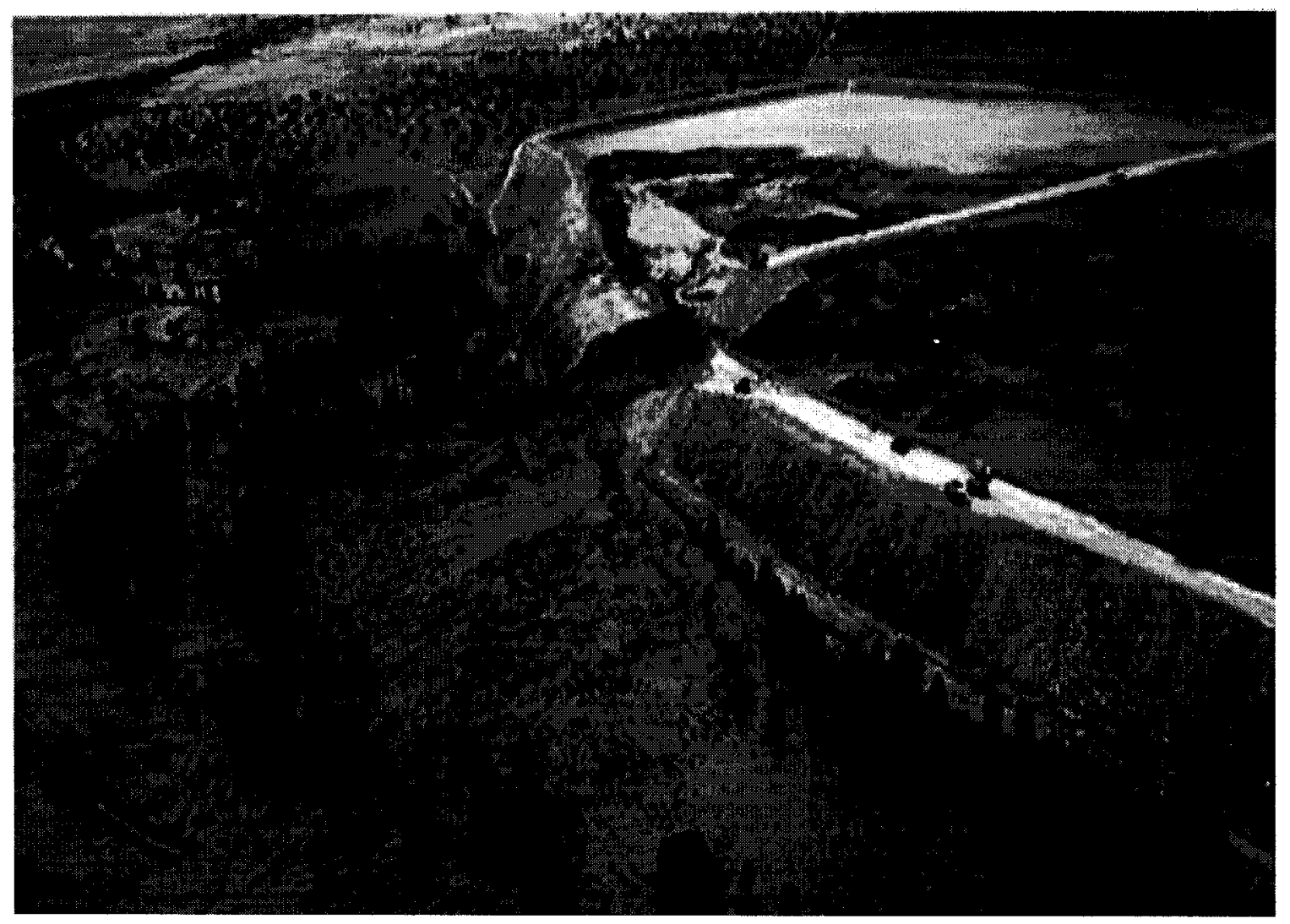

Figure 1.2: Dam failure at mine site. 


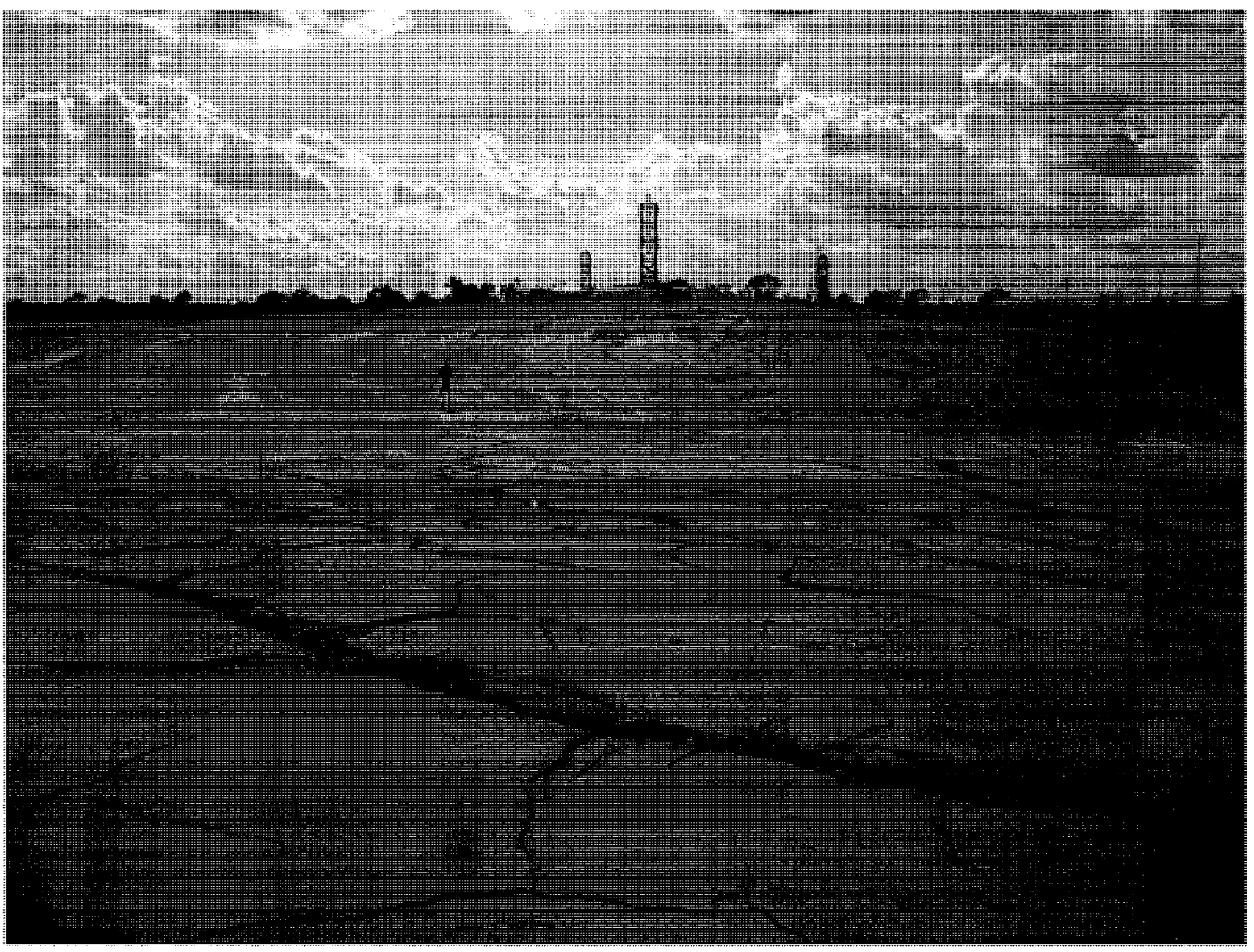

Figure 1.3: Surface deposition of paste tailings at the Bulyanhulu mine in Tanzania.

Figure 1.3 shows paste deposition at the Bulyanhulu mine site in Tanzania. Paste dries in a relatively short period of time in an arid climate. This can allow movement of machinery on the tailings impoundment within several days after the end of deposition, which facilitates closure of the impoundment with a soil cover. There is no risk of dam failure, and significant amounts of water are saved. Consider that the solids concentration of conventionally deposited gold tailings is $50 \%$, compared with $70 \%$ for paste. Assuming 10,000 tons per day 
was deposited as slurry at $50 \%$ solids concentration; the mine facility can reclaim 2000 tones of water per day by using paste surface deposition at $70 \%$ solids concentration.

The Bulyanhulu mine is the first gold mine to use paste surface deposition for tailings disposal. The mine is located within the Victorian Greenstone Belt in northern Tanzania. This site has a semi-arid climate with rainy season that lasts only a very short duration throughout the year. The annual rainfall is of approximately $1200 \mathrm{~mm}$ while annual potential evaporation is of $1600 \mathrm{~mm}$ (Theriault et al., 2003). The short rainy season in that region contributes to additional costs for usage and transport of water in the facility. At Bulyanhulu, paste was chosen as it increased the recycling of water within the facility, thereby minimizing the operational cost due to transporting water to the site. At Bulyanhulu paste tailings deposition is cycled between 5 towers, allowing for desiccation and strength gain at the deposition points as shown in Figure 1.4. 


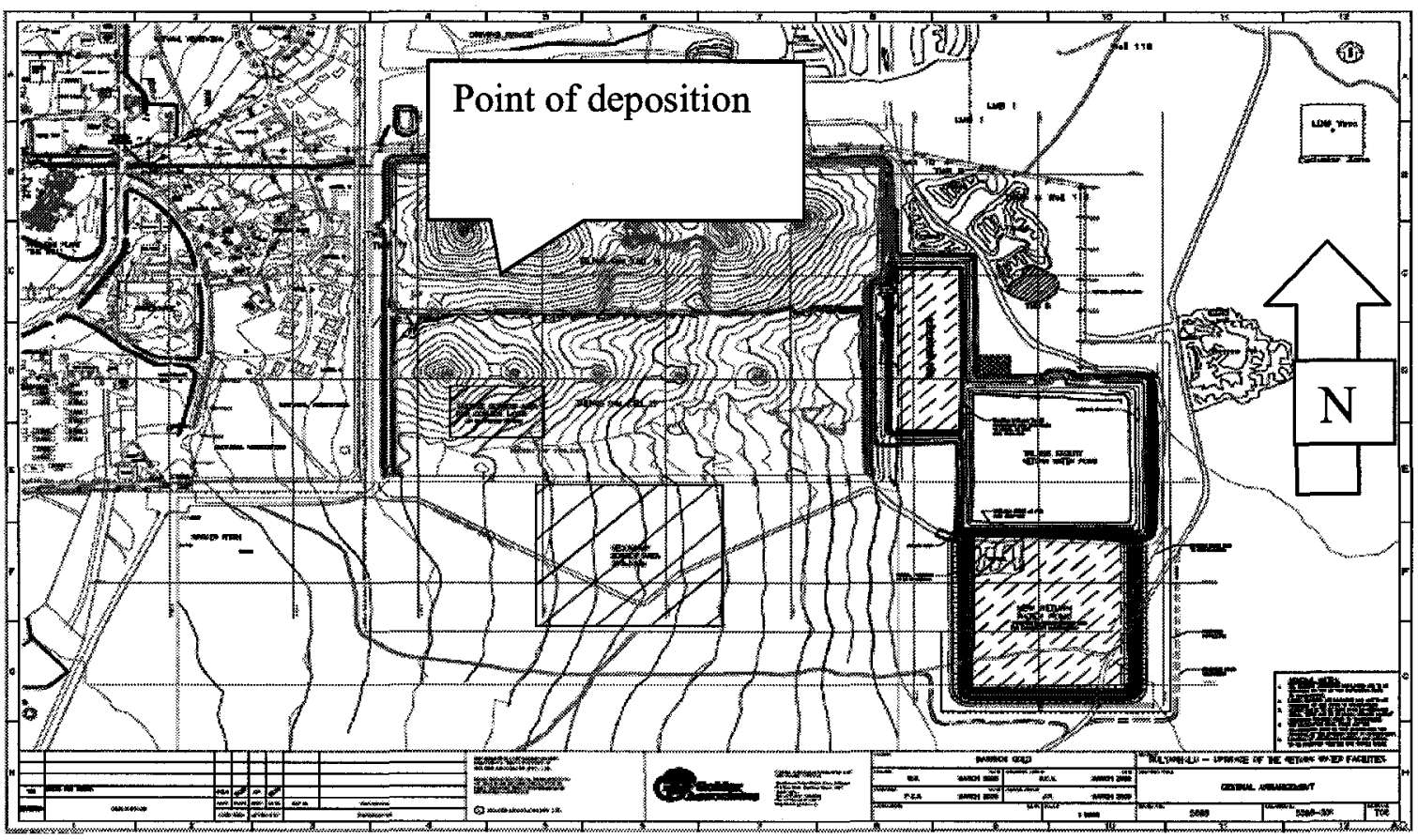

Figure 1.4: Bulyanhulu mine surface deposition layout

Figure 1.4 shows the physical layout of Bulyanhulu mine tailings deposition site. At present, the mine cycles deposition between towers one through five This allows a certain time for the previously deposited tailings to dry and desiccate. Once the deposited tailings gained strength another cycle of deposition will take place in a similar fashion. After the desired stack height is achieved, deposition will expand towards the South and use a second row of 5 towers as deposition points. 


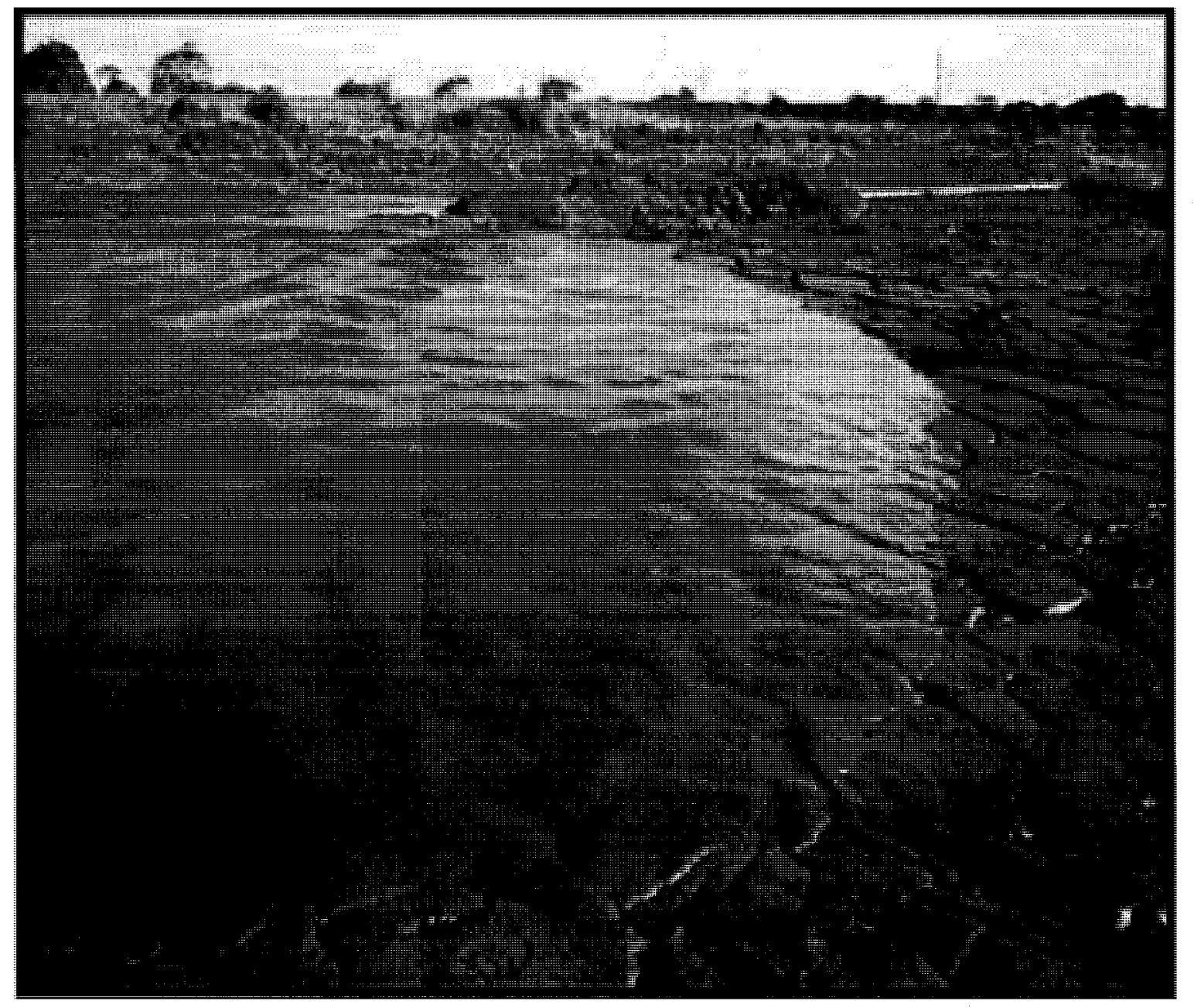

Figure 1.5: Active deposition of a new fresh layer on top of an older desiccated layer.

Figure 1.5 shows deposition of new layer on top of an older desiccated layer. The underlying layer is highly desiccated, as shown by the degree of cracking. Accurately predicting the amount of evaporation from the tailings that occurs over the course of a deposition cycle is required to optimally plan surface deposition. This can be illustrated by Figure 1.6, which shows the relationship between evaporation, diffusion of oxygen and void ratio from a shrinkage curve. Figure 1.6 shows evaporation from a freshly deposited layer plays a significant role in strengthening the tailings. However, excess evaporation will desaturate the 
tailings and increase the ingress of oxygen. This ingress of oxygen increases the risk of acid generation through oxidation of sulphide minerals. As void ratio decreases the tailings gain strength and density. On the other hand, as the void ratio decreases there is an increase of oxygen diffusion, which is indicated by the relative index for oxygen diffusion (Aachib et al., 2004; Yanful, 1993). The diffusion of oxygen into the tailings will increase after the air-entry value of the tailings is exceeded. Thus, while evaporation is desirable up to a point, to densify and strengthen the tailings, too much evaporation may increase the risk of acid generation.

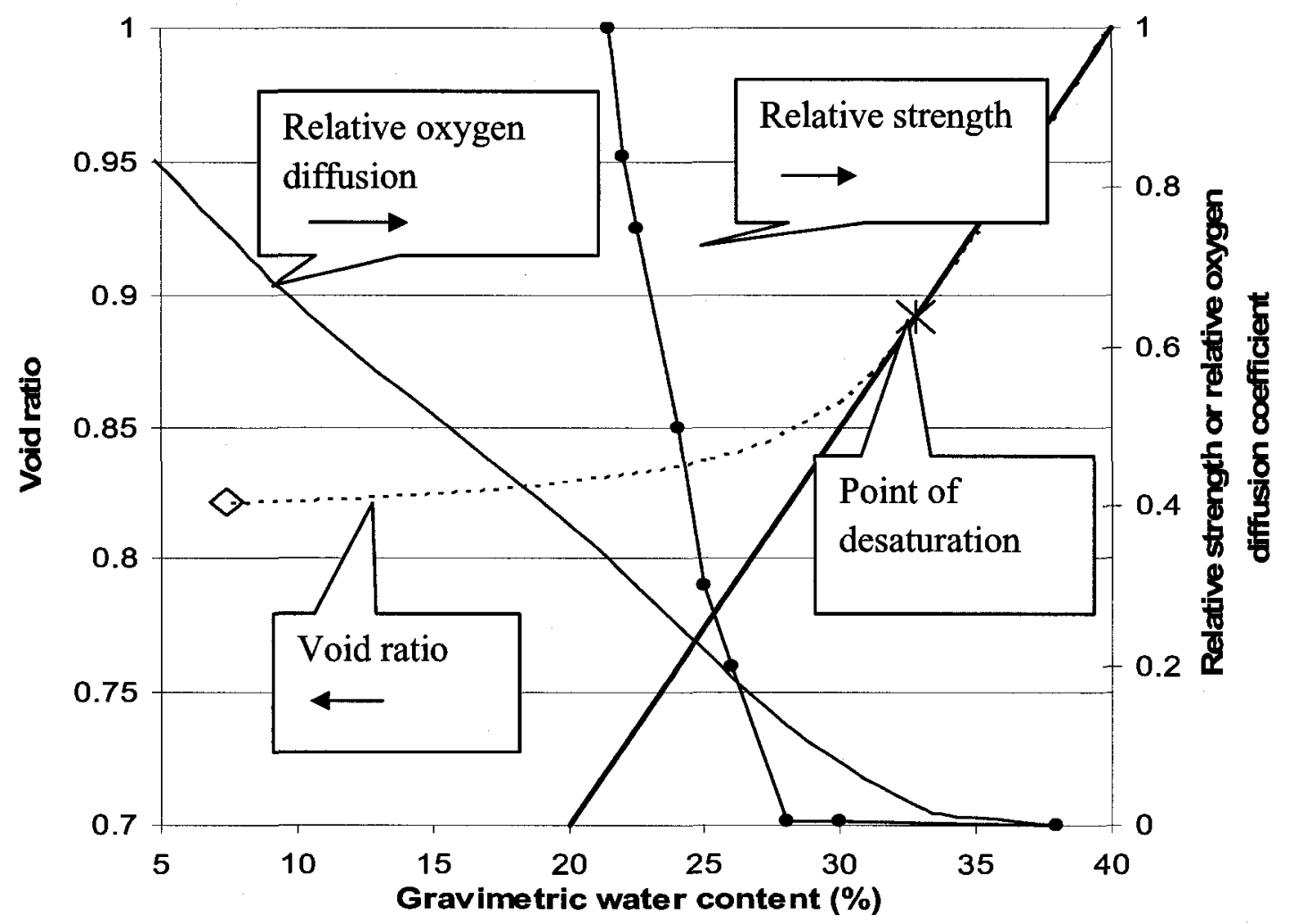

Figure 1.6: Relationship between degree of saturation, void ratio, oxygen diffusion and gravimetric moisture content (modified from Simms et al., 2007). 
The mine can control the degree of evaporation by regulating the deposition cycle and layer thickness. The evaporative behavior is influenced by a number of factors, as shown in Figure 1.7. This includes the effect of salts, albedo, unsaturated flow, cracks, and interlayer interaction. The primary goal of this thesis is to understand the inter layer flow and the evolution of evaporation during multi-layer deposition. This will facilitate the Bulyanhulu mine and future mines to more rationally plan their tailings deposition.

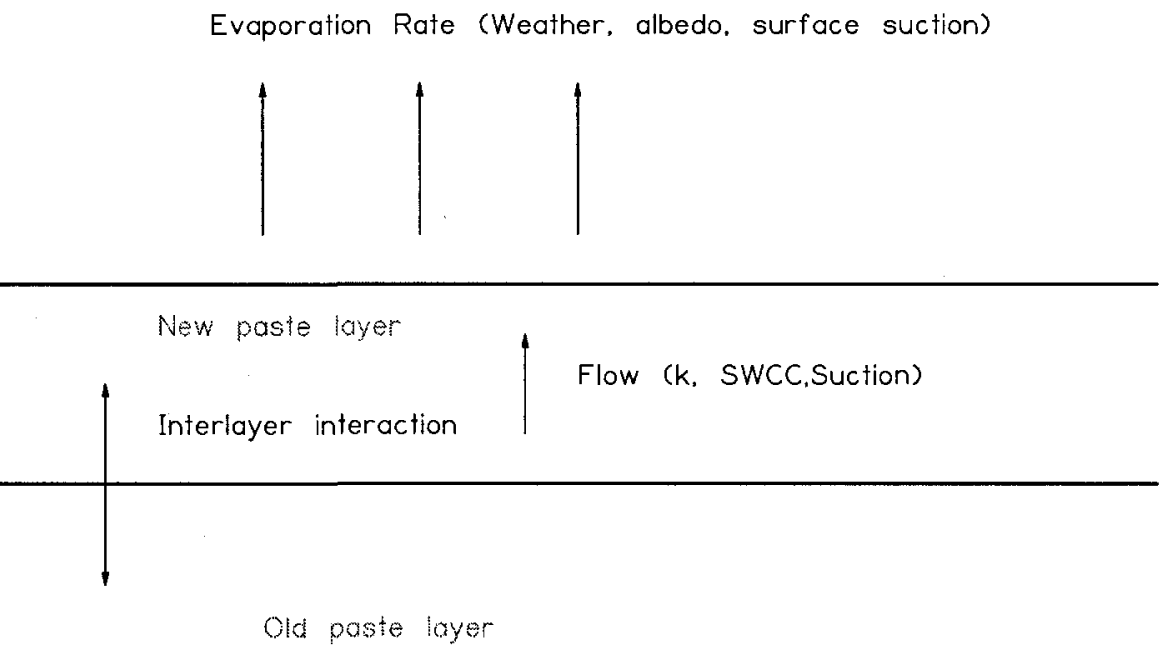

Figure 1.7: Factors controlling drying of a freshly deposited layer (after Simms et al., 2007). 


\subsection{Previous Studies}

Laboratory drying tests have been conducted on single layers of Bulyanhulu Gold mine tailings (Simms et al., 2007). These tests included "small-scale" column tests and "largescale" tests in a $2 \mathrm{~m}$ by $1 \mathrm{~m}$ by $1 \mathrm{~m}$ rectangular box (Simms et al., 2007). The rate of drying, within the profile depth of a single layer paste tailings, was modelled using the SoilCover unsaturated flow model (Wilson et al., 1994). Field trials were also conducted at Bulyanhulu site by two students from University of Toronto during the summers of 2004 and 2005 (Simms et al., 2007). It was shown that a reasonable prediction of evaporation rate could be made for single layers up to a certain time after deposition. In the field, predicted and measured evaporation rates began to diverge after three weeks. Simms et al. (2007) showed that this was due to the buildup of salts on surface. It was also shown that the final void ratio through desiccation was generally larger than predicted from the ASTM shrinkage test (Couto et al., 2006). Significant cracking was also observed in both laboratory tests and the field, but an investigation on the effect cracking on evaporation was not performed.

\subsection{Objectives and Scope}

The overall objective of this research is to study the mechanics of unsaturated flow in multilayer deposition of paste tailings. The following is a list of objectives for this thesis.

1. Investigate unsaturated flow and evaporation in laboratory simulations of multilayer paste tailings deposition

2. Investigate the applicability of methods to predict the soil-water characteristic curve (SWCC) from grain size distribution to silt-size materials such as tailings.

3. Determine the factors that influence the final void ratio obtained by desiccation. 
These objectives are described in the following sections.

\subsubsection{Multilayer Unsaturated Flow and Evaporation in Laboratory Experiments}

In the field, fresh layers of paste tailings are initially deposited on a prepared ground surface. Subsequent layers are placed on top of the previously deposited layers, once each previously placed layer has been allowed to dry and gain strength. The hydrological processes, which facilitate drying of the paste deposition, are infiltration, evaporation, and interlayer interaction. The effect of the older dried layer on multilayer deposition needs to be investigated. This earlier dried layer may play a significant role in assisting the drying process by drawing the moisture from the freshly deposited layer. Accurately predicting the rate of evaporation and understanding the effect of the older dried layer on a freshly deposited layer (interlayer interaction) is fundamental in designing and optimizing the deposition process. Consequently multilayer paste deposition was simulated using small scale column drying tests for two tailings from two different mines (Toromocho and Bulyanhulu), and using one large scale drying test for Bulyanhulu tailings. The results of these experiments were analyzed using a one dimensional (1-D) unsaturated flow model. An attempt was made to characterize the effect of cracking on the evaporation rate by mounting the "large-scale" drying test on load cells to enable direct measurement of the evaporation rate. 


\subsubsection{Methods to Predict Soil-Water Characteristic Curve (SWCC) from Grain Size Distribution}

The water holding capacity of a particular soil can be indirectly derived from its soil-water characteristic curve (SWCC). The SWCC of a soil depends on the particle size distribution of the soil and their matrix arrangement to form the pore space. Therefore, the SWCC plays a fundamental role in understanding the flow of water in porous media. In addition, SWCC is fundamental parameter used in unsaturated flow modelling.

Laboratory measurement of the SWCC for a particular soil needs extensive work, time and cost and has been a challenge to the application of unsaturated soil mechanics to conventional geotechnical practice. This has prompted researchers to develop methods to estimate the SWCC from readily obtainable soil properties such as grain size and the Atterberg Limits.

Predictions of SWCC from grain size distribution using Fredlund et al. (2002) and from basic geotechnical properties using Aubertin et al. (2003) were tested using silt sized artificial soils. The proposed models work well for coarse grain soils. This part of the thesis examines the application of these methods to tailings and artificial silts of known grain size. Silts were used as tailings are typically silt sized. 


\subsubsection{Determine the Factors that Influence the Final Void Ratio Obtained by Desiccation}

In mine waste management, the stability of tailings and their susceptibility to liquefaction, whether deposited on surface or underground, is a function of the void ratio achieved through environmental drying and/or consolidation (Fourie et al., 2003). For near-surface geotechnical structures such as embankments, or natural slopes, prediction of long-term behaviour and susceptibility to rainfall induced collapse is a function of their unsaturated properties, which themselves are dependant on the volume change the soils experience due to wet /dry cycles.

It has been recognized for some time that the initial degree of saturation of compacted clayey soils has some impact on the shape of the shrinkage curve. Where decreasing the initial degree of saturation results in a gentler slope of the shrinkage curve and a higher final void ratio (Fredlund and Rahardjo, 1993). Of late this phenomenon is of increasing interest to geotechnical engineers dealing with unsaturated soils.

In particular, it has been noted that the final void ratio achieved through drying in surface deposited silt-sized tailings is often considerably higher than the void ratio predicted from the standard ASTM shrinkage limit test. This has been observed both in laboratory drying tests as well as in the field (Couto et al., 2006; Theriault et al., 2003).

The objective is to examine this phenomenon in more detail, by performing drying tests using two artificial silts. The rationale for employing the artificial silts is that their properties, 
particle size distribution, and particle shape are known, which provides a more solid footing for understanding the fundamental behaviour of drying of silts. For comparison with a "real" material, the same test was done on samples of gold tailings.

\subsection{Organization of Thesis}

The primary objectives of the thesis was to study the mechanisms of unsaturated flow in multilayer deposition of paste tailings and to evaluate how well a 1D unsaturated flow model software package could simulate these processes. Due to the delay in receiving the Bulyanhulu and Toromocho mine tailings, the second and third objectives were introduced, completed and formed the basis of two conference papers. Appendix A contains "The influence on the initial degree of saturation on the shrinkage curve of silts". Appendix B contains "Methods to predict unsaturated properties of soils from grain size-applicability to silts".

The outline of the thesis presents as follows

Chapter 2: Presents the literature review related to unsaturated flow in soils, and evaporation from soil surface.

Chapter 3: Presents the materials which was used for the experiment and the different methods used during the study.

Chapter 4: Describes the implementation of the numerical simulation using a 1D unsaturated flow model software (SoilCover).

Chapter 5: Presents the results and discussion section.

Chapter 6: Presents summary, conclusion and recommendations drawn from the experiments. 


\section{Literature Review}

\subsection{Introduction}

Paste or thickened tailings deposition is considered as an alternative to conventional deposition. This is due to the number of risks associated with conventional tailings deposition, such as risk of catastrophic dam failure, risk of acid drainage, and excess water usage increases operational cost.

Paste tailing deposition is itself, however vulnerable to acid generation if there is excess drying. As the soil starts to dry, it will desaturate quickly once the air-entry value (AEV) of the soil is passed. The diffusion of oxygen will increase as the soil desaturates, which leads to oxidation of pyrite or sulphide minerals within the tailings (Aachiab et al., 2004; Yanful el al., 1993). On the other hand, drying to a degree is helpful in gaining strength and density. This densification gives structural stability and provides progressive closure for the waste impoundment as the structure allows the use of machinery on the impoundment to place a final cover.

Understanding the factors controlling evaporation from paste is important in order to optimize paste deposition in a waste impoundment. The following sections describe the relevant fundamental concepts, including flow in unsaturated soils, and the theory of evaporation from soil surfaces. 


\subsection{Phase Relationships}

Saturated and an unsaturated soils are mixtures of several phases. Saturated soil is composed of two phases; namely, solid particles of the soil and the water in the pore spaces, while unsaturated soil is composed of four different phases. These phases are solid particles, water, air and a contractile skin or an air-water interface (Fredlund and Morgenstern, 1977). The contractile skin or air-water interface has the ability to exert a tensile pull, referred as surface tension.

The relationship between different phases can be expressed using the following formulas:

1. Porosity: is the ratio of volume of voids to the total volume.

$$
n=\frac{V_{v}}{V}
$$

where: $\quad n=$ porosity [\%]

$$
\begin{aligned}
& V_{v}=\text { volume of voids }\left[\mathrm{cm}^{3}\right] \\
& V=\text { total volume }\left[\mathrm{cm}^{3}\right]
\end{aligned}
$$

2. Void Ratio: is defined as the ratio of volume of voids to the volume of solids, and expressed as:

$$
e=\frac{V_{v}}{V_{s}}
$$

where: $\quad e=$ void ratio [\%]

$$
V_{s}=\text { volume of solids }\left[\mathrm{cm}^{3}\right]
$$


3. Moisture content: gravimetric water content is defined the ratio of mass of water to the mass soil solids, and is expressed as follows:

$$
w=\frac{m_{w}}{m_{s}}
$$

where: $\quad w=$ gravimetric water content $[\%]$

$$
\begin{aligned}
& m_{w}=\text { mass of water [gm] } \\
& m_{s}=\text { mass of solid particles [gm] }
\end{aligned}
$$

Volumetric water content is defined as the ratio of volume of water to the total volume, and is expressed as:

$$
\theta=\frac{V_{w}}{V}
$$

where: $\quad \square=$ volumetric water content [\%]

$$
V_{w}=\text { volume of water }\left[\mathrm{cm}^{3}\right]
$$

4. Degree of saturation: is defined the ratio of volume of water to the volume of voids, and is expressed as follows:

$$
S=\frac{V_{w}}{V_{v}}
$$

where: $\quad \mathrm{S}=$ degree of saturation [\%] 
Bulk and dry density of soils are defined as following:

$$
\begin{aligned}
& \rho_{d}=\frac{m_{s}}{V} \\
& \rho_{b}=\frac{m_{s}+m_{w}}{V}
\end{aligned}
$$

where: $\quad \rho_{d}=\operatorname{dry}$ density $\left[\mathrm{gm} / \mathrm{cm}^{3}\right]$.

$$
\rho_{b}=\text { bulk density }\left[\mathrm{gm} / \mathrm{cm}^{3}\right] \text {. }
$$

The volumetric and gravimetric water contents may be related by the following expression:

$$
\theta=\frac{\rho_{d}}{\rho_{w}} w
$$

where: $\quad \rho_{w}=$ density of water $\left[\mathrm{gm} / \mathrm{cm}^{3}\right]$

The specific gravity is defined by:

$$
G_{s}=\frac{\rho_{s}}{\rho_{w}}
$$

where: $\quad G_{s}=$ specific gravity of solid particles [unit less]

$$
\begin{gathered}
\rho_{s}=\text { density of solid particles }\left[\mathrm{gm} / \mathrm{cm}^{3}\right] \\
\rho_{s}=\frac{m_{s}}{V_{s}}
\end{gathered}
$$




\subsection{Hydraulic Head, Soil Suction and Relative Humidity}

The hydraulic potential energy of water or total head is a measure of energy in the water phase. Hydraulic head comprises three components. These are gravitational head, pressure head and velocity head. In soils, it is commonly assumed that the velocity head is very small compared to the pressure and gravitational heads (Fredlund and Rahardjo, 1993). Hydraulic head is the sum of pressure head and elevation head and is expressed as the following:

$$
h=Z+\frac{u_{w}}{\rho_{w} g}
$$

where: $\quad h=$ hydraulic head $[\mathrm{m}]$

$$
\begin{aligned}
& u_{w}=\text { pore-water pressure head }[\mathrm{Pa}] \\
& g=\text { gravitational accelaration }\left[\mathrm{m} / \mathrm{sec}^{2}\right] \\
& \rho_{w}=\text { densitiy of water }\left[\mathrm{kg} / \mathrm{m}^{3}\right] \\
& Z=\text { elevation }[\mathrm{m}]
\end{aligned}
$$

The soil is called fully saturated when the pore spaces between the solid particles are filled with water and unsaturated when the pore spaces are filled partially with water and partially with air. Therefore, soils located below the water table are saturated soils. Soils located above the water table (and above the capillary fringe) will have water deficiency due to evaporation to the atmosphere and percolation to the water table. These soils are called unsaturated soils. In the unsaturated region or as the soil starts to desaturate, the porepressure is negative. This negative pore-water pressure contributes to the soil suction. 
Soil Suction is defined as the free energy state of soil water (from Edlefsen and Anderson, 1943). The thermodynamic relationship between the free energy of soil water (or soil suction) and the partial pressure of the pore water vapour is given as follows (Fredlund and Rahardjo, 1993):

$$
\psi=-\frac{R T}{v_{w o} \omega_{v}} \ln \left(\frac{v_{v}}{v_{v o}}\right)
$$

where:

$$
\begin{aligned}
& \psi=\text { total suction }[\mathrm{kPa}] \\
& R=\text { the universal gas constant }\left[\mathrm{J} \cdot \mathrm{mol}^{-1} \cdot \mathrm{K}^{-1}\right] \\
& T=\text { absolute temperature }[\mathrm{K}] \\
& v_{w o}=\text { specific volume of water }\left[\mathrm{m}^{3} \cdot \mathrm{kg}^{-1}\right] \\
& \omega_{v}=\text { molecular mass of water vapour }\left[\mathrm{kg} \cdot \mathrm{kmol}^{-1}\right] \\
& v_{v}=\text { partial pressure of pore water vapour }[\mathrm{kPa}] \\
& v_{v o}=\text { saturation pressure of vapour above pure water }[\mathrm{kPa}] \\
& \qquad R H=\frac{v_{v}}{v_{v o}}
\end{aligned}
$$

where: $\quad R H=$ relative humidity [unit less]

The total suction has two components, matric suction and osmotic suction. Total suction is the sum of these two components are expressed as:

$$
\psi=\left(u_{a}-u_{w}\right)+\pi
$$


where:

$$
\begin{aligned}
& \psi=\text { total suction }[\mathrm{kPa}] \\
& u_{a}=\text { pore-air pressure }[\mathrm{kPa}] \\
& u_{w}=\text { pore-water pressure }[\mathrm{kPa}] \\
& \pi=\text { osmotic suction }[\mathrm{kPa}]
\end{aligned}
$$

Matric suction is the difference between pore-air pressure, $u_{a}$ and pore-water pressure, $u_{w}$ across the air-water interface. Saturated soils will have negative matric suction as a result of excess pore-water pressure than pore-air pressure.

As the soil desaturates, the contractile skin becomes subjected to the pore-air pressure, $u_{a}$ since the pore-air pressure becomes greater than the pore-water pressure, $u_{w}$ and the radius of curvature of the contractile skin tends to decrease. Matric suction is also expressed using Kelvin's capillarity model equation as follows:

$$
\psi_{m}=\left(u_{a}-u_{w}\right)=\frac{2 T_{s}}{R_{s}} \cos \alpha
$$

where: $\quad \psi_{m}=$ matric suction $[\mathrm{kPa}]$

$$
\begin{aligned}
& T_{s}=\text { surface tension between pore space and soil particles }[\mathrm{N} / \mathrm{m}] \\
& R_{s}=\text { radius of curvature of the contractile skin }[\mathrm{m}] \\
& \alpha=\text { contact angle }
\end{aligned}
$$


The contact angle for soils with mixture of water is close to 180 degrees. Therefore, equation 2.3.5 will be reduced to:

$$
\psi_{m}=\frac{2 T_{s}}{R_{s}}
$$

Osmotic Suction is a suction caused due to the presence of ionic concentration in porewater. The presence of ions in the pore water decreases the vapour pressure release as a result of molecular attraction between the ions and water molecules. The relationship between osmotic suction and ionic strength of a solution is given by Van't Hoff equation (Sudhakar et al., 2005)

$$
\pi=i M R T
$$

where:

$$
\begin{aligned}
& \pi=\text { osmotic pressure }[\mathrm{kPa}] \\
& M=\text { molarity of the pore solution }\left[\mathrm{mol} \cdot \mathrm{L}^{-1}\right] \\
& T=\text { absolute temperature }[\mathrm{K}] \\
& R=\text { universal gas constant }\left[8.32 \mathrm{~L} \cdot \mathrm{kPa} \cdot \mathrm{mol}^{-1} \cdot \mathrm{K}^{-1}\right] \\
& i=\text { Van't Hoff factor }
\end{aligned}
$$

A number of empirical formulae are proposed to calculate the osmotic suction from electrical conductivity of salt dissolved solution. The USDA calibration curve relates the osmotic suction $(\pi)$ to the EC of pore water containing mixture of dissolved salts according to the following equation: (Fredlund and Rahardjo, 1993; Sudhakar et al., 2005). 


$$
\pi=31.92 E C^{1.08}
$$

where: $\quad \mathrm{EC}=$ the difference between electrical conductivity of the pore water in $\left[\mathrm{mS} \cdot \mathrm{cm}^{-1}\right]$ and the reservoir water in the odeometer cell.

\subsection{Theory of Soil-Water Characteristic Curve (SWCC)}

The soil-water characteristic curve (SWCC), also referred to as the soil moisture retention curve or water-retention curve, describes the relationship between the soil moisture content and the matric potential.

In a soil, the pore space created between two solid particles will be filled either with water or gases. Pores filled with water will constantly subjected to opposite forces either on process of retaining or losing the water. Water can be retained in the pore spaces as a result of adsorption, matric suction and osmotic suction. Similarly, water can be lost from the pore space as a result of evaporation to the atmosphere, partitioning from liquid phase to gas phase within the pore or drain due to gravity. These opposite forces, to retain or to lose water from the pore space, induce the phenomena called suction.

Adsorption is the molecular attraction between solid particle surfaces and water molecules. Adsorption is more significant for soils composed of smaller particles such as clay. Soils, composed of smaller particles have higher relative surface area and higher adsorbed volume 
of water. Capillarity is the commonly observed phenomenon whereby water rises up a glass tube immersed in a free water surface. The surface tension of the liquid supports the weight of the water. Capillarity may be related to matric suction through a well-known YoungLaplace equation (Fredlund and Rahardjo, 1993). The smaller the tube radius, the greater the matric suction required to drain it. The same principle operates for soil pores. Water may also be retained in soils by osmotic suction, which is due to the molecular attraction of water to ions dissolved in the pore water (Fredlund and Rahardjo, 1993).

The SWCC is commonly plotted as volumetric water content, gravimetric water content, or degree of saturation, versus suction. Soils composed of small sized particles exhibit higher suctions prior to drainage than soils with coarse size particles as a result, small sized particles have higher water holding capacity compared to coarse sized particles.

Soils with larger grain size (such as sand) have smaller surface tension between pore spaces and water as compared to soils with smaller grain sizes (such as clays). This smaller surface tension gives low water holding capacity as compared to the water holding capacity for clay soils. Sand soils will begin to desaturate very quickly compared to the clay soils. This point of desaturation is called air-entry value and, often interpreted as the suction required to drain the largest pore-size of the soil (Fredlund and Rahardjo, 1993). As suction increases, it will reach a point at which a large increase in suction is required to drain more water from the pores. This point is called the residual water content (Fredlund and Rahardjo, 1993). At this point, the water phase becomes discontinuous and is only present in isolated pockets. Water 
can then only be removed by evaporation and / or by flowing in thin films along the soil grain surfaces. Clayey soils often do not show either a distinct AEV or residual water content.

The SWCC depends, in part, upon whether the soil is losing or gaining water. This variation is termed hysteresis (Fredlund and Rahardjo, 1993). For adsorption, the suction at which significant water starts entering the soil can be lower than the suction required draining the soil to the residual water content.

A number of empirical formulas developed to represent soil-water characteristics curves of soils. van Genutchen (1980) proposed a three parametric equation to fit a wide range of soils and expressed as:

$$
w_{w}=w_{r v g}+\left(w_{s}-w_{r g}\right)\left\{\frac{1}{\left[1+\left(a_{v g} \psi_{m}\right)^{n_{v g}} m^{m_{v g}}\right.}\right\}
$$

where: $\quad w_{w}=$ gravimetric water content at a particular matric suction $[\%]$

$w_{s}=$ saturated gravimetric water content $[\%]$

$w_{r v g}=$ residual gravimetric water content $[\%]$

$a_{v g}=$ fitting soil parameter (inverse of soil suction) at the inflection point of the curve 
$n_{v g}=$ fitting parameter related to rate of desaturation of the soil

$m_{v g}=$ fitting parameter related to the curvature in high matric suction range

Fredlund and Xing (1994) proposed a flexible, continuous function extending at water content of zero at a suction $10^{6} \mathrm{kPa}$ and expressed as:

$$
w_{w}=w_{s}\left[1-\frac{\left(\ln \left(1+\frac{\psi_{m}}{h_{r}}\right)\right)}{\left(\ln \left(1+\frac{10^{6}}{h_{r}}\right)\right)}\right]\left[\frac{1}{\left\{\ln \left[\exp (1)+\left(\frac{\psi_{m}}{a_{f}}\right)^{n_{f}}\right]\right\}^{m_{f}}}\right]
$$

where: $\quad w_{s}=$ saturated gravimetric moisture content $[\%]$

$h_{r}=$ constant parameter used to represent soil suction at the residual water content

$a_{f}=$ fitting parameter corresponding to soil suction at the inflection point, related air entry value

$n_{f}=$ fitting parameter related to rate of desaturation of the soil

$m_{f}=$ fitting parameter related to curvature of the function at high suction range

\subsection{Unsaturated Hydraulic Conductivity}

The flow of water in soil is derived from Darcy's Law. Hydraulic conductivity for saturated soils is considered relatively constant. Research has shown that Darcy's law also applies for 
the flow of water through unsaturated soils. However, unsaturated hydraulic conductivity is a function of water content or matric suction (Buckingham, 1907; Richard, 1931; Childs and Collis-George, 1950).

The relative unsaturated hydraulic conductivity is defined by the ratio of unsaturated hydraulic conductivity at a given suction to saturated hydraulic conductivity. The relative unsaturated hydraulic conductivity, $\mathbf{k}_{\mathbf{r}}$, is expressed:

$$
k_{r}=\frac{k(\theta)}{k_{s}}
$$

where:

$k(\theta)=$ hydraulic conductivity at some volumetric water content $\theta$ $\left[\mathrm{m} \cdot \mathrm{sec}^{-1}\right]$

$k_{s}=$ the saturated hydraulic conductivity $\left[\mathrm{m} \cdot \mathrm{sec}^{-1}\right]$

Hydraulic conductivity of saturated soils is a function of pore size, or moisture content. Saturated hydraulic conductivity is also a function of void ratio within a given soils such as sand.

In unsaturated soil, flow of water will depend on water filled pores. Flow of water is continuous when the soil has higher moisture. As the soil starts to desaturate, there will be entrance of air into the pore spaces and start to create discontinuity between liquid water phases. The flow of water becomes tortuous as the soil desaturates (Fredlund and Rahardjo, 1993). As the soil dries out, the matric suction increases leading to decrease volume of water 
in the pores. Hydraulic conductivity will be considered zero, when it reaches a point where water may become disconnected in the soil.

Since the unsaturated hydraulic conductivity is difficult to measure experimentally, it is often predicted from the measured SWCC by a variety of semi-empirical methods, given that the saturated hydraulic conductivity is known. Many empirical correlations for estimating relative hydraulic conductivity have been derived by various authors (Gardner, 1958; Brooks and Corey, 1964; Laliberte et al., 1968; Fredlund and Rahardjo, 1993; Fredlund and Xing, 1994b).

For example, the hydraulic conductivity for unsaturated soils can be calculated using Mualem-van Genutchen equation as follows (van Genutchen, 1980):

$$
k_{r}\left(\psi_{m}\right)=\frac{\left\{1-\left(a_{v g} \psi_{m}\right)^{n_{v g}-1}\left[1+\left(a_{v g} \psi_{m}\right)^{n_{v g}}\right]^{-m_{v g}}\right\}^{2}}{\left[1+\left(a_{v g} \psi_{m}\right)^{n_{v g}}\right]^{m_{v g} / 2}}
$$

where:

$k_{r}\left(\psi_{m}\right)=$ relative hydraulic conductivity at a given matric suction

$a_{v g}, n_{v g}, m_{v g}$ are fitting parameters obtained by fitting the measured soil-water characteristic curve with Equation 2.4.2. 


\subsection{Liquid Flow in Unsaturated Soils}

The flow of water in soil could happen as liquid or vapour phase. Darcy's Law will be used to derive the one-dimensional liquid flow equation for unsaturated soil (Fredlund and Rahardjo, 1993). The difference between the amount of water passing in and out of a small element of soil can be equated to the change in stored water in that small element, and expressed as:

$$
\frac{\partial \theta}{\partial t}=\frac{\partial}{\partial x}\left(-k_{x} \frac{\partial h}{\partial x}\right)
$$

Similarly, the differential equation for liquid water transport for two-dimensional flow can be derived as follows:

$$
\frac{\partial \theta}{\partial t}=\frac{\partial}{\partial x}\left(-k_{x} \frac{\partial h}{\partial x}\right)+\frac{\partial}{\partial y}\left(-k_{y} \frac{\partial h}{\partial y}\right)
$$

The stored water in a given soil unit can be also related to the stress state. In unsaturated soil, the stress state of the soil is expressed using two parameters, namely the stress parameter ( $\sigma$ $\mathrm{u}_{\mathrm{a}}$ ) and matric suction $\left(\mathrm{u}_{\mathrm{a}}-\mathrm{u}_{\mathrm{w}}\right)$. The change in water content may be expressed as (Fredlund and Rahardjo, 1993):

$$
\frac{\partial \theta}{\partial t}=m_{1}{ }^{w} \frac{d}{d t}\left(\sigma-u_{a}\right)+m_{2}{ }^{w} \frac{d}{d t}\left(\sigma-u_{a}\right)
$$

where: $\quad \partial \theta / \partial t=$ the rate of change in volumetric water content 
$m_{1}{ }^{w}=$ the rate of change in water content with changes in applied normal stress

$m_{2}{ }^{w}=$ the rate of change in water content with suction, or the slope of the SWCC at a particular suction

$\sigma=$ normal stress

In many flow modelling problems, changes in total stress and air pressure are often ignored. In SWCC tests, the air pressure is equal to the total stress. In both cases, suction is the only pertinent stress variable. Therefore, the equation for two-dimensional flow may be written as:

$$
m_{2}{ }^{w} \frac{d}{d t}\left(u_{a}-u_{w}\right)=\frac{\partial}{\partial x}\left(-k_{x} \frac{\partial h}{\partial x}\right)+\frac{\partial}{\partial y}\left(-k_{y} \frac{\partial h}{\partial y}\right)
$$

\subsection{Vapour and Heat Transfer}

The flow of water vapour in unsaturated soil can be described using Fick's Law (Philip and de Vries 1957; de Vries, 1975; Fredlund and Dakashanamurthy 1982):

$$
V_{v a p}=-D_{v} \frac{\partial P_{v}}{\partial y}
$$

where: $\quad V_{v a p}=$ one-dimensional flux of water vapour $\left[\mathrm{M} \cdot \mathrm{L} \cdot{ }^{-2} \cdot \mathrm{T}^{-1}\right]$

$$
\begin{aligned}
& P_{\nu}=\text { partial pressure of water vapour }[\mathrm{kPa}] \\
& D_{\nu}=\text { diffusion coefficient of water through the soil }\left[\mathrm{kg} \cdot \mathrm{m} \mathrm{kN}^{-1} \cdot \mathrm{sec}^{-1}\right]
\end{aligned}
$$




$$
\begin{aligned}
& D_{v}=(\varepsilon)(\delta)\left(D_{v a p} \frac{\omega_{v}}{R T}\right) \quad \text { (Wilson, 1990) } \\
& \varepsilon=\text { tortuosity factor },=\delta^{2 / 3} \\
& \text { (Lai et al., 1976) } \\
& \delta=\text { cross-sectional area of soil available for vapour flow (i.e. (1-S) n) } \\
& D_{\text {vap }}=\text { molecular diffusivity of water vapour in air }\left[\mathrm{m}^{2} \cdot \mathrm{sec}^{-1}\right] \\
& \omega_{\nu}=\text { the molecular weight of water, }\left[0.018 \mathrm{~kg} \cdot \mathrm{mol}^{-1}\right] \\
& R=\text { universal gas constant, }\left[8.314 \mathrm{~J} \cdot \mathrm{mol}^{-1} \cdot \mathrm{K}^{-1}\right] \\
& T=\text { temperature, }[\mathrm{K}] \\
& n=\text { porosity } \\
& S=\text { degree of saturation } \\
& D_{v a p}=0.229 \times 10^{-4}\left(1+\frac{T}{273}\right)^{1.75} \quad \text { (Kimball et al., 1976) }
\end{aligned}
$$




$$
C_{v}=\frac{1}{\rho_{w}}\left(\frac{P+P_{v}}{P}\right)
$$

where: $\quad P=$ the total atmospheric pressure $[\mathrm{kPa}]$

$$
P_{v}=\text { the partial pressure due to soil vapour }[\mathrm{kPa}]
$$

The vapour pressure is related to the total suction of the soil through the relative humidity by

$$
R H_{s}=e^{\psi g \omega_{\nu} / R T}
$$

The solution for the derived one dimensional vapour flow depends on the temperature and transport of heat through the soil, which may be described by:

$$
C_{h} \frac{\partial T}{\partial t}=\frac{\partial}{\partial y}\left(\lambda \frac{\partial T}{\partial t}\right)-L_{v}\left(\frac{P+P_{v}}{P}\right) \frac{\partial}{\partial y}\left(D_{v} \frac{\partial P_{v}}{\partial y}\right)
$$

where: $\quad C_{h}=$ specific heat of soil

$\lambda=$ thermal conductivity

$L_{v}=$ latent heat of vapourization of water

$P=$ total pressure

$P_{v}=$ partial vapour pressure

$D_{v}=$ diffusion coefficient of water through the soil

It is important to note that these equations do not account for the effects of soil-structure change due to changes in water content, such as occur by consolidation. 


\subsection{Evaporation and Coupled Soil-Atmosphere Interaction}

\subsubsection{Surface Energy Balance Equation}

Solar radiation, wind speed, relative humidity, air temperature are the major climatic factors that control evaporation at the soil surface. Evaporation, in part, depends on the available energy for phase change at the soil surface. The energy budget may be written as:

$$
R_{n}=L_{v} E+H+G
$$

where:

$$
\begin{aligned}
& R_{n}=\text { net radiation } \\
& L_{v}=\text { latent heat of vaporization } \\
& E=\text { evaporation } \\
& H=\text { convective sensible heat flux } \\
& G=\text { conducted heat flux into soil-surface or water body }
\end{aligned}
$$

Each term in Equation 2.8.1.1 can further be defined as:

Latent heat flux:

$$
L_{v} E=-L_{v} K_{v} \frac{d \rho_{v}}{d z}=-L_{v} k_{v} \rho \frac{d h_{s}}{d z}
$$

where: $\quad k_{v}=$ the eddy transfer coefficient of the water vapour $\left[\mathrm{m}^{2} \cdot \mathrm{sec}^{-1}\right]$,

$$
\begin{aligned}
& \rho_{\nu}=\text { the vapour density in air, } \\
& \rho=\text { the density of moist air, }
\end{aligned}
$$




$$
\begin{aligned}
& z=\text { the distance upwards from the surface and } \\
& h_{s}=\text { the specific humidity in air. }
\end{aligned}
$$

Sensible Heat Flux:

$$
H=-\rho c_{\rho m} k_{h} \frac{d T_{d}}{d z}
$$

where: $\quad k_{h}=$ the eddy transfer coefficient of heat $\left[\mathrm{m}^{2} \cdot \mathrm{sec}^{-1}\right]$

$$
\begin{aligned}
& \rho=\text { the density of the moist air, } \\
& c_{p m}=\text { the specific heat of moist air at constant pressure } \\
& T_{d}=\text { the dry bulb temperature. }
\end{aligned}
$$

The ratio of the sensible heat flux to latent heat of flux is called the Bowen ratio (Bowen 1926).

$$
\beta_{o}=\frac{H}{L_{v} E}
$$

Substituting equation (2.8.1.4) into equation (2.8.1.1) and rearranging will give a simple formula to calculate the latent heat flux:

$$
L_{v} E=\frac{\left(R_{n}-G\right)}{\left(1-\beta_{o}\right)}
$$

Subsurface Heat Flux: 
Heat transfer also occurs from ground surface to layers beneath (subsurface). This transfer of heat is through conduction. One dimensional heat conduction in soil can be expressed as:

$$
G=-\lambda \frac{d T}{d z}
$$

where: $\quad \lambda=$ thermal conductivity.

In soils, the transfer of heat depends on the medium and proportion of the medium materials (Solids, water and air). For example the presence of water will also influence the transfer of heat due to convection. Therefore, $\lambda$ also represent the apparent thermal conductivity. Substitution of the above equation in the equation of conservation of heat produces

$$
C_{v h} \frac{\partial T}{\partial t}=\frac{\partial}{\partial z}\left(\lambda \frac{\partial T}{\partial z}\right)
$$

where: $\quad C_{v h}=$ volumetric heat capacity of the soil.

Both $\lambda$ and $C_{v h}$ vary depending on volume fractions of soil solids, water and air.

\subsubsection{Potential Evaporation}

Thornthwaite (1948) defined potential evaporation (PE) as "maximum rate of evaporation from a pure water surface under a given climatic condition." The potential rate of evaporation can be computed using Penman's equation (1948)

$$
P E=\frac{\Gamma}{\Gamma+\eta}\left(R_{n}-G\right)+\frac{\eta}{\eta+\Gamma} E_{a}
$$


where: $\quad \Gamma=$ slope of saturation vapour pressure temperature curve at a given temperature

$$
\eta=\text { psychrometric constant }
$$

$$
R_{n}-G=\text { Slope of the relationship between net radiation minus ground heat flux }
$$

$$
E_{a}=f(w)\left(e_{s}-e_{a}\right)
$$

On the right hand side equation 2.8.2.1 the first term describes the contribution of heat to evaporation while the second describes the contribution to evaporation arising from the gradient in vapour pressure. When there is no significant radiation. Penman equation will be reduced to equation 2.8.2.3

$$
E=f(w)\left(e_{s}-e_{a}\right)
$$

where: $\quad E=$ rate of evaporation $\left[\mathrm{mm} \cdot\right.$ day $\left.^{-1}\right]$

$$
\begin{aligned}
& e_{s}=\text { saturation vapour pressure of water at surface temperature }[\mathrm{kPa}] \\
& e_{a}=\text { vapour pressure of air in the atmosphere above the water surface }[\mathrm{kPa}] \\
& f(w)=\text { turbulent exchange function }
\end{aligned}
$$

Application of Equation 2.8.2.3 to field problems is difficult since it requires accurate determination of turbulent exchange function.

Potential rate of evaporation is only controlled by climatic conditions, such as temperature, relative humidity, vapour pressure, solar radiation and wind speed. 


\subsubsection{Evaporation from Soil-Water Mixture}

The rate of evaporation from a soil-water surface is known as actual rate of evaporation (AE). Evaporation from a saturated soil is close to the potential rate of evaporation, if the albedo and the ionic strength of the pore-water pressure is low. As the supply of water becomes limited at the surface, the actual rate of evaporation eventually becomes less than potential rate of evaporation (Gray, 1970; Brutseart, 1982).

Figure 2.8.3 shows that as soil dries, it passes through three different stages. Stage I occurs when the soil is near saturation and its rate of drying is close to the rate of potential evaporation. At Stage II, the flow of moisture to the surface becomes limited as a result of desaturation and associated reduction in hydraulic conductivity. The limited upward flow of water decreases the availability of moisture for evaporation and leads to a decrease in the actual rate of evaporation compared to potential evaporation. At Stage III actual rate of evaporation decreases further as the soil continues to dry and desiccate. At this stage the liquid-water phase becomes discontinuous and the actual rate of evaporation is very small (Hillel, 1980).

Evaporation at Stage I can be determined from climatic conditions, however Stage II and III are controlled with climatic conditions and the properties of the soil such as hydraulic conductivity, and vapour diffusivity. 


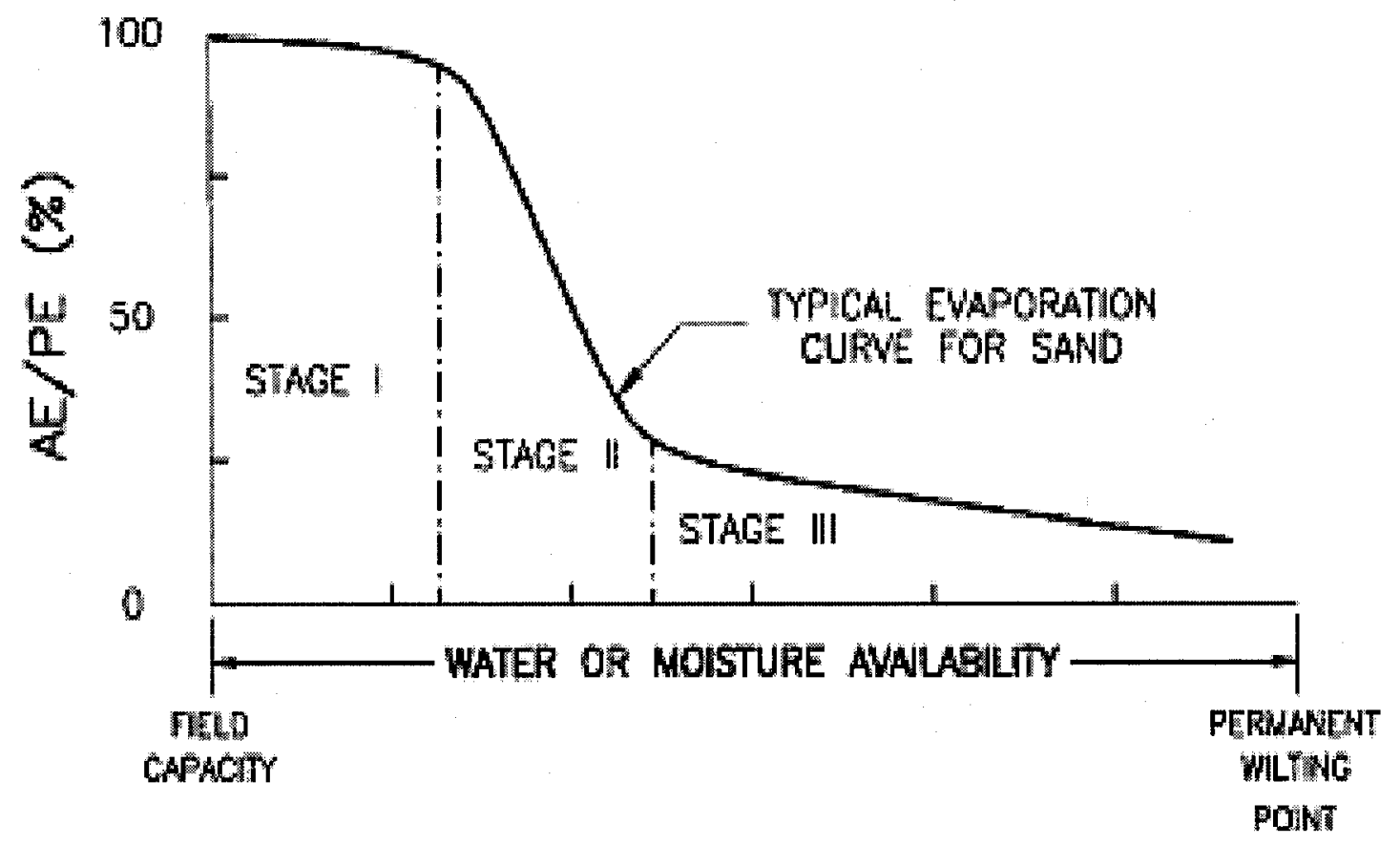

Figure 2.8.3: The relationship between rate of actual evaporation and potential evaporation (AE/PE) and water availability (from Hillel, 1980).

\subsubsection{Modelling of Evaporation at the Soil-Water Surface}

The actual rate of evaporation at Stage I can be modelled using Penman's equation (1948). However, Penman's equation is not suitable to model for Stage II and III drying as it's only controlled by climatic conditions.

Wilson et al. (1994) modified the Penman equation to account for the decrease in evaporation rate due to an increase in total suction at the soil surface

$$
A E=\frac{\Gamma R_{n}+\eta E_{a}}{\Gamma+\eta A}
$$


where: $\quad A E=$ actual evaporation flux from soil surface $\left[\mathrm{mm} \cdot \mathrm{day}^{-1}\right]$

$\Gamma=$ the slope of the saturation vapour pressures and temperature curve at the relevant temperature

$R_{n}=$ net solar radiation at soil surface $\left[\mathrm{mm} \cdot \mathrm{day}^{-1}\right]$

$\eta=$ psychrometric constant

$$
E_{a}=f(w) \times e_{a}\left(\frac{1}{R H_{a}}-\frac{1}{R H_{s}}\right)
$$

where: $\quad f(w)=$ depends on the mixing characteristics of the air, and was expressed by penman (1948) as:

$$
f(w)=0.35\left(1+0.146 w_{a}\right)
$$

where:

$$
W_{a}=\text { wind speed }\left[\mathrm{km} \cdot \mathrm{hr}^{-1}\right]
$$

Wilson et al (1994)'s modification is in Equation 2.8.4.2 for $\mathrm{E}_{\mathrm{a}}$, where the relative humidity $(\mathrm{RH})$ at the soil surface is determined from the total suction.

As the soil dries, the vapour pressure in the pores will decrease. However, AE/PE is approximately unity until a total suction is greater than $3000 \mathrm{kPa}$. The rate of actual evaporation decreases for total suction greater than $3000 \mathrm{kPa}$. Wilson et al. (1997) demonstrated this phenomenon in evaporation experiments on variety of soils. The relationship between relative humidity and the total suction at the soil surface is given by equation 2.8.4.4. This relationship in shown in Figure 2.8.4. 


$$
R H=e^{\psi \omega_{\nu} / R T}
$$

where: $\quad R H=$ relative humidity at the soil

$\Psi=$ total suction

$\omega_{v}=$ molecular weight of water

$R=$ universal gas constant

$T=$ absolute temperature

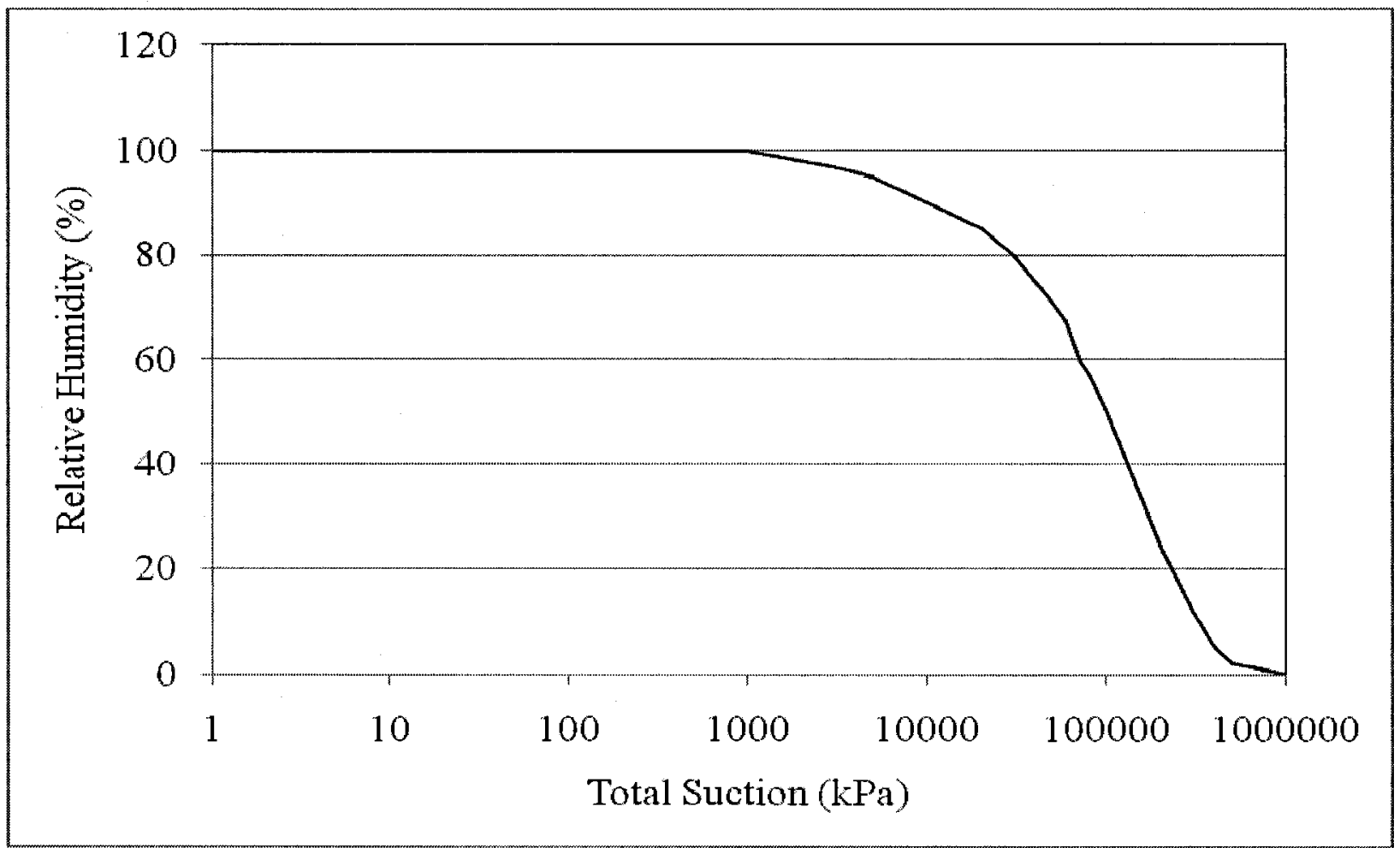

Figure 2.8.4: Relationship between the total suction and relative humidity (from Wilson et al., 1997). 


\subsubsection{Other Factors Affecting Evaporation from a Soil Surface or Tailings Surface}

Actual rate of evaporation from soil surface is also controlled by:

1. Effect deformation properties (Cracking)

2. Effect of salinity

\subsubsection{Effect of Deformation Properties}

The presence of fine particle in tailings, such as clay and silt makes the tailings susceptible to volume change due to desiccation and lateral shrinkage. The development and propagation of cracks was also observed during drying of deposited tailings. The development of cracks increase the surface area exposed to the atmosphere and possibly leads to an increase the rate of evaporation. One dimensional moisture flow modeling may underpredict the rate of evaporation from cracks since evaporation at the crack surface is happening in two dimensions. The evaporation from shrinkage cracks may be significant and this contributes to water loss from the tailings.

Several researchers reported that according field and laboratory investigation, development of cracks increase the rate of evaporation by taking water from the deeper zone of the soil profile (Adams et al., 1969; Selim and Kirkham, 1970; Ritchie and Adams, 1974; Hatano et al., 1988). In particular, after the horizontal soil surface becomes dry, evaporation from cracks may be a significant contribution to water loss from the soil. 
Abu-Hejleh and Znidarcic (1995) carried out numerical simulation of desiccation of soft clay using large-strain model. The model can describe three-dimensional shrinkage and crack propagation, but evaporation from the cracks may not be modelled correctly.

Fujiyasu (1997) investigated effect of cracks on rate of evaporation at Yoganup North Mine tailings pond and reported that in $1 \mathrm{~m}$ depth deposition more than $80 \%$ of the total evaporation occurred from the cracks after the horizontal surface of the tailings became very dry.

Thus, effect of cracks and lateral shrinkage may have significant effect on rate of evaporation from tailings surface. However, there is no theoretical or empirical model to quantify evaporation from cracks has been developed up to date.

\subsubsection{Effect of Salts}

Evaporation of saturated soils and tailings occurs at the surface. For salt containing soils, salt crust formation occurs at the surface where water vaporizes. During evaporation upward movement of moisture brings the salts to the surface and as the water vaporizes, the salts precipitated at the surface. Salt precipitation may occur below the soil surface when the soil 
surface is very dry. However, evaporation from such a dry soil surface occurs at a very low rate, even without the effect of salinity.

The precipitation of salts at the surface affects the rate of evaporation through different ways. Many researchers have shown that evaporation from a salt-encrusted surface is extremely low.

\subsection{High Albedo (Shortwave Reflectivity)}

Precipitated salt at the surface increases the reflectivity (high albedo) of the incoming shortwave length and reduces the energy balance by affecting the net radiation to uptake water. Effect of albedo was measured in Great Salt Lake West Desert in Utah and albedo was measured 0.24 on wet salt crust as compared to 0.75 on a dry crust (Malek et al., 1990). Brutsaert (1982) reported different albedo measurements of soils and reported that albedo values of soils are considerably lower than 0.75 values for the dry salt crust. This level of albedo significantly reduces the amount of net radiation received by the ground surface.

Hillel (1977) investigated effects of different albedo's, 0.05 and 0.5 for the same soil, on rate of evaporation using non-isothermal soil moisture flow model. It was also reported that the low albedo can cause $30 \%$ high rate of evaporation as compared to the higher albedo. Therefore, precipitation of salts contributes to less evaporation from the surface by reflecting the shortwave radiation. 
Fujiyasu (1997) found that albedo can increase up to 0.75 in slurried tailings. Simms et al. (2007) found that the albedo of the Bulyanhulu tailings increase up to 0.3 both in field and laboratory measurements.

\subsection{Low Vapour Density of Highly Saline Water}

Evaporation at surface may also be reduced due to decrease in vapour gradient between the soil surface and the air above the surface. The low saturation vapour density of saline water decreases the vertical vapour density gradient over the surface. For example, assuming the soil water encrusted with salt is probably equal to the saturation concentration, For Sodium Chloride, the vapour density that is in equilibrium with soil surface solution is $76 \%$ of vapour density of fresh water. The decrease in vapour density gradient decreases the rate of evaporation at the surface.

\subsection{High Salt Crust Resistance to Moisture Transfer}

Lee (1972) investigated the effect of salt crust resistance to upward moisture transfer by removing the soil and reported a thin brine surface tends to form on top of the solution during evaporation. This brine surface decreases evaporation (Turk, 1970). Malek et al. (1990) measured the water vapour transfer resistances of salt encrusted surfaces and suggested that the thin salt crust has a very high resistance to water vapour transfer. Chen (1992) reported that the porous structure and dryness nature of salt crust reduces the capillary rise of moisture and reduces removal of vapour from the soil surface. Zawislanski et al. (1992) showed that the rates of evaporation from salt-encrusted surfaces are similar to those observed from a soil with surface mulch (Gardner and Fireman, 1958) and suggested that the salt crust on the soil may have an effect similar to mulch. 
In general, Evaporation from saline soils is considerably less than from fresh water soils with the same soil properties.

Fujiyasu, (1997) investigated effect of salts on tailings evaporation at the laboratory and field and reported that after formation of salt crusts, the actual evaporation rates were less than $20 \%$ of the fresh water even when the initial salinity was moderate $(52 \mathrm{~g} / 1)$ as compared to evaporation rate from a slurry of salinity $107 \mathrm{~g} / 1,10 \%$ that of fresh water.

\subsection{Suction Measurement}

Matric suction and total suction can be measured by variety of methods. In this thesis, we use Heat Dissipation sensor and tensiometers. Other commonly used methods include relative humidity measurement and filter paper methods (Fredlund and Rahardjo 1993).

\subsubsection{Heat Dissipation Sensors}

The Heat Dissipation Sensor (HDS) is a commercially available sensor which uses a heat dissipation technique to indirectly measure the soil water matric potential. The HDS is comprised of a thermocouple, a heating element and a porous ceramic cup. The heating element is positioned inside the cylindrical porous ceramic cup and the thermocouple is located in the middle between the heating element and the cylindrical porous ceramic cup (Flint et al., 2002). 
When a constant power is dissipated from the line heat source, the temperature increase near the heat source will depend on the thermal conductivity of the ceramic/water complex surrounding the heater. A temperature increase is caused by heat that is not dissipated. As the water content and thermal conductivity of the ceramic increases, the temperature increase as measured by the thermocouple will be reduced because conduction of the thermal energy from the heat source is greater. A drier sensor will have a lower thermal conductivity, so the thermal energy will not dissipate as quickly and the temperature rise will be greater (Manual L-229).

\subsubsection{Delta Tensiometers (T5)}

The UMS T5 tensiometer is commercially available probe and used to measure the water tension in the soil in an unsaturated zone. This smaller size of T5 probe gives an advantage over other type of tensiometer due to imposing minimum disturbance of the sample experiments (Manual Delta UMS).

The body consists of pressure transducer supply and pressure reference lead. The sensor functions on a principle of the change in electric resistance on deformation of silicon semiconductors as a result of "Piezoresistive effect". This change in electrical resistance is processed to a defined signal. The deformation is caused by the pressure (or water tension) on the silicon chip, which is very thin and therefore extremely sensitive to pressure variations. The tensiometer cup comprises the ceramic end and the acrylic plastic shaft. The tensiometer ceramic acts like a porous filter. Firstly, it is water permeable, so that the water 
tension of the soil can be transmitted to the tensiometer water and, via this, to the pressure transducer. Secondly, when wet, it is impermeable to air below a certain pressure, so that a "water tension" (under-pressure) can build up in the tensiometer cup. Every ceramic is carefully selected by UMS for a defined pore size and homogeneous pore structure. The AEV of the ceramic tip is $300 \mathrm{kPa}$.

\subsection{Axis Translation Technique}

Axis translation is a technique used to measure pore water pressure of unsaturated soils using positive pore air pressure as a reference (Hilf, 1956). It is difficult to measure negative pore water pressure greater than to -1 atmosphere as most instruments will cavitate at this pressure Laboratory measurement of unsaturated soils can be performed by translation of the original reference axis to pore-air pressure.

Axis translation technique uses the pore air pressure, $u_{a}$, equal to the applied external pressure and the pore-water pressure, $u_{w}$ at zero. Therefore, the change in matric suction is the change in air pressure, as $\psi_{m}=\left(u_{a}-u_{w}\right)$. In otherwords, the pore-water pressure can be raised to a positive value that can be measured without cavitation occurring. The axistranslation technique has been successfully applied by numerous researchers to the volume change and shear strength testing of unsaturated soils (Bishop and Donald, 1961; Gibbs and Coffey, 1969b; Ho and Fredlund, 1982a) The use of axis translation technique requires the control of pore-air pressure and the measurement of pore-water pressure. 


\section{Materials and Methods}

\subsection{Introduction}

\subsubsection{Bulyanhulu Mine Tailings}

Most of the laboratory experiments were performed on non-plastic gold tailings obtained from the Bulyanhulu mine in Tanzania. Though the tailings were shipped at a pumping water content of $40 \%$ gravimetric water content (GWC), the tailings were consolidated during transport and arrived at a GWC ranging from $25-30 \%$, covered with a layer of bleed water. Prior to the testing, the tailings were remixed with the bleed water to bring the initial water content back to the pumping water content, using a paint mixer and by hand.

Basic geotechnical properties were determined on the tailings in laboratory according to the ASTM standards of D854 (specific gravity test), D4318 (Atterberg limits), D427 (shrinkage limit), and D422-63 (particle size analysis using hydrometer). Saturated hydraulic conductivity was determined using falling head test. Properties of the tailings are presented in Table 3.1.1, and the particle size distribution is shown in Figure 3.1.1

Table 3.1.1: Material properties of the Buyanhulu tailings.

\begin{tabular}{|l|l|}
\hline Properties & Values \\
\hline Specific gravity & 2.98 \\
\hline$D_{10}, D_{50}, D_{60}$ (micron) & $2,35,55$ \\
\hline$C_{u}\left(D_{60} / D_{10}\right)$ & 27.5 \\
\hline$W_{l}, W_{p}, W_{s h}(\%)$ & $20,19,20$ \\
\hline$k_{s a t}(\mathrm{~m} / \mathrm{sec})$ & $2 \times 10^{-7}$ \\
\hline
\end{tabular}




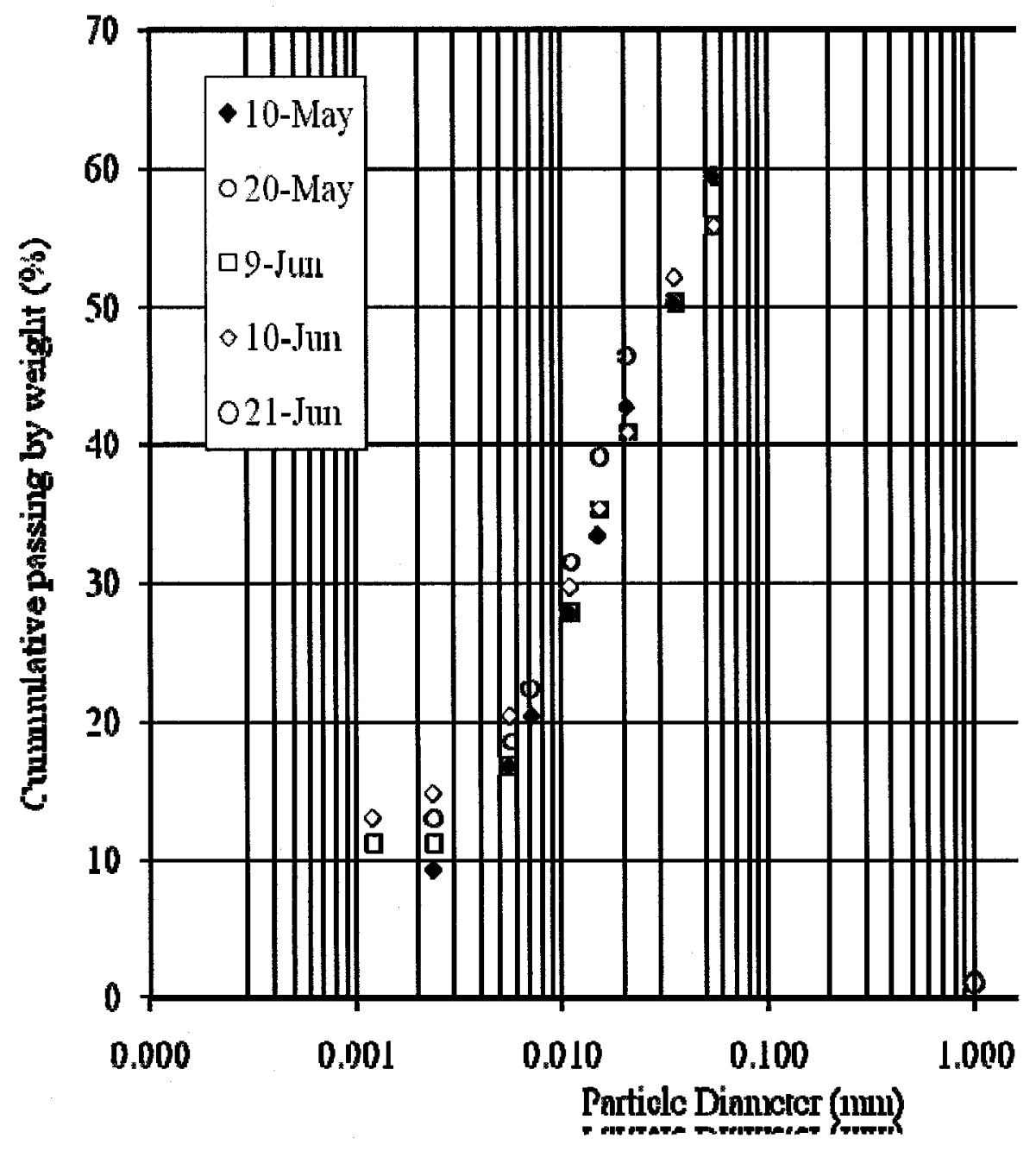

Figure 3.1.1: Particle size distribution for Bulyanhulu tailings using a hydrometer test.

The SWCC for the Bulyanhulu tailings was obtained in the laboratory using a volumetric pressure extractor plate (Model 1250). The experimental setup and the technique in obtaining the data points for the SWCC test are described in detail in a separate section.

The solid and liquid phases of the Bulyanhulu tailings were analyzed for elemental composition at Acutest laboratories. These results are in Appendix C and D. The most 
notable species in the pore-water were Iron $31100 \mathrm{mg} / 1$ in liquid phase and $78400 \mu \mathrm{g} / \mathrm{g}$ in solid phase; Calcium $7030 \mathrm{mg} / \mathrm{l}$ in liquid phase and $17700 \mu \mathrm{g} / \mathrm{g}$ in solid phase; Magnesium $2010 \mathrm{mg} / \mathrm{l}$ in liquid phase and $5070 \mu \mathrm{g} / \mathrm{g}$ in solid phases.

\subsubsection{Toromocho Mine Tailings}

Small scale drying tests were performed on Toromocho mine tailings. The tailings were shipped with $40 \%$ gravimetric moisture content (GWC). The tailing consolidated through self-weight during transportation to a range of 25-28\% GWC and covered with the bleed of water inside the plastic bag. Before the experiment, the tailings were prepared to have uniform GWC by remixing the covered water using a paint mixer and by hand.

Basic geotechnical properties were determined on Toromocho tailings in the laboratory. These laboratory experiments were done according to the ASTM standards of D854 (specific gravity test), D4318 (Atterberg limits), D427 (shrinkage limit), and D422-63 (particle size analysis using hydrometer). Falling head test was used to determine saturated hydraulic conductivity. Properties of the tailings are presented in Table 3.1.2, and the particle size distribution is shown in Figure 3.1.2.

Table 3.1.2: Material properties of Toromocho tailings.

\begin{tabular}{|l|l|}
\hline Properties & Values \\
\hline Specific gravity & 3.00 \\
\hline$W_{l}, W_{p},(\%)$ & 20,18, \\
\hline$k_{s a t}(\mathrm{~m} / \mathrm{sec})$ & $2 \times 10^{-7}$ \\
\hline
\end{tabular}




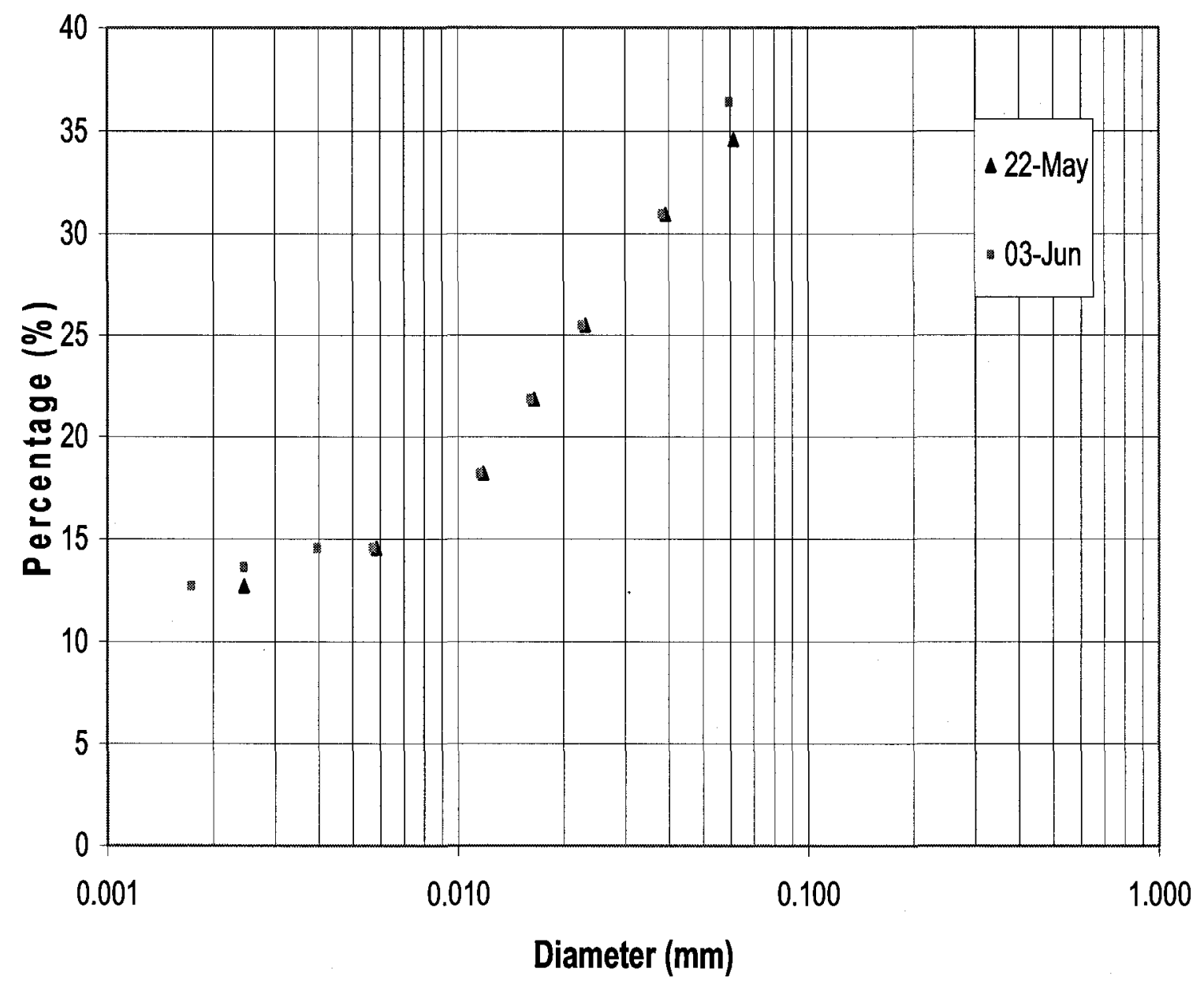

Figure 3.1.2: Particle size distribution for Toromocho tailings using hydrometer test. 


\subsection{Large-Scale Experimental Setup for Bulyanhulu Tailings Drying Test}

\subsubsection{Potential Evaporation (PE)}

$\mathrm{PE}$ at the laboratory was measured two different ways. First, five smaller buckets were filled with water and placed at different locations within the box to observe the effect of the different locations on evaporation. Wind was induced using commercial fans mounted on two sides of the box facing each other. Several tests were done on how the wind within the box was distributed and the effect of fans facing each other by adjusting the fan speed and alternatively operating the fans. The weight, temperature and relative humidity at $1 \mathrm{~m}$ from the bottom of the box was recorded daily. Second, weight was measured again without the fans operating. This assumption was to account for the effect of radiation on evaporation. Measurements with respect to weight, temperature and relative humidity values were recorded. Effect of radiation was ignored since the rate of evaporation was calculated to be less than $0.065 \mathrm{~mm} /$ day when the fans were turned off.

Consequently Wind was the main factor for loss of water during the drying test. Wind speed was calculated using the Penman equation, by equating the measured potential evaporation at a given temperature and relative humidity. Wind speed was calculated to be $29 \mathrm{~km} / \mathrm{hr}$ for the large scale test.

\subsubsection{First Layer Deposition}

A steel box $2.7 \mathrm{~m}$ long, $1.47 \mathrm{~m}$ wide and $1 \mathrm{~m}$ deep was used for the large scale evaporation experiments. Two wooden board separators were placed inside the box at $0.6 \mathrm{~m}$ distance from each end of the box. The separated sections at either end of the box were used as extra 
room for the researchers to pour the sample and collect samples during the test. A load cell (WM-II Model from Artech Industries Inc.) was used to measure the weight of the experimental box as the drying test progressed. Four load cells were placed on the floor to carry each corner of the box. Each load cell has a capacity of $2272.73 \mathrm{~kg}$. The total weight was recorded using datalogger every 10 seconds. Figure 3.2.1 and Figure 3.2.2 show a top and side view of a single load cell, respectively. Figure 3.2.3 shows the layout of the load cell prior the experimental setup. Figures 3.2.4 and Figure 3.2.5 shows the outer and inner views of the steel box prior the deposition of the tailings.

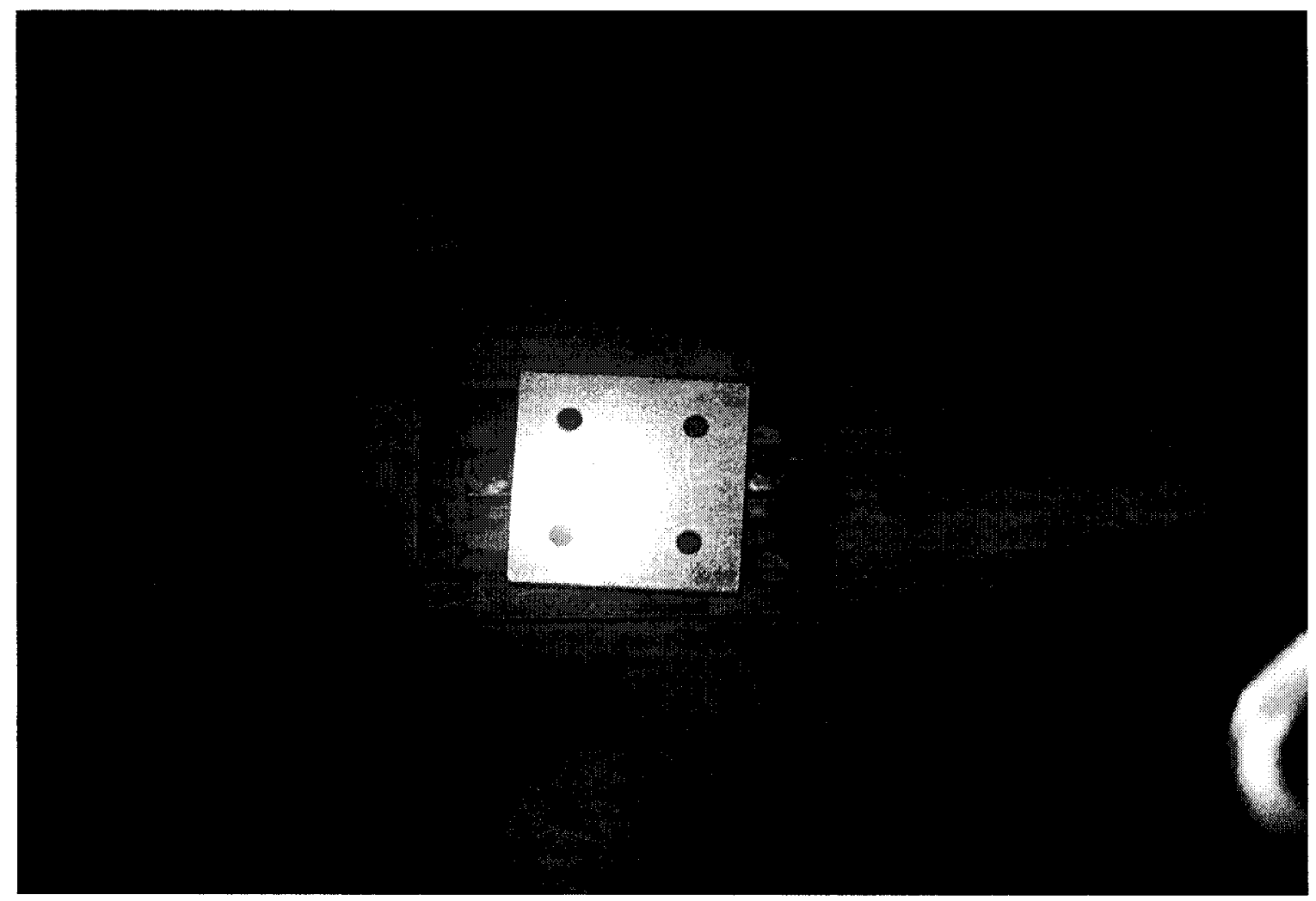

Figure 3.2.1: Top view of a load cell with a capacity of $2272.73 \mathrm{~kg}$ (Artech Industries Inc.). 


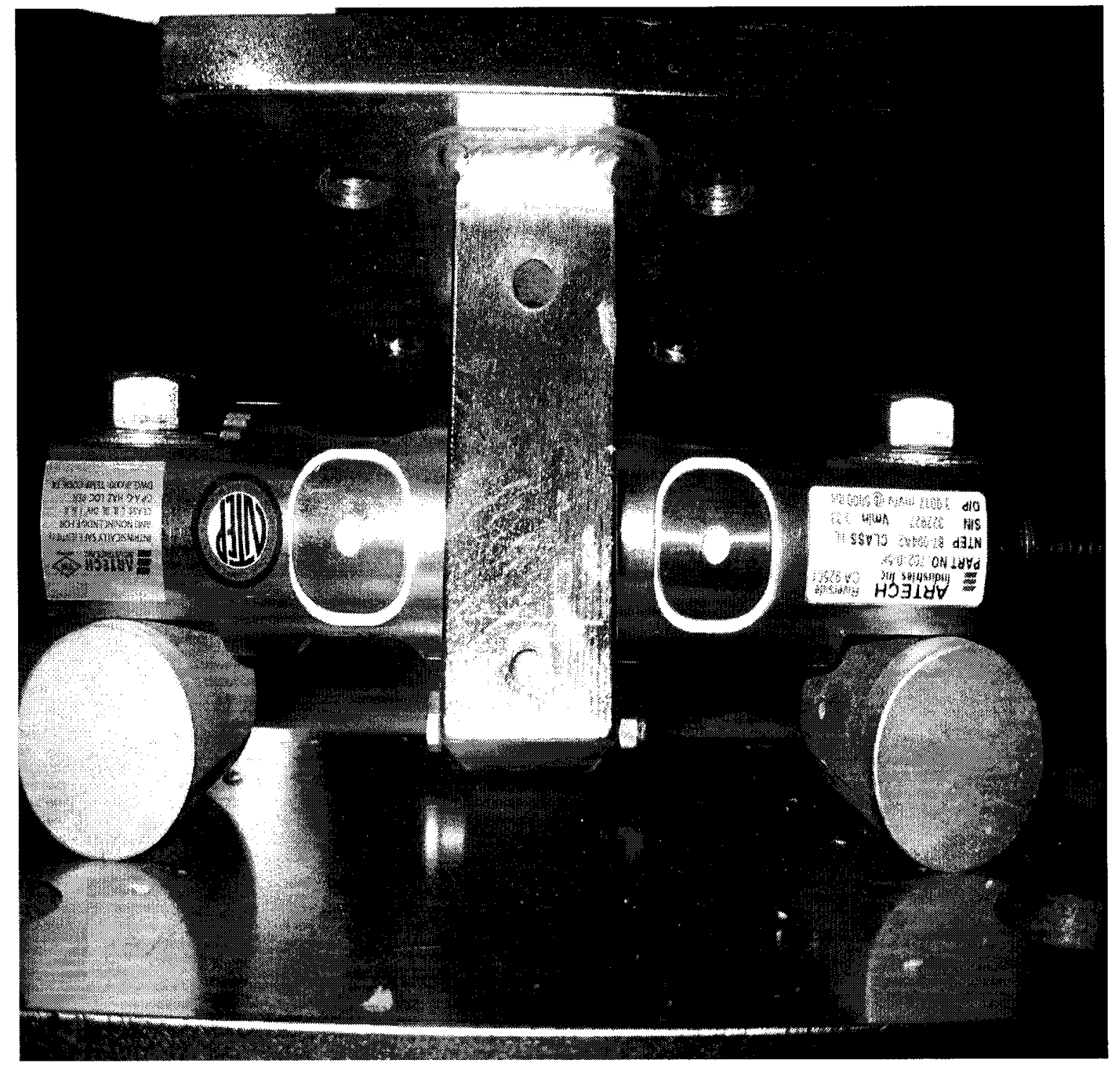

Figure 3.2.2: Side view of a load cell with a capacity of $2272.73 \mathrm{~kg}$ (Artech Industries Inc.). 


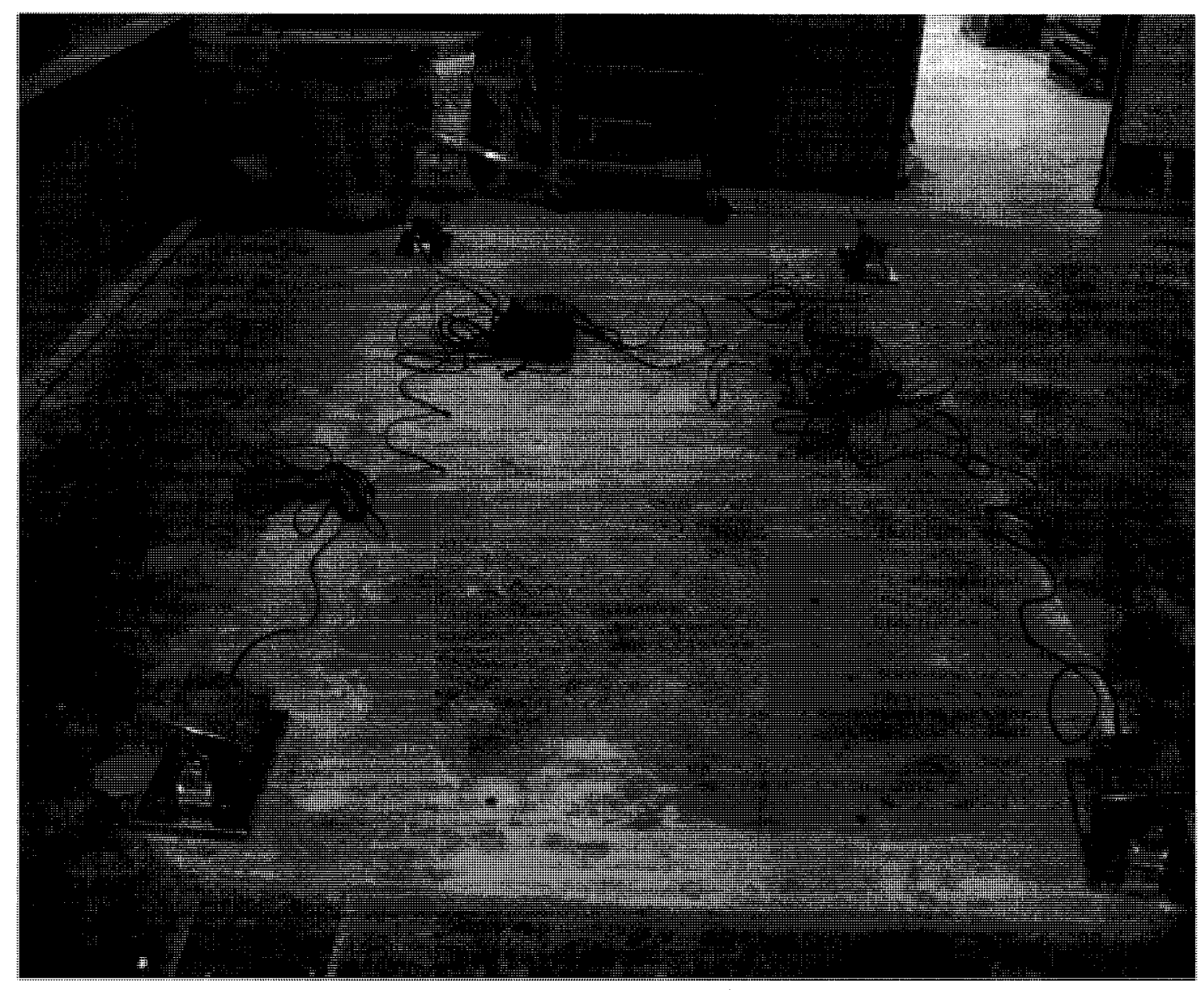

Figure 3.2.3: Layout of a load cells prior the experimental setup. 


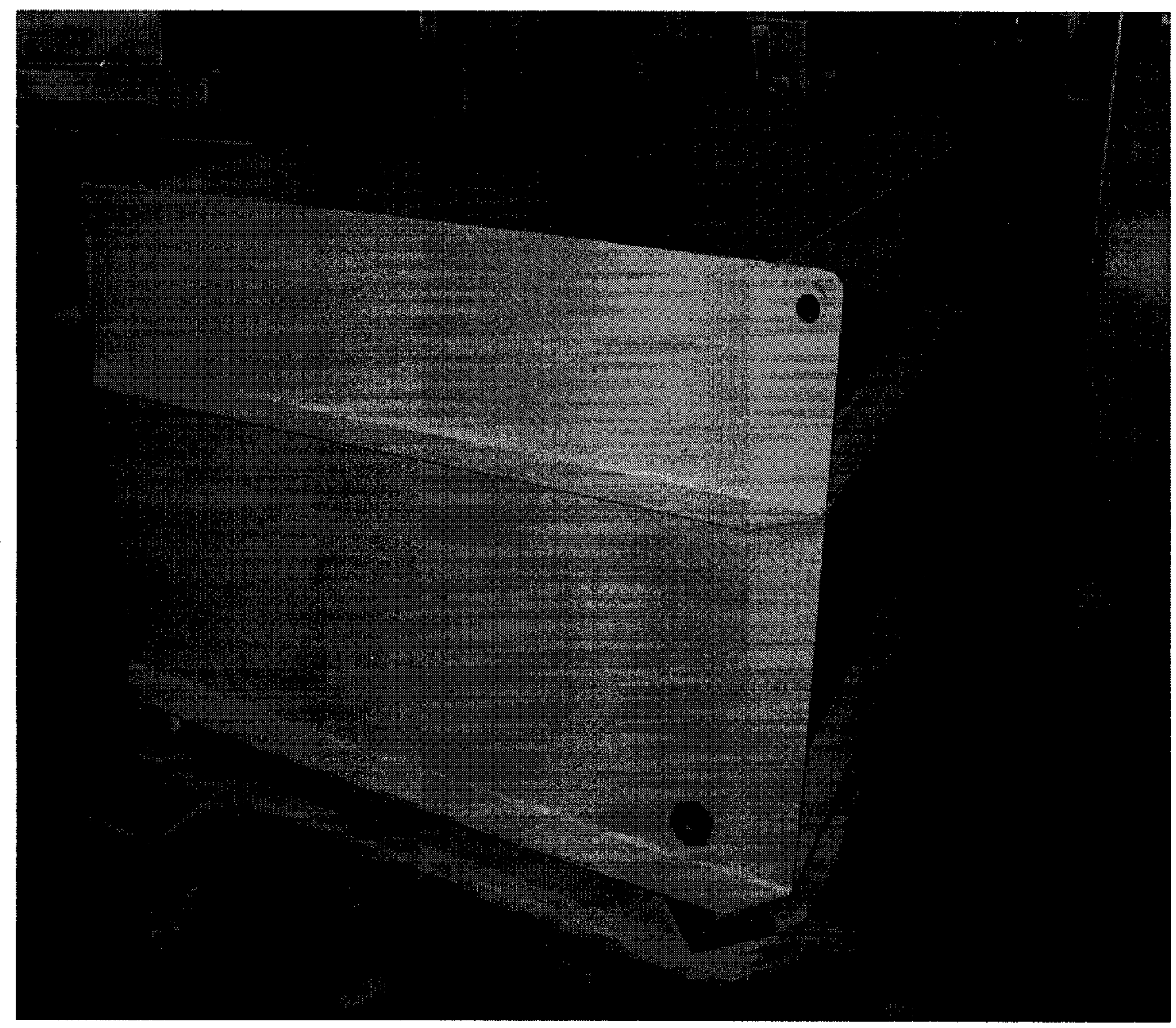

Figure 3.2.4: Outer view of an empty box on top of the load cell prior the drying test. 


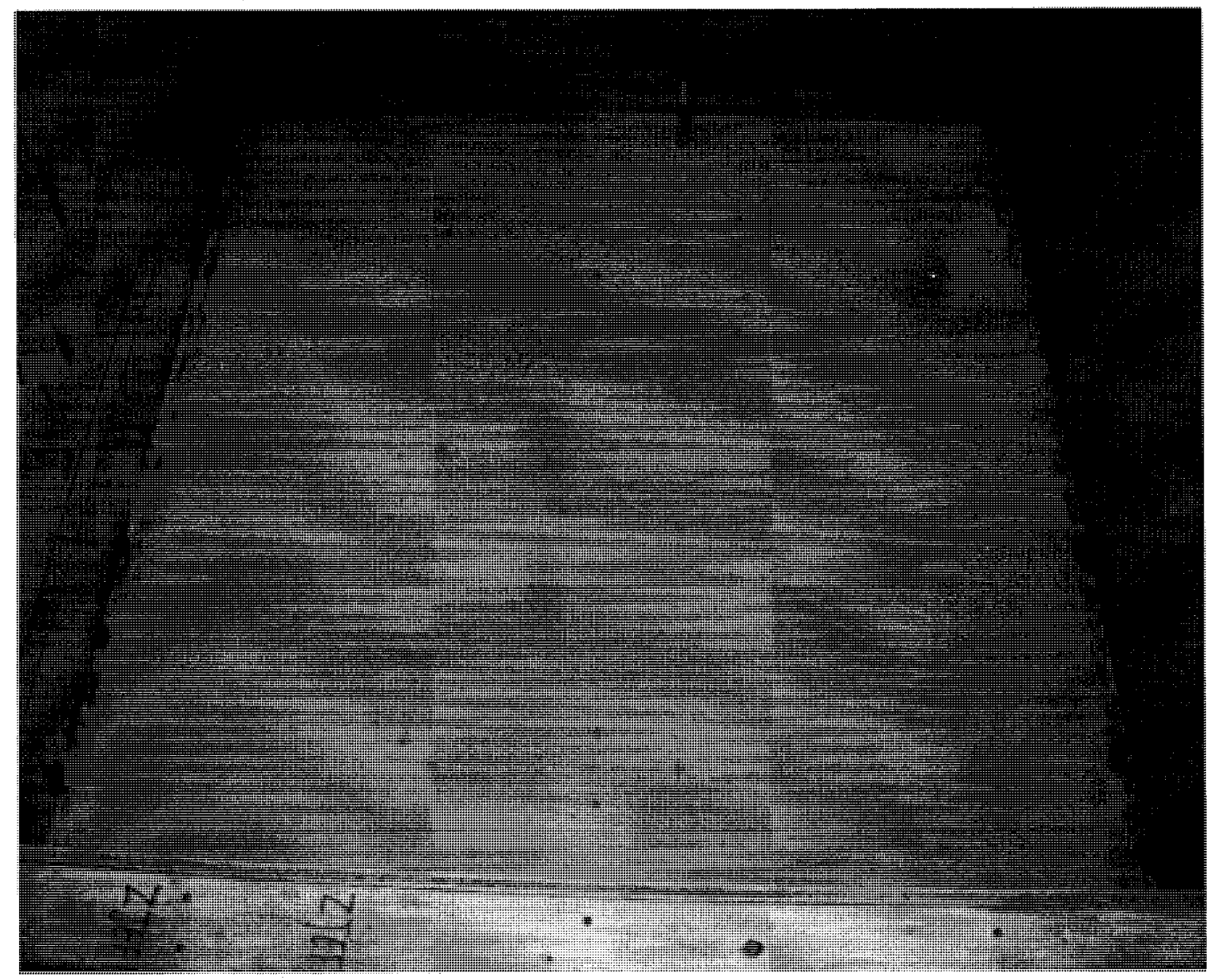

Figure 3.2.5: Inner view of large scale box prior to surface deposition of mine tailings.

The first layer of Bulyanhulu tailings were poured into the empty box after proper mixing, using hand and paint mixer to bring to $40 \% \mathrm{GWC}$ as shown in Figure 3.2.6. A $1.47 \mathrm{~m}$ by $1.52 \mathrm{~m}$ by $11 \mathrm{~cm}$ deep layer was placed. Two commercial fans were placed on each side of the box, facing opposite direction, to simulate wind in the field as shown in Figure 3.2.7. The room temperature, relative humidity was measured and recorded at $1 \mathrm{~m}$ above the bottom of the box using USB datalogger from Omega Engineering Inc. Measured relative humidity, 
temperature and calculated PE for each day are plotted on Figure 3.2.8. The first layer tailings were dried for ten days. Figure 3.2.9 shows the first layer drying test deposition.

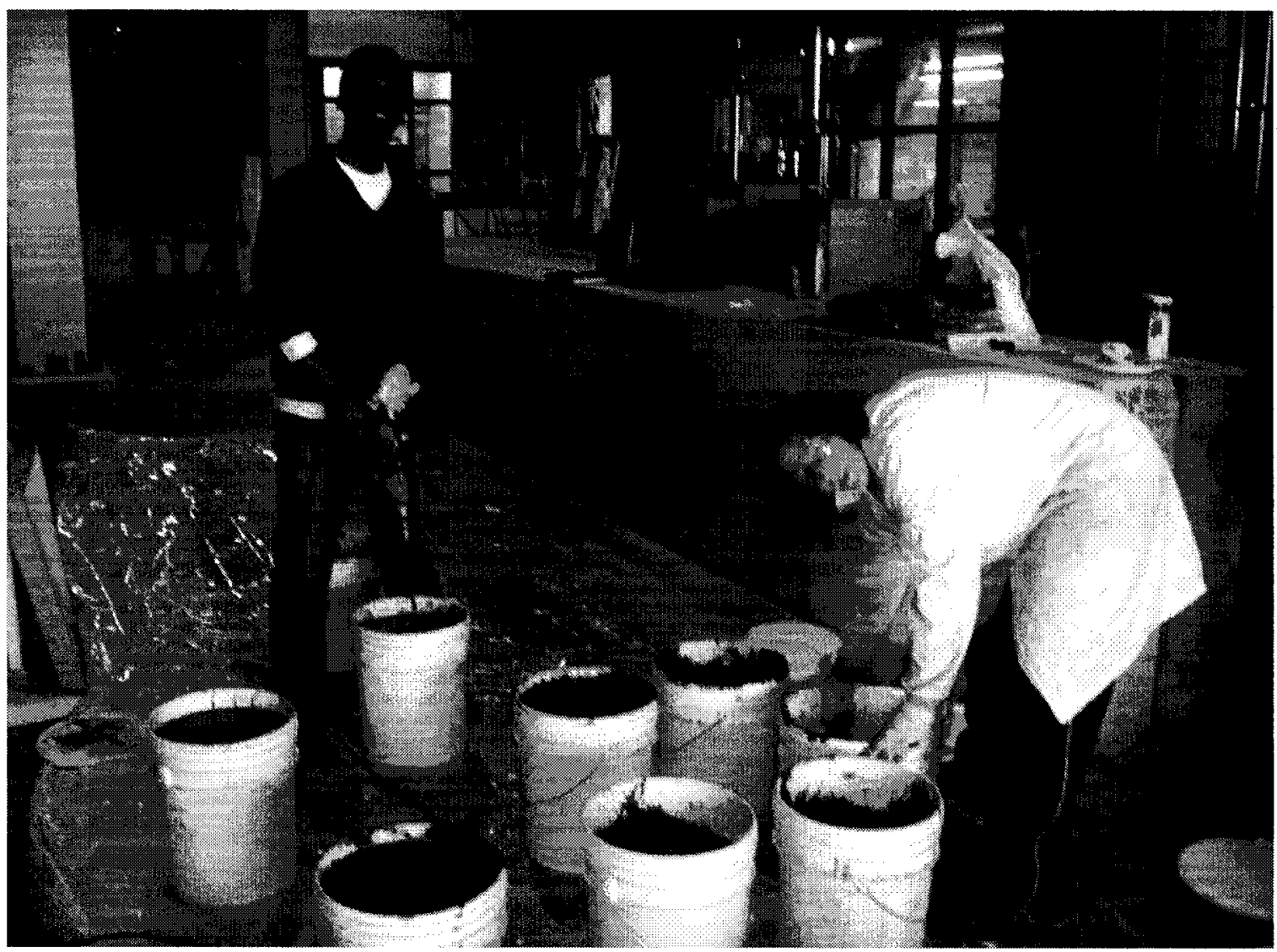

Figure 3.2.6: Tailings were mixed using paint mixer and by hand before deposition. 


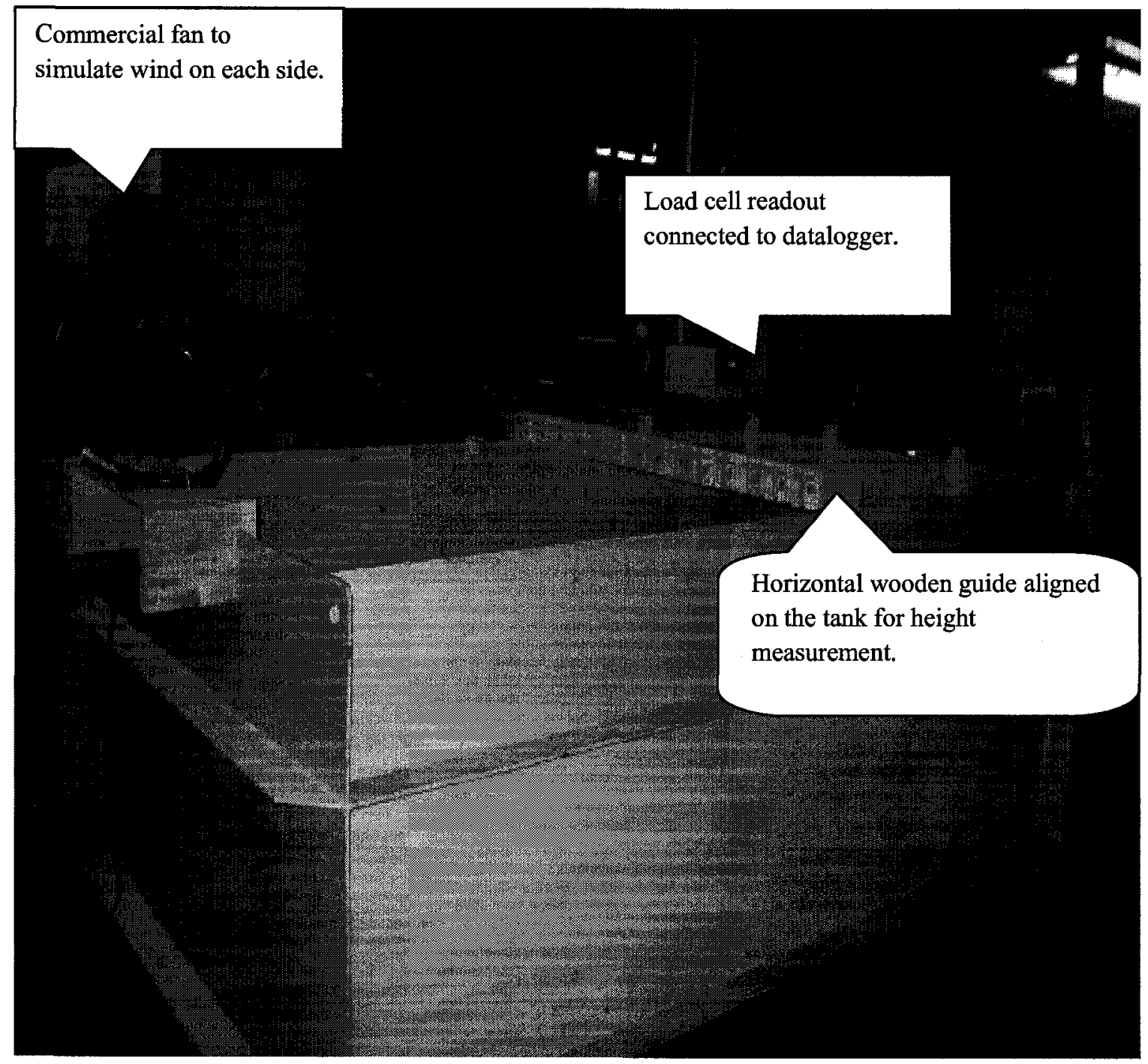

Figure 3.2.7: Laboratory large scale experimental set up for drying test. 


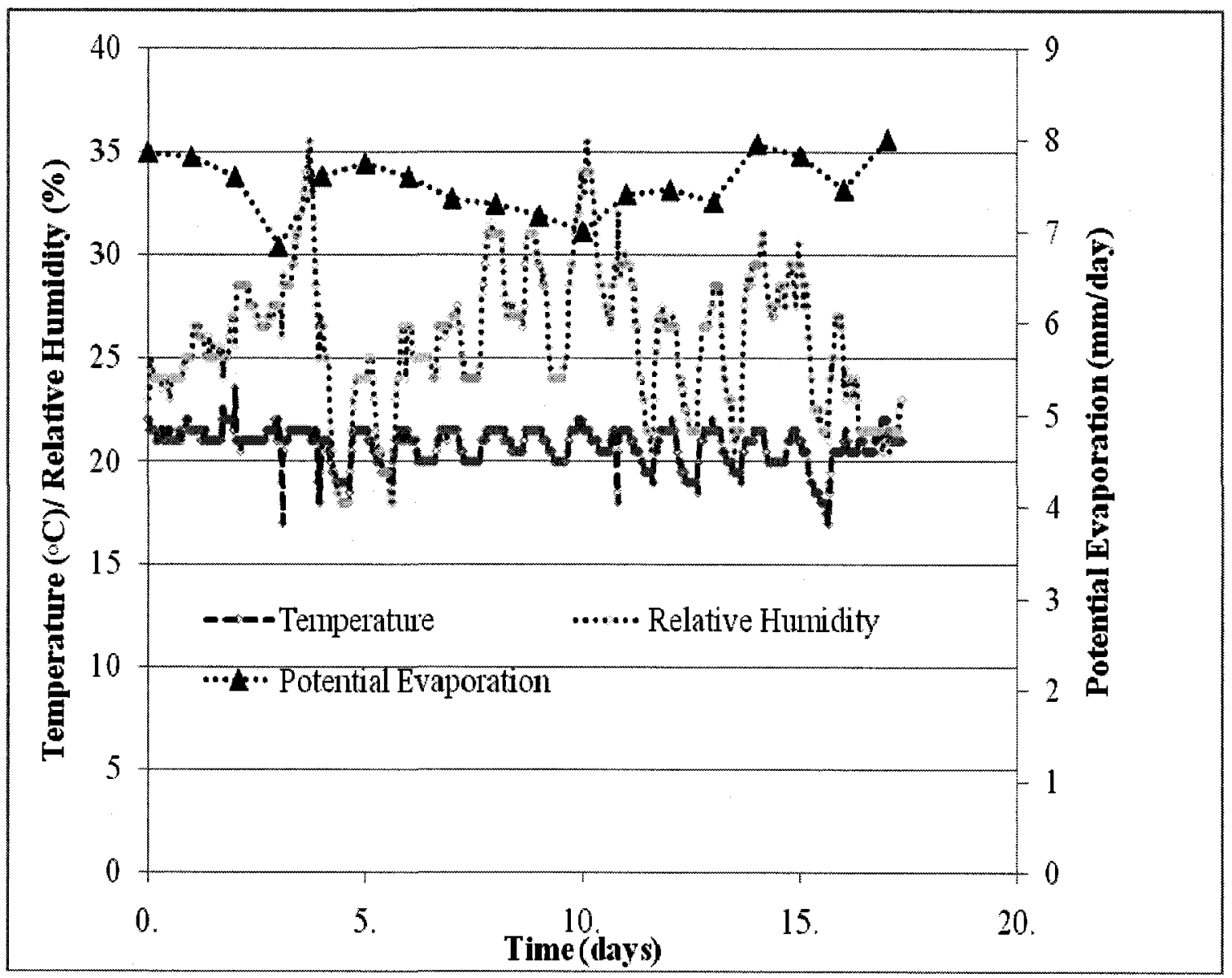

Figure 3.2.8: Computed potential evaporation, daily temperature and relative humidity data for large scale Bulyanhulu drying test. 


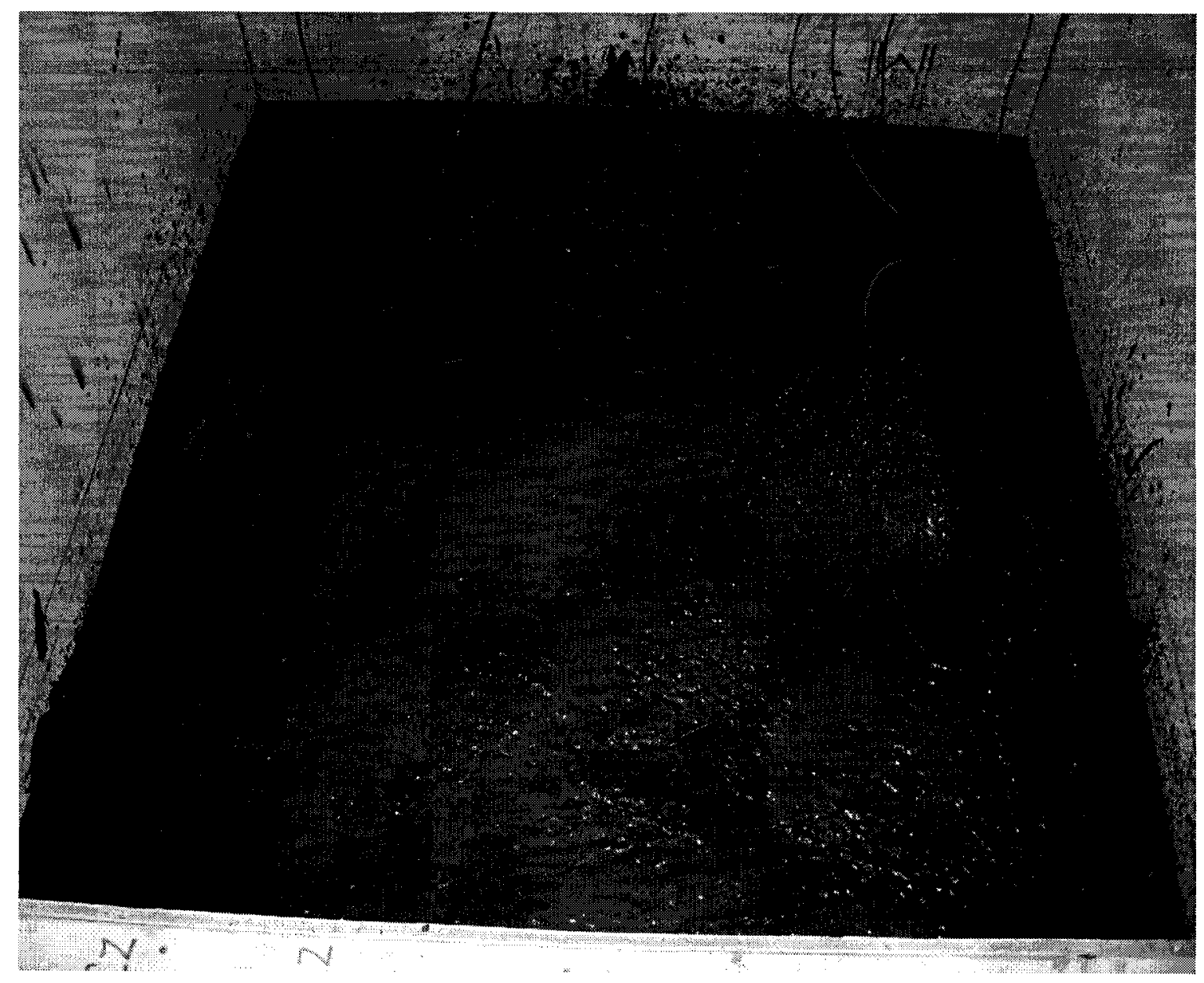

Figure 3.2.9: First layer large scale drying test.

The tailings were instrumented with two types of suction probes. Four Campbell Scientific 229-L heat-dissipation sensors (HDS) were installed at different heights. The locations of HDS sensors were know only to $10 \mathrm{~mm}$ accuracy, due to the size of the sensors and the capacity for vertical drift during settlement of the tailings. The HDS sensors were located at 0-10 mm, $40-50 \mathrm{~mm}, 80-90 \mathrm{~mm}$ and $80-90 \mathrm{~mm}$ from the bottom of the tank. Similarly three delta T5 tensiometers (T5) were inserted at different location. The locations were $40-50 \mathrm{~mm}$, $80-90 \mathrm{~mm}$ and $80-90 \mathrm{~mm}$ from the bottom of the box. 
Each HDS was calibrated from 20 to $2500 \mathrm{kPa}$ by a commercial laboratory. The heater in each sensor was activated every hour (for details please see Section 2.9.1 Heat Dissipation Sensors). The T5's have a tip with an air-entry value of about $300 \mathrm{kPa}$, and are conditioned using cycles of vacuum and overpressure prior to their use in the experiments in order to eliminate the cavitation nuclei (Guan and Fredlund, 1997). This allows the T5's to operate above $100 \mathrm{kPa}$ matric suction for a period of time, until diffusion of air into the sensors induces cavitation. Data from the T5's were recorded every 10 seconds, while data from the HDS were recorded hourly.

Daily volume change measurements were employed using a wooden guide aligned across the tank. This wooden guide moved across the top surface of the box. Holes were drilled in the wooden guide at spaces that varied from $100-150 \mathrm{~mm}$ to allow for dropping a ruler perpendicular to the surface. Assuming the wooden guide is located in y direction, the box was marked at $15 \mathrm{~cm}$ intervals as a mesh in the $\mathrm{x}$ direction. The topography of the top of the tailings was measured once a day at the grid point locations.

Surface gravimetric water content was measured daily from the top $10 \mathrm{~mm}$ and a GWC profile with depth was measured every week. Conductivity of the pore-water was measured using a pore-water squeezer every two days by taking a small sample from the top $10 \mathrm{~mm}$. The development of cracks was estimated by sketching the major and tributary cracks and 
assigning reference numbers to each crack line. As shown in Figure 3.2.10 each crack line width was measured using a ruler. The length of the crack was measured using a flexible teflon tape placed along the top of the crack. The depth of the crack was estimated visually without destroying the microstructure of the tailings. The volume of the cracks was estimated and daily photographs were also taken.

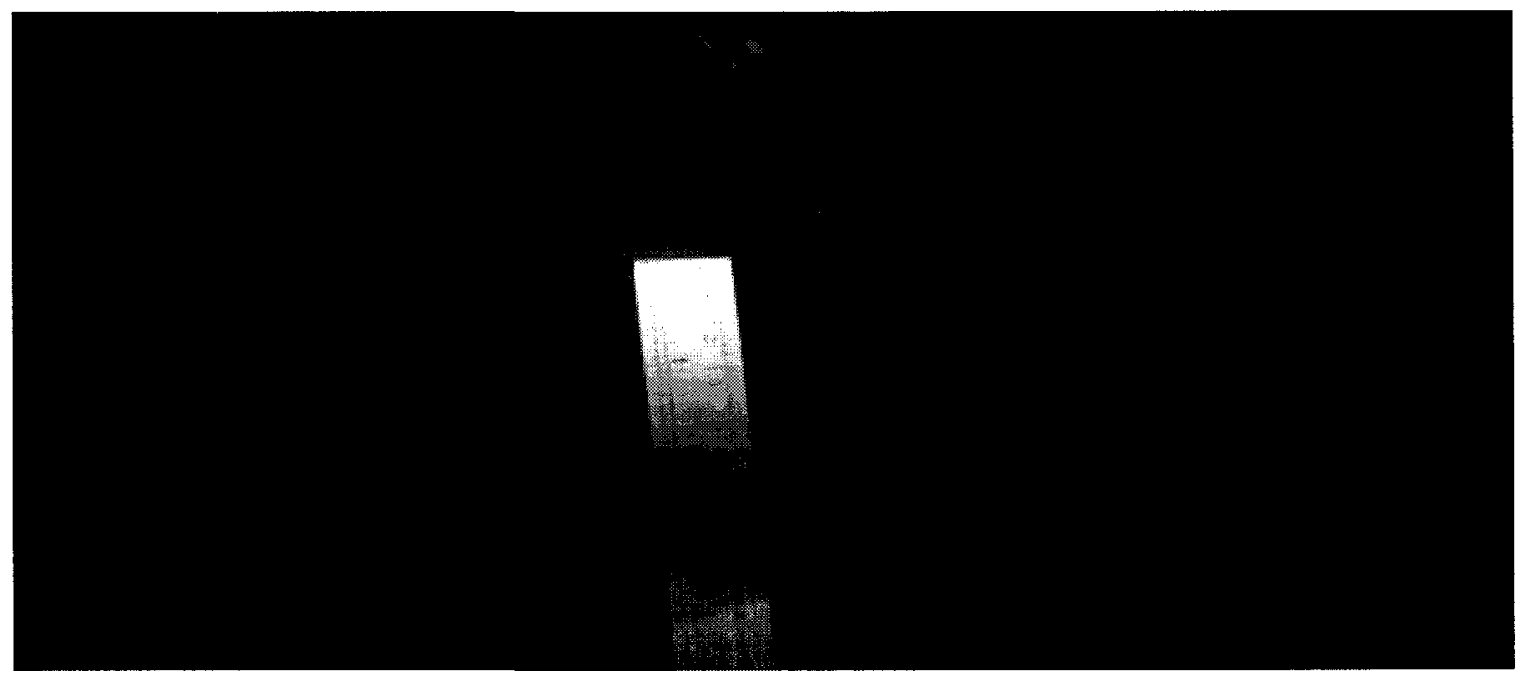

Figure 3.2.10: Crack width and length measurements.

\subsubsection{Second Layer Deposition}

On day 11 , a second fresh layer was prepared at $40 \% \mathrm{GWC}$ and placed on top of the first dried layer. The second layer was $8 \mathrm{~cm}$ in depth immediately after it was placed.

Matric suction in the second layer was measured using four HDS sensors and four T5 tensiometers. The location of the HDS sensors was $1-2 \mathrm{~cm}, 4-5 \mathrm{~cm}, 7-8 \mathrm{~cm}$ and 7-8 $\mathrm{cm}$ from the top of dried layer. The T5s were located $1-2 \mathrm{~cm}, 1-2 \mathrm{~cm}, 5-6 \mathrm{~cm}$ and $7-8 \mathrm{~cm}$ from the top 
of dried layer. Matric suction measurements were recorded by the datalogger from four T5 and eight HDS; four in each layer. The T5's located in the first layer cavitated on day 5.

Each day volume, gravimetric moisture content and conductivity measurements were determined as described in the previous section. The second layer was allowed to dry for 5 days before rewetting.

\subsubsection{Rewetting}

The large scale experiment was rewetted fifteen days after the deposition of the first layer and five days after the deposition of the second layer to simulate a rainfall event. A volume of $159 \mathrm{~L}$ was added during rewetting and increased the average GWC from $16.5 \%$ to $25.7 \%$. Rewetting was achieved by adding water slowly and gently from the top. The fans were turned off for 6 hours to allow infiltration of water to the bottom of deposited layer. Leakage of tailings with water was observed from the partitioned box to the adjacent empty space located on each side. This leakage were scooped and returned to the original partitioned area manually. Three of the T5's placed at the second layer were cavitated and did not record. Only one of the T5's was recording during rewetting for two more days.

\subsection{Small-Scale Experimental Setup for Bulyanhulu Tailings Drying Test}

\subsubsection{Potential Evaporation (PE)}

PE was measured by placing a water filled bucket on top of a scale and the weight, temperature and relative humidity were recorded in the laboratory. Similar to the large scale 
test, wind speed was calculated using a modified Penman equation by equating the measured $\mathrm{PE}$ in the laboratory and solving for wind speed using measured temperature and relative humidity. Wind speed was $27 \mathrm{~km} / \mathrm{hr}$. The effect of radiation was ignored since the rate of evaporation was $0.02 \mathrm{~mm} /$ day when the fans were not operating.

\subsubsection{First Layer Deposition}

A bucket with an average diameter of $265 \mathrm{~mm}$ was used to conduct the small column tests for Bulyanhulu tailings. Tailings were prepared to $41.5 \%$ GWC prior to deposition using a paint mixer and by hand. A depth of $120 \mathrm{~mm}$ was poured into the bucket for the first layer drying test.

Matric suction was measured using two HDS sensors and two T5 tensiometers for the first layer drying test and recorded by a datalogger. The HDS sensors were placed into the bucket at a location of $20-30 \mathrm{~mm}$ and $100-110 \mathrm{~mm}$ from bottom of the bucket and $\mathrm{T} 5$ tensiometers were also placed $30-40 \mathrm{~mm}$ and $100-110 \mathrm{~mm}$ from the bottom of the bucket. Simulated wind was induced using a commercial fan, which was placed adjacent to the bucket. The bucket was mounted on top of a scale and the weight was recorded to a data logger every ten seconds.

Daily temperature and relative humidity of the room were recorded using USB datalogger from Omega Engineering Inc and plotted in Figure 3.3.1. 
Daily volume change due to self weight consolidation and lateral shrinkage was recorded using reference marks. These reference marks were placed inside the bucket as a graduated scale. The first layer was allowed to dry for 15 days.

One new T5 was placed 10-20 mm near the surface before the end of the first layer.

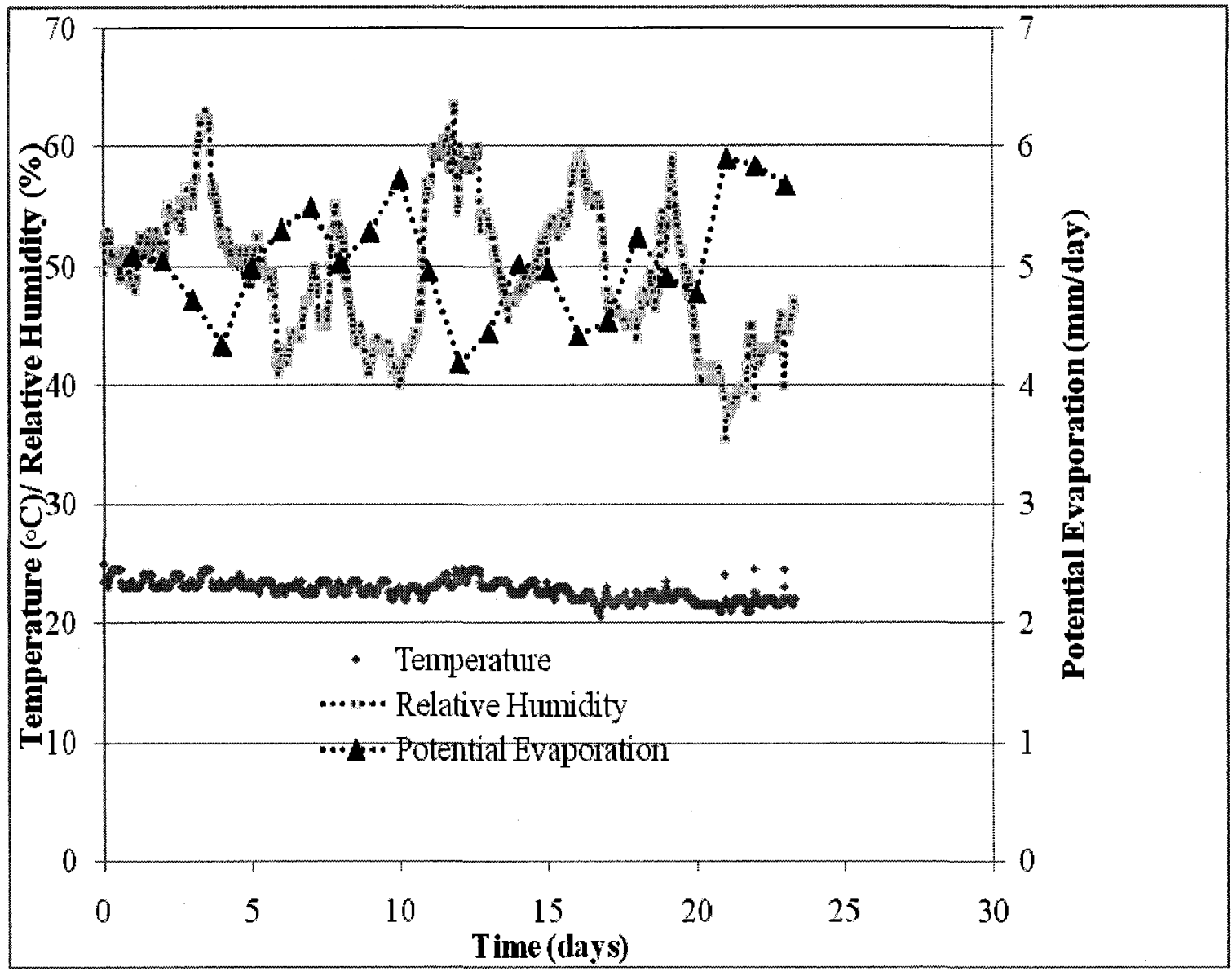

Figure 3.3.1: Computed PE, daily temperature and relative humidity for small scale Bulyanhulu drying test.

Figure 3.3.2 to Figure 3.3.4 show the general setup details for small scale drying test. 


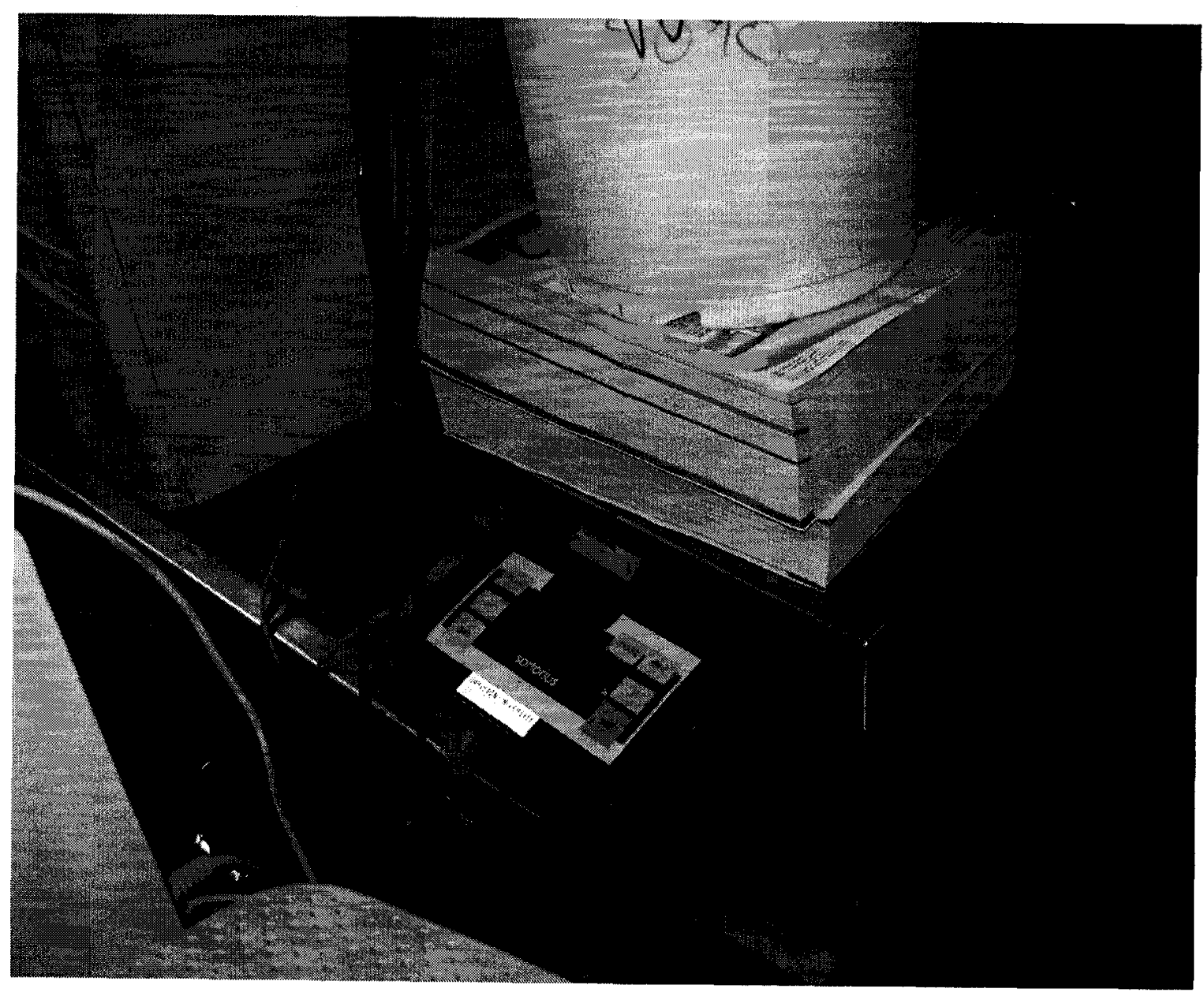

Figure 3.3.2: The bucket was mounted on a scale and weight was measured and recorded. 


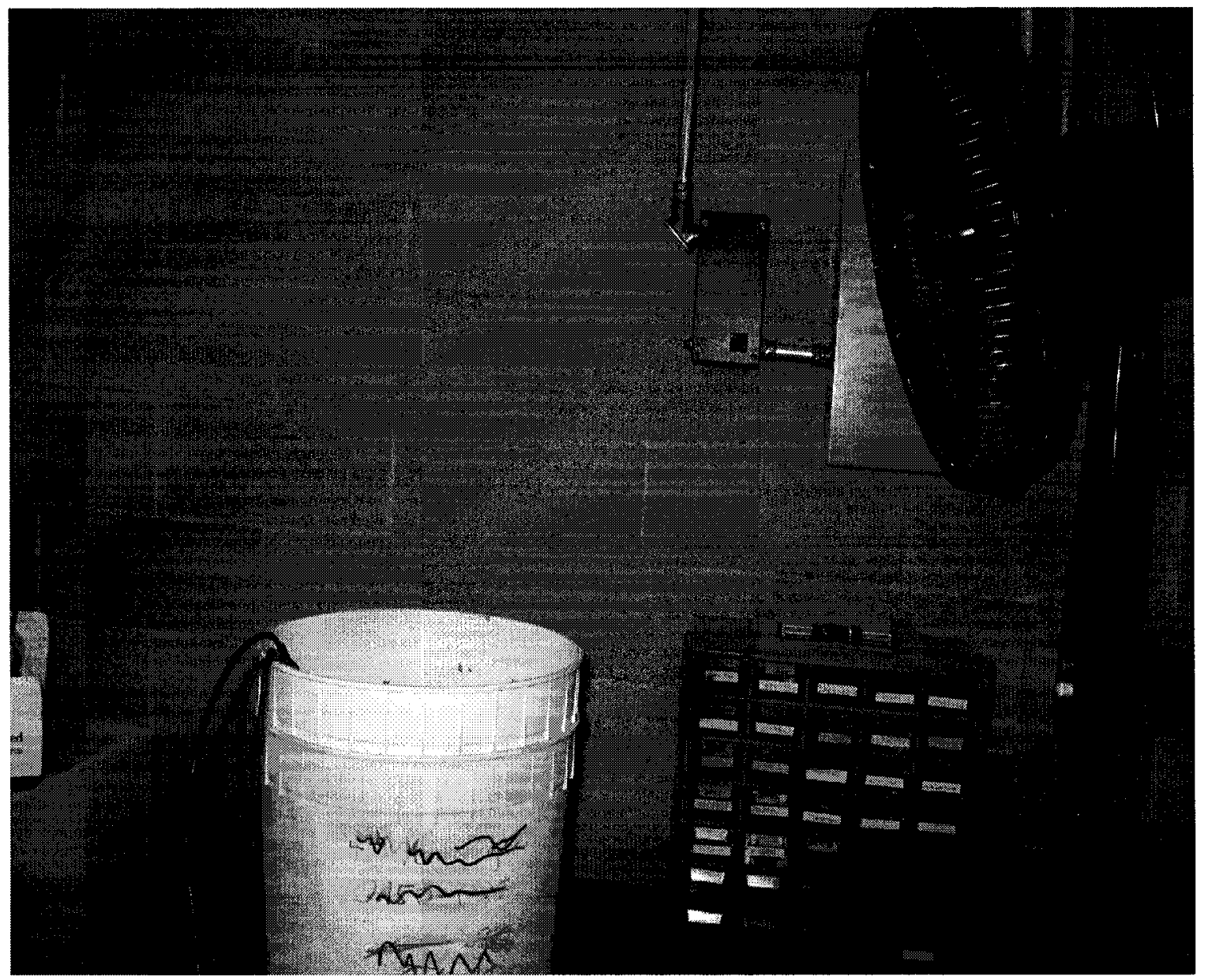

Figure 3.3.3: Wind was induced to simulate evaporation using a commercial fan in small scale drying test. 


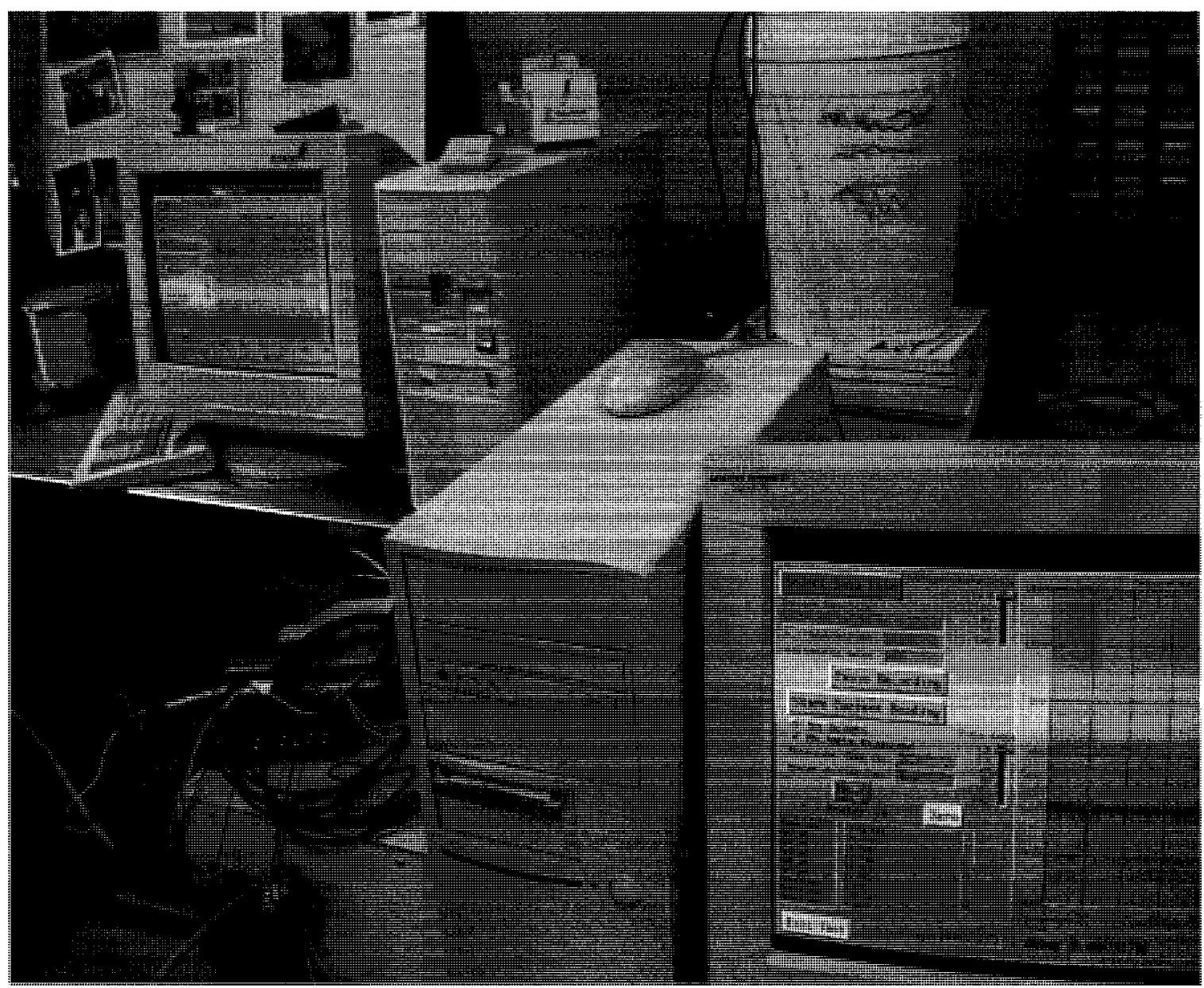

Figure 3.3.4: Datalogger used to record the weight and matric suction measurements from HDS sensors and T5 tensiometers.

\subsubsection{Second Layer deposition}

A second $100 \mathrm{~mm}$ layer of properly remixed tailings at $40 \%$ GWC was added on day 15 . The total height was increased to $210 \mathrm{~mm}$ by day 15 given $100 \mathrm{~mm}$ for the first layer and $110 \mathrm{~mm}$ for second layer. Two additional HDS sensors and two T5 tensiometers were used to measure the matric suction from the second layer. The HDS sensors were located at $120-130 \mathrm{~mm}$ and 180-190 $\mathrm{mm}$ from the bottom of the bucket. The two additional T5's were located at 140-150 
$\mathrm{mm}$ and $180-190 \mathrm{~mm}$ from the bottom of the bucket. These sensors were connected to a datalogger to record the matric suction measurements.

The second layer dried for ten days. At the end of the experiment gravimetric moisture content for profile with depth was measured and the location of sensors was also rechecked during dismantling as shown in Figure 3.3.5.

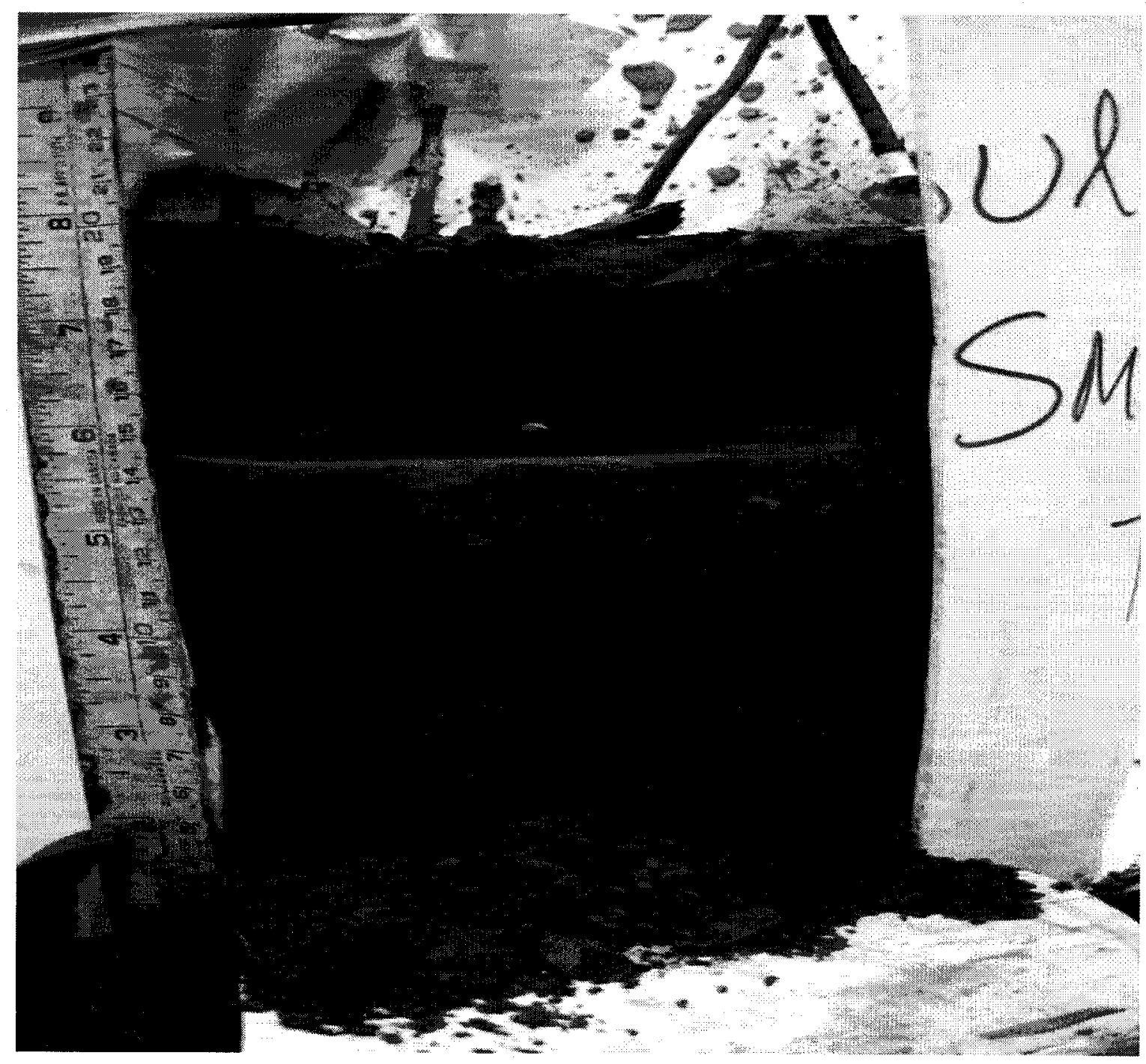

Figure 3.3.5: Dismantling small scale column drying test at the end of the experiment. 


\subsection{Small-Scale Experimental Setup for Toromocho Tailings Drying Test}

\subsubsection{Potential Evaporation (PE)}

Potential evaporation was measured by placing a water filled bucket on top of a scale and the weight, temperature and relative humidity were recorded manually in the laboratory. Similar to the small scale Bulyanhulu drying test, the Wind speed was calculated to be $27 \mathrm{~km} / \mathrm{hr}$ from measured potential evaporation, temperature, and relative humidity data.

\subsubsection{First Layer Deposition}

A bucket with average diameter of $217 \mathrm{~mm}$ was used to conduct the small column test. Initially, the proper mixed tailings were poured into the bucket and gave $110 \mathrm{~mm}$ depth of tailings deposition. Two HDS sensors were inserted into the tailings and was located at 10-20 $\mathrm{mm}$ and $80-90 \mathrm{~mm}$ from bottom of the bucket. One $\mathrm{T} 5$ tensiometer was placed at a location of $10-20 \mathrm{~mm}$ from the bottom of the bucket. Simulated wind was induced using a commercial fan, which was placed adjacent to the bucket. The matric suction was measured using HDS and T5 and the readout was recorded to the attached data logger. The bucket was mounted on top of a scale and the weight was measured and recorded every ten seconds.

Daily temperature and relative humidity of the room was recorded manually. Daily volume change due to self weight consolidation and lateral shrinkage was recorded. 


\subsubsection{Second Layer Deposition}

At day 9, a fresh layer of Toromocho tailings was prepared at $40 \%$ GWC and poured on top of the dried single layer to form $210 \mathrm{~mm}$ of total height. Two additional HDS sensors were placed at a location of $120-130 \mathrm{~mm}$ and $170-180 \mathrm{~mm}$ from the bottom of the bucket. One T5 was placed at a location of $120-130 \mathrm{~mm}$ from the bottom of the bucket tailings. Similarly those HDS and T5 are connected to a data logger to record the outputs.

\subsubsection{Rewetting}

The dried sample was rewetted by adding $3000 \mathrm{ml}$ of water from the top and left overnight to infiltrate to the bottom of the bucket. Precautions were taken while adding water so as not to deform the surface of the dried sample; hence the water was added slowly. The fan was turned off for the first night to let the added water resaturate the sample and the drying test started up the following day. The location of the second T5 sensor was right 10-20 mm from the top since the $\mathrm{T} 5$ which was located $120 \mathrm{~mm}$ from the bottom cavitated during the drying period. A new T5 from the top layer was inserted and was located about $180-190 \mathrm{~mm}$ from the bottom of the bucket. The HD sensors are the same as first drying test. The rewetted process brings to $32 \%$ of gravimetric moisture content before the fan was turned on. 


\subsection{Laboratory Measurement of Soil Water Characteristics Curve (SWCC)}

\subsubsection{SWCC Experimental Setup for Bulyanhulu Tailings}

A Volumetric Pressure Extractor (Model 1250) from Soil Moisture Equipment Corp. was used to directly measure the SWCC for Bulyanhulu tailings in the laboratory. This volumetric pressure extractor plate has a ceramic disk with an air-entry value of $500 \mathrm{kPa}$ and works in conjunction with the hysteresis attachments. These hysteresis attachments are used to accurately measure flows of water in and out of the extractor plate by using ballast tube, air trapper and burette.

The ceramic disk was placed in a bowl of water to saturate prior to the test. Sample of Bulyanhulu tailings were prepared at $40 \%$ GWC and poured into the apparatus and left to settle for one day without applying any pressure, (i.e. pressure equals $0 \mathrm{kPa}$ ).

This apparatus is used according to the well-known axis translation principle (Section 2.10) to obtain the SWCC, where matric suction is generated by applying air pressure while maintaining the pore-water pressure at a constant value. Specified air pressure was applied using compressed nitrogen from a pressurized cylinder. Equilibrium is attained when moisture outflow from the extractor to the attached hysteresis tube ceases. Once the equilibrium is reached, the air pressures released and the extractor cover is removed to measure the volume change measurements. 
Volume change, due to consolidation and lateral shrinkage, was calculated using a noncontact displacement sensor. This displacement sensor is hanged in a fixed position and uses ultrasonic beam of ray to measure the displacement from this fixed position to the surface of the material. The surface of the material was visualized by moving the surface horizontally at predetermined position under the sensor. The sensor measured average height at each given point. Averaging overall points will give the average height of the material. The measured displacement with the cross sectional area of the extractor gives the total volume of the sample at each applied pressure. Degree of saturation at each applied pressure was back calculated from volume-mass relationships. Only the drying curve of SWCC was tested in the laboratory.

The gravimetric moisture content for the applied pressure was calculated using weight difference before and after the applied pressure. The sample was weighed by disconnecting the tube from the hysteresis tube to prevent water from re-entering to the extractor. 


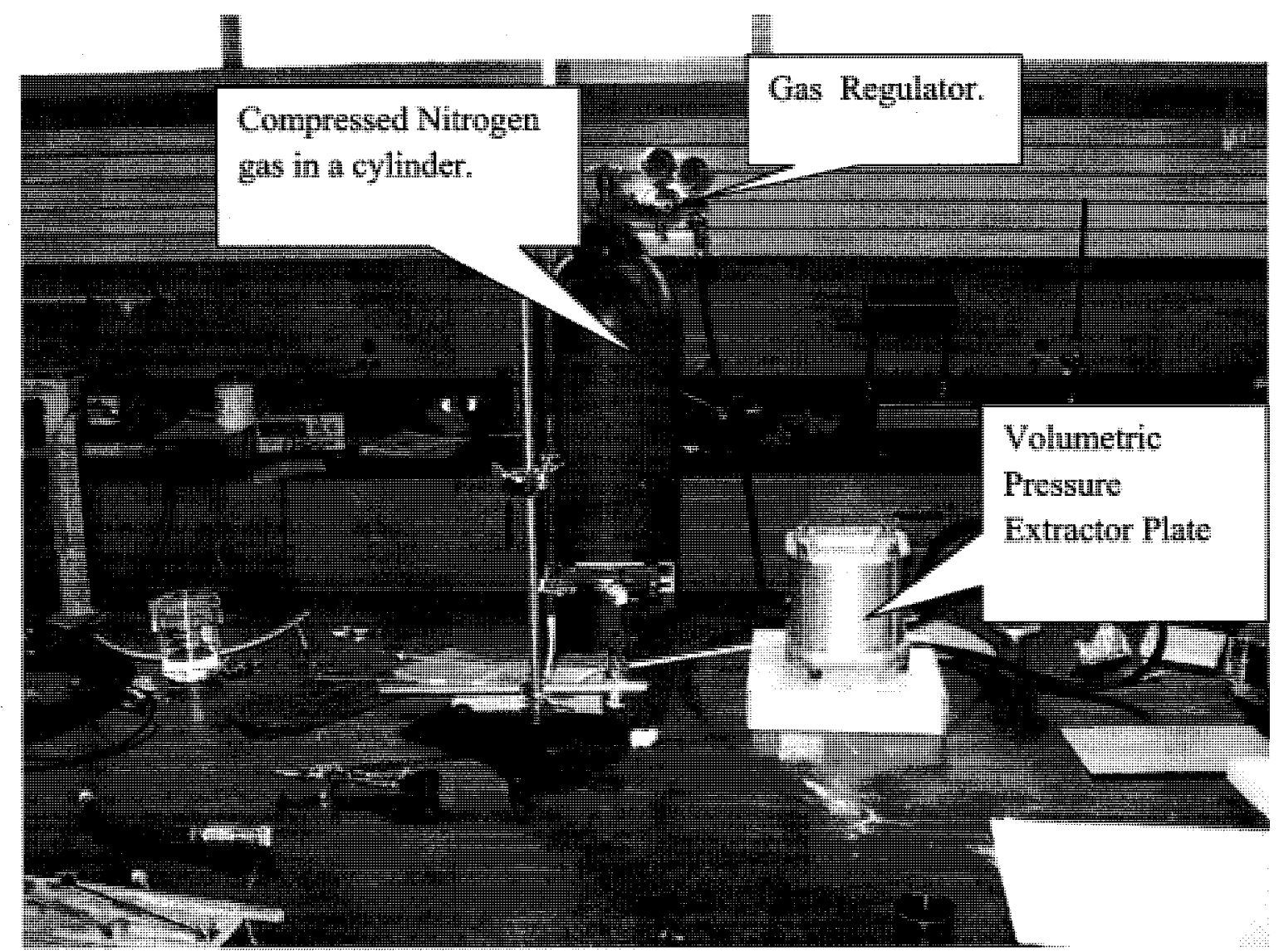

Figure 3.5.1: Soil-water characteristic curve experimental setup using a volumetric pressure extractor plate.

\subsubsection{SWCC Experimental Setup for Toromocho Tailings}

The SWCC for the Toromocho mine tailings were attained in the laboratory using the axistranslation technique with volumetric pressure extractor plate. Initially the sample was prepared at $40 \%$ GWC and followed similar experimental setup and procedure as described in the previous section on experimental setup for soil-water characteristic curve. 


\section{Numerical Simulation}

\subsection{Introduction}

SoilCover is a software package used to model 1D unsaturated flow. SoilCover was used to model both large and small scale drying tests. SoilCover uses Richard's equation, Fick's and Fourier's laws as the fundamental theories to model the flows of liquid water, vapour and conductive heat in the soil profile, respectively. Liquid and vapour fluxes are solved using Richard's equation and through diffusion, respectively. Coupling of these functions is achieved from the relationship between vapour pressure and total suction (Wilson et al., 1994):

$$
R H=e^{\psi \omega / R T}
$$

where: $\quad R H=$ relative humidity

$$
\begin{aligned}
& \psi=\text { total suction }(\mathrm{kPa}) \\
& \omega_{\nu}=\text { molecular weight of water }(\mathrm{kg} / \mathrm{mol}) \\
& R=\text { universal gas constant } \\
& T=\text { absolute temperature. }
\end{aligned}
$$

SoilCover employs a modified Penman equation to predict the rate of evaporation as a function of suction at the surface (for detail, Section 2.5.).

$$
\frac{A E}{P E}=\left[\frac{e^{\psi \omega_{\nu} / R T}-R H_{a}}{1-R H_{a}}\right]
$$


where:

$A E=$ actual evaporation,

$P E=$ Potential Evaporation

$R H_{a}=$ relative humidity of the air above the evaporating surface.

SoilCover allows for the calculation of PE if the user enters wind speed, net solar radiation, air temperature, and $\mathrm{RH}$.

\subsection{Finite Element Mesh}

A user specified mesh was generated for each experimental setup to simulate element sizes. Minimum and maximum element sizes were used at different depth within the profile. Minimum element sizes of $2 \mathrm{~mm}$ were used near the surface and between interfaces of two layers and different materials. Further away from the boundaries and surface element size was increased up to $10 \mathrm{~mm}$.

To account for shrinkage in the model simulation, SoilCover was used to simulate the experiment as a series of one day simulations. At the end of each one day simulation, the SoilCover mesh was adjusted to account for the shrinkage using the relationship of void ratio versus matric suction Simms et al. (2007) given in Figure 4.1.1. Void ratio as a function of gravimetric moisture content was calculated as the tailings consolidated by self-weight for each day. Using the SWCC, each GWC converted to its equivalent matric suction values. This void ratio with matric suction relation gives to calculate the change in total volume as daily matric suction values are generated from SoilCover. The height of the mesh will be recalculated from the change in total volume. 


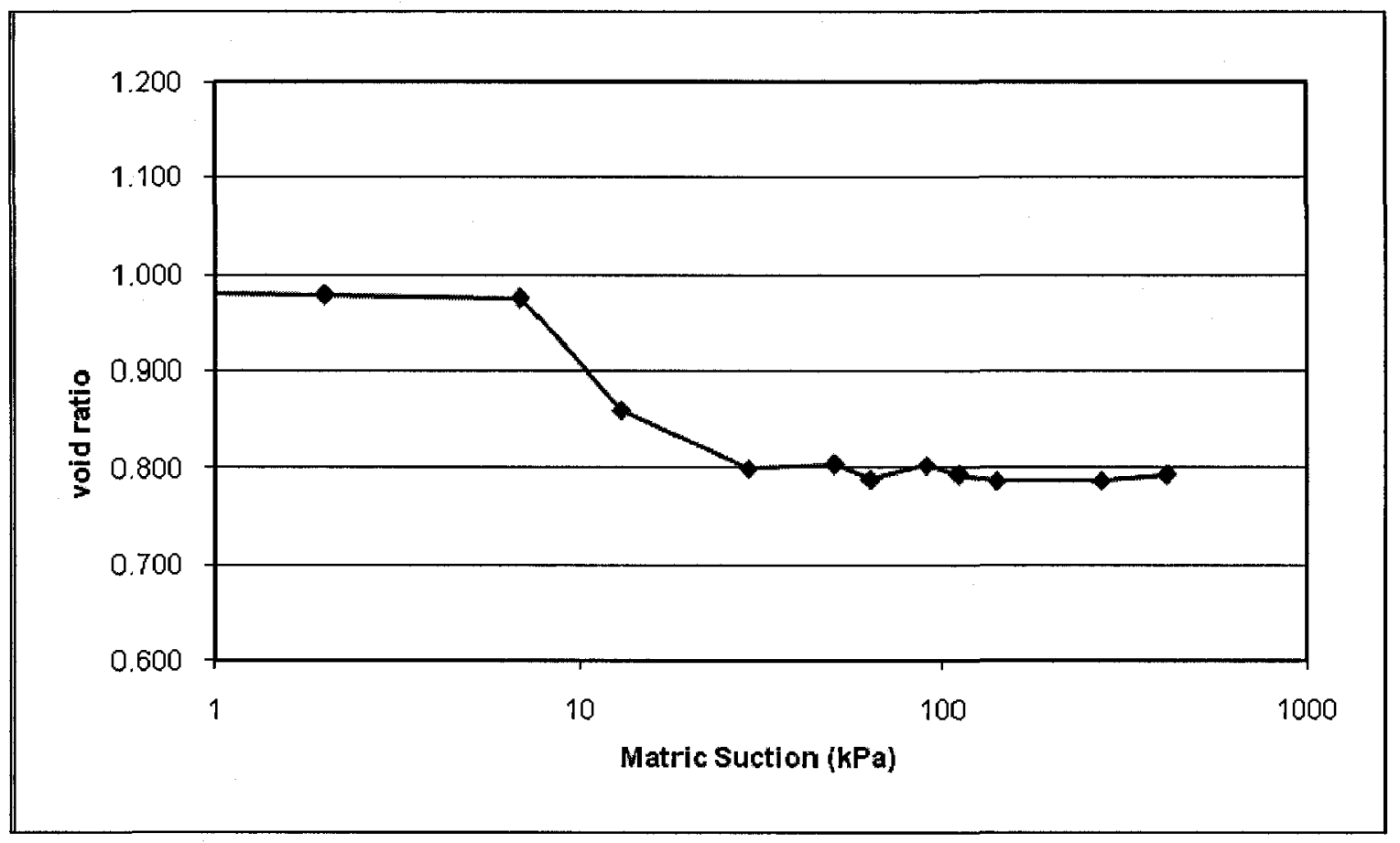

Figure 4.1.1: Void ratio as a function of matric suction (Simms et al., 2007).

\subsection{Initial Conditions}

Air temperature can be specified by the user as an initial condition. For both large and small scale tests a temperature of $22{ }^{\circ} \mathrm{C}$ was employed for bottom and top surfaces. The user may also specify a distribution of matric suction as an initial condition. For each test, hydrostatic distributions of matric suction were used as initial condition by resetting the matric suction to zero at the bottom of the tailings.

\subsubsection{Second Layer Initial Condition}

Hydrostatic distribution was used as initial condition for both top and bottom boundaries of second layer. SoilCover calculated matric suction profiles at the end of previous drying period were used as initial conditions for the older layer. 


\subsection{Boundary Conditions}

SoilCover calculated potential evaporation from daily climatic data, which were inserted by a user. SoilCover calculates heat flux, moisture flux and matric suction along the profile depth using the specified climatic data. The bottom boundary condition for moisture was no flow. This was implemented manually by simulating a $20 \mathrm{~mm}$ thick impermeable layer with hydraulic conductivity of $5 \times 10^{-15} \mathrm{~m} / \mathrm{s}$ and low air entry value of $0.1 \mathrm{kPa}$. The thickness was adjusted until there is no significant drainage coming out from the bottom.

\subsection{Material Parameters}

\subsubsection{Unsaturated hydraulic conductivity}

SoilCover uses a built-in function to calculate the unsaturated hydraulic conductivity from the given soil-water characteristic curve using a method by Fredlund et al. (1994). However, such a method does not account for the change in volume during drying and leads to an error on the degree of saturation estimation. To correct the error on degree of saturation of the drying test, manual adjustment was done by fitting the degree of saturation calculated based on volume change measurements recorded during the SWCC test using van Genutchen equation and generating unsaturated hydraulic conductivity using Mualem-van Genuctchen method (1980). The degree of saturation is calculated based on volume change measurements recorded during the SWCC test. 


\subsubsection{Thermal Conductivity}

The thermal conductivity of a soil can be defined as the amount of heat that flows through a unit area of soil in a unit time, under a unit gradient. The rate at which heat is transferred within a soil depends on the temperature gradient and the thermal conductivity of the soil. The transfer of heat within as soil is a function of water content. High moisture content of a soil gives greater transfer of heat.

A user has the option of specifying thermal conductivity data or using SoilCover to generate data. SoilCover generates a thermal conductivity function using the method proposed by Johansen (1975).

Saturated hydraulic conductivity, porosity, specific gravity of the material were given by the user as $5 \times 10^{-7} \mathrm{~m} / \mathrm{sec}, 0.47$ and 2.98 , respectively.

The $m_{v}$ parameter, which is the storage parameter in the governing mass transport equation for positive pore pressures, is used to simulate the initial self-weight consolidation phase of each test. The following $m_{v}$ values were used: 


\begin{tabular}{|l|l|}
\hline Experments & $\boldsymbol{m}_{\nu}(\mathbf{1} / \mathbf{k P a})$ \\
\hline Large scale Bulyanhulu multilayer drying test & 0.0 \\
\hline Small scale Bulyanhulu multilayer drying test & $5.2 \mathrm{E}-02$ \\
\hline Small scale Toromocho multilayer drying test & 0.07 \\
\hline Small scale Toromocho single layer drying test & 0.05 \\
\hline
\end{tabular}

Table 4.5.1: Different $m_{v}$ values used to simulate using SoilCover for different experiments.

Note that the $m_{v}$ value for the large-scale test was zero. This is because water generated by initial self-weight consolidation was free fo runoff the surface of the tailings. The $m_{v}$ value is selected in conjunction with the initial pore-pressure distribution to ensure that the software code simulates generation of water arising from self-weight consolidation. 


\section{Experimental Results and Discussions}

\subsection{Experimental Results for Soil-Water Characteristic Curve (SWCC)}

\section{For Tailings}

Figure 5.1.1 shows laboratory measured soil-water characteristic curve for the Bulyanhulu tailings.

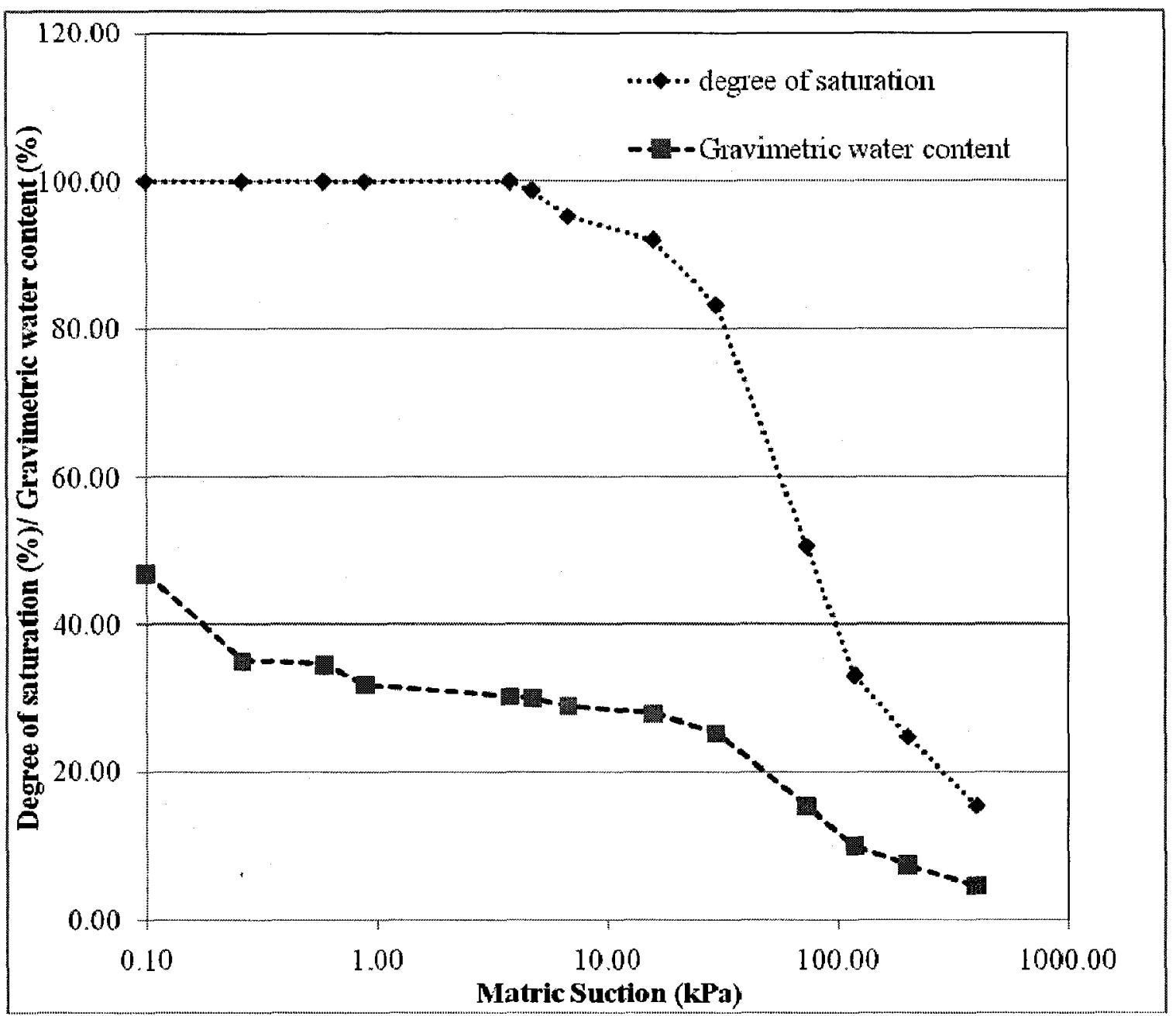

Figure 5.1.1: Soil-water characteristic curve for Bulyanhulu tailings. 
The soil-water characteristic curve (SWCC) for Toromocho tailings is given in Figure 5.1.2.

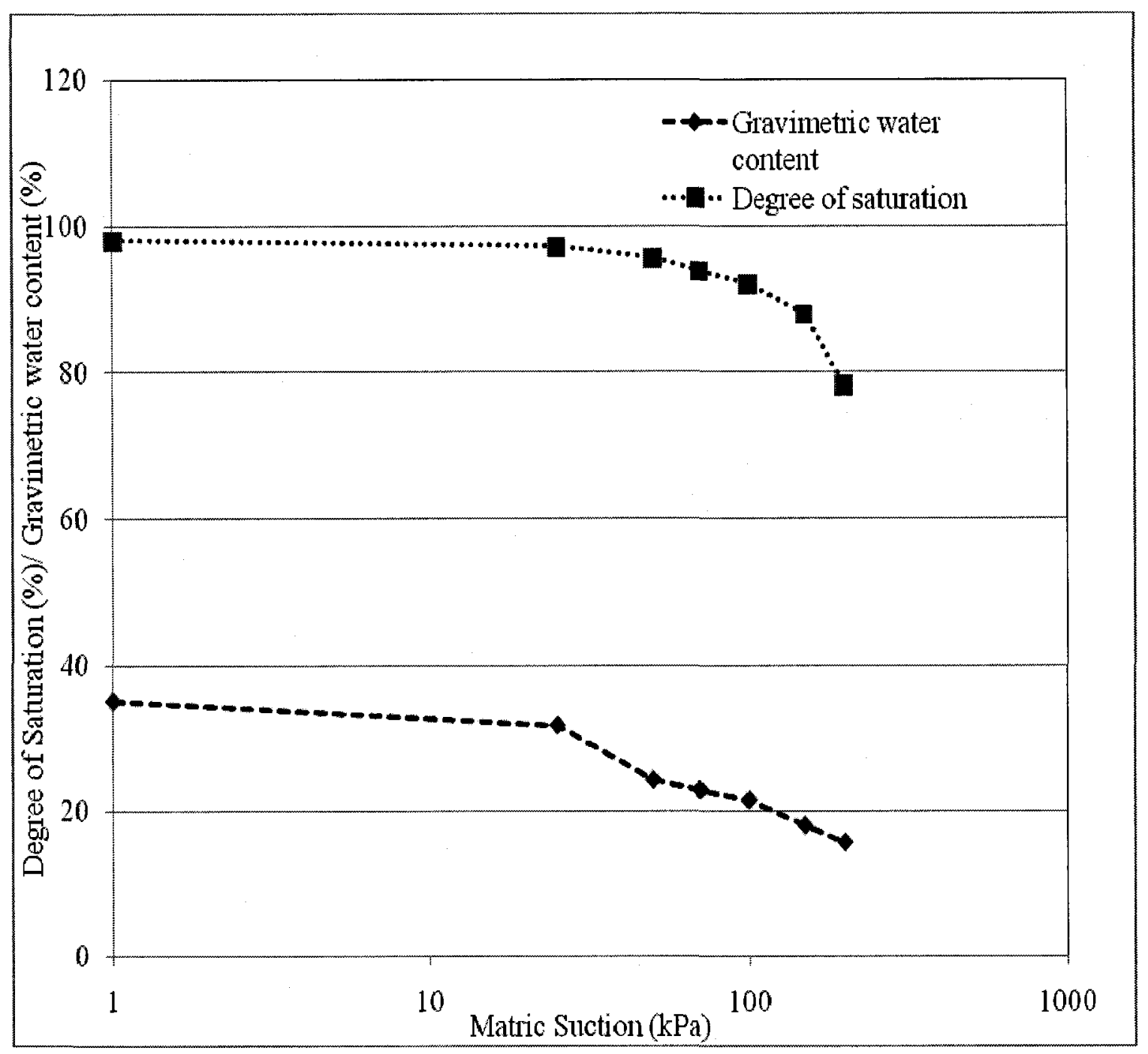

Figure 5.1.2: Soil-water characteristic curve for Toromocho tailings.

SWCC for Toromocho tailings differ from Bulyanhulu tailings in terms of slope. This is due to the different particle size distributions of the two tailings. Particle size of a soil influences the pore size distribution within the given soil. Soils composed of uniform particle sizes exhibit a steeper slope in their SWCC as compared to soils composed of particles sizes with a varied range of particles sizes. As the varied range for particle size becomes larger the larger 
pores will be filled with smaller particle sizes and hence reduce the availability of pores for moisture transfer.

\subsection{Large-Scale Multilayer Surface Deposition}

\subsubsection{Introduction}

The data presented includes average parameters such as overall evaporation rate, gravimetric water content, and volume change. These average parameters are first presented, followed by more detailed data on moisture content and matric suction.

Figure 5.2.1 shows cumulative evaporation, void ratio, average gravimetric water content and degree of saturation for the large scale drying test. Each function in Figure 5.2.1 is discussed in their respective sections given below.

\subsubsection{Degree of Saturation}

Initially, the first layer started at a degree of saturation of $97 \%$, which decreased to $35 \%$ by the end of day 10 . The overall degree of saturation of both layers increased to $83 \%$ during the addition of the second layer and later decreased to $57 \%$ by day 15 (end of second layer). Similarly, the degree of saturation increased to $93 \%$ during rewetting and decreased subsequently as a result of evaporation as shown in Figure 5.2.1. 


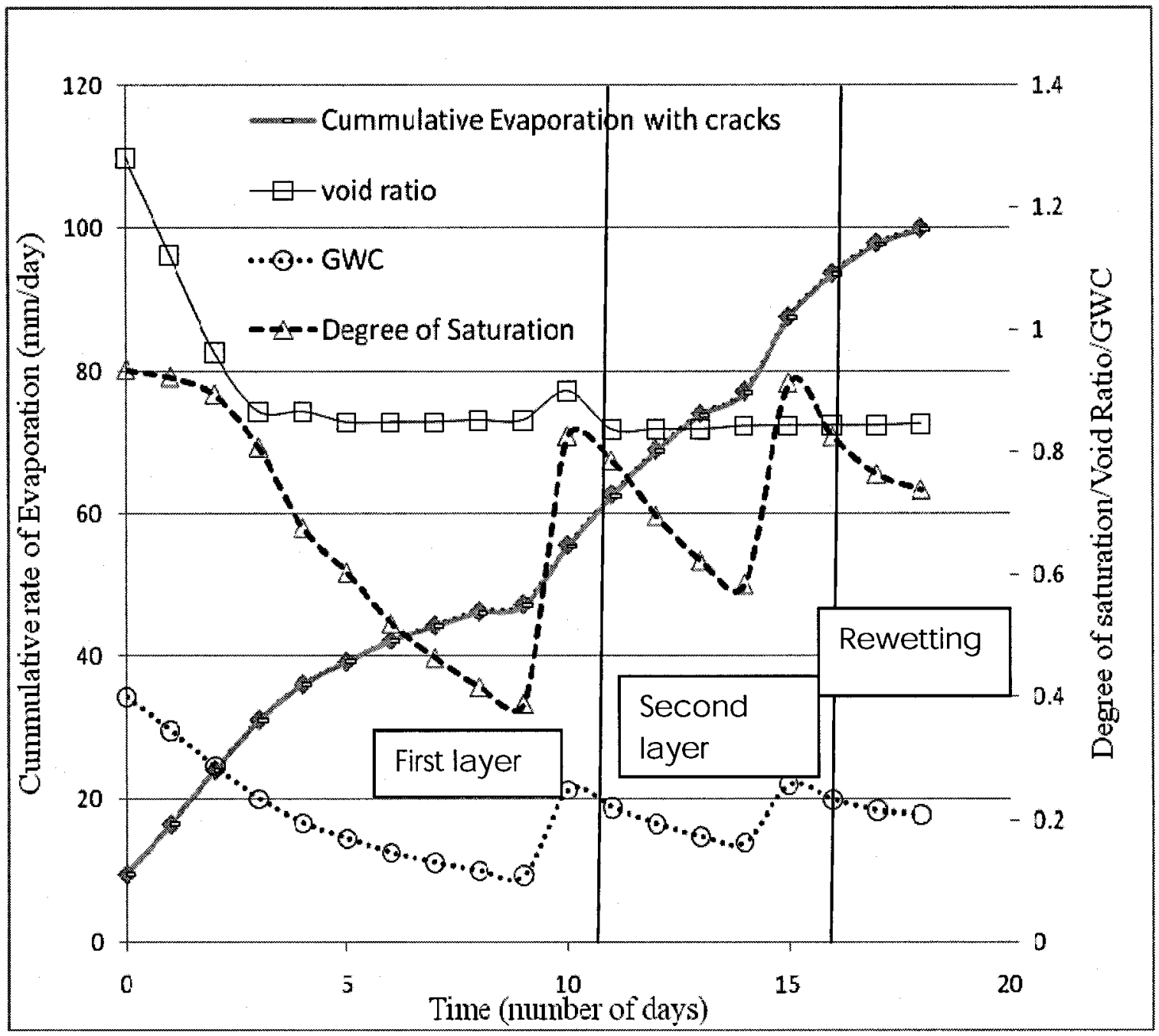

Figure 5.2.1: Cumulative evaporation, degree of saturation, void ratio and average GWC for the large scale Bulyanhulu drying test.

\subsubsection{Volume Change and Cracking}

Volume change expressed in terms of decrease in height, and decrease in void ratio throughout the large-scale test is shown in Figures 5.2.2.1 and Figure 5.2.2.2. The thickness of the first layer was $110 \mathrm{~mm}$. During day 1, a considerable amount of self-weight consolidation occurred, as evidenced by drainage out of the wooden barriers into the side compartments of the box. This drainage was removed using rags. Subsequent to day 1 , no 
significant drainage was observed. The depth of the first layer at day 10, prior to deposition of the second layer was $80 \mathrm{~mm}$. The total depth increased to $170 \mathrm{~mm}$ after the deposition of the second layer, and was further reduced to $150 \mathrm{~mm}$ by day 15 . No significant vertical volume change was observed during the period of rewetting.

As the paste tailings dried out there was also lateral shrinkage away from the walls. The change in surface area due to shrinkage was estimated and accounted for in the daily total volume calculations. On day 3 there was $3-5 \mathrm{~mm}$ separation of the tailings from the walls and the separation increases to $5-10 \mathrm{~mm}$ by day 5 . Separation distance from the walls was greater along the wooden walls $(10 \mathrm{~mm})$ as compared to the steel walls $(5 \mathrm{~mm})$.

Cracks started forming at day 2 over night to day 3 . Void ratios calculated accounting for cracks and horizontal shrinkage, and void ratios calculated accounting only for vertical shrinkage alone, are both shown in Figure 5.2.2.2.

Void ratio, without cracks, decreases from 1.28 to 0.86 in the first four days as the tailings dried out. This void ratio further reduced to 0.84 by day 6 and no volume change was observed till the end of first layer (by day 10). Separation from the walls was observed to increase for the first six days up to a maximum of $10 \mathrm{~mm}$. 
The average void ratio increased after the second layer was placed to 0.9 by day 10 and reduced to 0.83 by day 12 . During rewetting, the average void ratio increased to 0.85 as a result of increase in total volume. The minimum void ratio achieved from large scale is consistent to laboratory and field measurements of void ratio from previous studies (Simms et al., 2007).

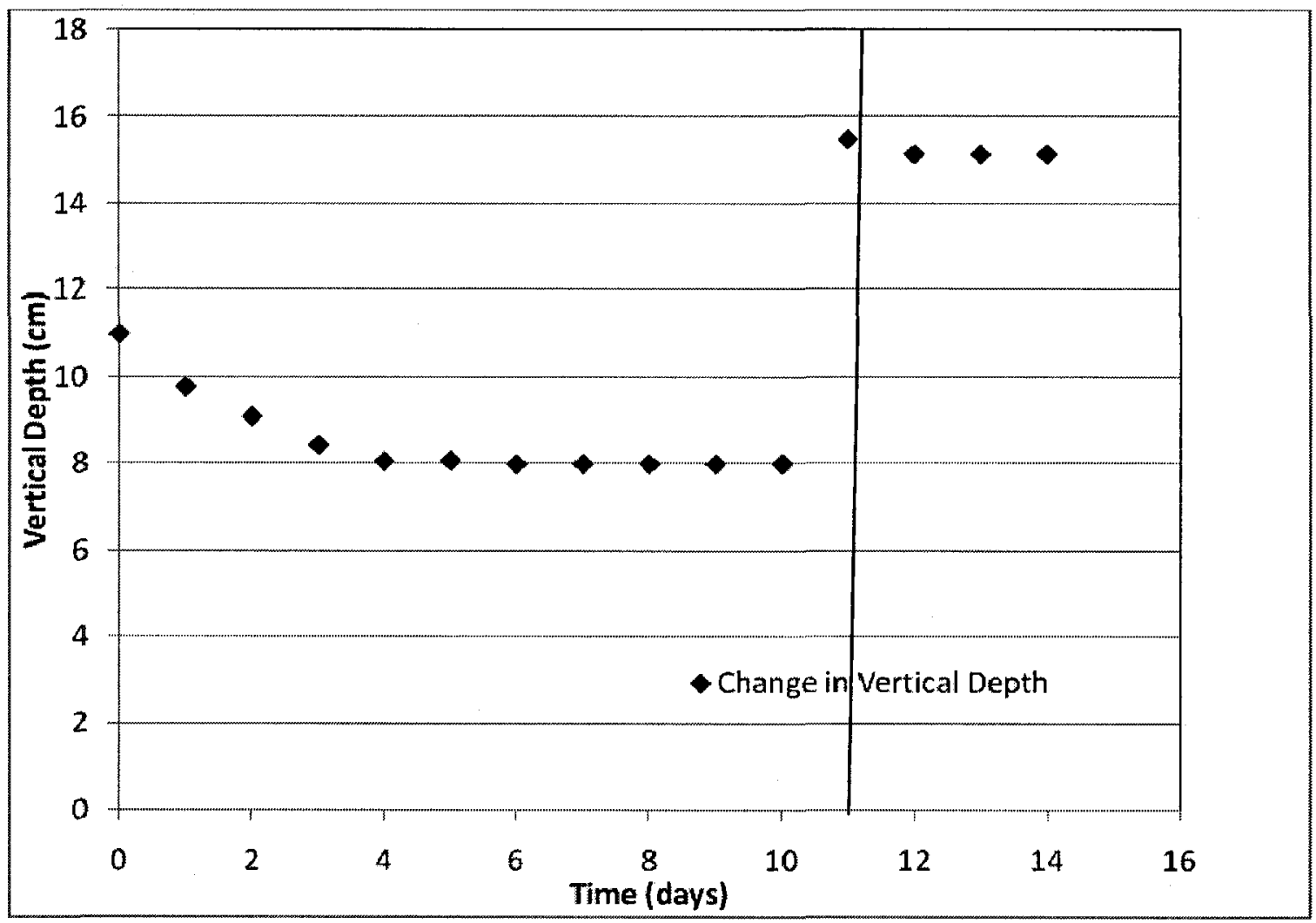

Figure 5.2.2.1: Change in vertical depth with time for large scale test.

The void ratio accounting for cracks starts at 1.28 and reduced to 0.85 in the first four days, and reduced to 0.79 by day 6 , since cracks were formed during day 2 to day 3 and propagate 
until the end of day 6. The propagation of cracks was not significant after day 6; therefore there was no volume change till the end of day 10. Figure 5.2.2.2 shows void ratio accounting for vertical volume change only and volume change due to cracks and lateral shrinkage.

Development and propagation of cracks were also observed from day 10 to day 12 after the second layer was placed. However, during rewetting the opening of cracks were reduced significantly.

Visual observation for the development of cracks and their propagation can be followed up using daily pictures taken in section 5.2.7. 


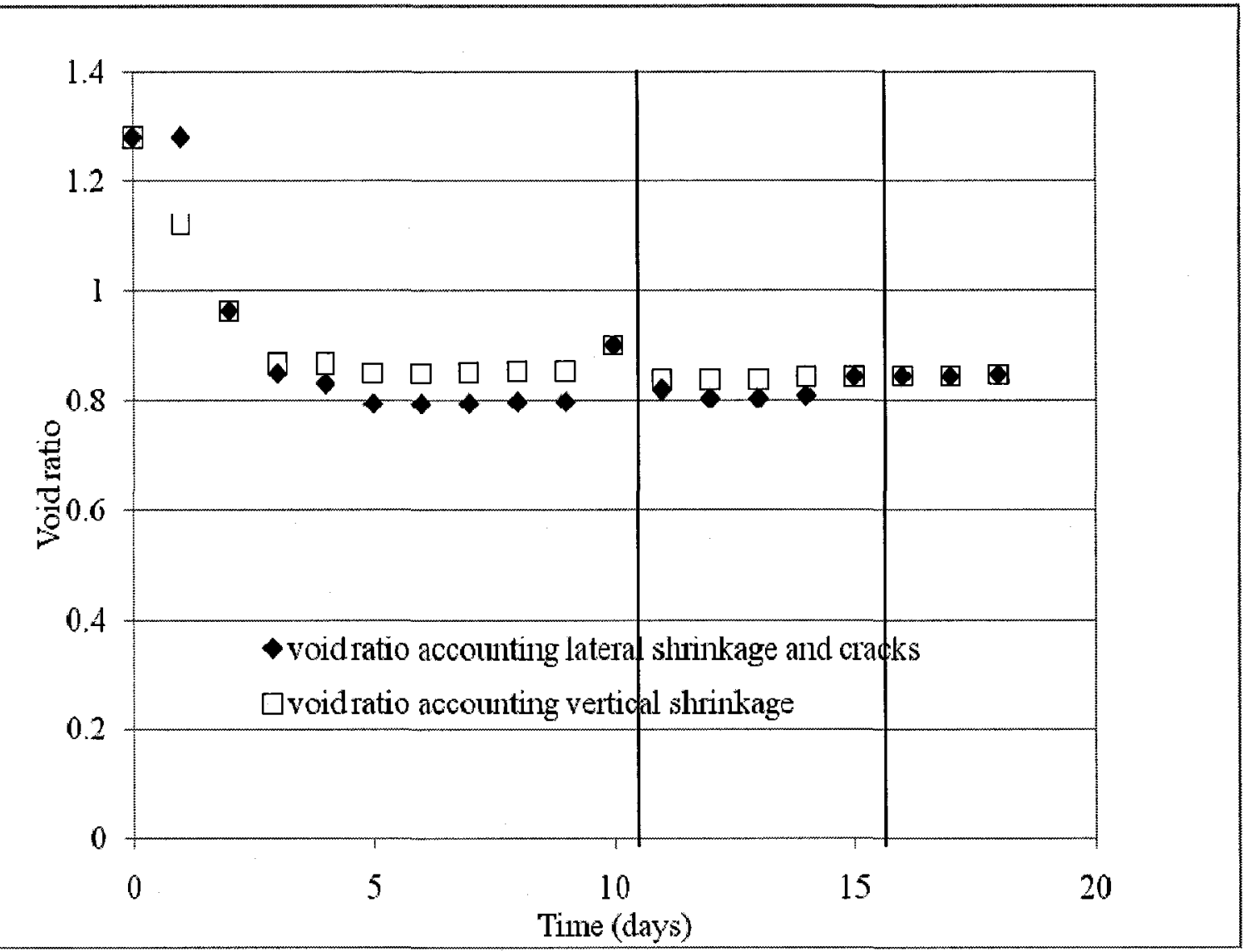

Figure 5.2.2.2: Void ratio calculated using only vertical shrinkage and using for lateral shrinkage and cracks.

\subsubsection{Evaporation}

In this section, measured evaporation rates are compared with values predicted by the SoilCover model. The rate of evaporation was calculated from daily change in weight. The difference in daily weight due to loss of water is considered as the evaporated water from the given surface area. This assumption overestimates the rate of evaporation on day 1 since there was leakage of water to each of the partition sides. The calculated rate of evaporation from the laboratory test is $9.6 \mathrm{~mm} /$ day while the potential evaporation gives $7.87 \mathrm{~mm} /$ day as 
shown in Figure 5.2.3.1. The increase in the measured evaporation is due to the leakage of water through the partitioned sides and increased surface area available for evaporation.

On day 2 there was no significant bleed water to the adjacent sides of the partition area and the rate of evaporation reasonably agreed with potential and actual evaporation rates between days 2 and 4 . However, there was a small difference of the calculated and predicted actual evaporations as the tailings dried out from day 5 to day 10 as shown in Figure 5.2.3.1. This difference may be due to the effect of cracks, which increase the surface area exposed to the atmosphere.

On day 10 , a fresh second layer was added on top of the dried first layer and rate of potential and actual evaporation is given in Figure 5.2.3.1. The predicted and measured rate of evaporation reasonably agreed on day 10 and 11 . Cracks were also formed and developed the same day of second layer placed. The small difference in actual rate of evaporation between days 12 to 14 is potentially due to cracks, for the same reason as indicated for the end of first layer drying period.

On day 15 the two layers were rewetted and some water ran off the tailings to the partitioned sides. The increase in rate of evaporation is due to the increase in surface area as the result of flow of water to the partition sides. Note: removal of water was attempted continuously from 
the partitioned sides. SoilCover was not able to predict the actual rate of evaporation by day 16 to 19 and this will be discussed in Section 5.5.

Effect of cracks may increase the rate of evaporation; therefore, closer observation to the rate of evaporation for the first 4 days was important since cracks developed on day 2 overnight to day 3. Figure 5.2.3.2 shows the rate of evaporation for each day seems fairly uniform indicating the rate of evaporation was relatively higher on day 1 and 2 compared to days 3 and 4 where cracks formation and propagation takes place.

The actual evaporation rate measured during the experiment and computed using SoilCover are in a good agreement throughout the drying periods except on day 17 to 19 after rewetting. 


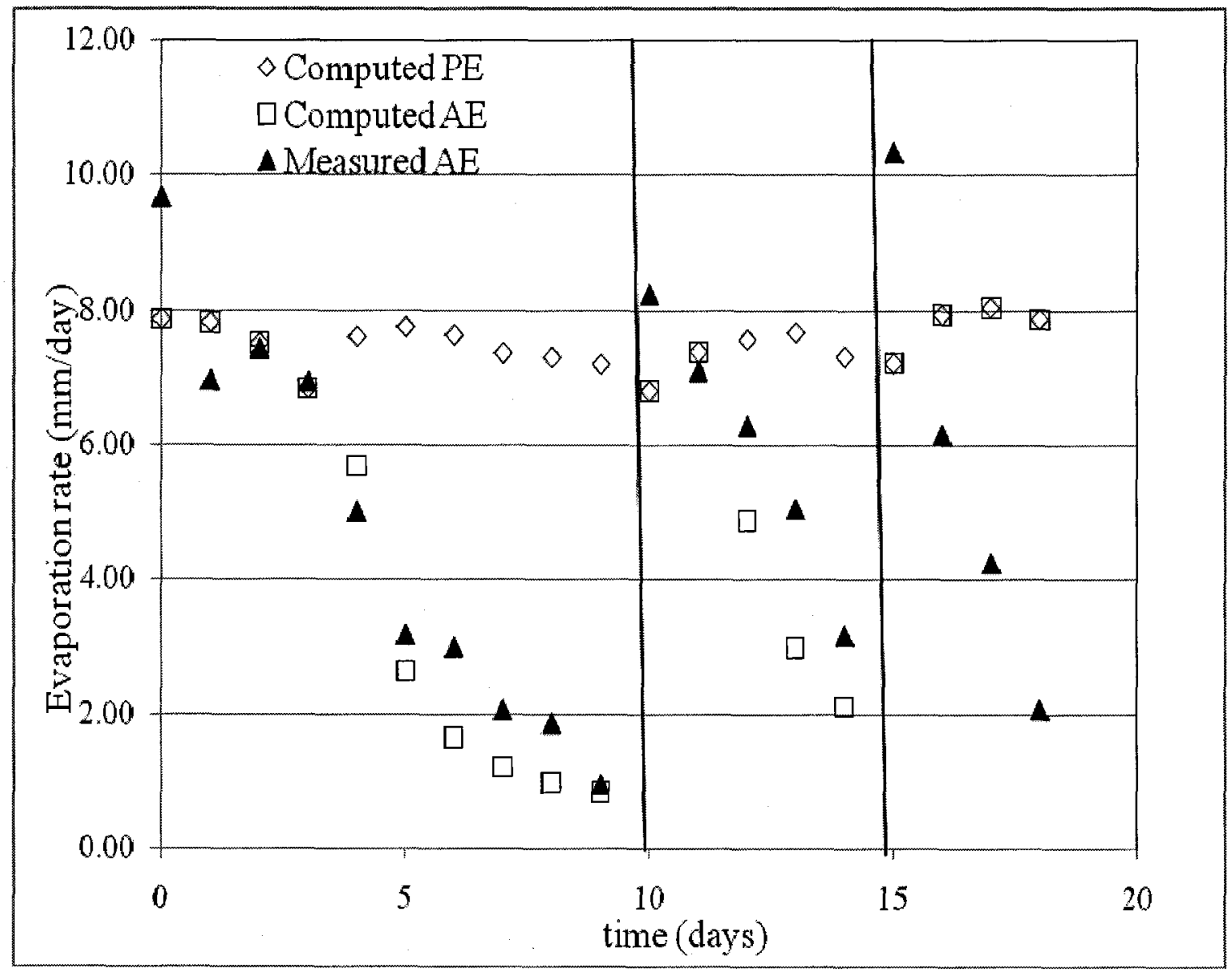

Figure 5.2.3.1: Measured and computed actual evaporation, and computed potential evaporation for large-scale drying test. 


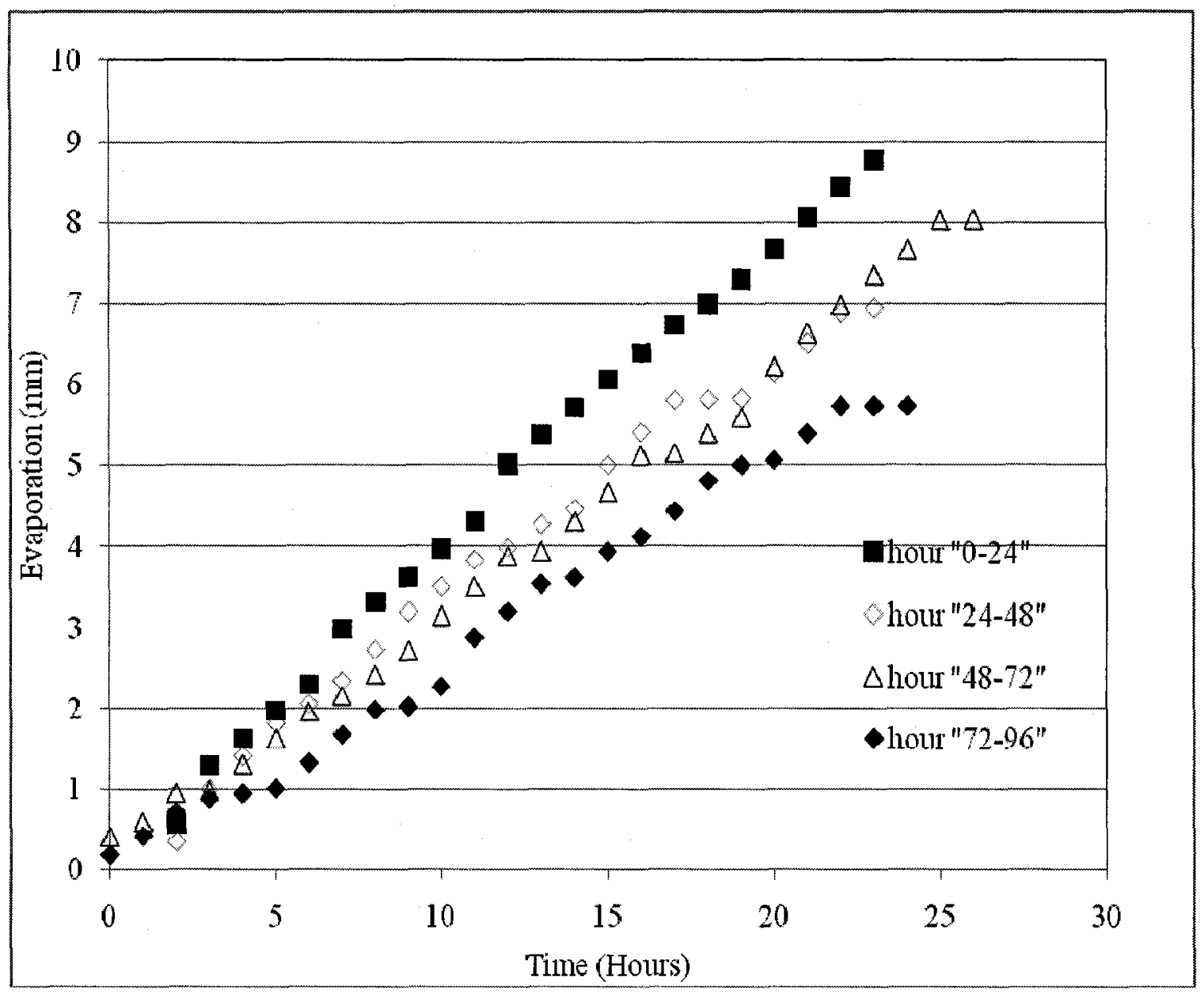

Figure 5.2.3.2: Hourly rate of evaporation for the first 4 days of the drying test.

\subsubsection{Salt Crust Formation and Conductivity}

The conductivity measurements were converted to equivalent osmotic suctions using the standard conversion USDA equation (Fredlund and Rahardjo, 1993). Figure 5.2.4.1 presents a plot of conductivity and osmotic suction versus time for the drying test. Figure 5.2.4.2 shows precipitation of salts on the surface and around the edge of cracks. For the first layer drying test, after 5-6 days of drying, it was impossible to remove samples with sufficient moisture to do the conductivity test. Similarly, during the second layer, it was only possible 
to remove water from the sample for the first three days. During rewetting, only on day 15 and day 16 was it possible to remove samples with enough moisture for the electrical conductivity test.

In all three stages, i.e first layer, second layer and rewetting, the measured conductivity shows an exponential pattern in general. This concept will be discussed in detail in Section 5.5 .

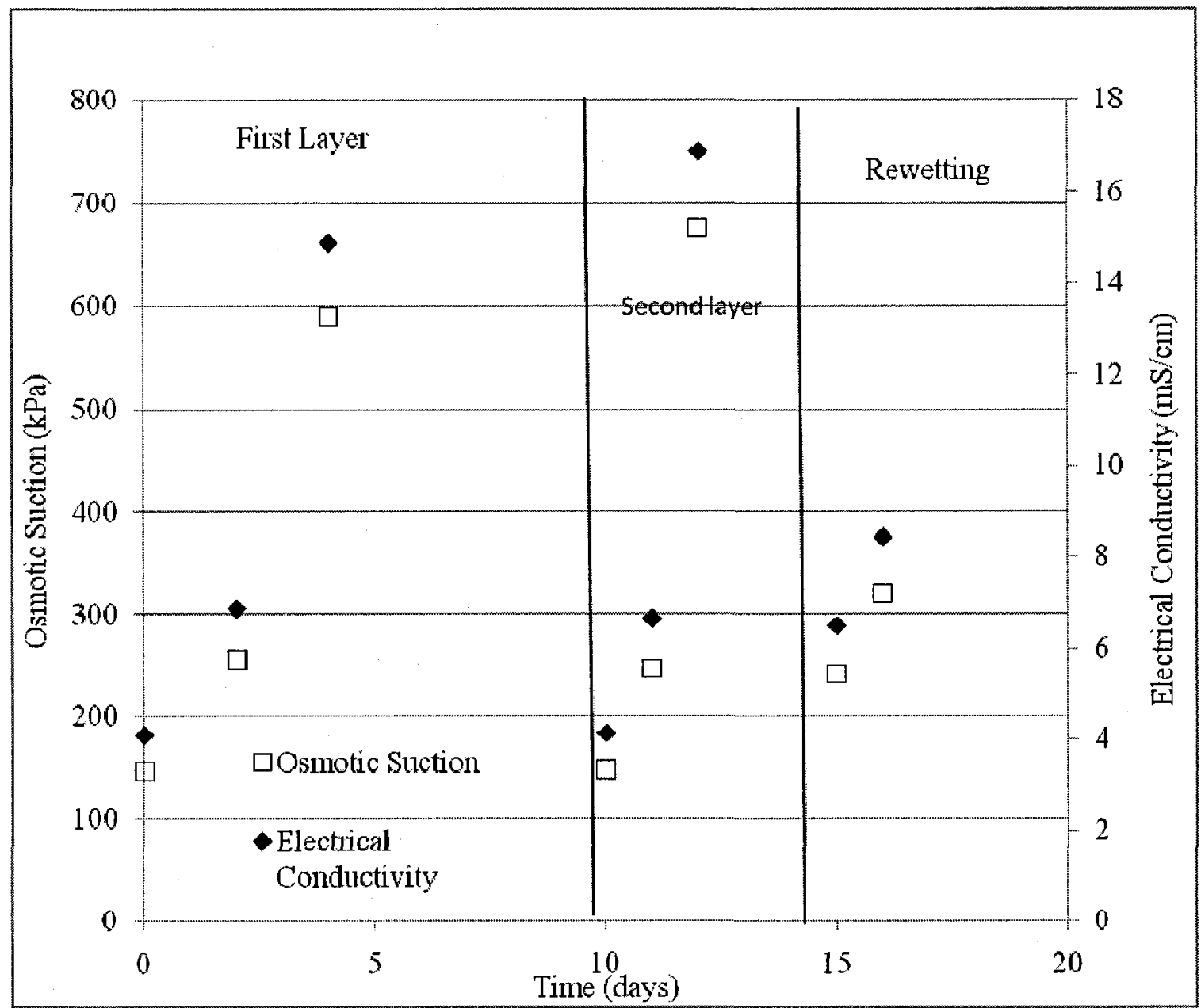

Figure 5.2.4.1: Conductivity and osmotic suction measurements. 


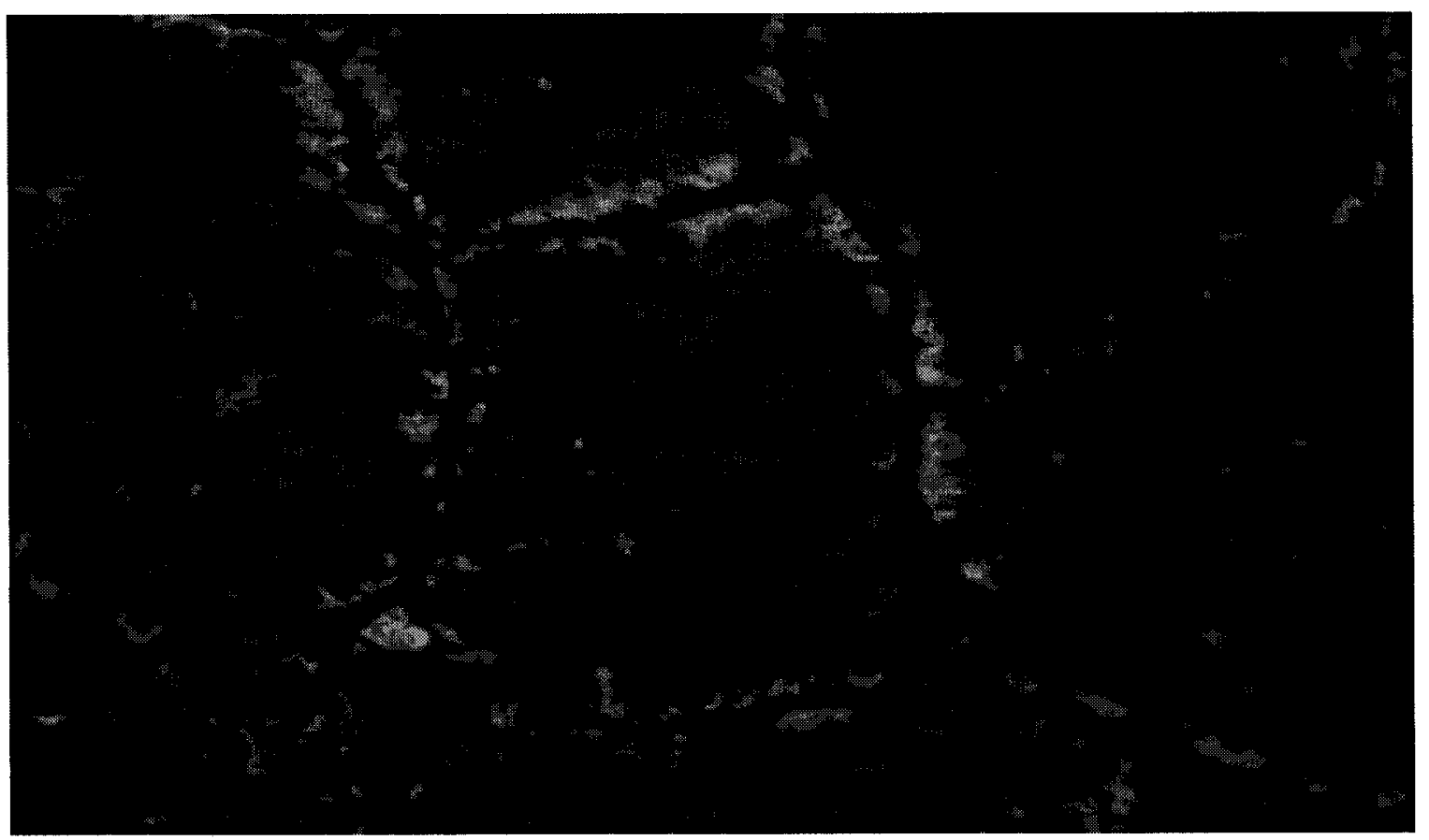

Figure 5.2.4.2: Precipitation of salt on surface and on edge of cracks.

\subsubsection{Gravimetric Water Content}

Measured GWC and average GWC can be seen in Figure 5.2.5.1. The surface layer dries faster than the average GWC of the profile during first, second layers and rewetting process. The distribution of GWC with depth can be seen in Figure 5.2.5.2. and Figure 5.2.5.3 for the two layers. In the first layer, it can be seen that the GWC profile shows a clear trend with depth as shown in Figure 5.2.5.2. Similarly, Figure 5.2.5.3 shows the profile depth for both layers and the GWC profile exhibits a trend with depth within each layer. 


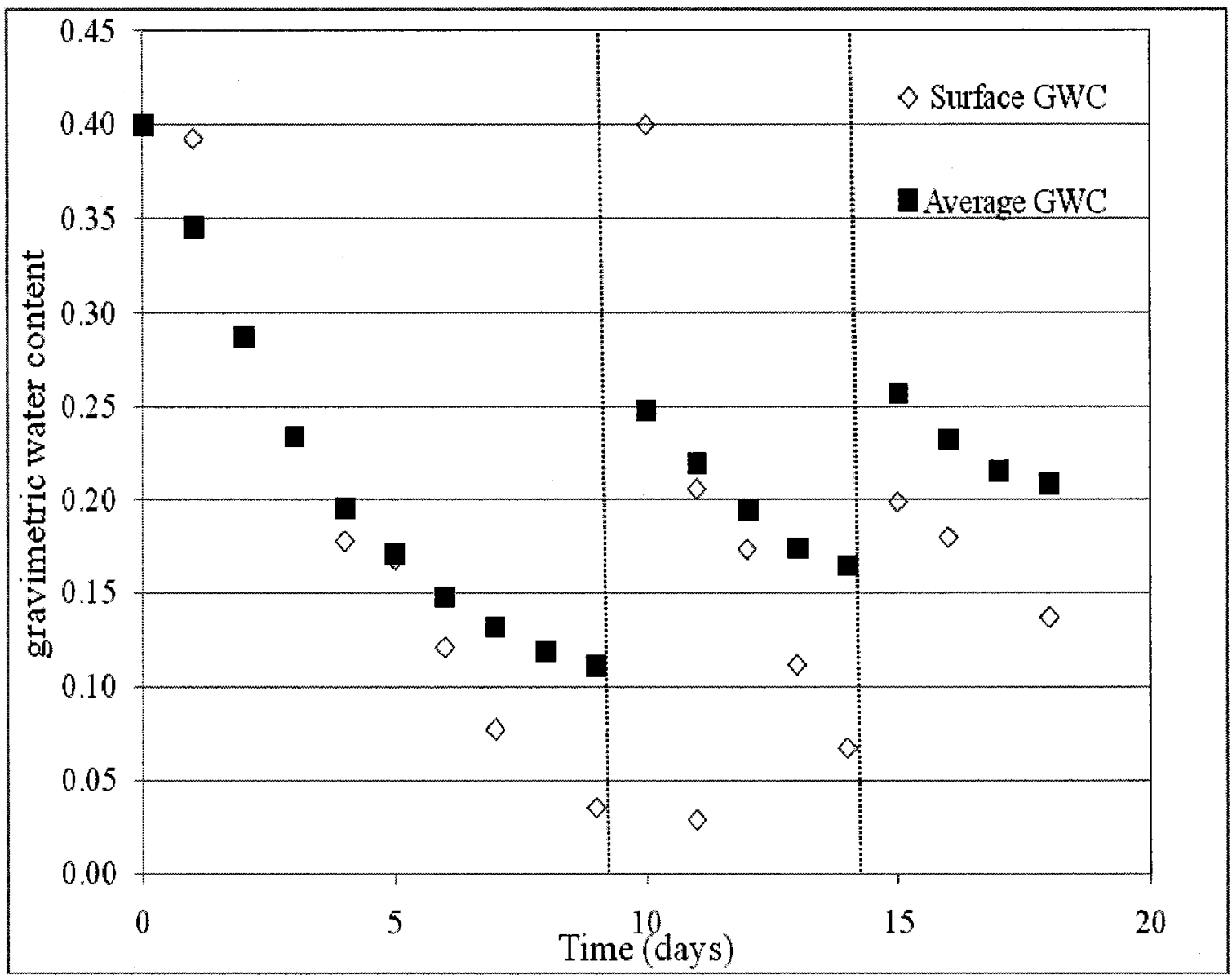

Figure 5.2.5.1: Average and surface gravimetric water contents.

Figures 5.2.5.2 and 5.2.5.3 also presents measured GWC near cracks with depth. However, the measured GWC did not show a significant pattern for the first layer. The measured GWC at the middle of surface and near cracks shows similar pattern at the end of second layer. 


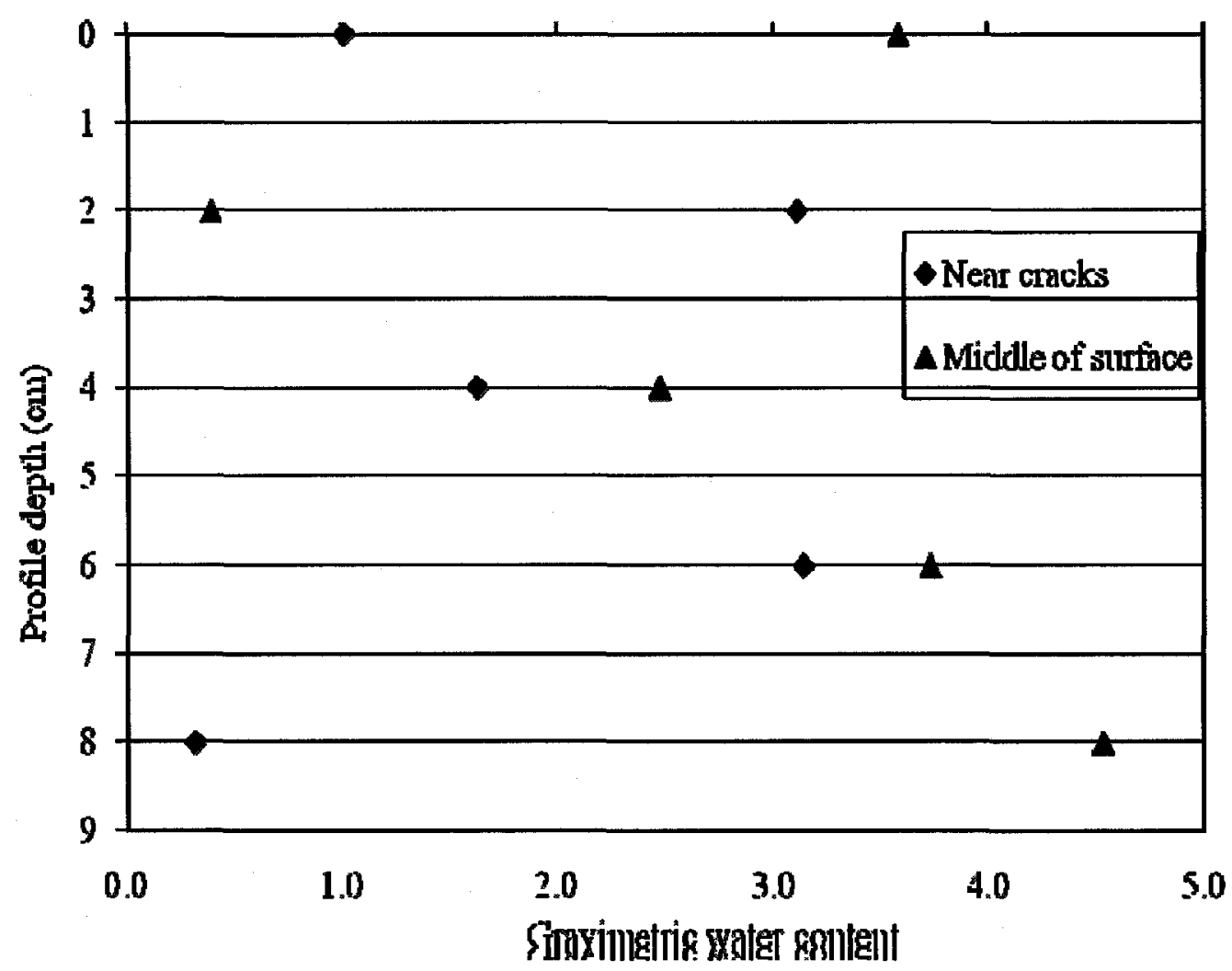

Figure 5.2.5.2: Measured GWC at middle and near cracks at day 10 . 


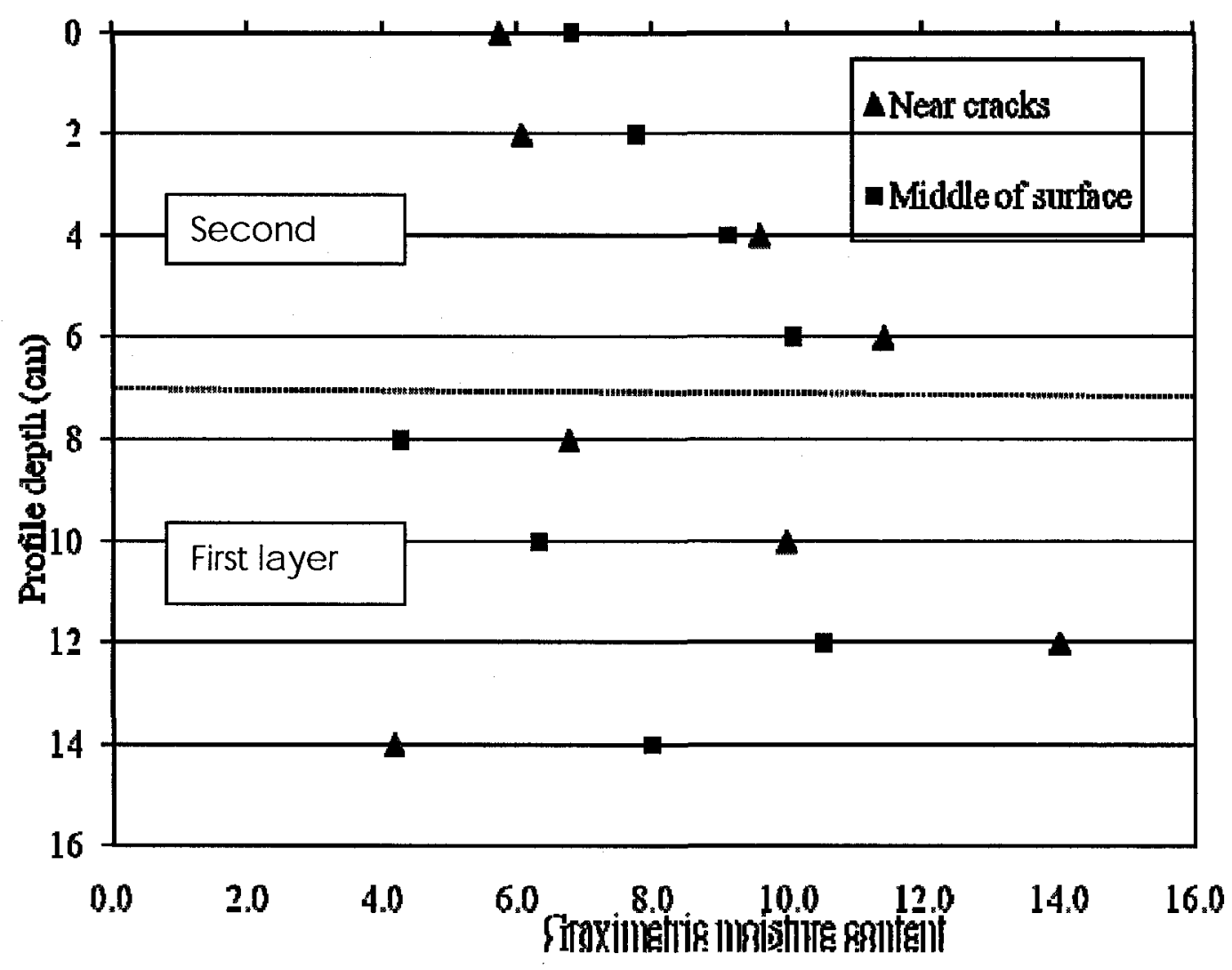

Figure 5.2.5.3: Measured GWC at middle and near cracks at day 15 end of second layer drying test with depth.

\subsubsection{Matric Suction}

Schematic representation for the location of $\mathrm{T} 5$ tensiometers is given in Figure 5.2.6.1. Matric suctions measured using $\mathrm{T} 5$ tensiometers for the first layer large scale drying test are plotted in Figure 5.2.6.2 In the first layer drying test, one of the T5's was located $40-50 \mathrm{~mm}$ from the bottom of the box and the second one was located $80-90 \mathrm{~mm}$ from the bottom. The suctions were very close throughout the drying period before the sensors cavitated. T5 located at $80-90 \mathrm{~mm}$ cavitated on day 3 , while the $\mathrm{T} 5$ located at $40-50 \mathrm{~mm}$ from bottom 100 
continued to measure matric suction measurements until day 7 . The cavitation of the bottom T5 can be seen in Figure 5.2.6.2, when the matric suction drops from $289 \mathrm{kPa}$ to $92 \mathrm{kPa}$.

Four T5 sensors were placed in the second layer. Two of the T5's were located at 10-20 mm above the top of first layer or $110-120 \mathrm{~mm}$ from the bottom of the tank. The other two T5's were located at $70-80 \mathrm{~mm}$ from the top of first layer or $170-180 \mathrm{~mm}$ from the bottom of the tank. One day after the second layer was deposited, the matric suction reached $115 \mathrm{kPa}$. As shown in Figure 5.2.6.3 matric suction measurements from all four T5's were very close. This shows there was relatively uniform distribution of matric suction with depth before day 11. Three of the four T5 tensiometers cavitated on day 11 and the fourth $\mathrm{T} 5$ cavitated on day 15.

During rewetting, three of the T5's which were located at the second layer measured matric suction for the first three days and cavitated as the tailings dried as shown in Figure 5.2.6.4. for $\mathrm{T} 53$, which was located $70-80 \mathrm{~mm}$ was measuring matric suction, the data was highly varied within a given time, therefore T5 3's measurement was not considered as valid. The T5 located 70-80 $\mathrm{mm}$ shows decrease during rewetting followed by an increase in matric suction measurement as the profile was rewetted. 


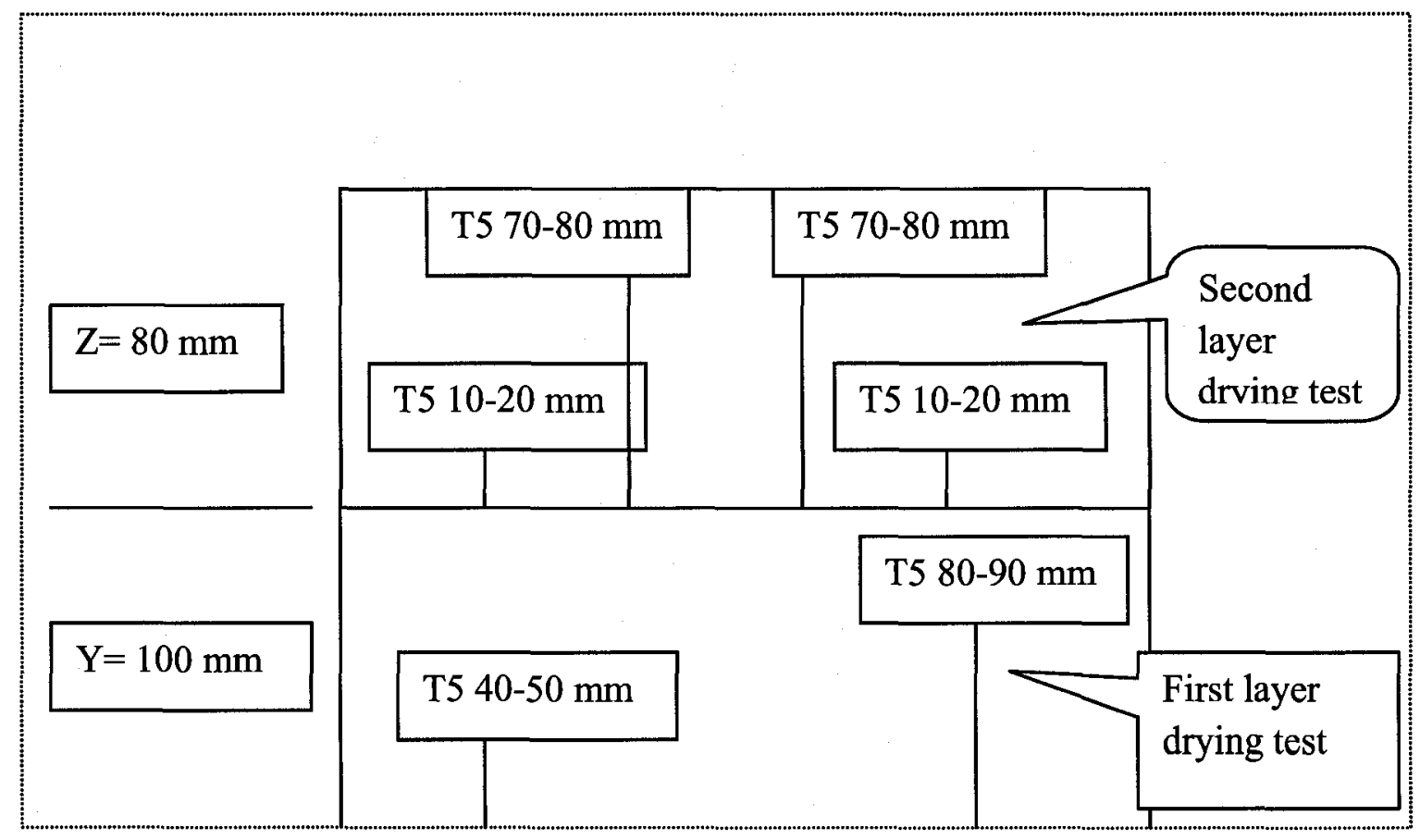

Figue 5.2.6.1: Schematic representation for the T5 tensiometers during large scale test. 


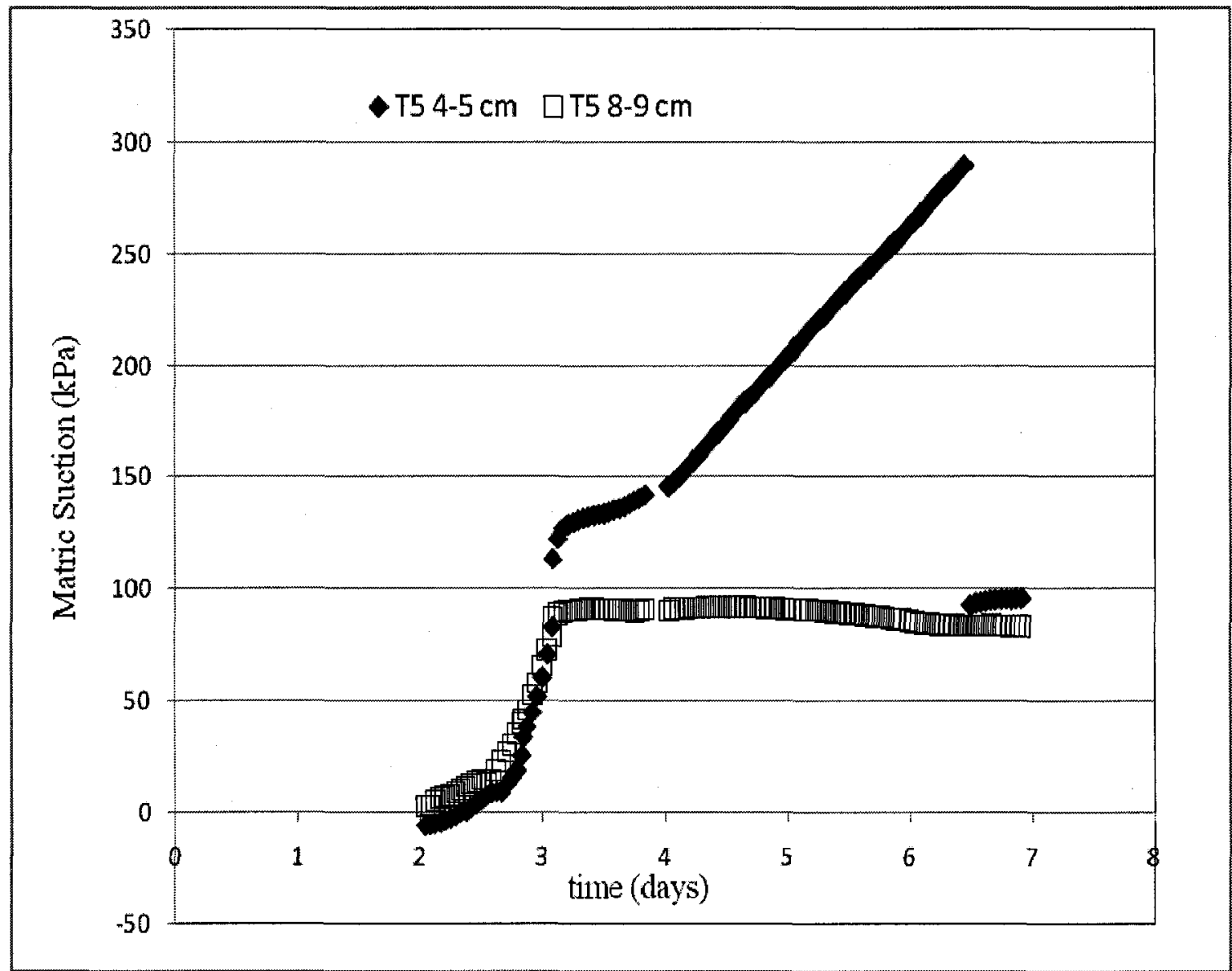

Figure 5.2.6.2: Matric suction measurement for first layer drying test using T5's. The T5's were located $40-50 \mathrm{~mm}$ and $80-90 \mathrm{~mm}$ from the bottom of the tank. 


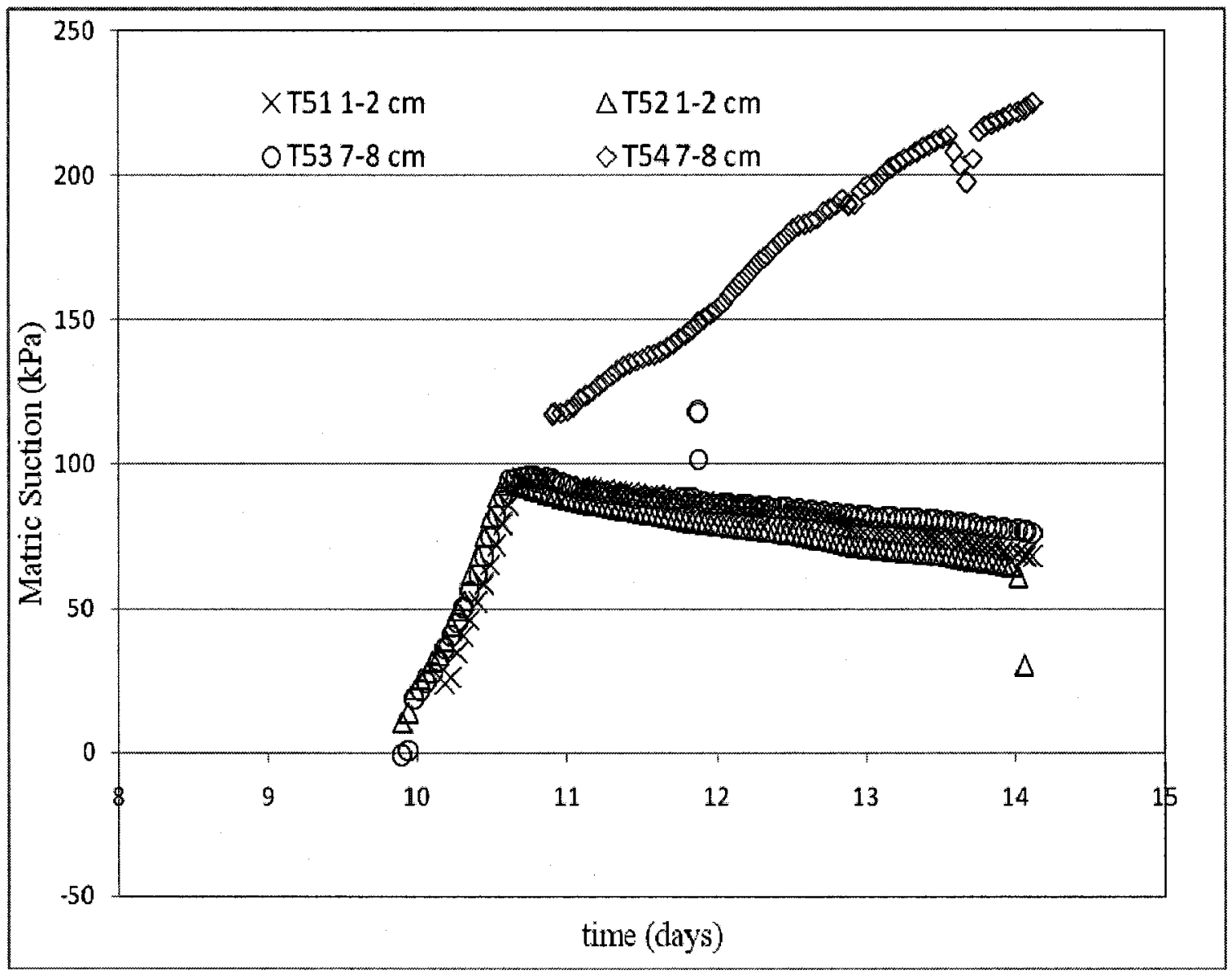

Figure 5.2.6.3: Matric suction measurement for second layer drying test using T5's. The tensiometers were located $10-20 \mathrm{~mm}, 10-20 \mathrm{~mm}, 70-80 \mathrm{~mm}$ and $70-80 \mathrm{~mm}$ from the top of dried first layer. 


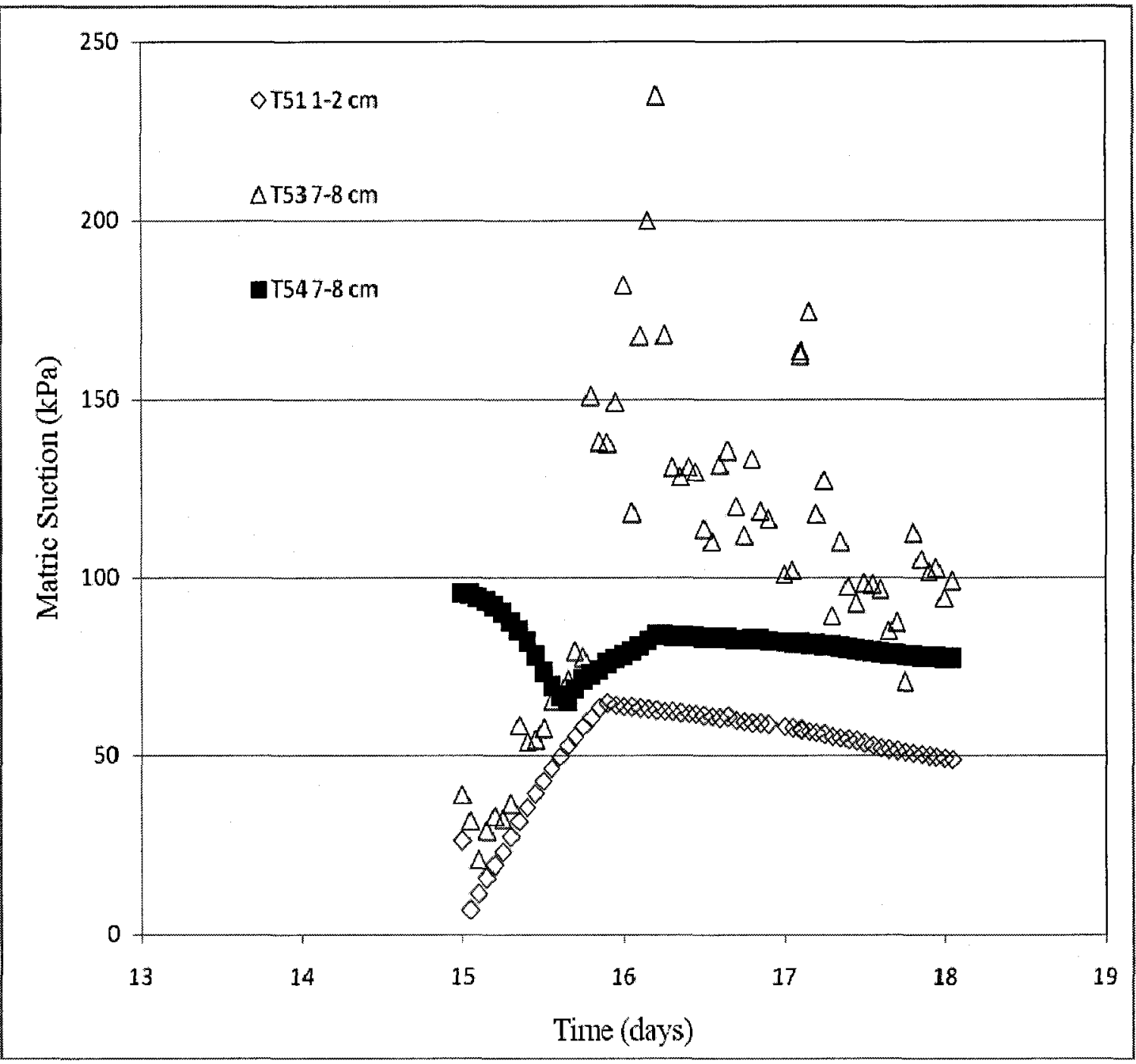

Figure 5.2.6.4: Matric suction measurement during rewetting of the large scale using T5's.

Matric suctions were also measured using L-229 Heat Dissipation sensors (HDS) as shown in Figure 5.2.6.5 and Figure 5.2.6.6. The matric suction readings were averaged over each day. HDS suctions are calculated from temperature changes after the heater is activated using calibrated empirical formulae, which are increasingly susceptible to error as the temperature goes higher. 


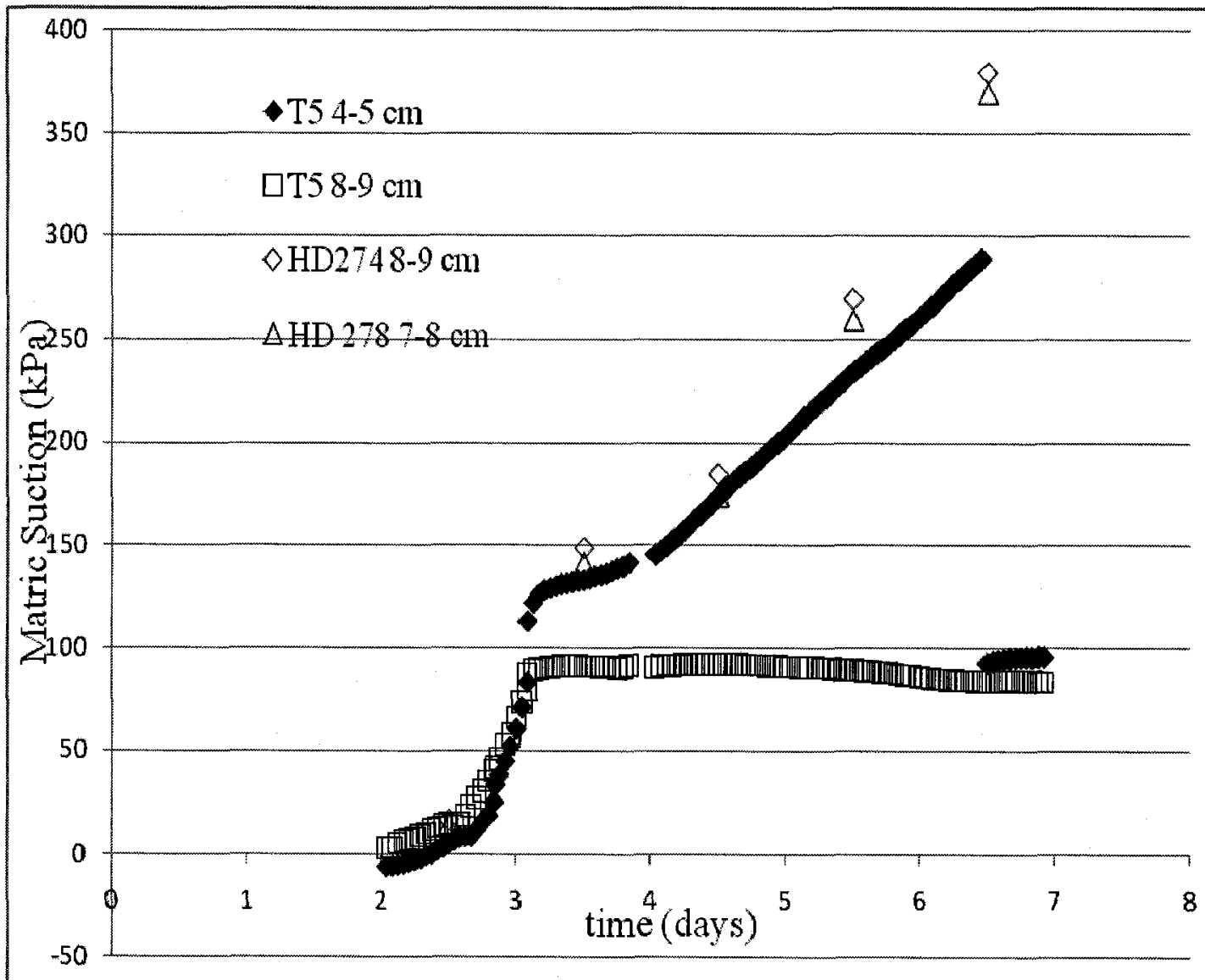

Figure 5.2.6.5: Matric suction measurement using T5 and HDS sensors for the first layer of large-scale drying test The tensiometers were located 40-50 $\mathrm{mm}$ and 80-90 $\mathrm{mm}$, and HDS were located $70-80 \mathrm{~mm}$ and $80-90 \mathrm{~mm}$ from the bottom of the tank. 


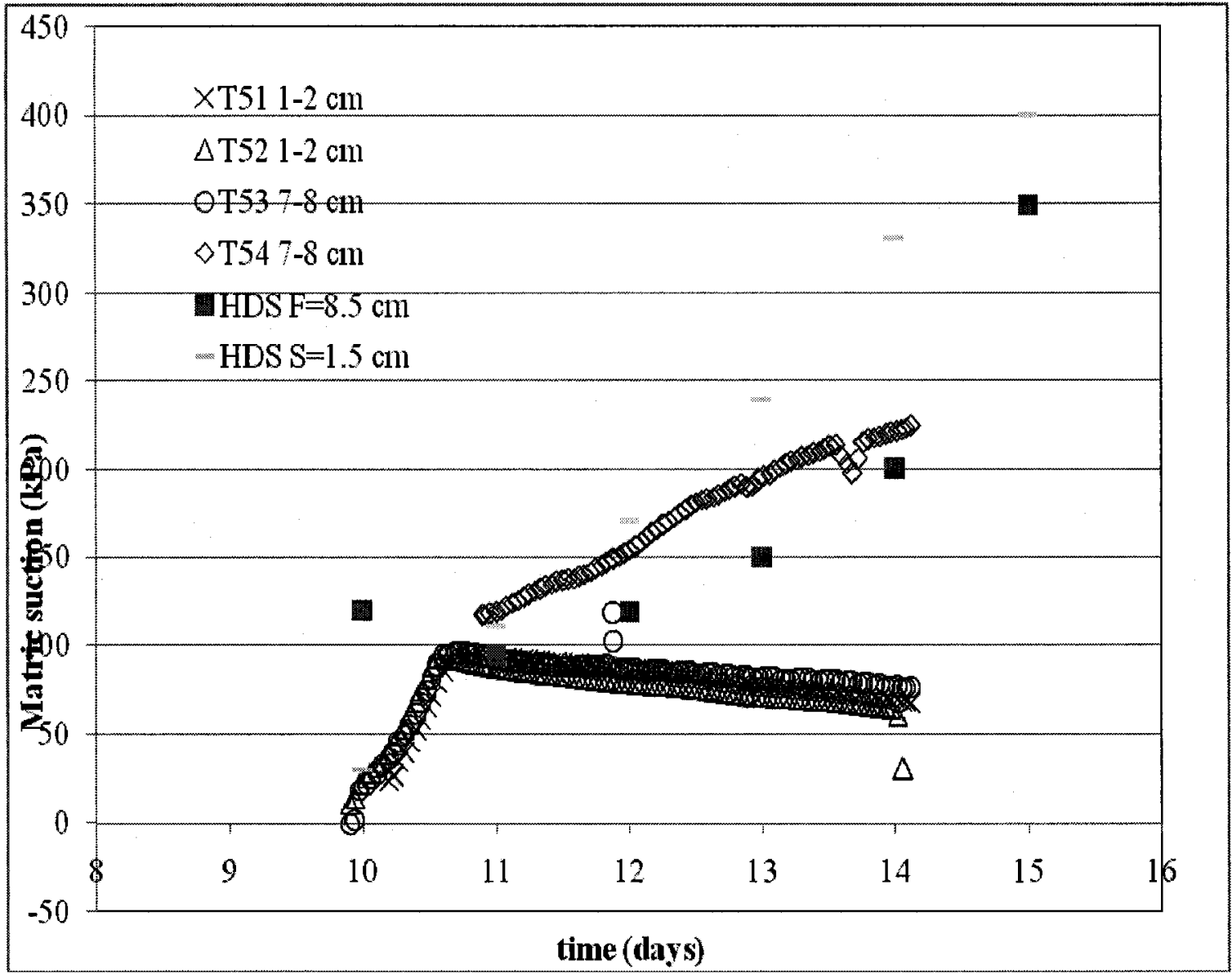

Figure 5.2.6.6: Matric suction measurement using T5 and HDS sensors for the second layer of large-scale drying test The tensiometers were located $10-20 \mathrm{~mm}, 10-20 \mathrm{~mm}, 70-80 \mathrm{~mm}$ and $70-80 \mathrm{~mm}$, and HDS were located first layer at $85 \mathrm{~mm}(\mathrm{~F}=85 \mathrm{~mm})$ and second layer at $15 \mathrm{~mm}(\mathrm{~S}=15 \mathrm{~mm})$.

Figure 5.2.6.7 shows sensitivity of Four HDS sensors. It shows that for high suctions a small change in the recorded temperature increase will result in a large change in suction. The matric suction measurements reasonablly agree on the first 4-5 days with the T5's. However, as the tailings dried the HDS sensors start to give results much more variable. 


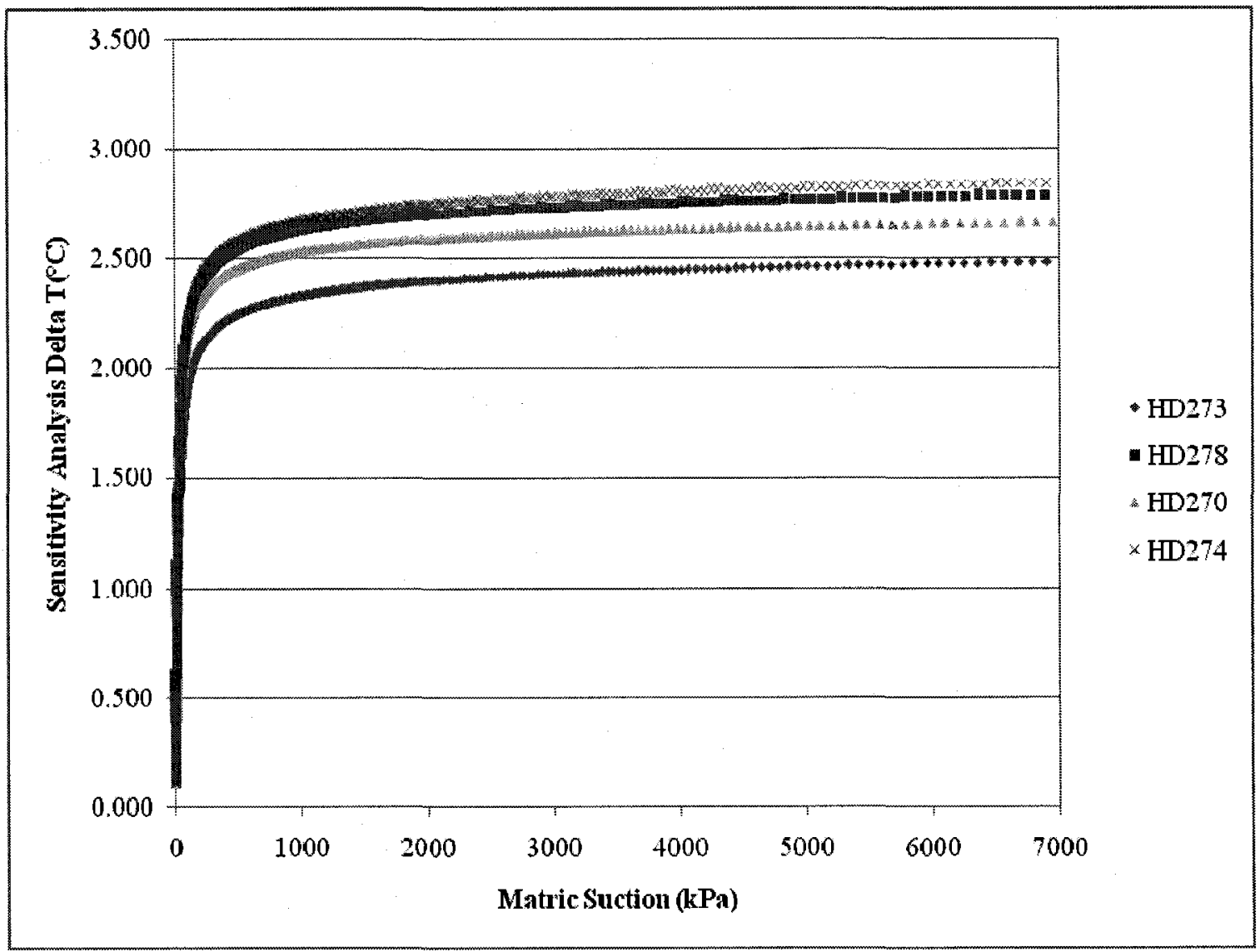

Figure 5.2.6.7: Sensitivity graph for HDS sensors.

In the second layer, four additional HDS sensor were placed to measure matric suction. After the deposition of second layer matric suction from HDS sensors were reasonablly agree with T5 measurements and SoilCover predictions as shown in Figure 5.2.6.9. The HDS sensors located in the first layer was also giving smaller matric suction measurements. This is due to the rewetting of the dried layer from the fresh second layer dries out. This shows the interlayer decrease in suction as it gained moisture from the top layer. 
SoilCover modelled matric suctions give reasonably a good agreement with the measured matric suction measurements using T5 and HDS sensors for both first and second layers as shown in Figure Figure 5.2.6.8 and Figure 5.2.6.9.

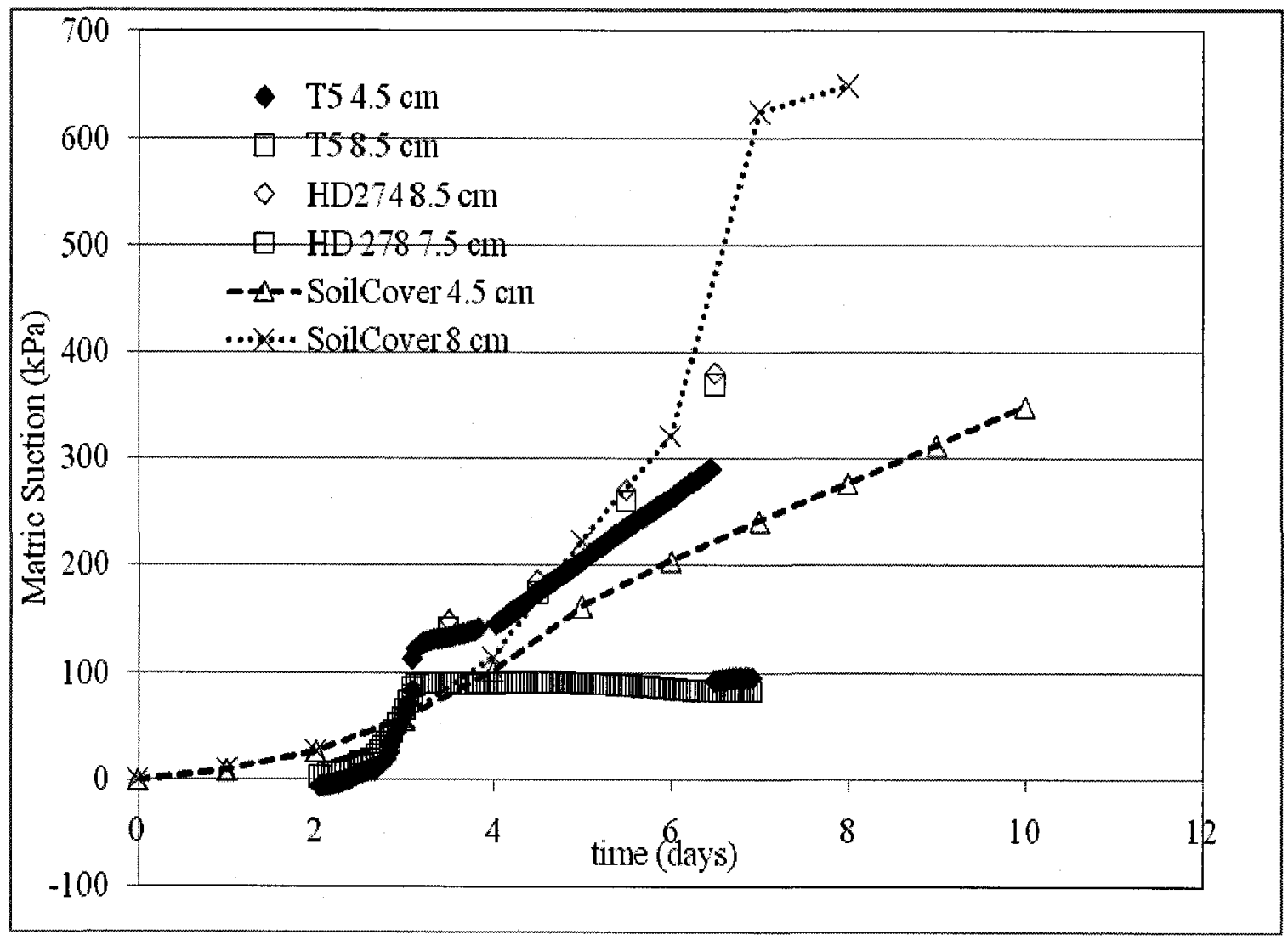

Figure 5.2.6.8: Measured using T5's and HDS sensors and SoilCover predicted matric suctions for the first layer drying test. 


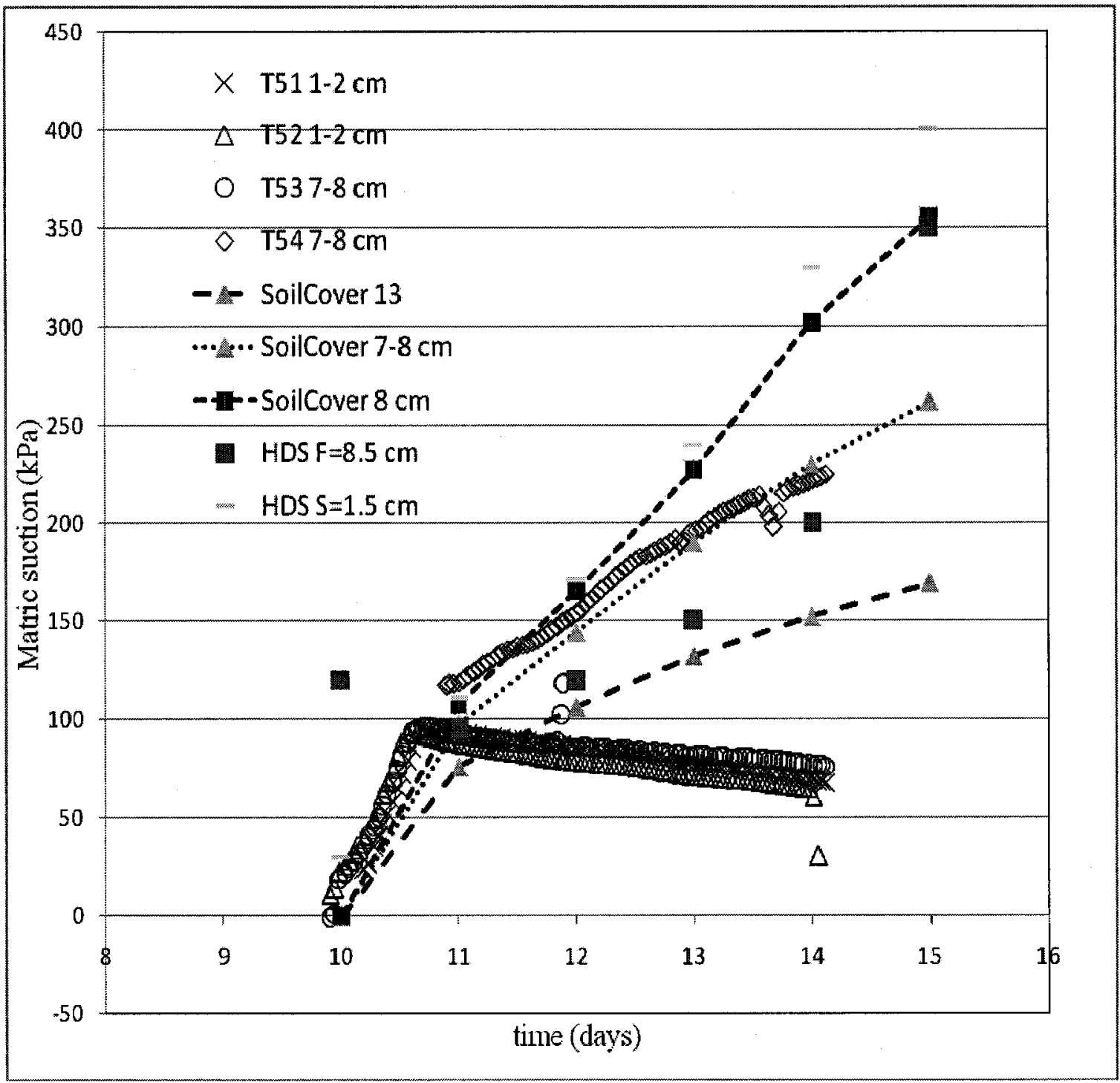

Figure 5.2.6.9: Measured using T5's, HDS and SoilCover predicted matric suctions for the second layer drying test. 


\subsection{Large-Scale Experimental Pictures}

Daily pictures were taken during first layer, second layer and rewetting of Bulyanhulu drying test as shown in Figure 5.2.7.1 to Figure 5.2.7.17. Crack formation and propagation, salt precipitation on the surface can be seen visually using the following Figures.

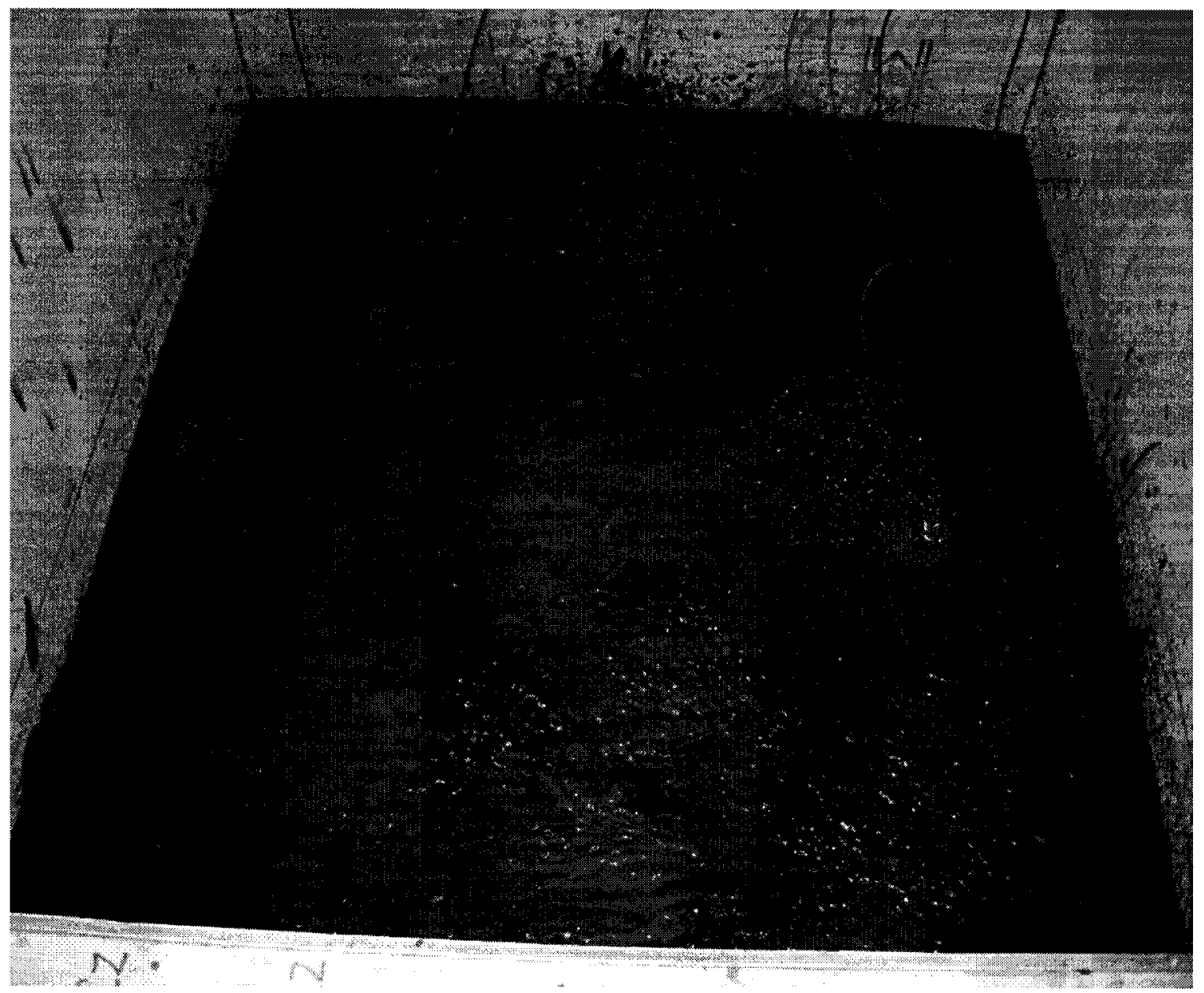

Figure 5.2.7.1: January 26/2008, Day 0 first layer drying test. 


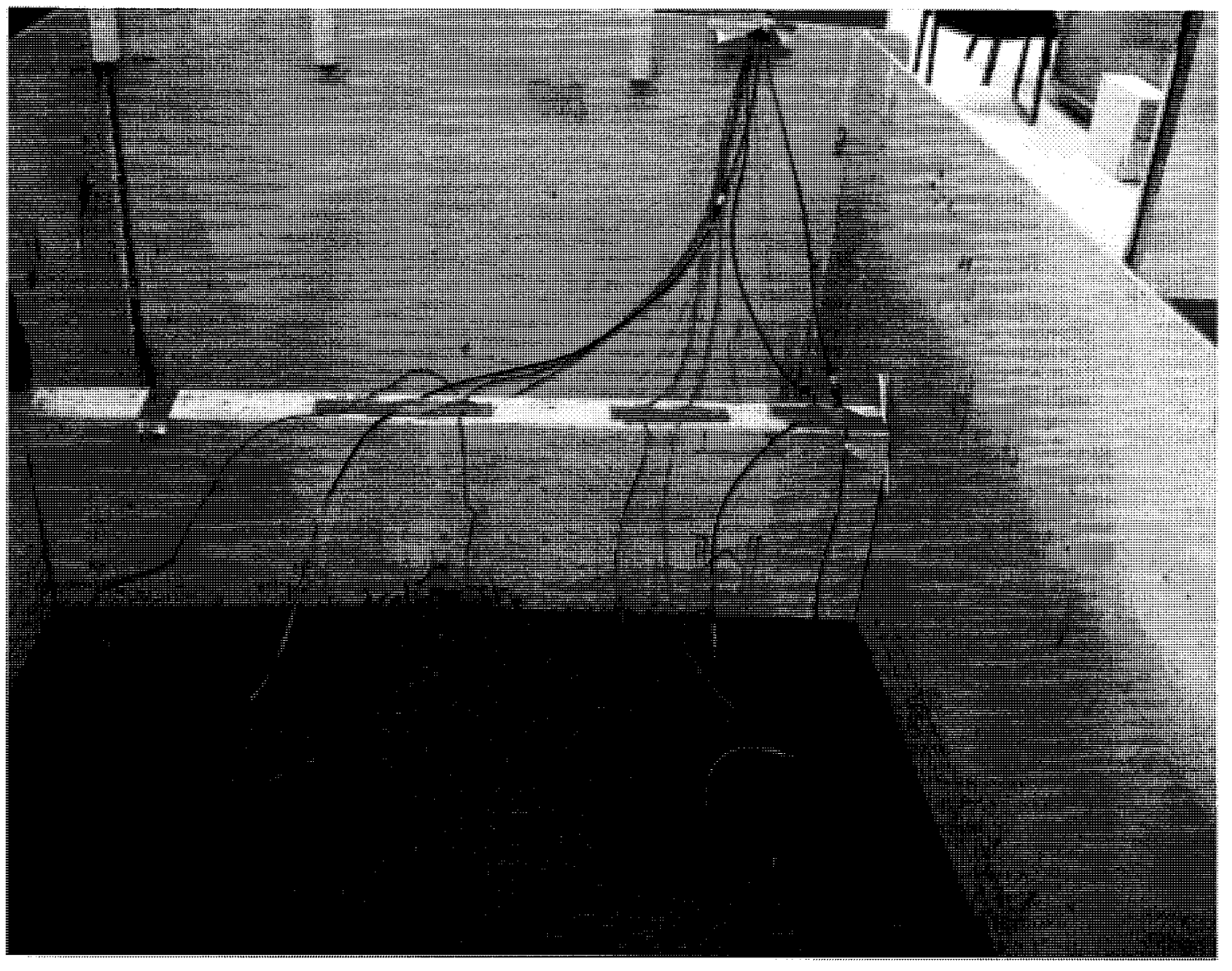

Figure 5.2.7.2: January 28/2008, second day of Bulyanhulu drying test. 


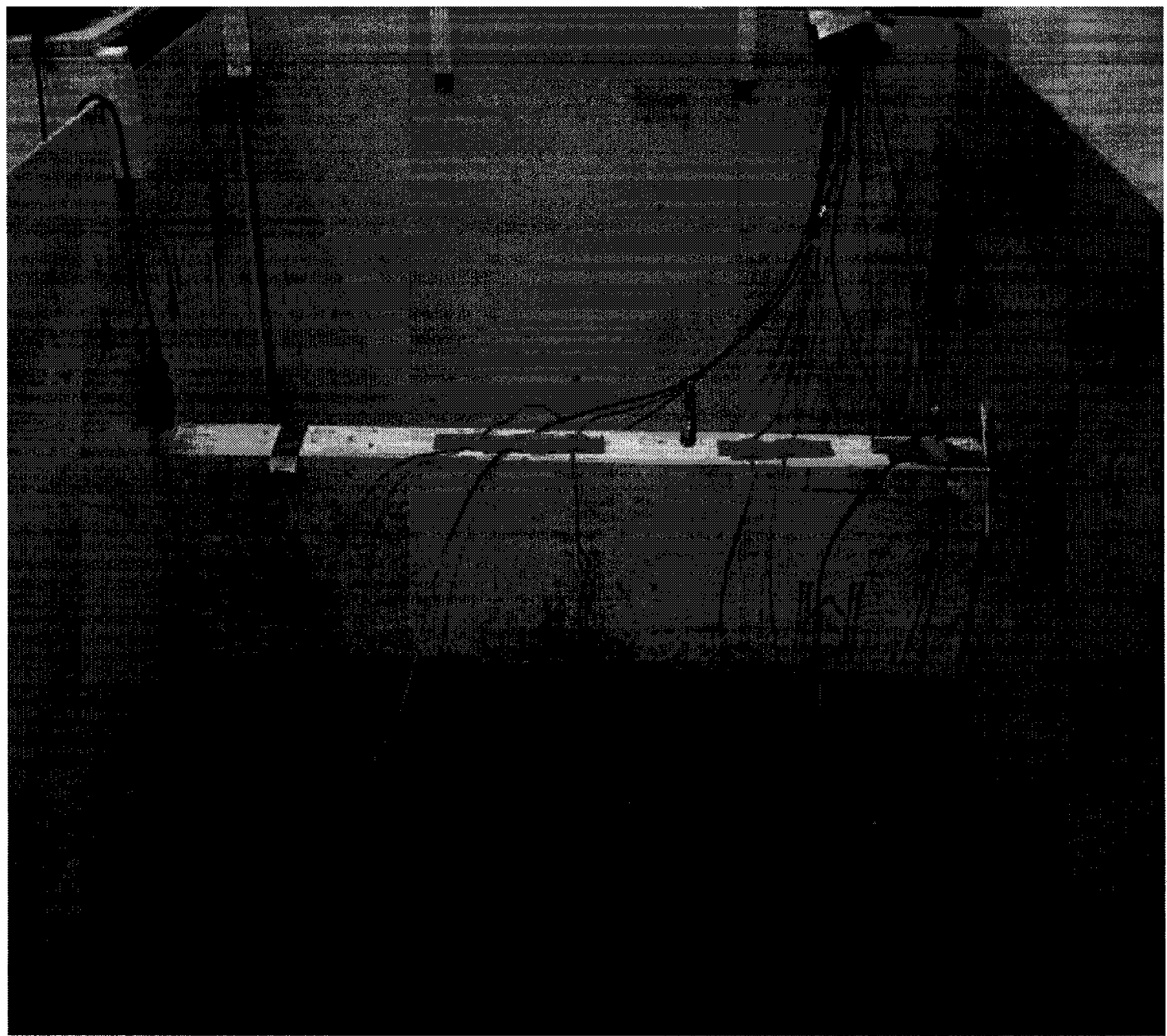

Figure 5.2.7.3: January 29/2008, day three first layer drying test. 


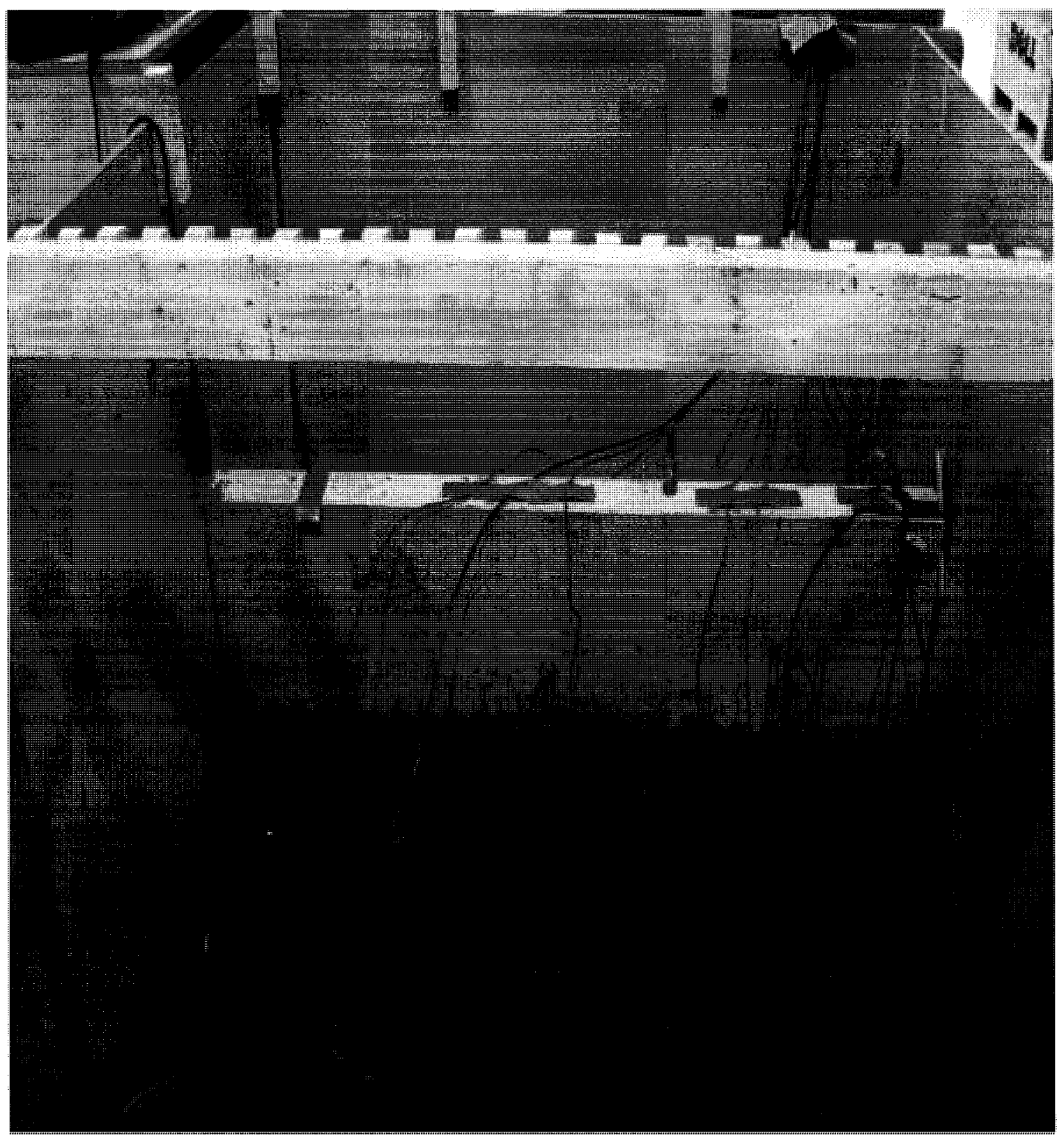

Figure 5.2.7.4: January 30/2008, day four first layer drying test. 


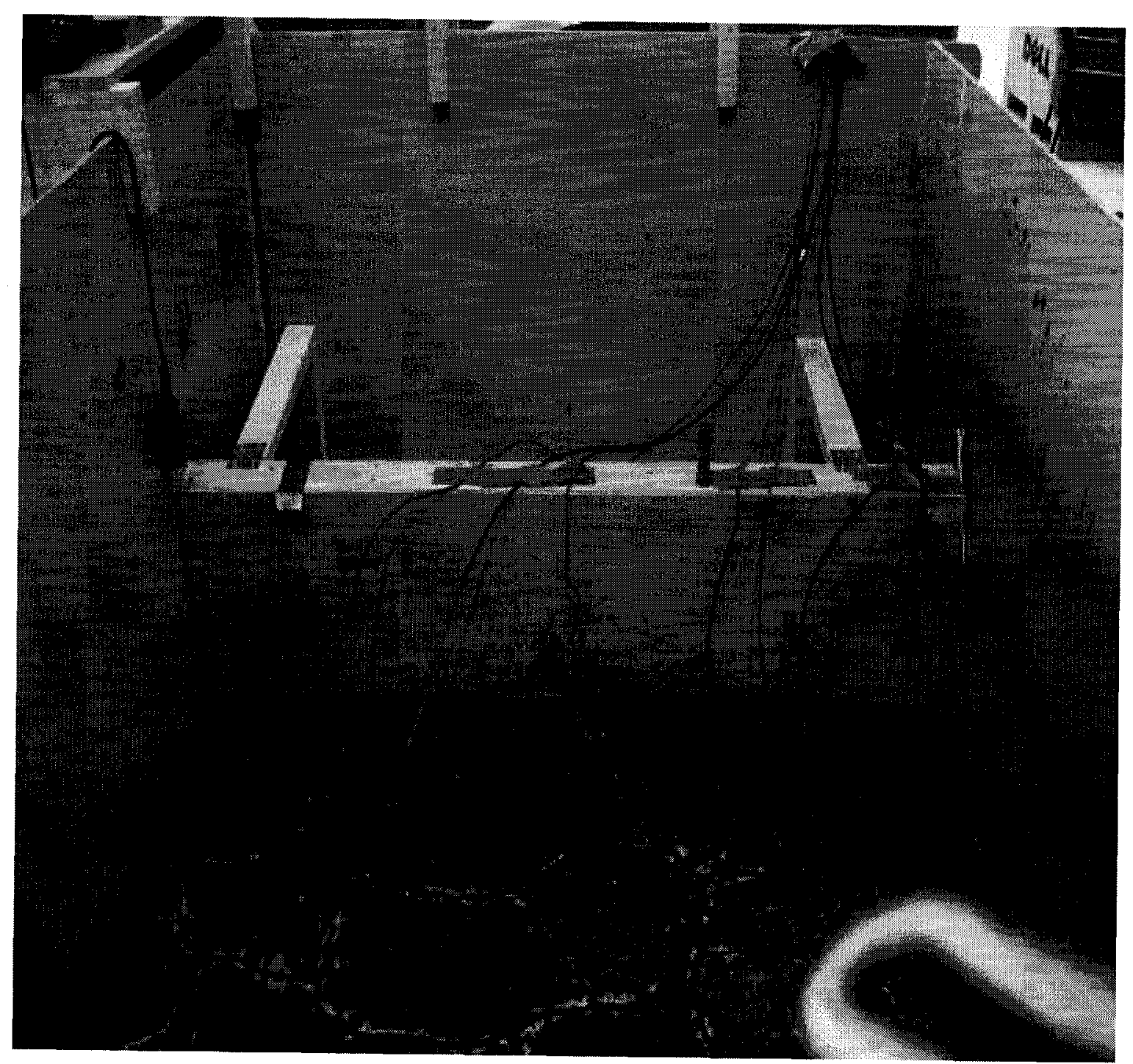

Figure 5.2.7.5: January 31/2007, days five of first layer drying test. 


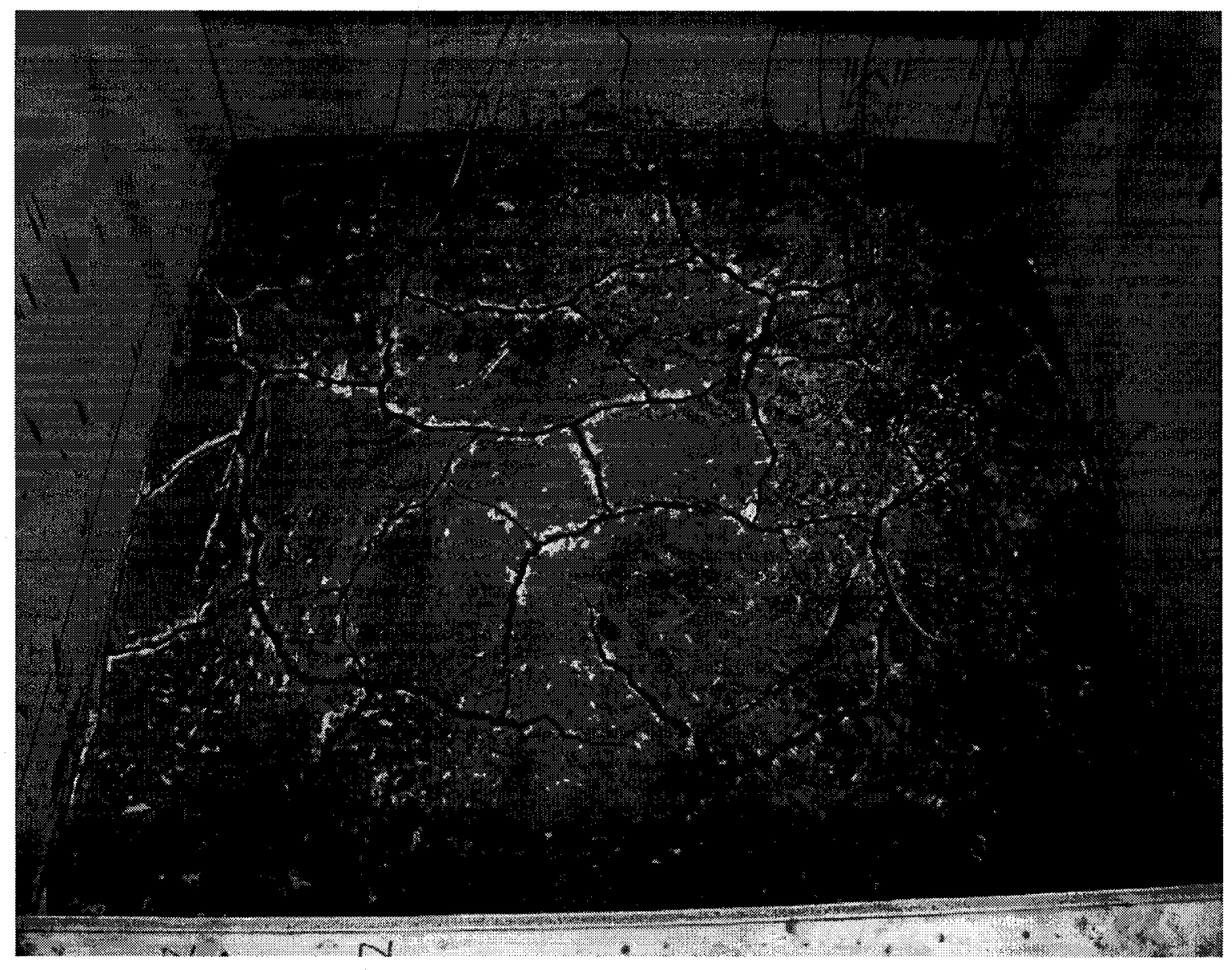

Figure 5.2.7.6: February 1/2008, day six of first layer drying test. 


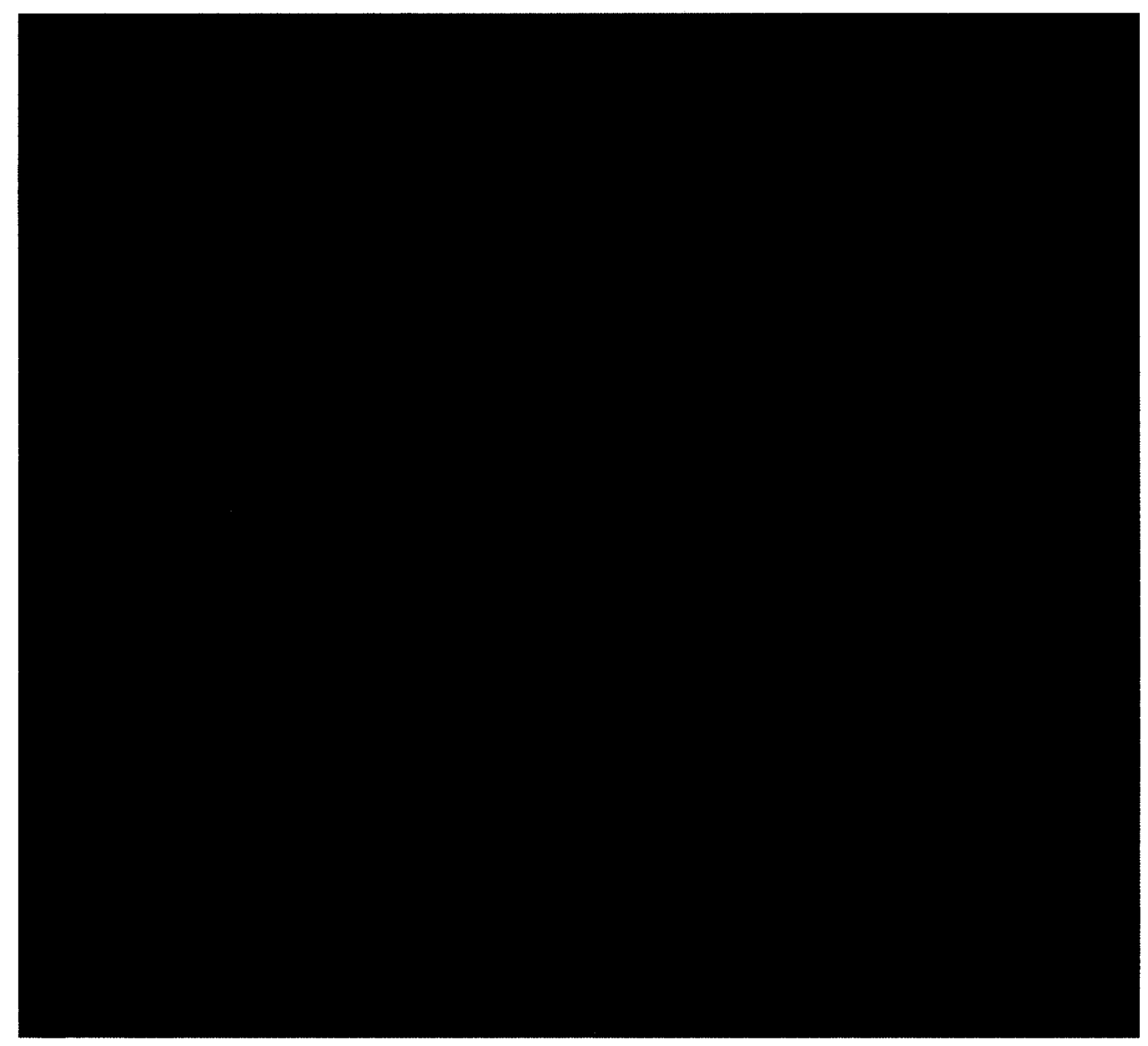

Figure 5.2.7.7: February 2/ 2008, day seven of first layer drying test. 


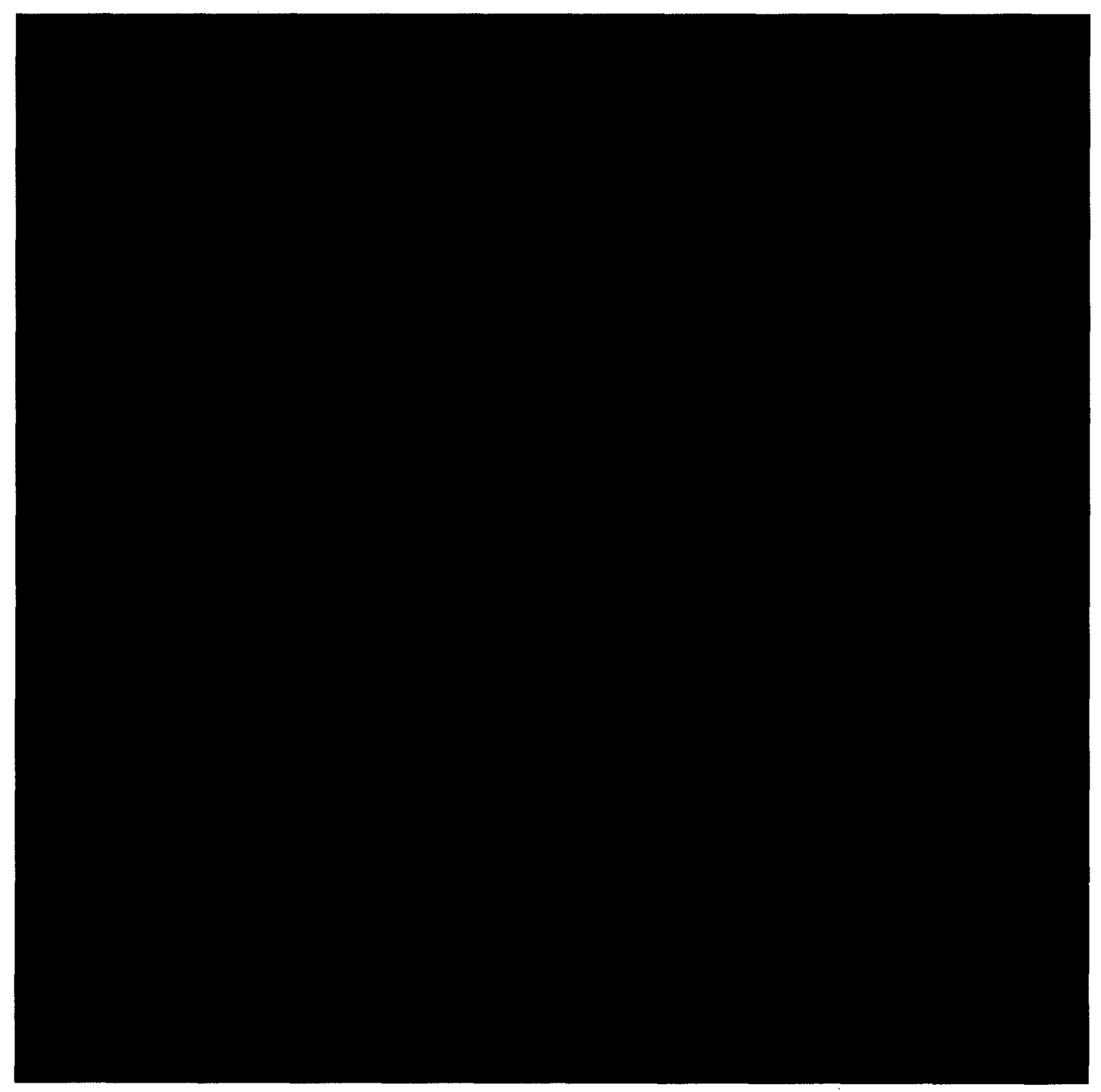

Figure 5.2.7.8: February 3/2008, day eight of first layer drying test. 


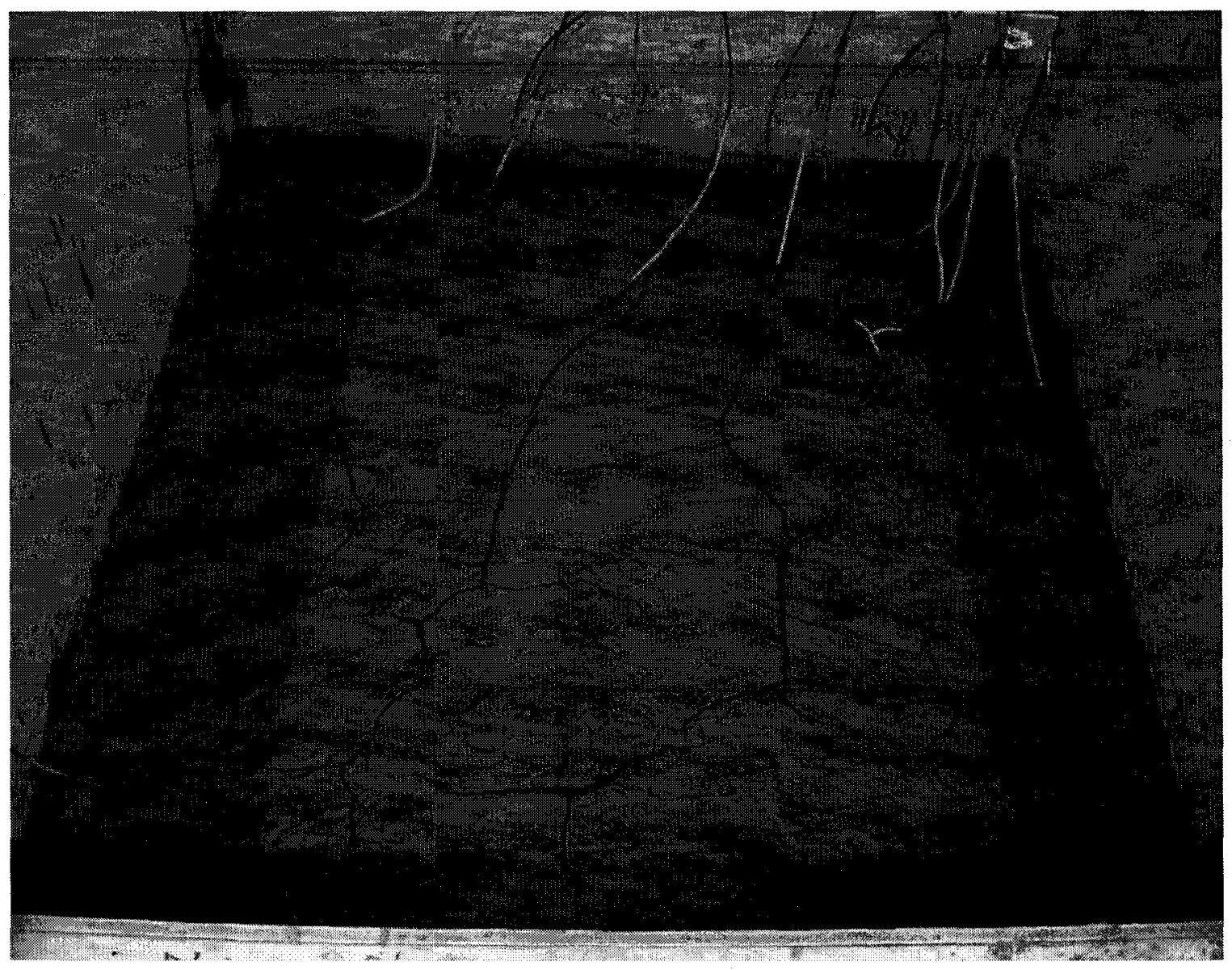

Figure 5.2.7.9: February 5/ 2008, day zero of second layer drying test ( -3 hours after deposition). 


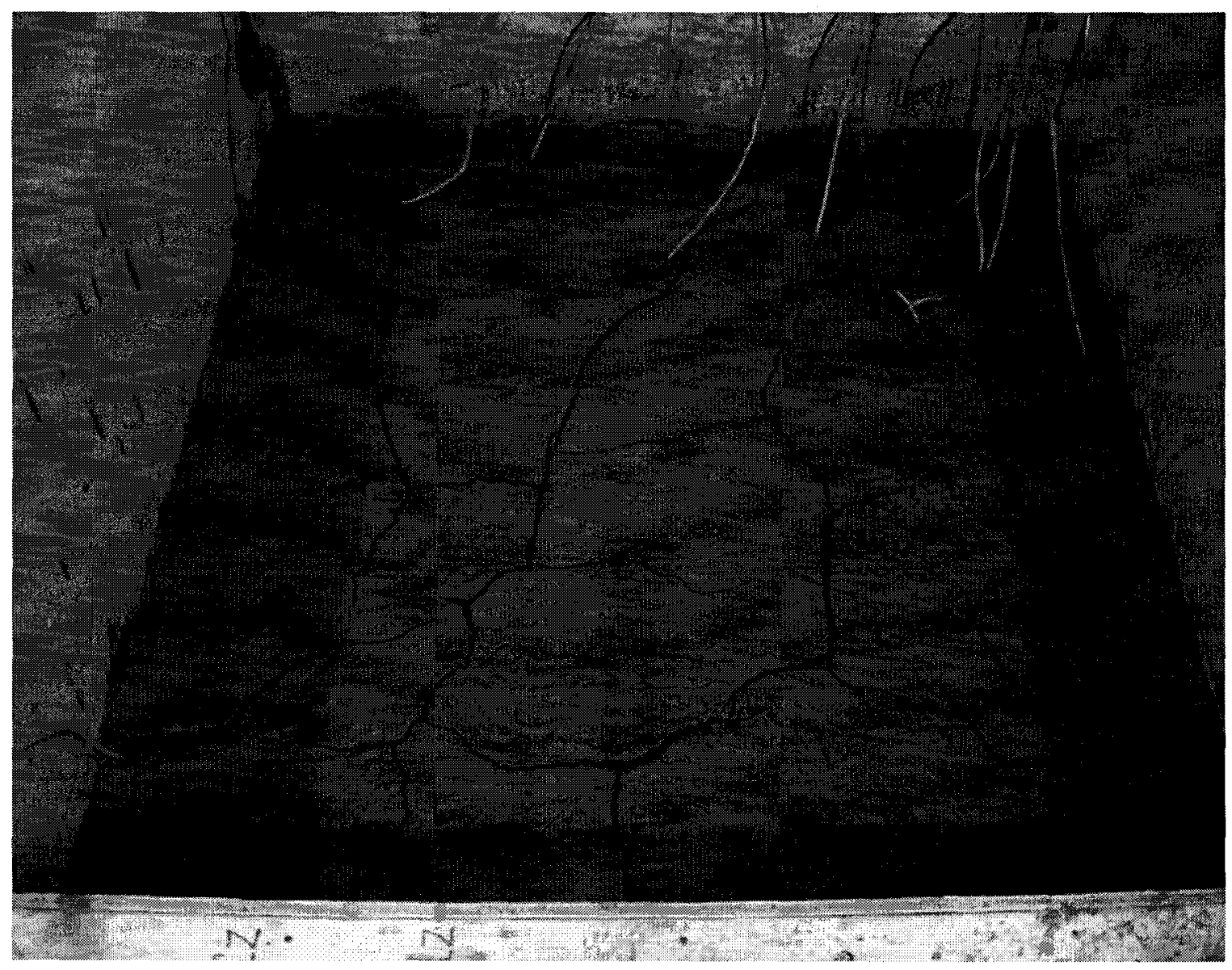

Figure 5.2.7.10: February 6/ 2008, day one of second layer drying test. 


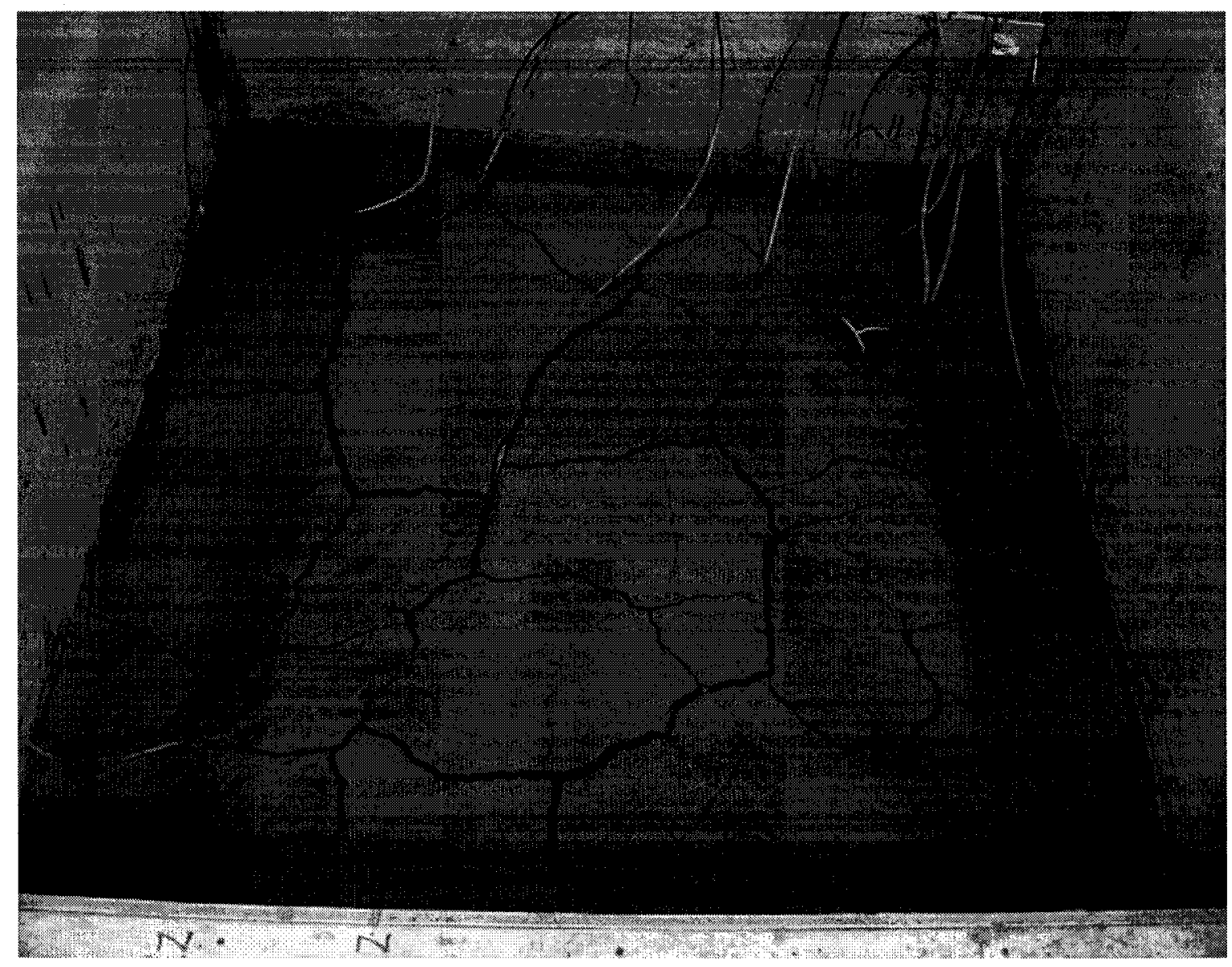

Figure 5.2.7.11: February 6/ 2008, day one of second layer drying test (late afternoon). 


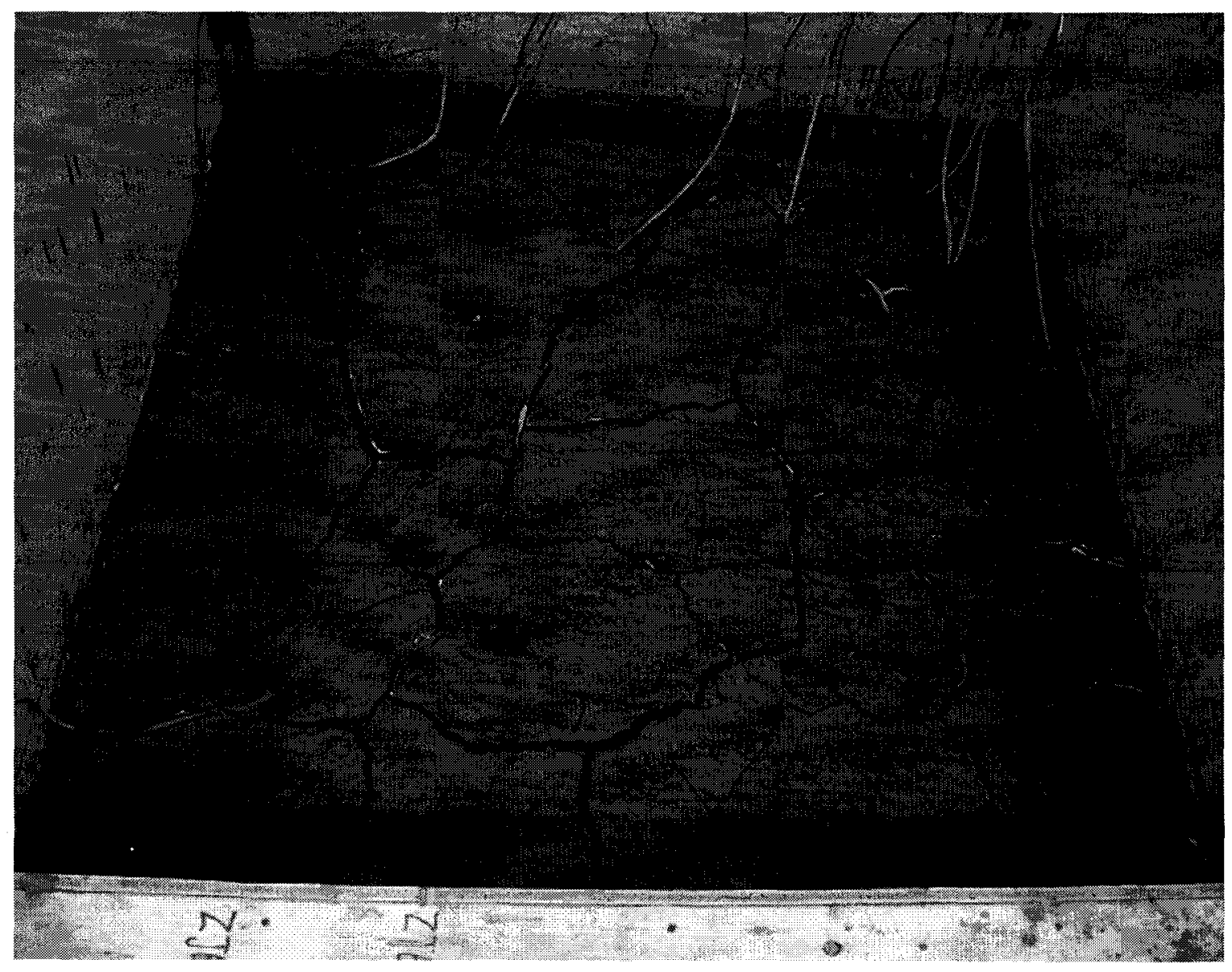

Figure 5.2.7.12: February 7 / 2008, day two of second layer drying test. 


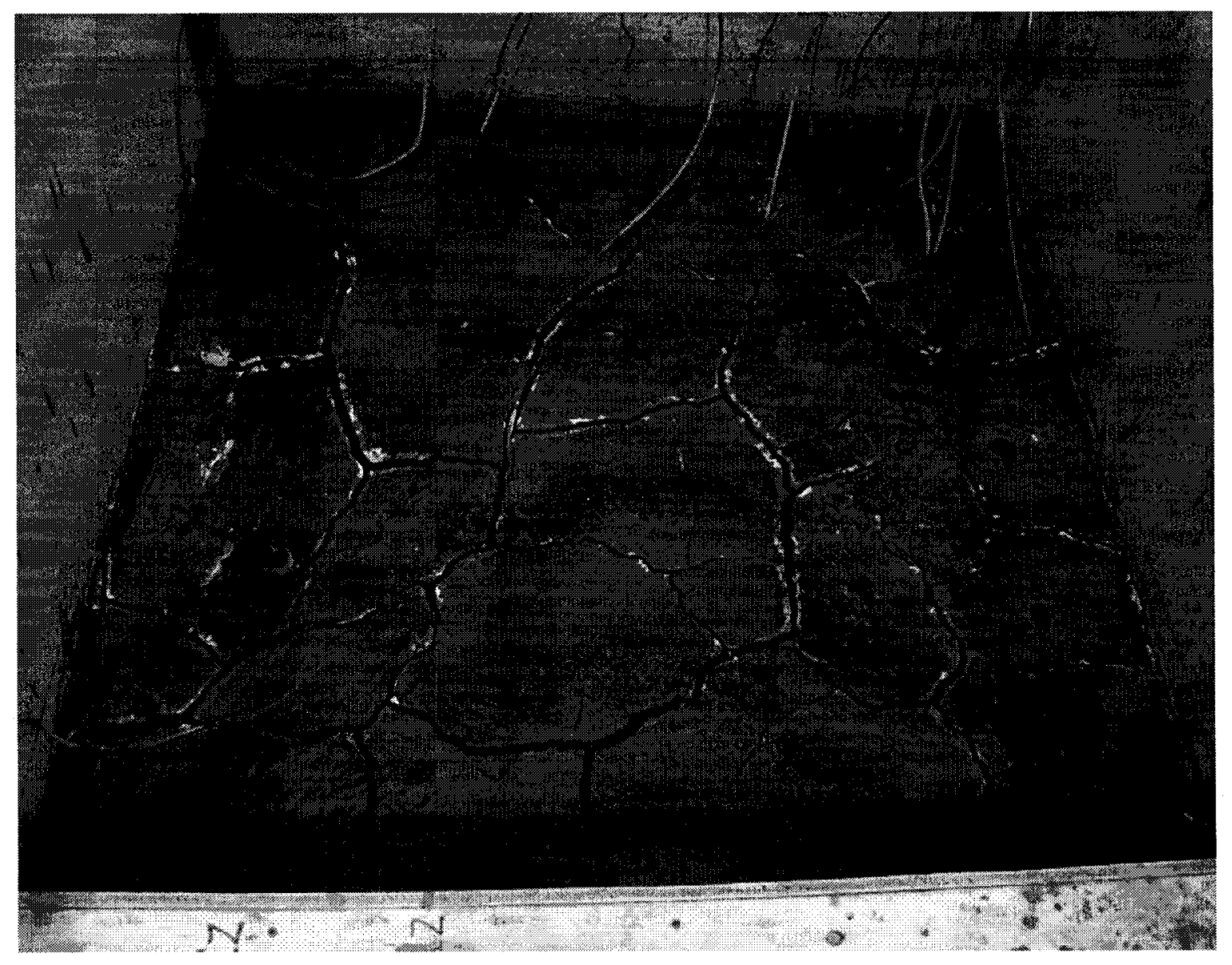

Figure 5.2.7.13: February $8 / 2008$, day three of second layer drying test. 


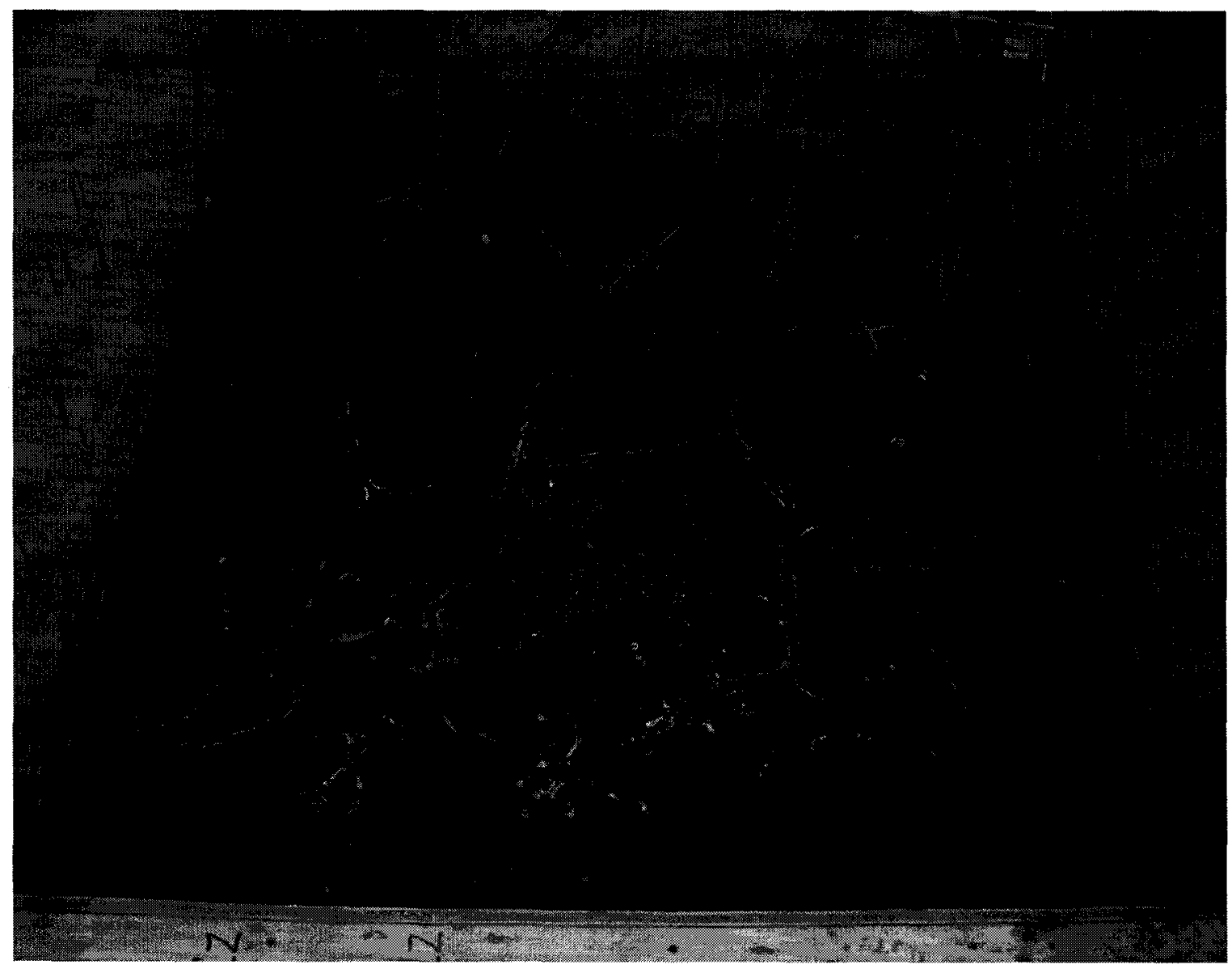

Figure 5.2.7.14: February $9 / 2008$, day four of second layer drying test. 


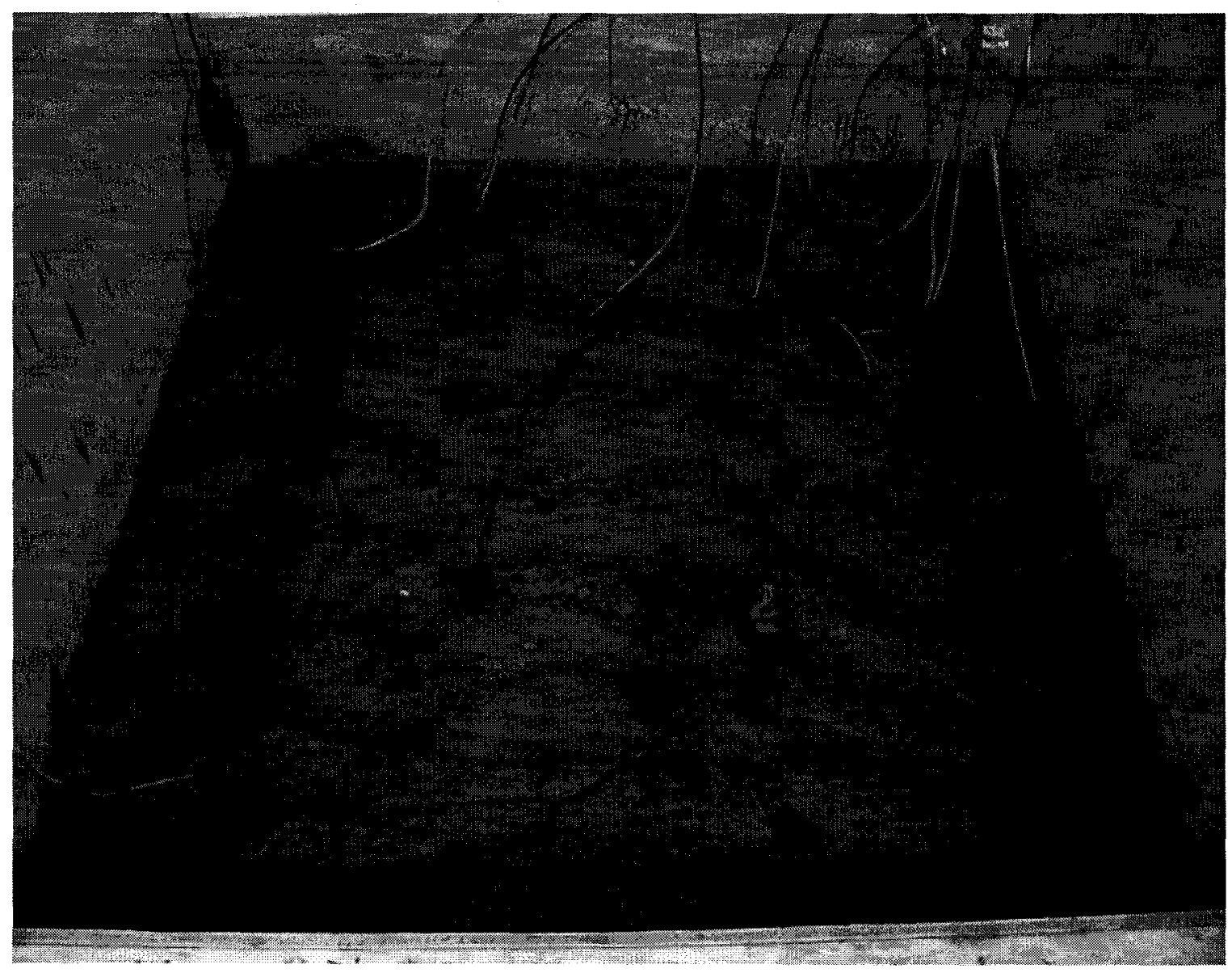

Figure 5.2.7.15: February 10/ 2008, day zero of rewetting. 




Figure 5.2.7.16: February 11/2008, day one of rewetting. 


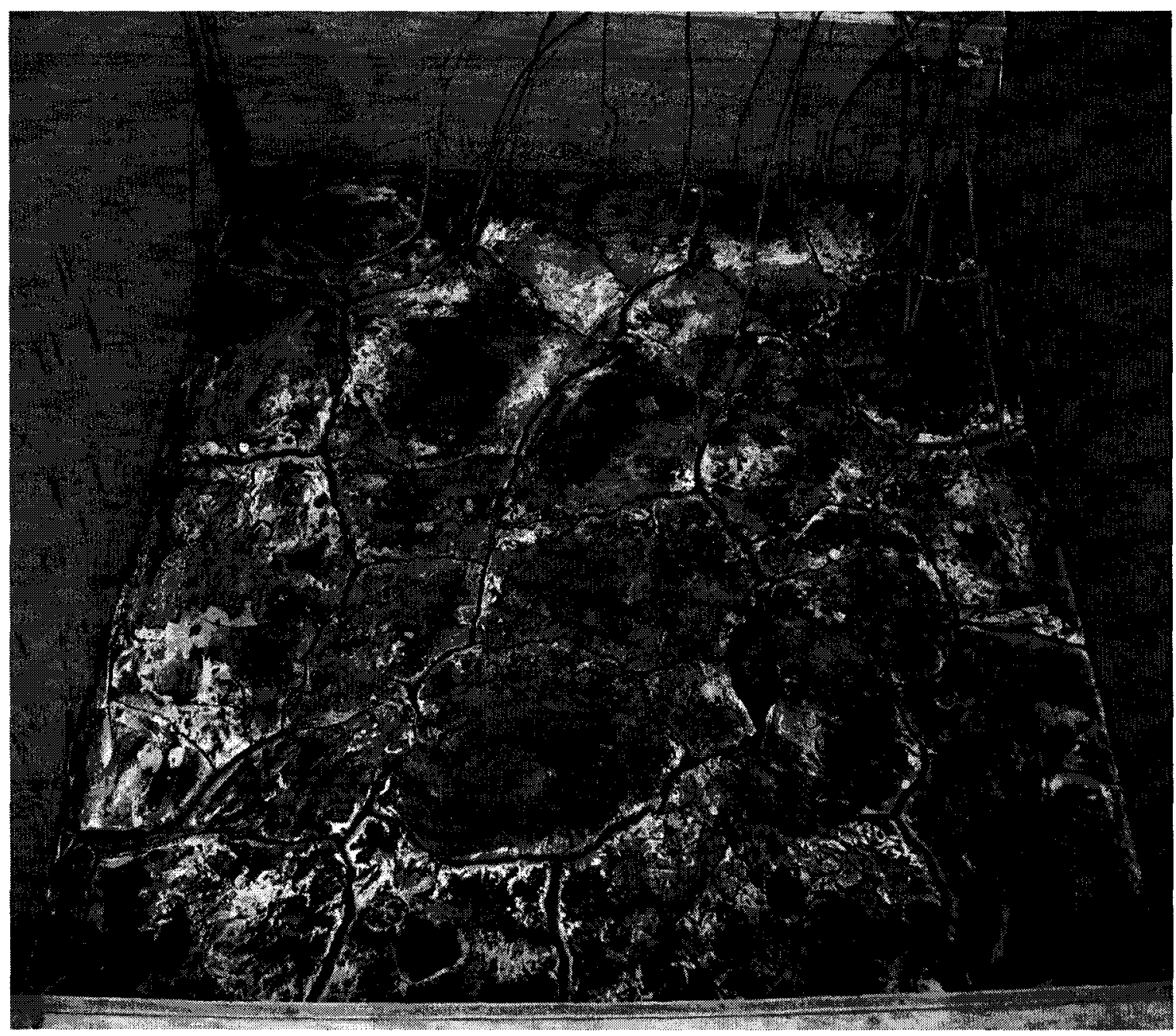

Figure 5.2.7.17: February 12/ 2008, day two of rewetting. 


\subsection{Small -Scale Multilayer Surface Deposition Bulyanhulu Tailings}

\subsubsection{Introduction}

Figure 5.3.1 gives cumulative evaporation, void ratio, average gravimetric water content and degree of saturation for the small scale drying test.

Initially, first layer drying test started at $110 \%$ degree of saturation and as the tailings dried out decreased to $16 \%$ by the end of day 15 . Degree of saturation increased to $65 \%$ during the addition of the second layer and later decreased to $37 \%$ by day 25 which is end of second layer drying test as shown in Figure 5.3.1.

Each function in Figure 5.3.1 is discussed in their respective sections given below. 


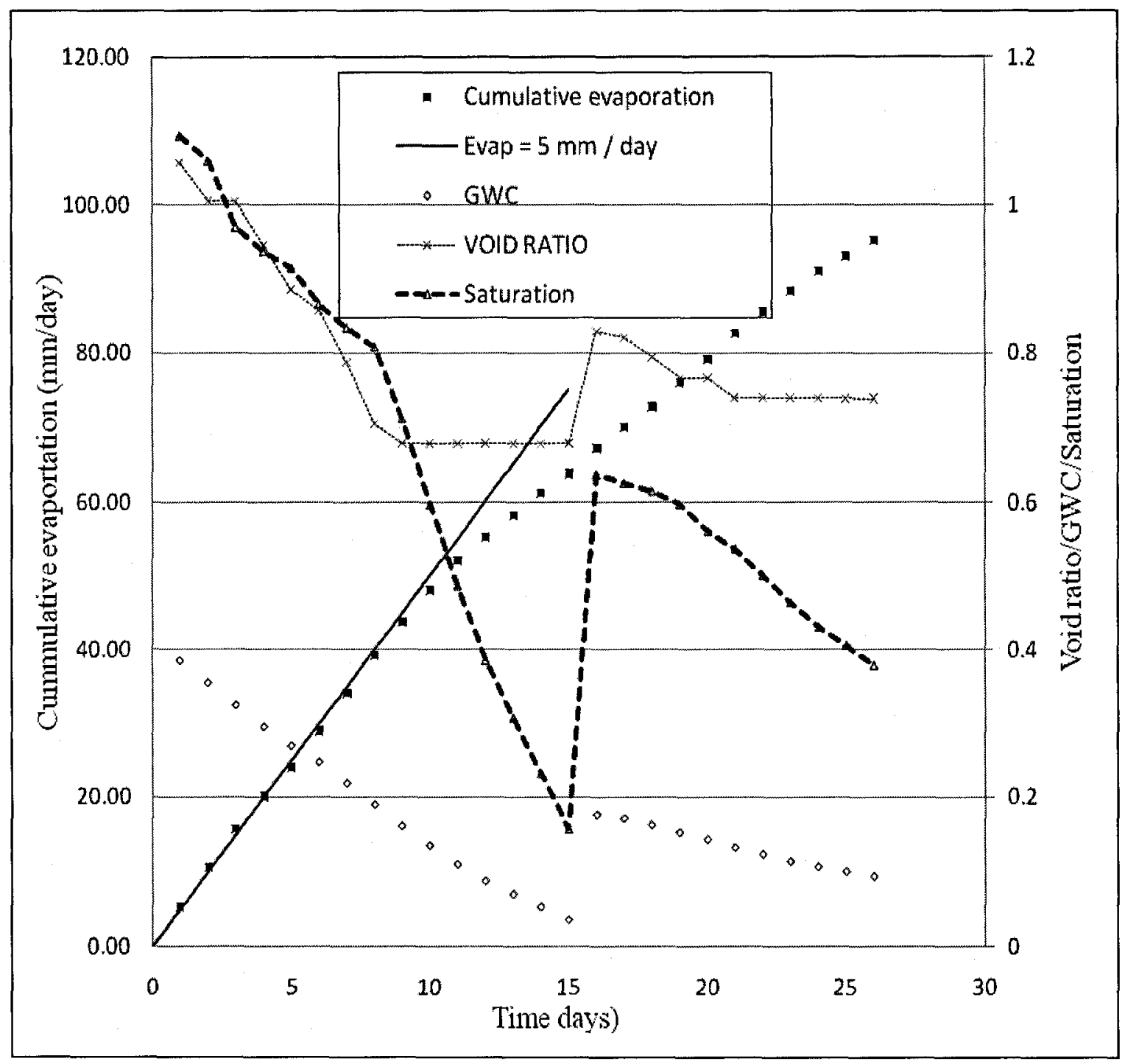

Figure 5.3.1: Cumulative evaporation, void ratio, saturation, GWC on small-scale multilayer drying test.

\subsubsection{Volume change}

During small scale drying test the tailings consolidated as the result of self weight for the first five days. The void ratio reduced from 1.1 to 0.92 by day 5 due to self-weight 
consolidation. Subsequently the final void ratio reduced to 0.68 by day 9 of the first layer. There was no volume change until the end of first layer by day 15 .

On day 15 , the addition of the second layer increased the void ratio to 0.83 as shown in Figure 5.3.2 and subsequently decreased to 0.74 by day 20 . There was no additional volume change until the end of second layer drying test.

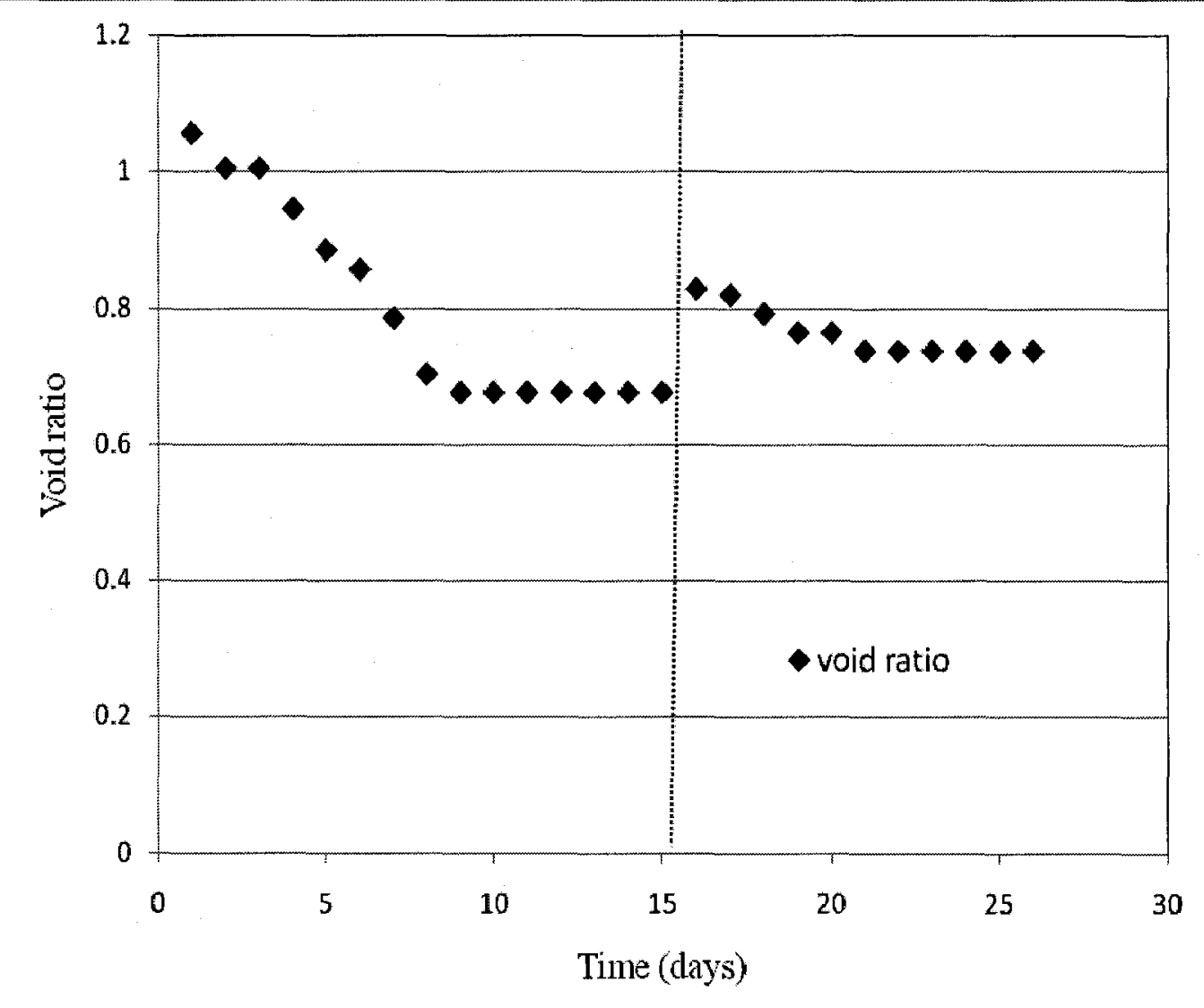

Figure 5.3.2: Void ratio with time for small scale drying test. 


\subsubsection{Evaporation}

Measured actual rate of evaporation, computed actual rate of evaporation using SoilCover and computed potential evaporation are shown in Figure 5.3.3.

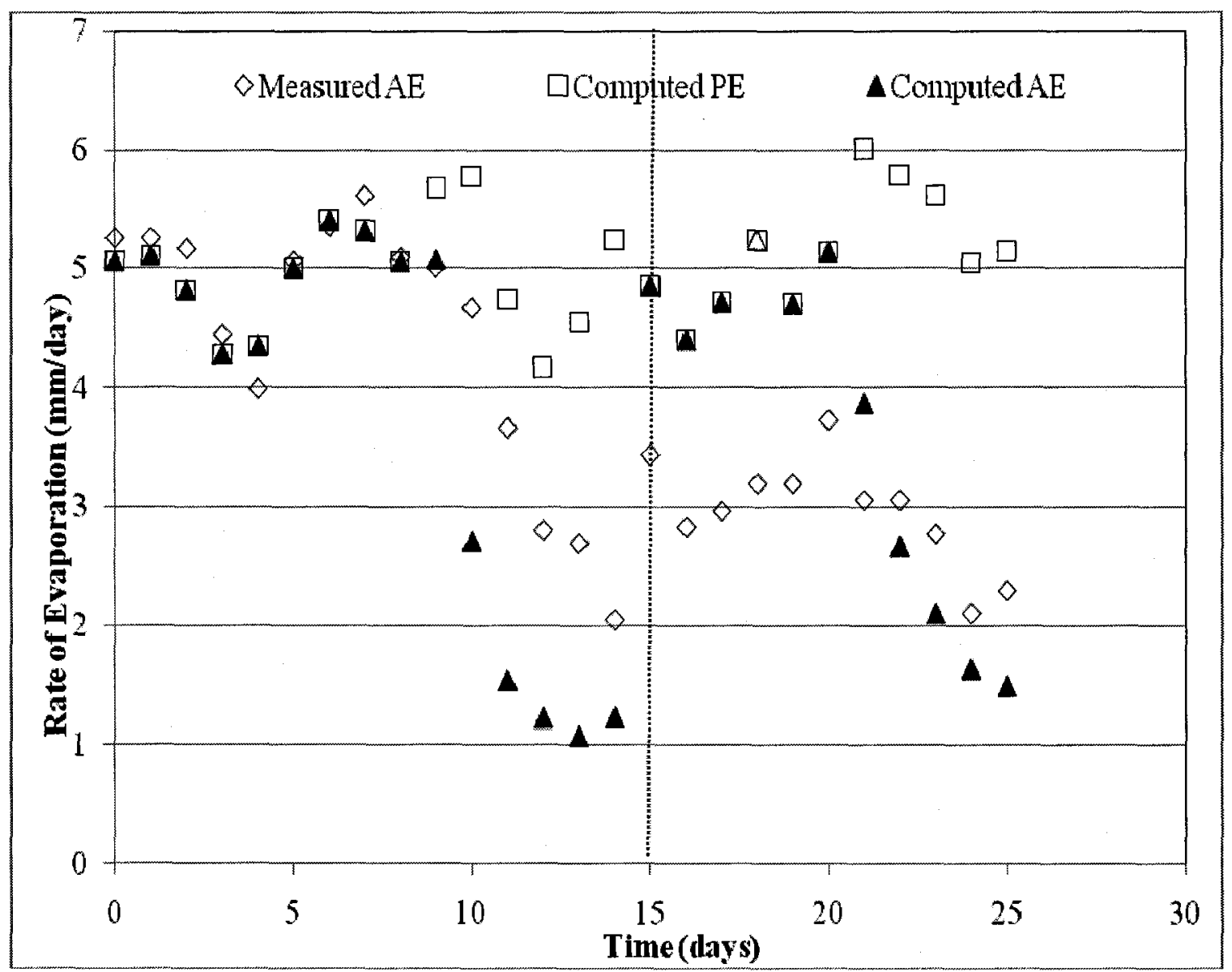

Figure 5.3.3: Measured, computed actual evaporation (AE) and potential evaporation (PE) from small-scale drying test. 
Measured, computed actual evaporation and computed potential evaporation reasonably agreed for the first seven days during the first layer drying test. During the first seven days significant amount of water was accumulated at the top surface while the tailings consolidated by self-weight. This confirms the drying test was still under stage I. On day 8 , measured and computed actual evaporation shows a good agreement. However, computed and measured actual evaporation shows difference by day 9 up until day 15 end of first layer drying test. This may be due to the formation of cracks at the surface and separation of the tailings from the walls of the bucket and increased the surface area exposed. A similar phenomenon happened during large scale drying test.

On day 15, a significant amount of salt precipitation was observed on top of first layer and by the end of day 15 to day 20, there was significant difference between measured and computed actual rate of evaporations. This is due to the accumulation of salts and a separate section will be presented to account the effect of salts.

\subsubsection{Gravimetric Water Content}

Figure 5.3.1 shows the change in gravimetric water content with time as the small scale tailings dried out. The first layer tailings reduced its GWC from $41 \%$ by day 0 to $5 \%$ by day 15. Addition of the second layer increased GWC to $19 \%$ by day 16 and eventually decreased to $9 \%$ at the end of second layer drying test. The second layer dried faster as the result of the first dried layer. 
Gravimetric moisture content with profile depth is shown in Figure 5.3.4. Measured gravimetric water content gives $9-10 \%$ is in good agreement as compared to overall average GWC 9\%. Measured GWC shows with profile depth seems uniform except at the interlayer interface. This could be due to the accumulation of salt at the end of the first layer. Accumulation of salt can be seen in Figures 5.3.6.4 and Figure 5.3.6.5.

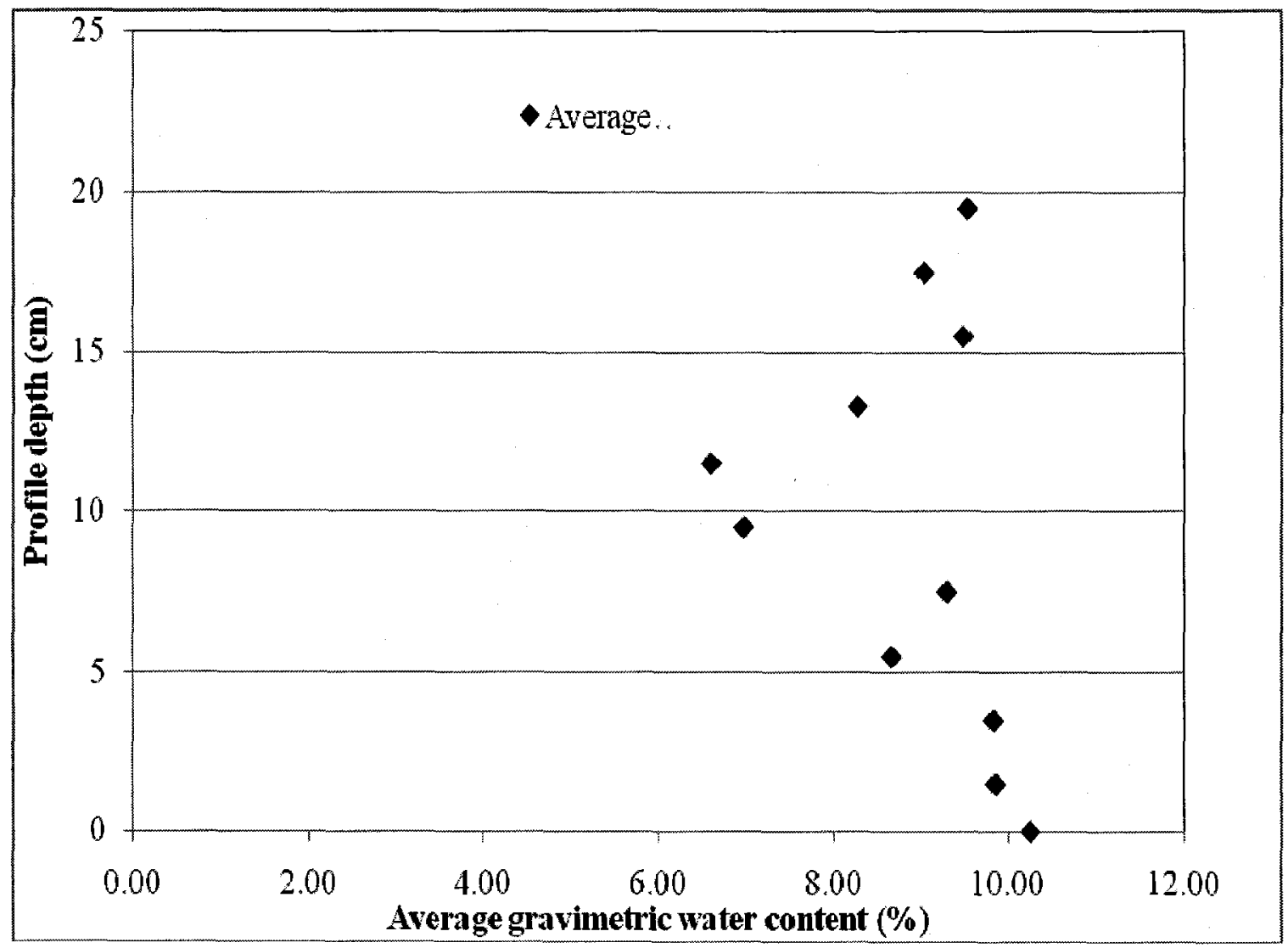

Figure 5.3.4: Gravimetric moisture content of small scale with profile depth. 


\subsubsection{Matric Suction}

Figure 5.3.5.1 and Figure 5.3.5.2 shows the matric suction measurements using T5 tensiometers for the first and second layers, respectively.

T5 measurements show there was a uniform distribution of matric suction with depth for the first 8 days. The T5 located near the surface cavitated on day 8 , while the T5 located at 90 mm cavitated on day 10 .

During the second layer drying as shown in Figure 5.3.5.2, the T5 located at the top of the first layer shows a decrease in suction during rewetting from the second layer within a few hours, and later starts to increase as the tailings are again dried by evaporation. During the period of second layer drying, there is a uniform suction distribution with depth. The T5 located $190 \mathrm{~mm}$ from the bottom of the bucket cavitated by end of day 16 at $91 \mathrm{kPa}$. The T5 located at the interlayer cavitated by day 17 .

Matric suction measurements using T5 tensiometers were in good agreement with the predicted matric suction using SoilCover as shown in Figure 5.3.5.3 and in Figure 5.3.5.4 for both first and second layers, respectively. 
The HD sensor located at the top of the first layer reports a decrease in suction after the deposition of the second layer. This is due to rewetting of the first layer. Measured and computed matric suctions are shown in Figure 5.3.4.2.

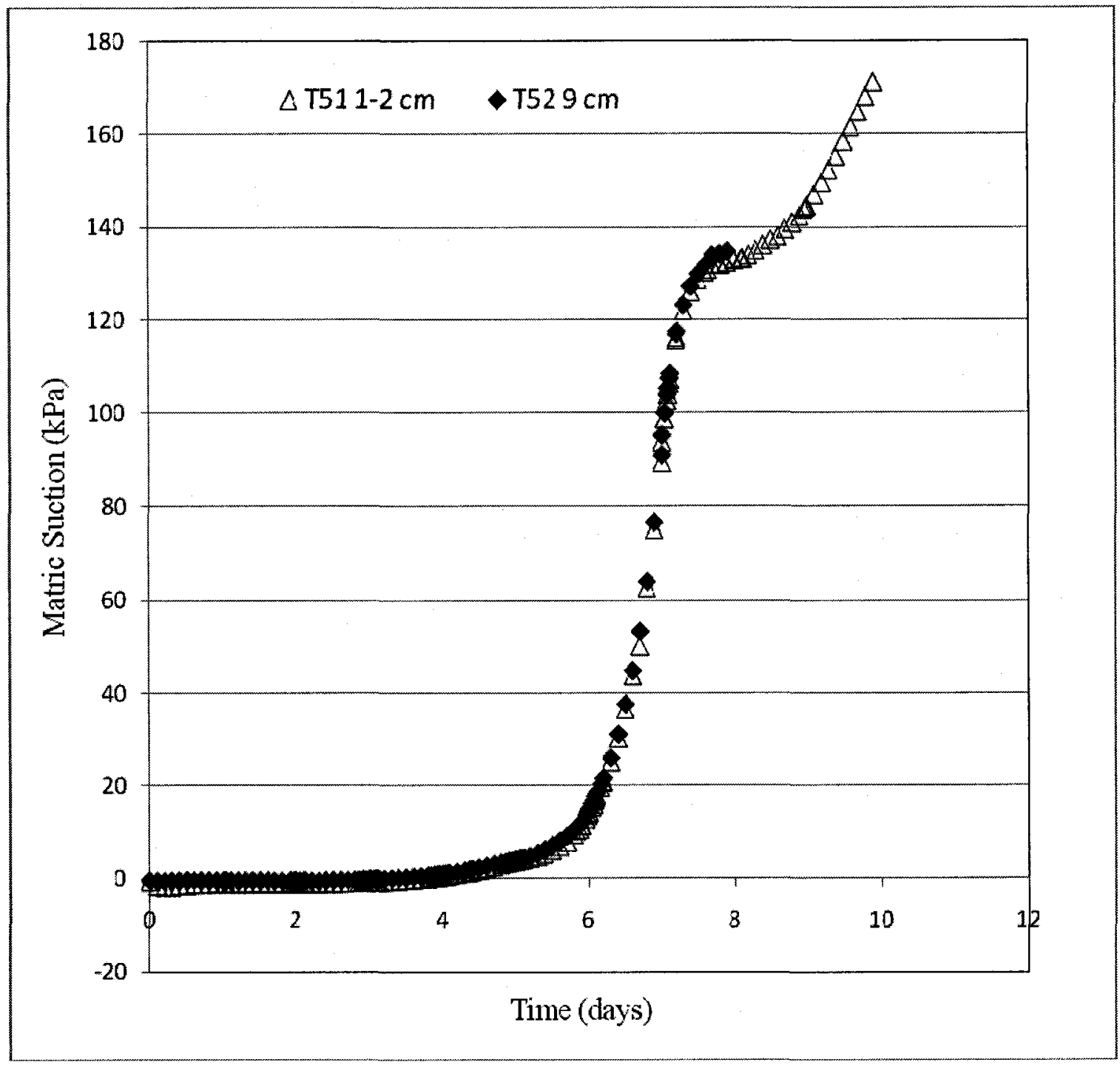

Figure 5.3.5.1: Matric suction measurements using T5 tensiometer for the first layer. 


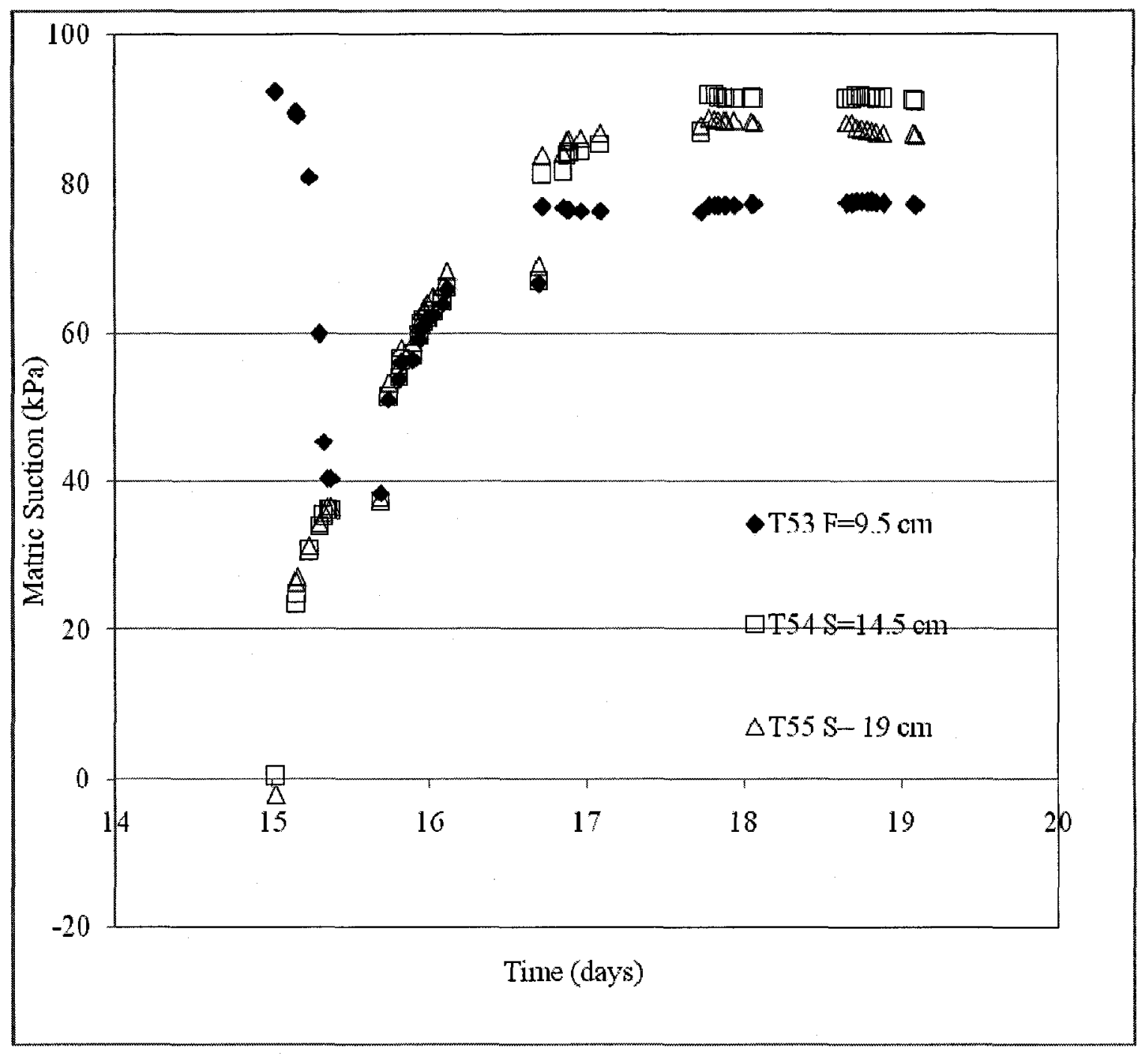

Figure 5.3.5.2: Matric suction measurement using T5's for second layer. the elevation of tensiometers given by letter "F" stands for first layer and letter "S" for second layer. 


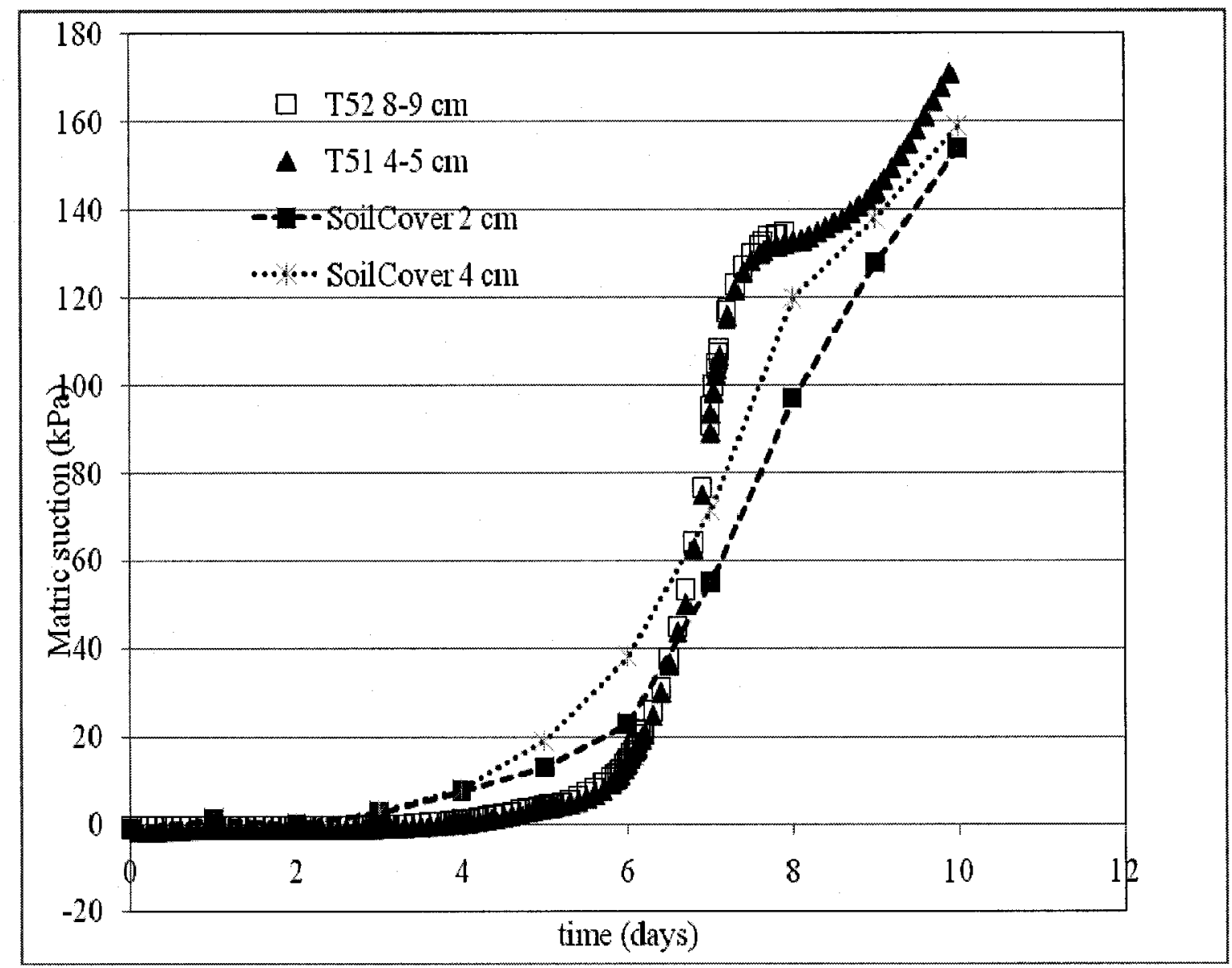

Figure 5.3.5.3: Matric suction measured using T5 and predicted using SoilCover for the first layer small scale drying test. 


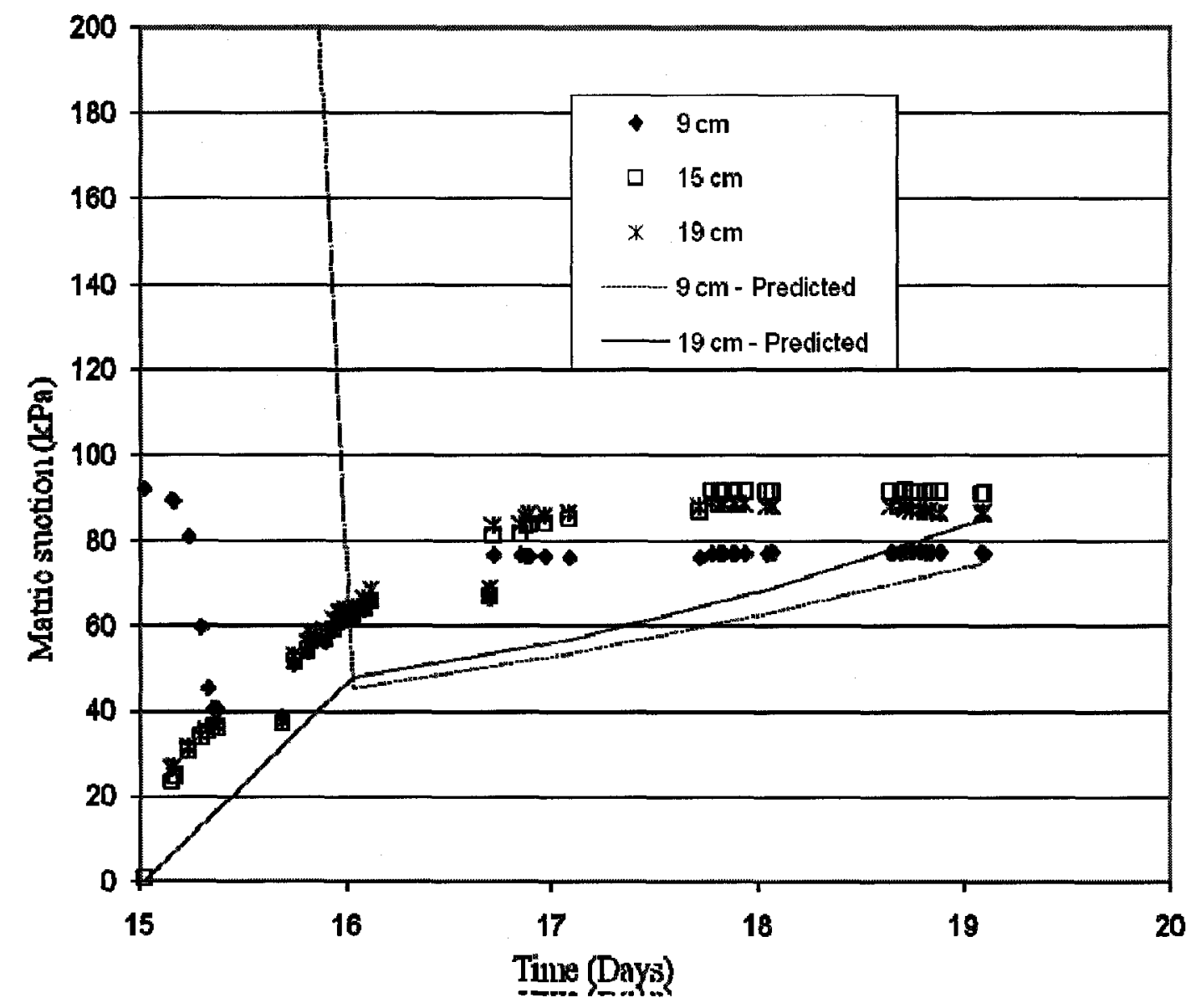

Figure 5.3.5.4: Matric suction measured and predicted after addition of the second layer in the small-scale drying test. 


\subsubsection{Small-Scale Experimental Pictures}

Figure 5.3.6.1 to Figure 5.3.6.7 shows some of the pictures taken during small-scale drying test for the Bulyanhulu tailings.

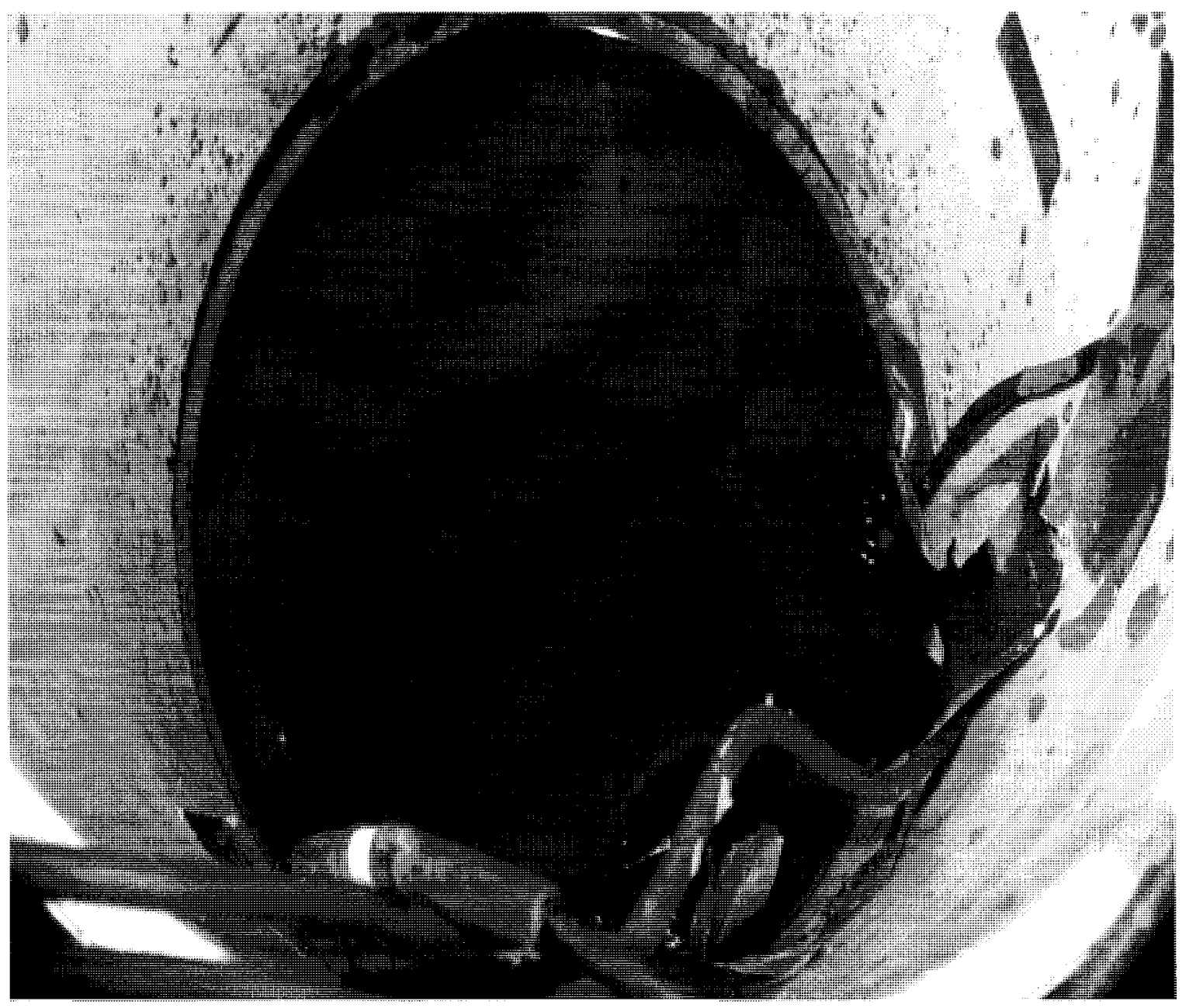

Figure 5.3.6.1: Bulyanhulu small-scale drying test by day 1 . 


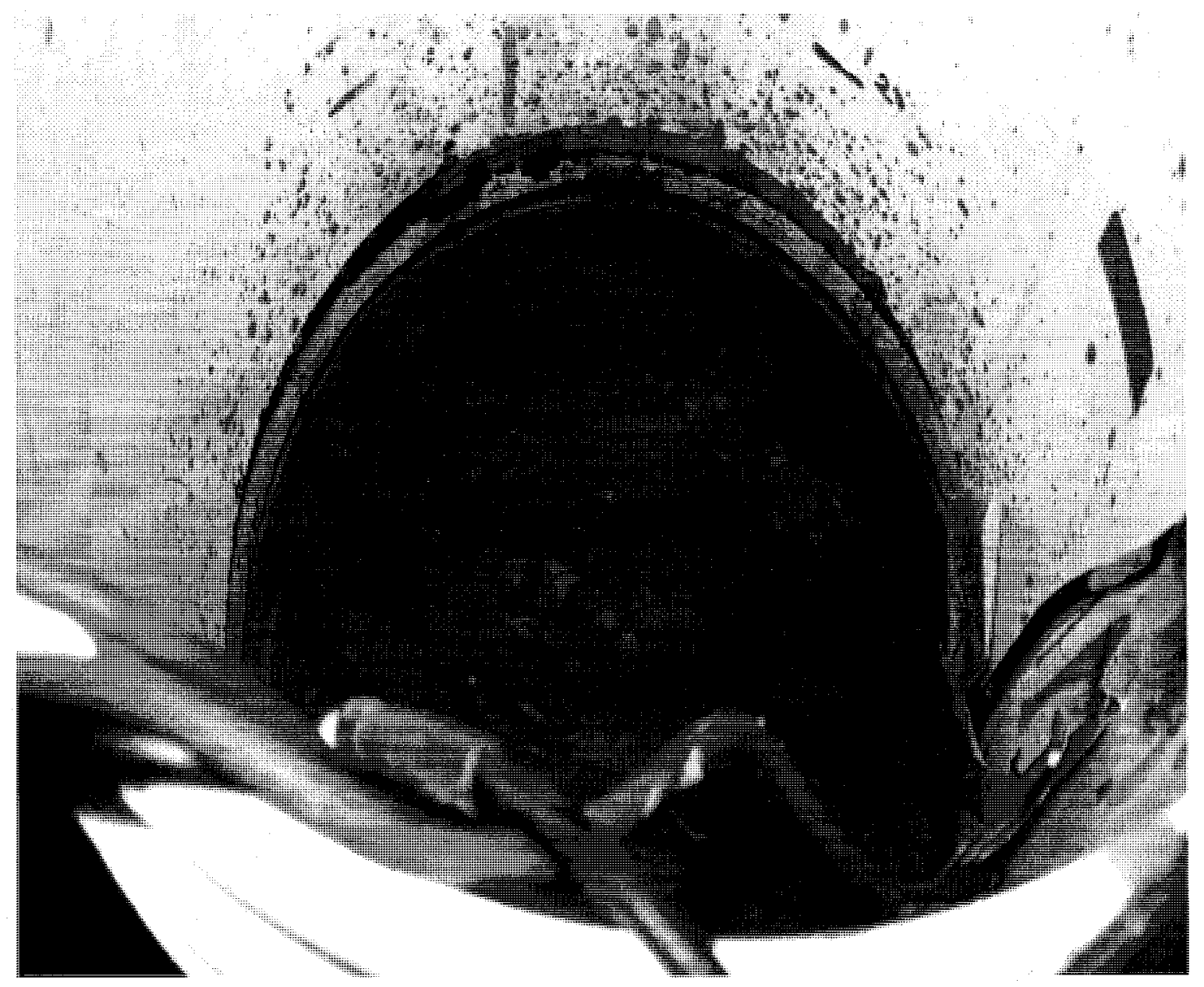

Figure 5.3.6.2: Bulyanhulu small-scale drying test by day 3 . 


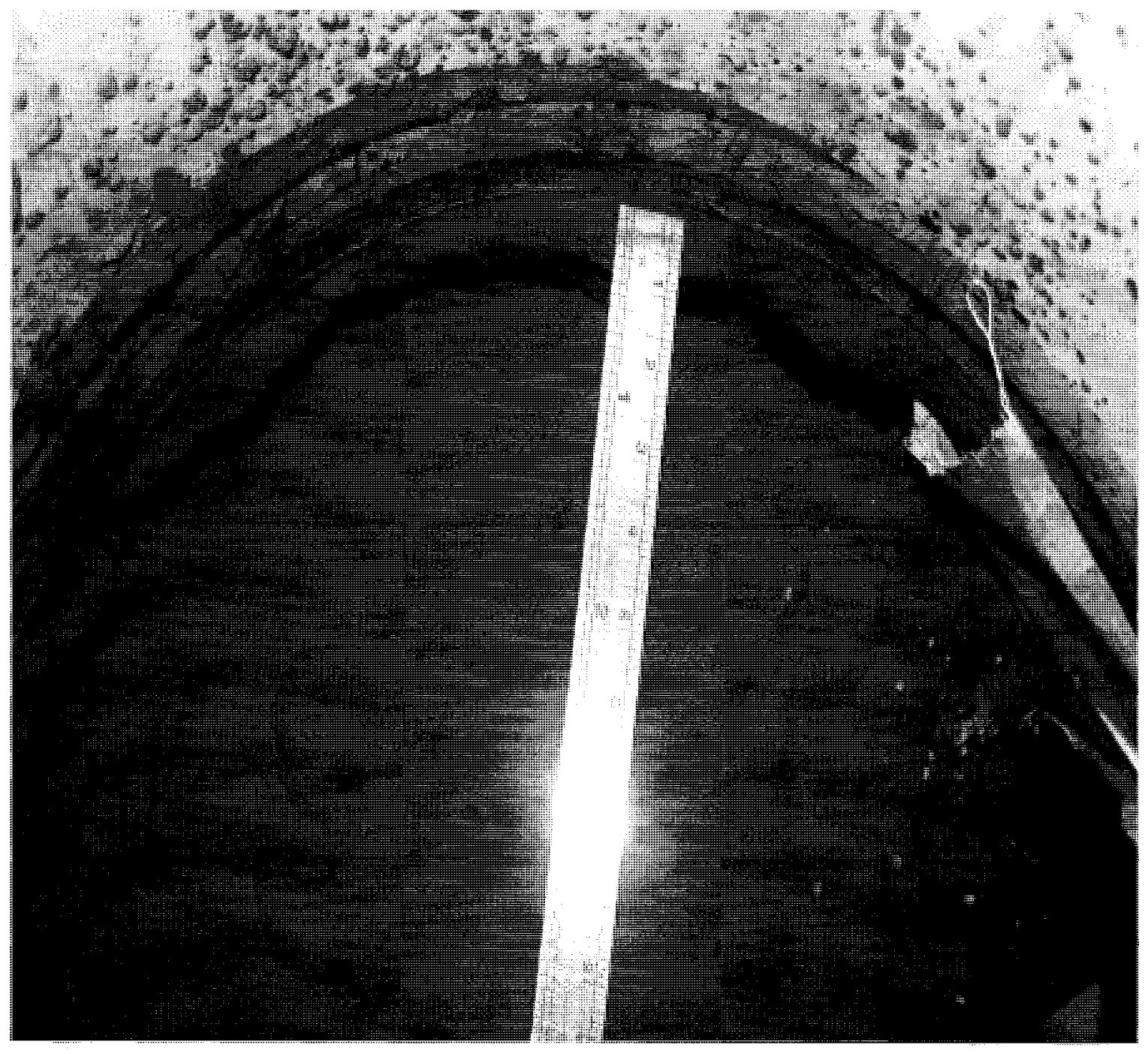

Figure 5.3.6.3: Bulyanhulu small-scale drying test, crack measurements by day 6 . 


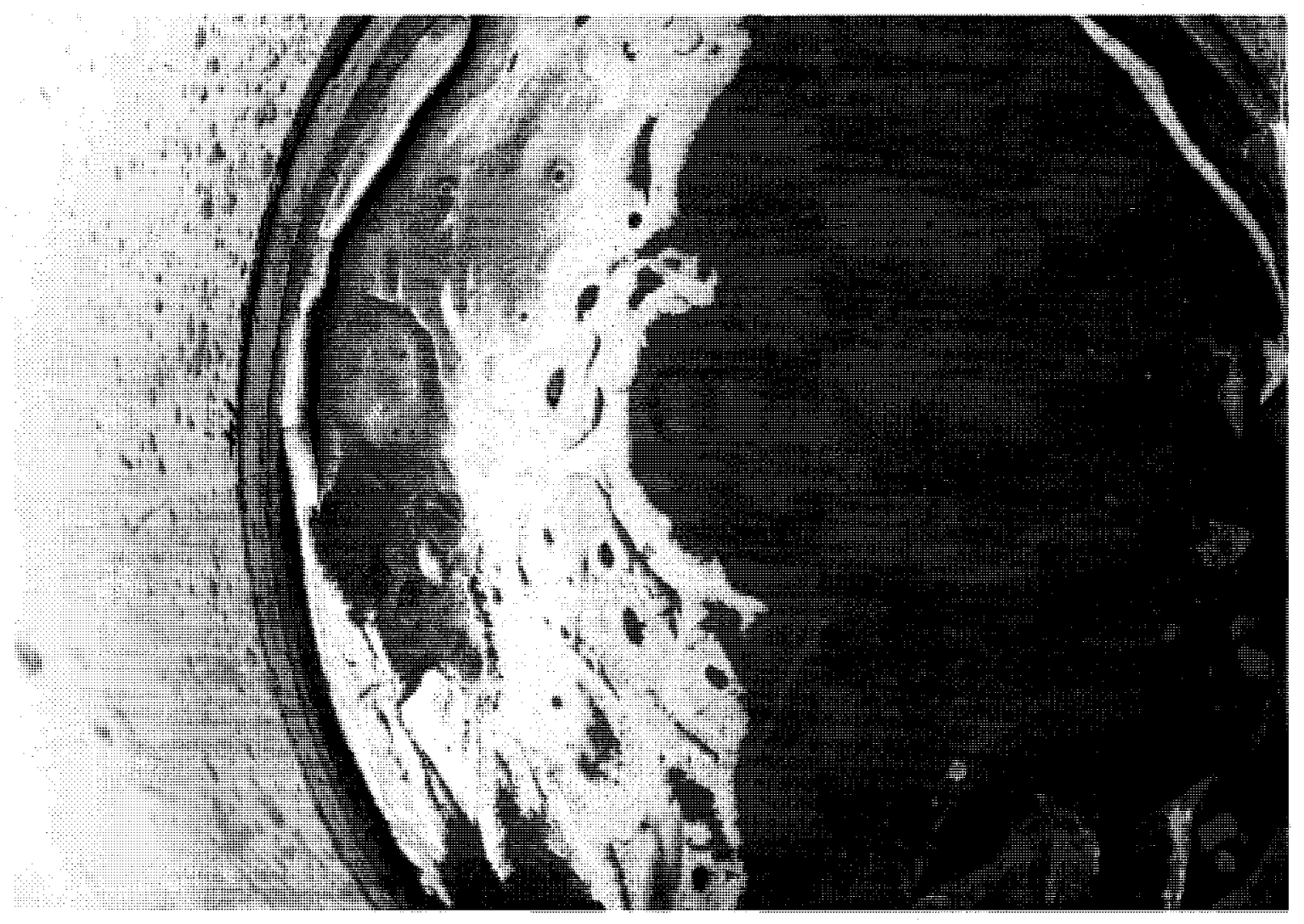

Figure 5.3.6.4: Precipitation of salts during first layer Bulyanhulu drying test, by day 9 . 


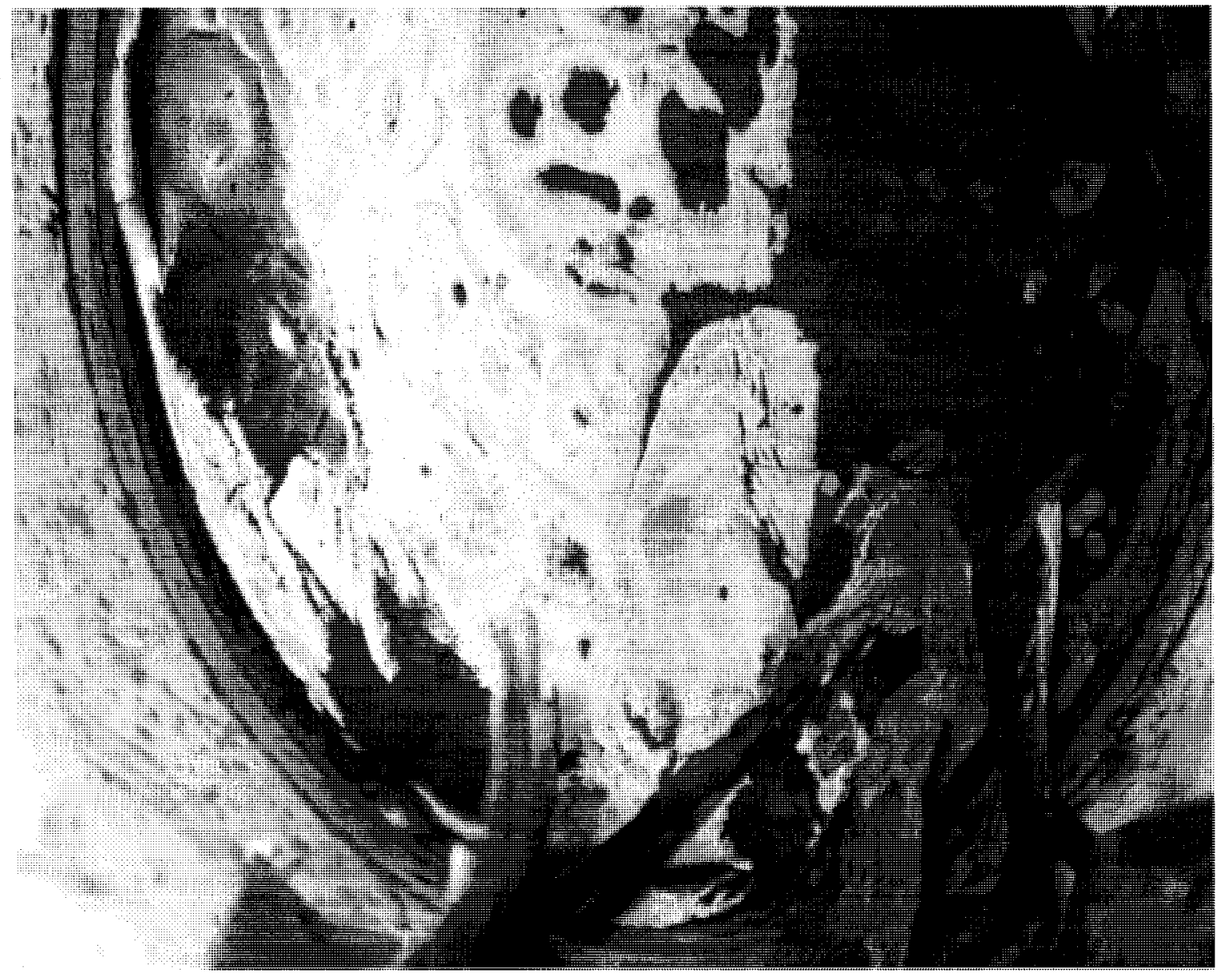

Figure 5.3.6.5: Precipitation of salts during first layer Bulyanhulu drying test, by day 10 . 


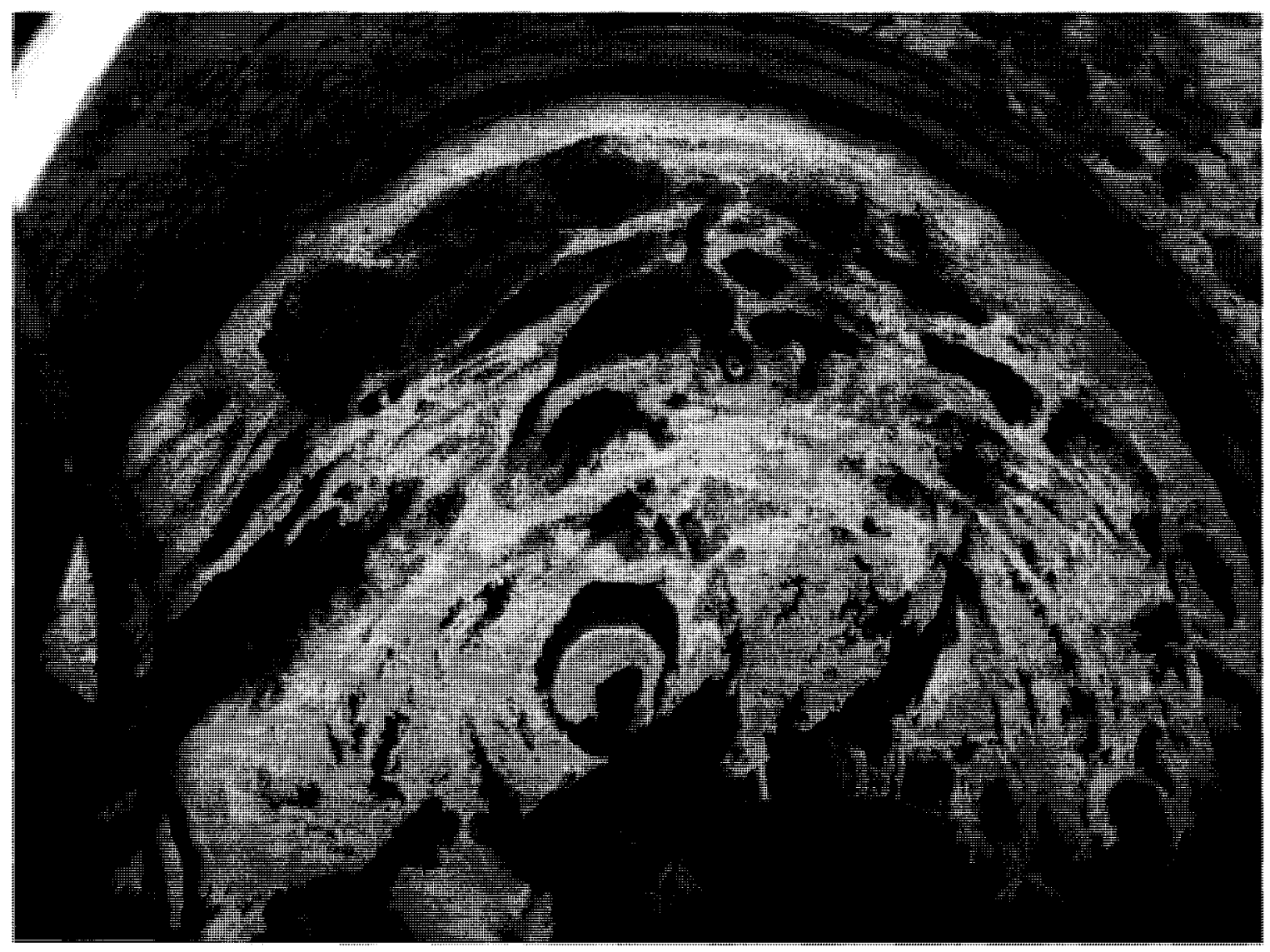

Figure 5.3.6.6: Precipitation of salts at the end of second layer Bulyanhulu drying test, by day 25. 


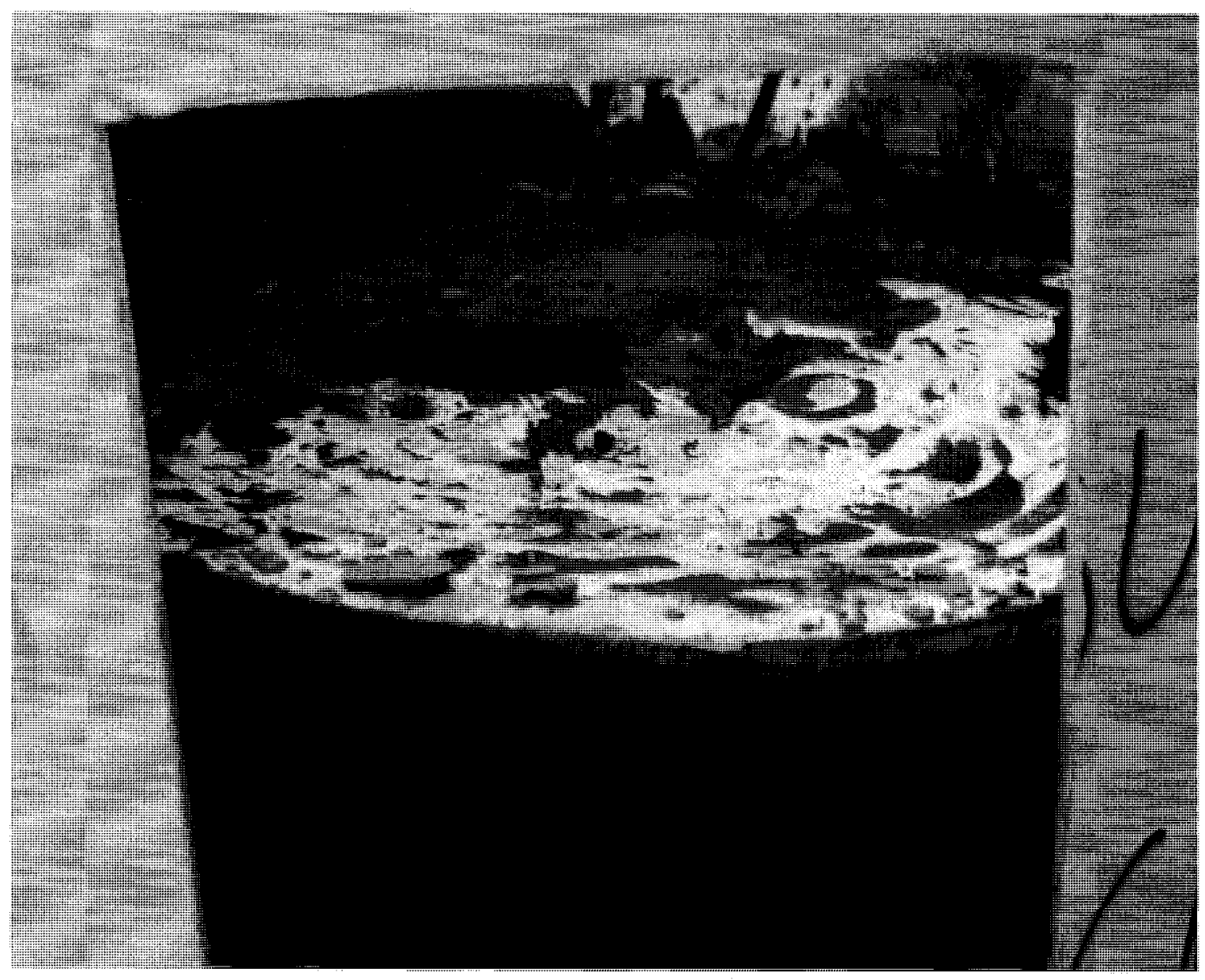

Figure 5.3.6.7: Small-Scale Bulyanhulu drying test during dismantling. 


\subsection{Toromocho Mine Tailings}

\subsubsection{Introduction}

The evolution of cumulative evaporation, average void ratio, and average gravimetric water content for the Toromocho small-scale drying test is plotted in Figure 5.4.1.

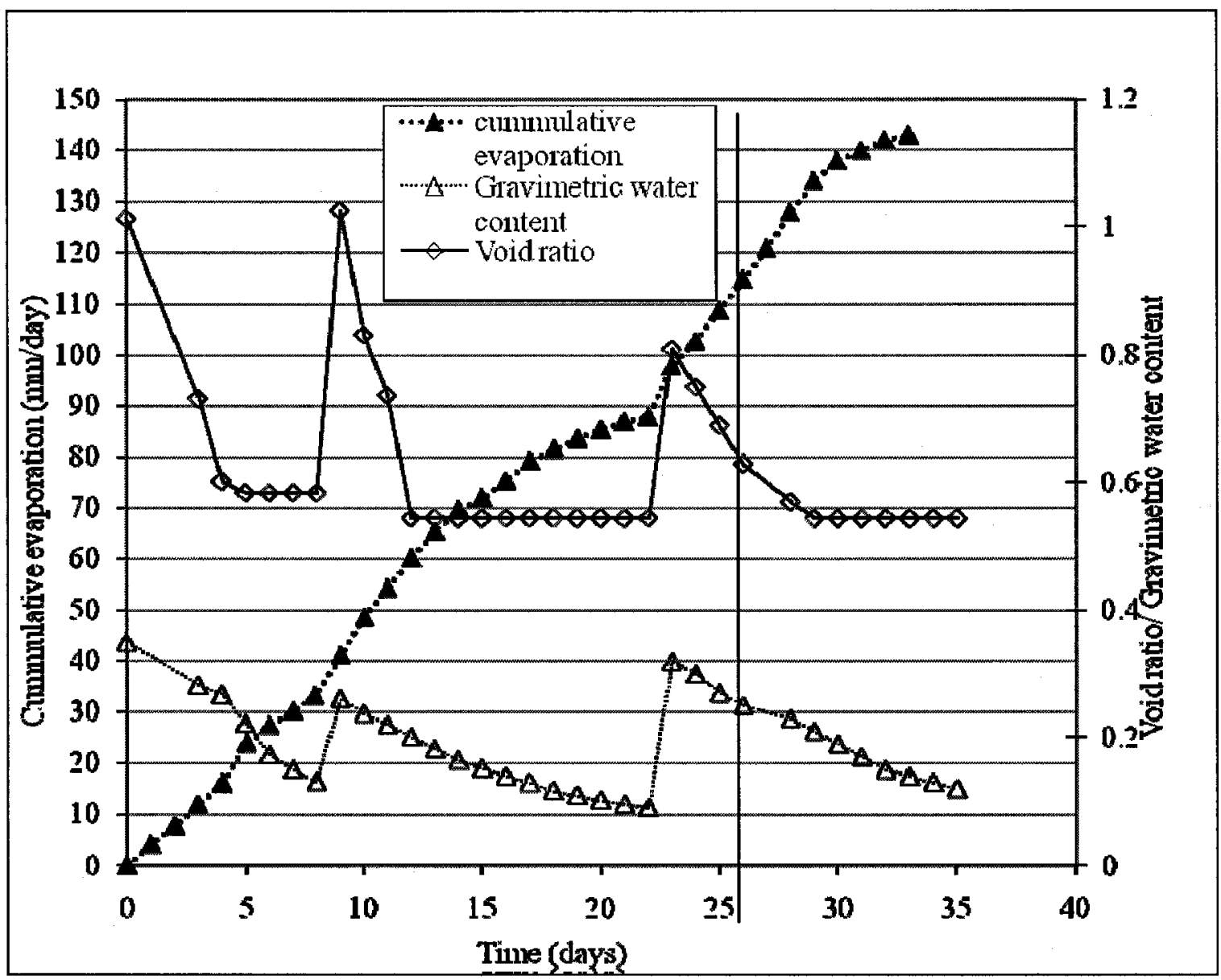

Figure 5.4.1: Cumulative evaporation, average void ratios, and gravimetric moisture contents. 


\subsubsection{Void Ratio}

The average final void ratio achieved by drying was 0.58 after the first layer and 0.55 after the second. It can be seen that the final void ratio is achieved more quickly in the second phase of drying. This is due to moisture flux into the underlying layer. If we compare the evaporation flux for a similar drop in void ratio between the two tests, for example between day 0 and day 6 and between day 9 and day 12, we have drops in void ratios of 1.01 to 0.58 and 1.03 to 0.55 , corresponding to evaporative losses of $26 \mathrm{~mm}$ and $19 \mathrm{~mm}$ respectively. For each layer, the maximum separation from the side of the container was $10 \mathrm{~mm}$.

During rewetting the void ratio increased to 0.81 as the total volume increased due to addition of water and eventually decreased to 0.54 as the tailings dried out. The void ratio's agreed with void ratio's achieved at the end of first layer, second layer.

\subsubsection{Evaporation}

The rate of evaporation was calculated daily from the change in weight. The difference in daily weight due to loss of water is considered as the evaporated water from the given surface area. Cumulative evaporation with time is plotted in Figure 5.4.1. Daily rate of evaporation was $4.5 \mathrm{~mm}$ in average for the first layer drying test. The rate of evaporation was $7 \mathrm{~mm} /$ day during the second layer drying test. The rate of evaporation decreased as the surface layer dried out. 
Note that the potential evaporation was initially higher for the second layer. This is simply due to the tailings being closer to the fan, as confirmed by drying tests using water at different levels.

During rewetting, the cumulative evaporation averages about $6 \mathrm{~mm}$ per day until day 29 , after which it falls off, eventually decreasing to $1.9 \mathrm{~mm}$ per day at day 32 .

\subsubsection{Gravimetric water content}

The first layer was placed with $36 \%$ of gravimetric water content and reduced to $12 \%$ at the end of first layer drying test by day nine. Second layer was placed with $40 \%$ of gravimetric moisture conten. At the end of second layer drying test (by day 22) average gravimetric water content was $5 \%$.

\subsubsection{Matric suction}

The matric suctions from two $\mathrm{T} 5$ tensiometers are shown in Figure 5.4.2. The tensiometers are located about $20-30 \mathrm{~mm}$ above the base of their respective layers. Note that the first tensiometer cavitated on day 7 and day 14 and the second tensiometer cavitated on day 16 . This figure shows that the second layer dried much faster than the first, and that there is a significant period of time when the suctions in both layers are quite close, from day 8 to about day 12. It is also interesting to look at day $8-9$, where the figure shows the older layer undergoing rewetting, absorbing moisture from the new layer. The slope of the tensiometer data for the second layer is initially much higher than the tensiometer data by the first layer! 
Note the suctions at the bottom of both layers are almost at the same value before they both start increasing.

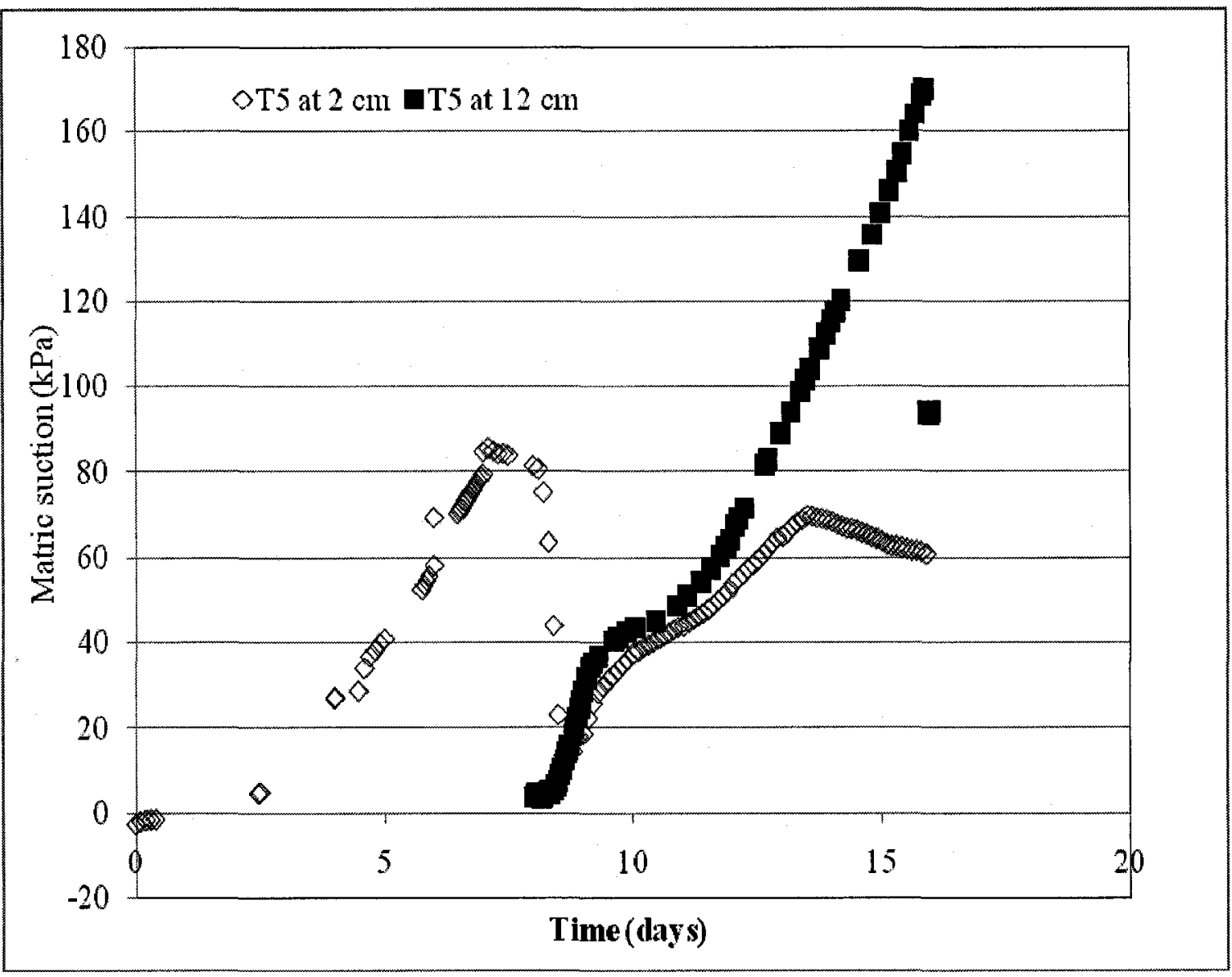

Figure 5.4.2: Matric suction measurement using T5 tensiometer from small-scale drying test.

Matric suction measurement during rewetting is plotted in Figure 5.4.3. The T5 at the bottom cavitated on day 6 , not surprising since this sensor had already cavitated during the initial 
drying test. The top sensor measured suctions until day 9 before cavitation (which occurred at $160 \mathrm{kPa}$ suction). As in the first test, the difference in suction reported by the two sensors is small.

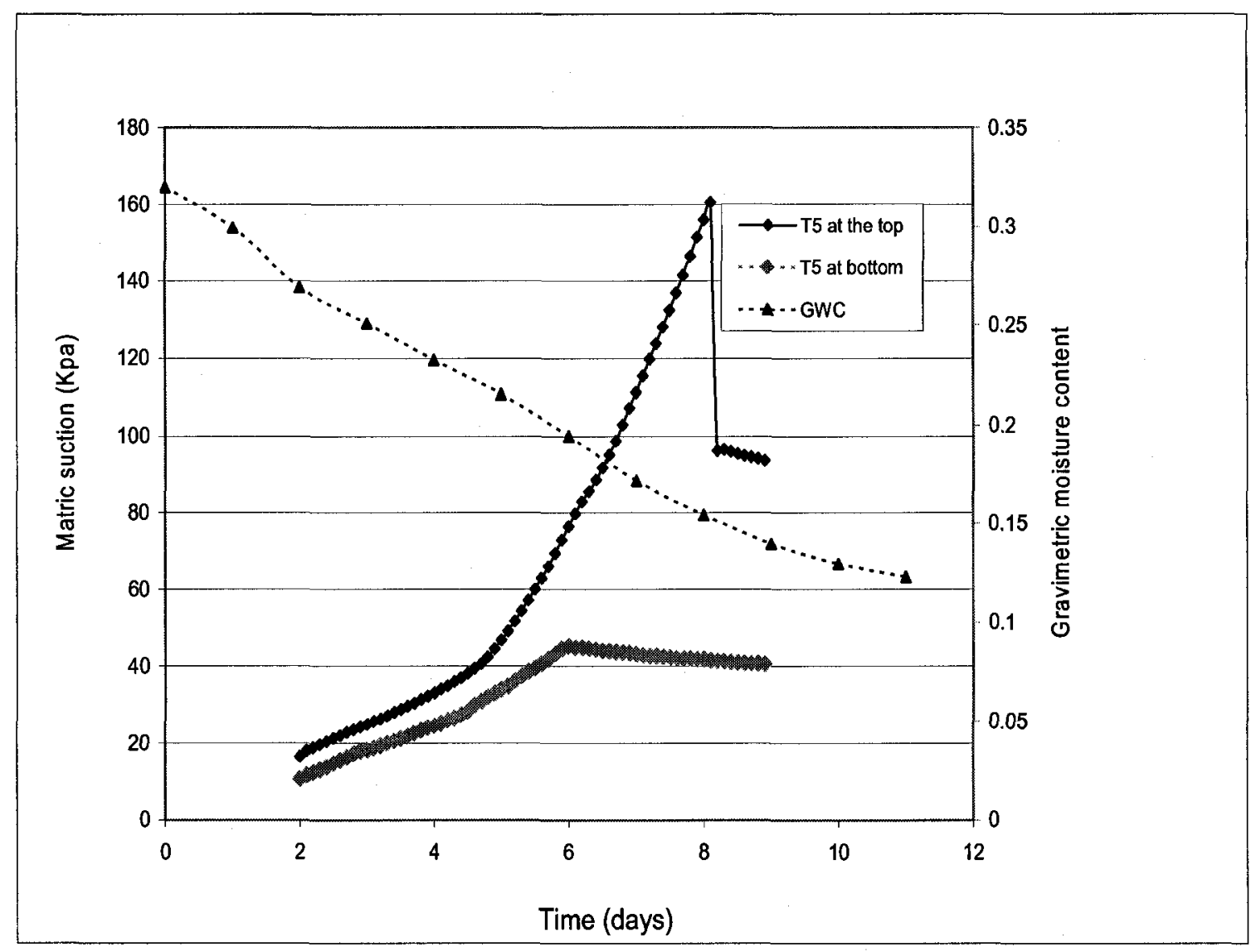

Figure 5.4.3: Matric suction measurements using T5 tensiometer after rewetting test.

Measured matric suction were reasonably in a good agreement with predicted matric suctions for using SoilCover software as shown in Figure 5.4.4. 


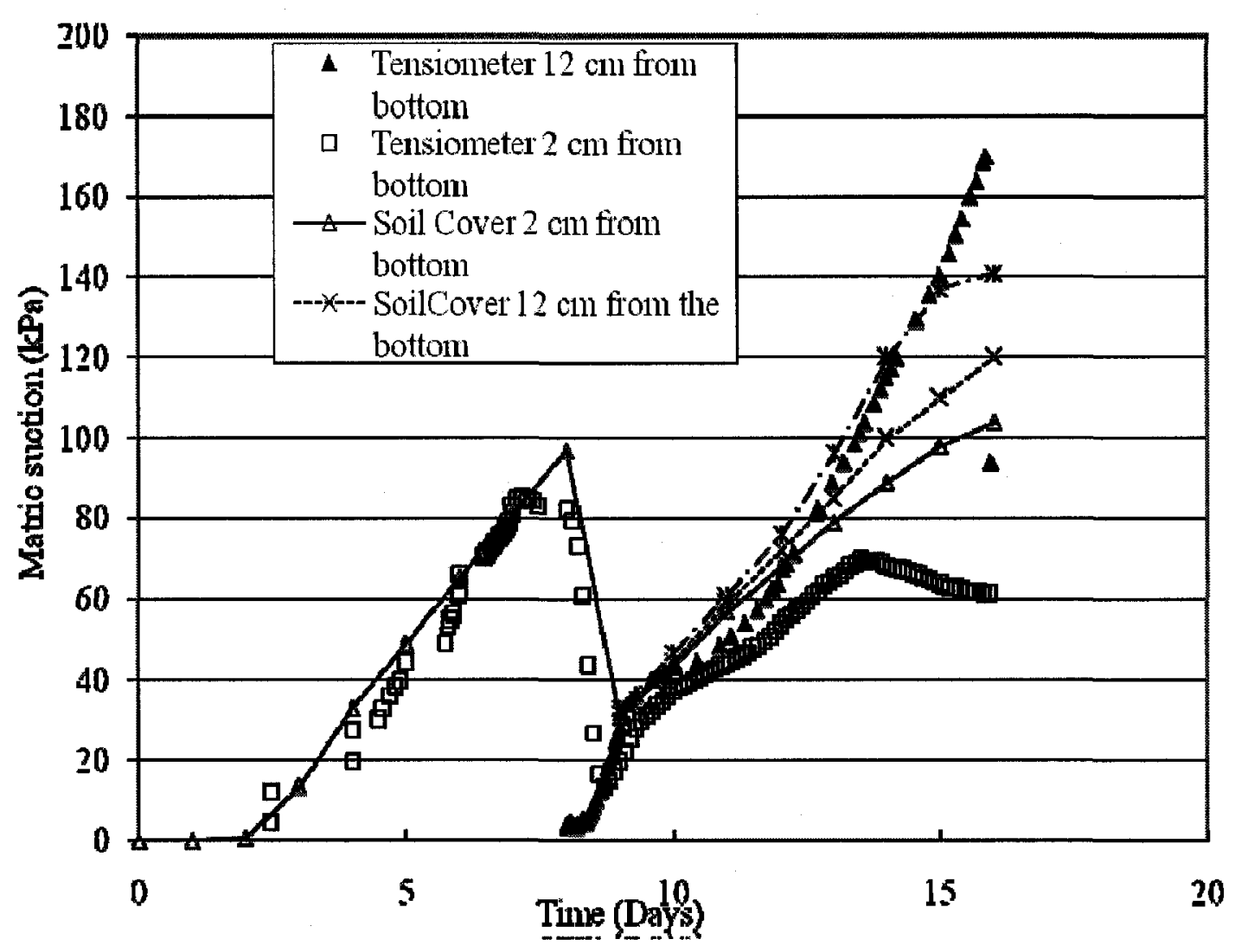

Figure 5.4.4: Matric suction measured and predicted for Toromocho tailings drying test.

\subsubsection{Small-Scale Single Layer Surface Deposition}

The evaporation rate for the single layer test of $220 \mathrm{~mm}$ averages $6 \mathrm{~mm}$ per day for the first ten days before declining. This is the same rate as observed in the rewetting test.

T5 measurements at the bottom and at the top of the bucket were very close as can be seen from Figure 5.4.3.2. The top T5 cavitated around day 9 while the bottom sensor lasted until day 11. 
The final void ratio achieved was 0.53 , comparable to the final void ratio achieved in the double layer drying test $(0.55)$. In both tests, it took about $60 \mathrm{~mm}$ of evaporation to achieve the final void ratio. As in the two layer test, there is only a small difference in suction with depth.

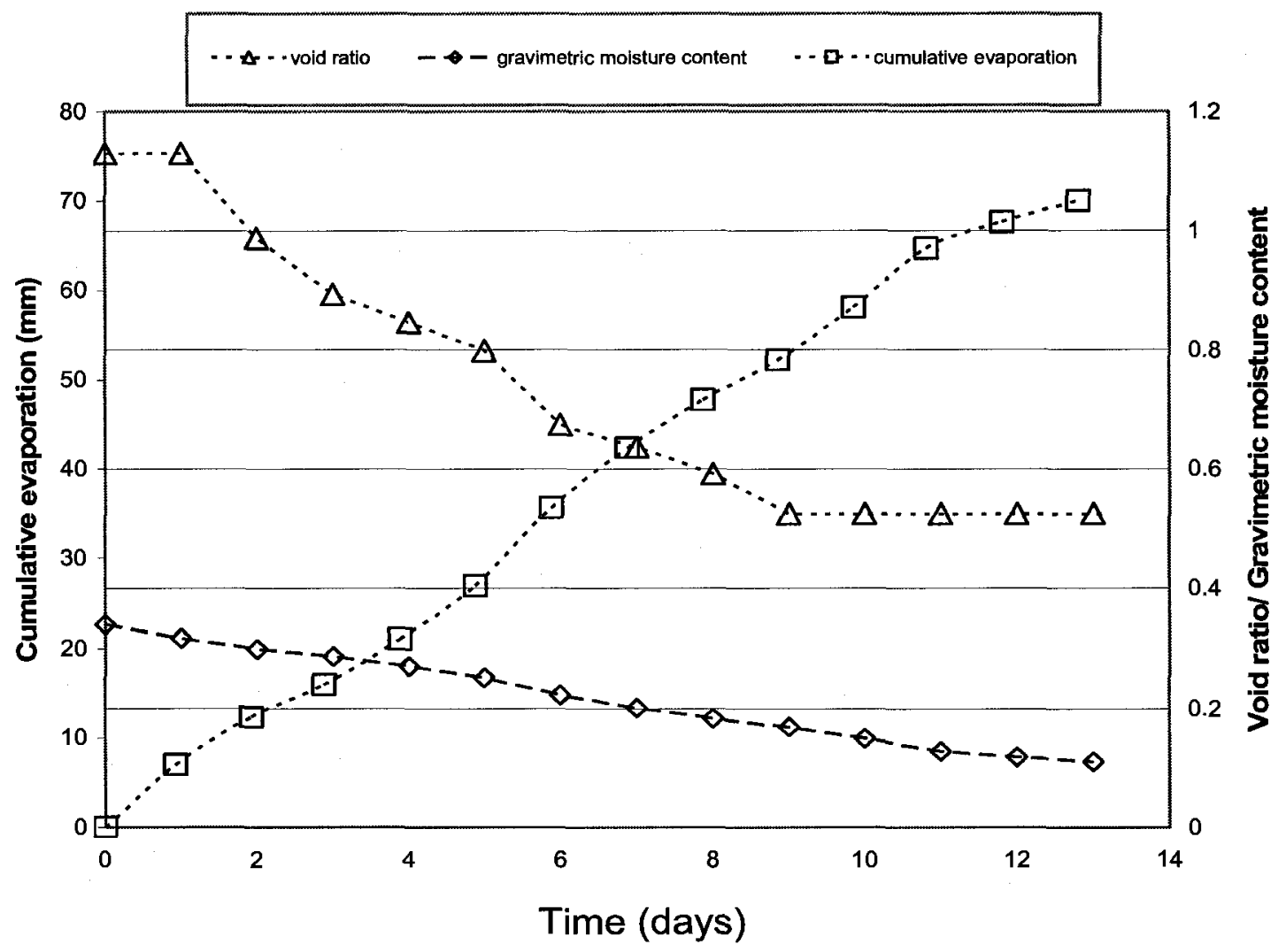

Figure 5.4.5: Cumulative evaporation, void ratio and gravimetric water content for single layer Toromocho drying test. 


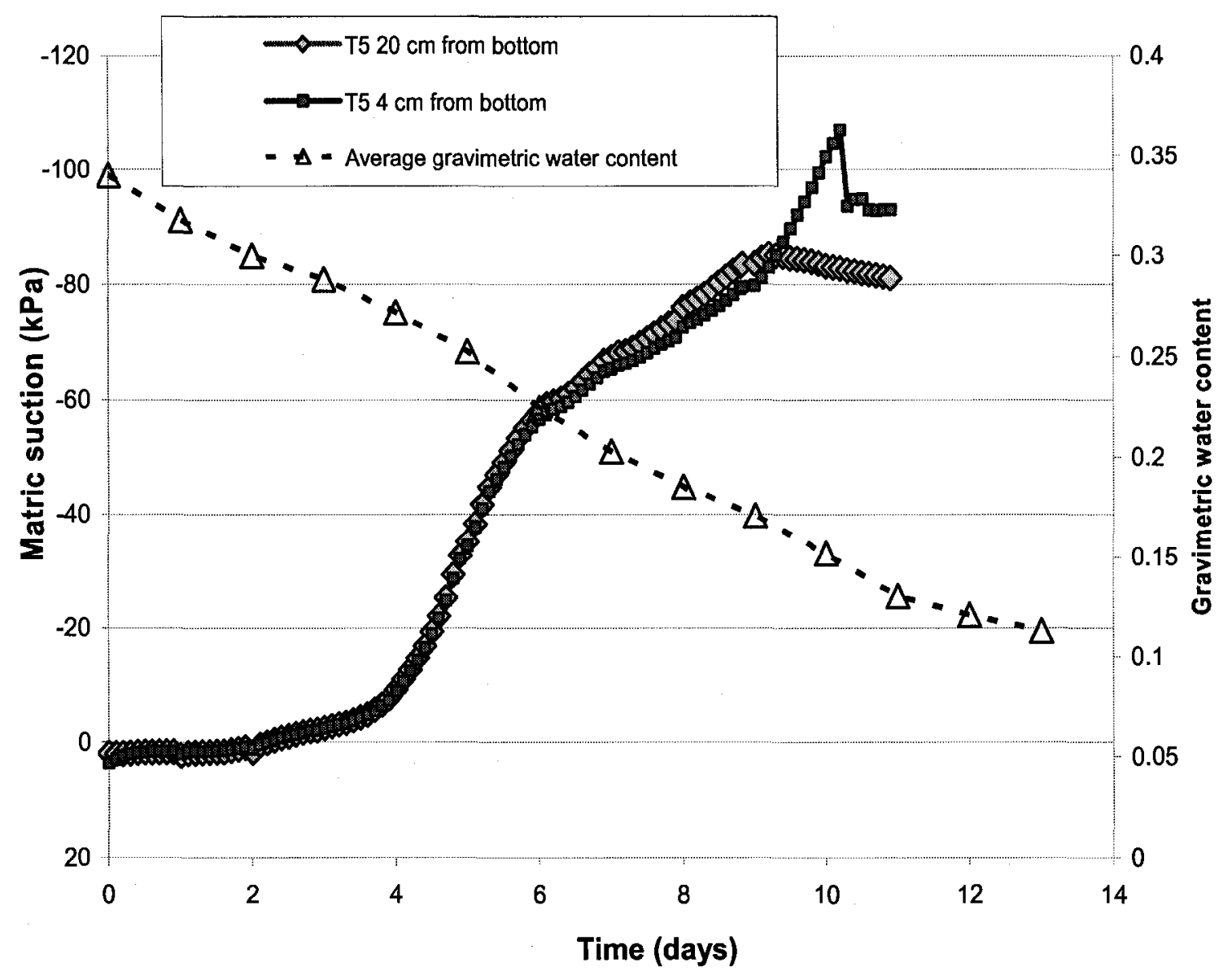

Figure 5.4.6: Matric suction measurements using T5 Tensiometer data from single layer drying test. 


\subsection{Discussion of Major Result for Drying Tests}

In this section, the major results are discussed under three different categories

1. Effect of older desiccated layer on drying of the second layer

2. Effect of cracks on rate of evaporation

3. Effect of salts on the rate of evaporation

\subsubsection{Effect of the Older Desiccated layer on Drying of the Second Layer}

Both large scale and small scale experiments confirm that the first layer facilitates the rate of drying of the second layer. For example, Figure 5.5.2 shows measured and predicted matric suctions from the Toromocho tailings drying test. There is a clear convergence of the measured matric suctions in both layers to nearly the same value within a day of addition of the second layer.

SoilCover is reasonably able to predict matric suction results for interlayer interaction. The best example is for the Toromocho tailings (shown in Figure 5.5.2): this is the best comparison as these suctions values change over a few days, as opposed to the Bulyanhulu tailings in which suctions would vary more quickly over time. A limitation of the SoilCover model, is that it only generates output once a day. Another unsaturated flow model should be used to model the Bulyanhulu results where the suctions vary quickly with time. 
Figure 5.5.3 shows an example of the comparison between the modelled and measured interlayer interaction for the Bulyanhulu tailings.

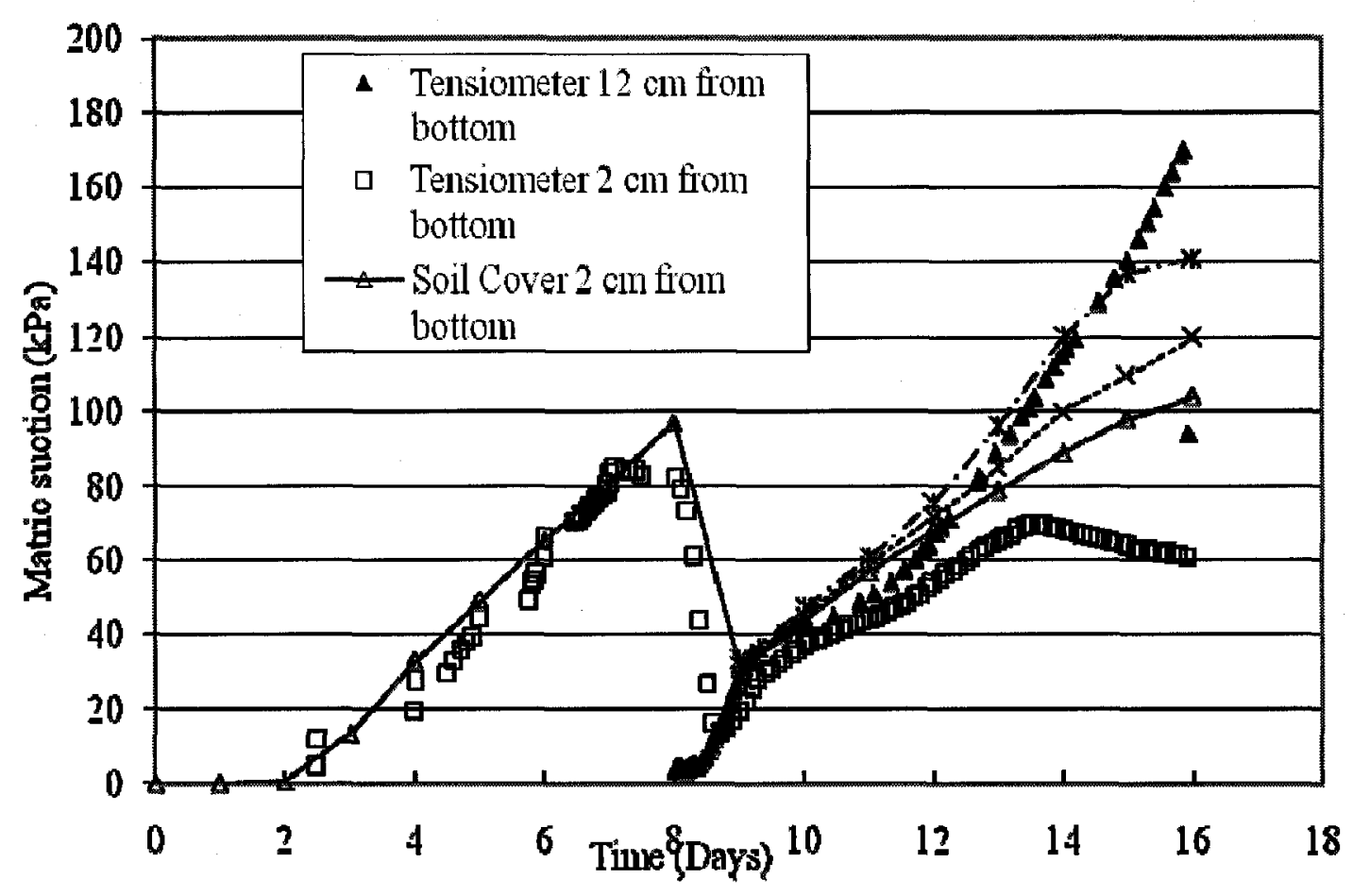

Figure 5.5.2: SoilCover prediction and measured matric suction for Toromocho tailings drying test.

Flow between the layers was closely observed by placing tensiometers close to the interlayer boundary. In Figure 5.5.3, the T5's located at the top of the first layer shows (T5 at $90 \mathrm{~mm}$ ) the rewetting process as the measured matric suction first decreases, as the first layer absorbs 
water from the second. In Figure 5.5.2, a similar phenomenon is displayed in the small scale Toromocho drying test.

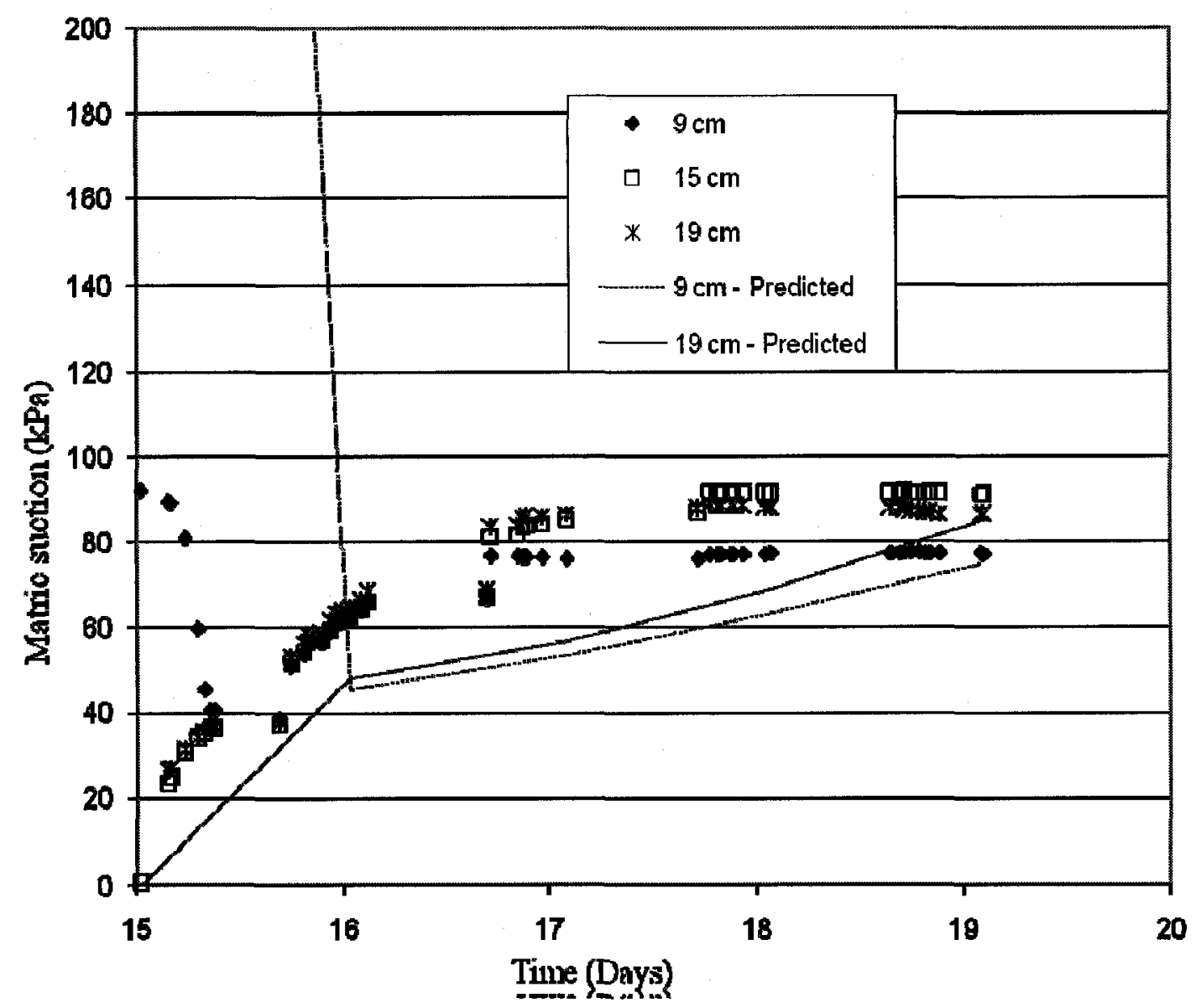

Figure 5.5.3: Interlayer matric suction using measured T5 and predicted SoilCover.

The effect of first dried layer can be further explained by examining the profiles of suction with depth. Figure 5.5.4 shows SoilCover predictions at the end of first layer drying and the first day of second layer drying test. As can be seen in Figure 5.5.4, by end of day 15 matric suctions near the surface of the first layer were high (approximately $10,000 \mathrm{kPa}$ right at the surface, not shown on the figure because of scale), while matric suctions in the fresh layer would initially be zero. The matric suction prediction at the end of day 16 shows a relatively 
uniform suction with depth of about $50 \mathrm{kPa}$. Note: SoilCover only give an output in every 24 hrs.

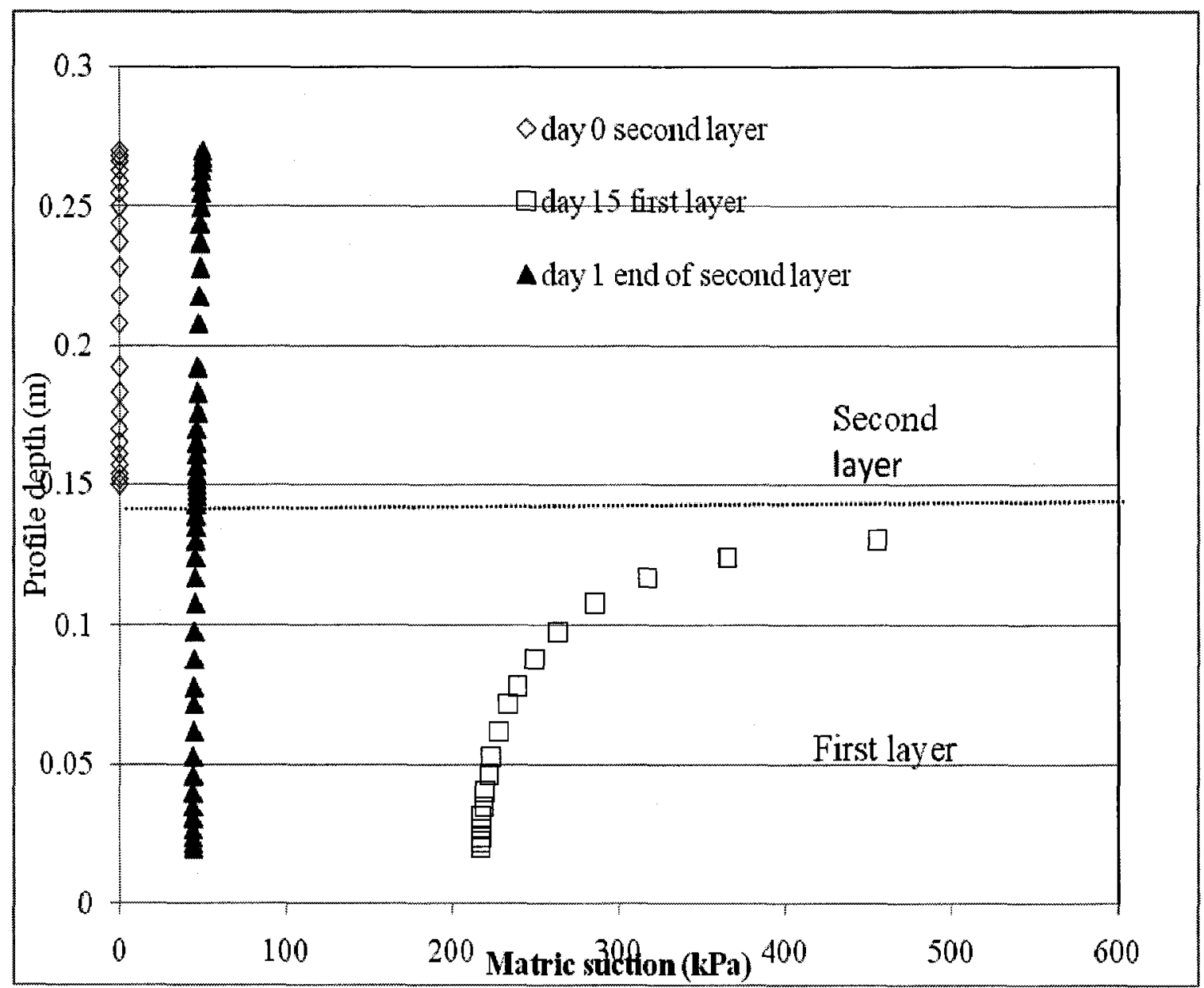

Figure 5.5.4: SoilCover prediction for small-scale drying test at the end of first layer and the first day of second layer.

Conceptually, moisture flows from the freshly deposited second layer to older dried layer and this can be presented using conceptual flow gradient as shown in Figure 5.5.5. The figure 
shows the increase in matric suction for the second layer and decrease matric suction of the first layer as a result of rewetting from the fresh second layer. By the end of day 1 for the second layer the matric suction with profile depth exhibits uniform measurements. The uniformity was achieved due to the transfer of moisture from the fresh layer to the dried layer as shown in Figure 5.5.5. The process of gradient flow can be supported using the measured T5's located in both layers as shown in Figure 5.5.6. The T5 located at first layer shows a decrease in matric suction initially and eventually records an increase in matric suction reading as the rewetting process is ongoing, while the T5's located in the fresh second layer shows an increase in matric suction as the moisture of the first layer soaked up by the first dried layer and as the moisture evaporates. 


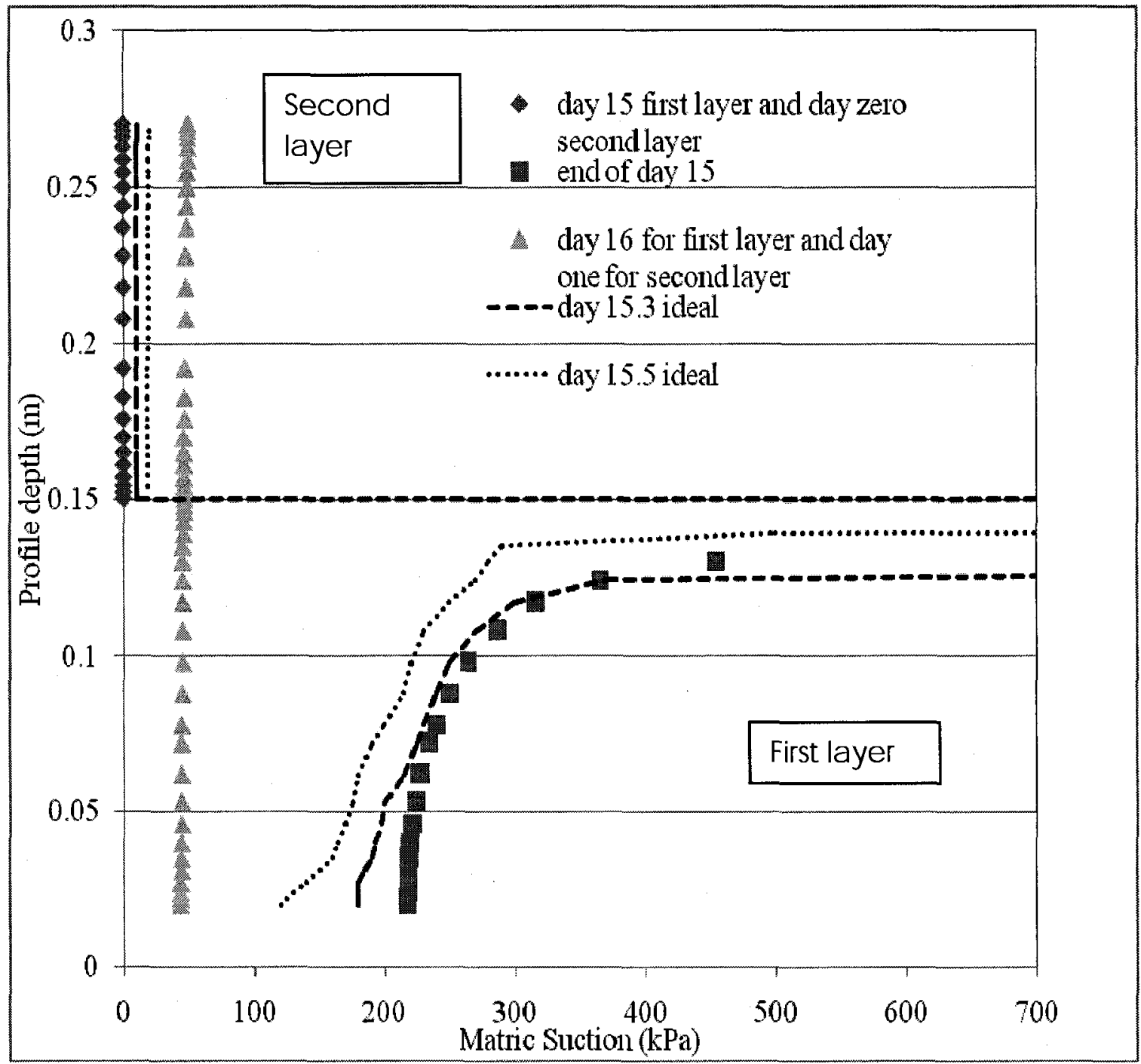

Figure 5.5.5: SoilCover prediction for small-scale drying test at the end of first layer and the first day of second layer and direct measured matric suction measurements using T5 tensiometres. 


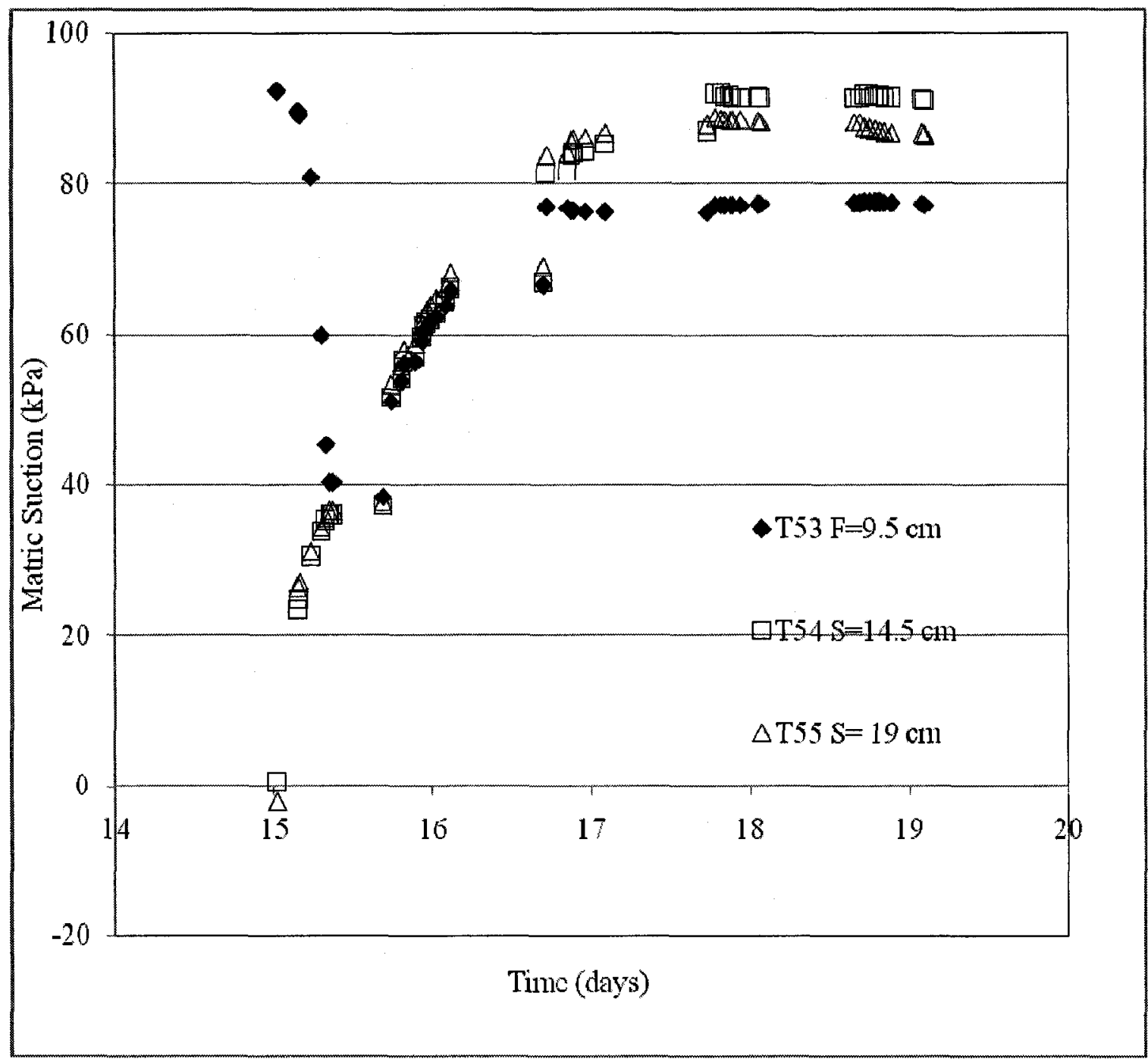

Figure 5.5.6: Matric suction measurement for small-scale drying test during the placement of second layer.

\subsubsection{Effect of Cracks on Rate of Evaporation}

Fujiyasu (1997) investigated the effect of cracks on rate of evaporation and reported there was a significant increase in evaporation rate as a result of crack formation. Fujiyasu (1997) reported that when Stage II evaporation occurs at the surface, cracks may generate 3 to 4 times greater evaporation than at the surface. However Fujiyasu's (1997) experiments were 
conducted on $1 \mathrm{~m}$ depth of tailings deposited as slurry. The experiments in this thesis were conducted using thinner layers, and were deposited at a much greater density than slurried tailings (Void ratio of $\sim 1.2$ compared to $\sim 3$ ).

During both small and large scale laboratory experiments, cracks were developed and expand up to certain point. The effect of cracks on rate of evaporation was closely observed on the large scale by measuring the hourly rate of water loss. See Figure 5.5.7. Cracking started on day 2 and continued to develop to day 4. See Figure 5.5.9 to 5.5 .11 daily photographs was taken during drying.

The expansion of cracks was not significant to increase the rate of evaporation. Figure 5.5.7 shows evenly rated evaporation for every day. The change in evaporation is due to the change in PE due to variation in relative humidity.

Cracks may have not contributed significantly to evaporation due to the smaller tailing depth used, $1 \mathrm{~mm}$ as compared to the $1 \mathrm{~m}$ deposition (Fujiyasu, 1997). In the field, the thicknesses of the layers are typically 2 to 3 times the layer depth simulated in the laboratory. However, it has been observed that the ratio between crack surface area and plan surface remains constant. From earlier studies, cracks are expected to contribute to evaporation after surface evaporation decreases. While the data allows for this possibility as predicted AE is smaller 
than measured $\mathrm{AE}$ in stage II drying (see Figures 5.5.7), this effect appears to be negligible for the Bulyanhulu tailings.

Formation and propagation of cracks are shown in Figures 5.5.9 to 5.5.12.

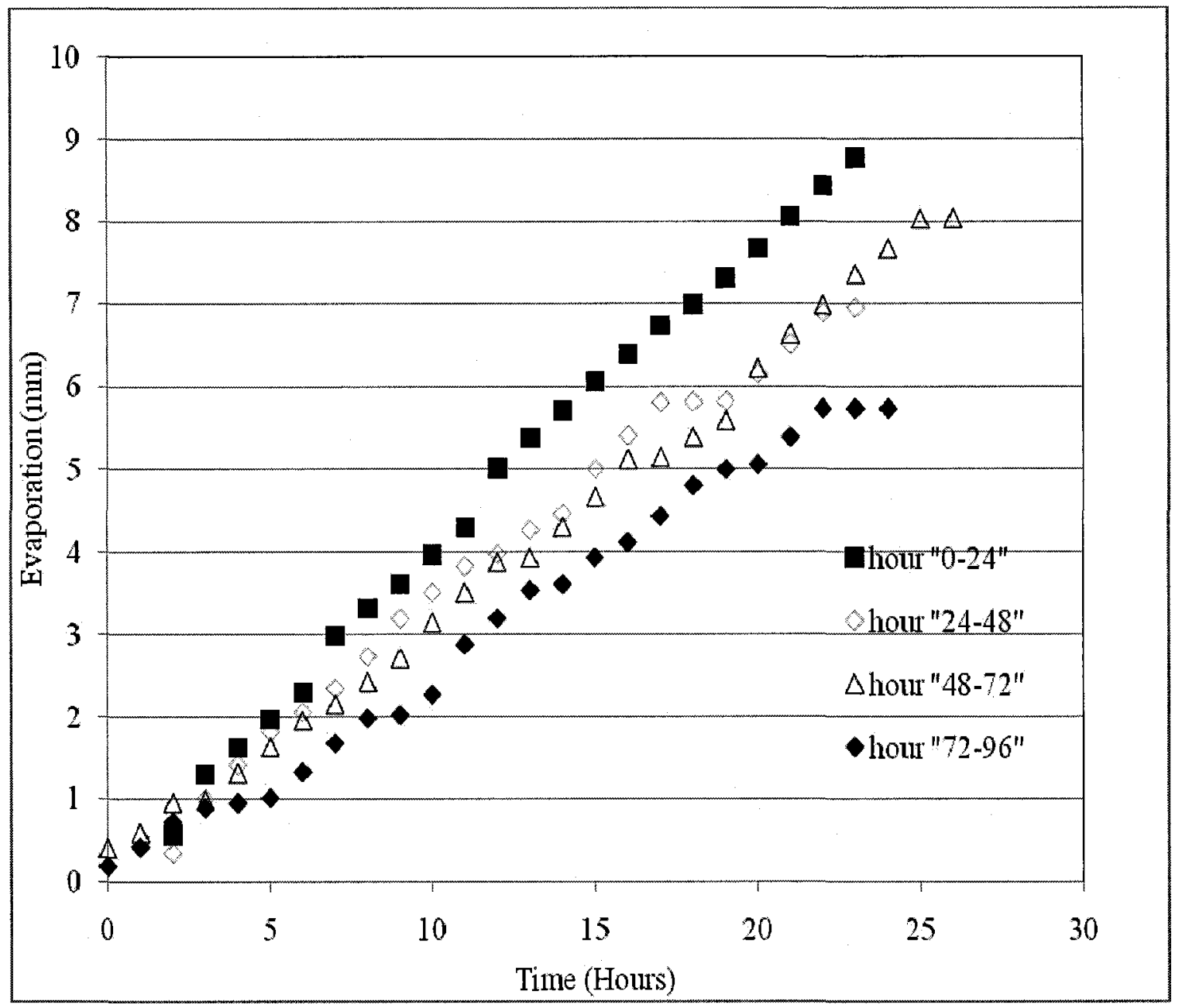

Figure 5.5.7: Effect of cracks on rate of evaporation. 


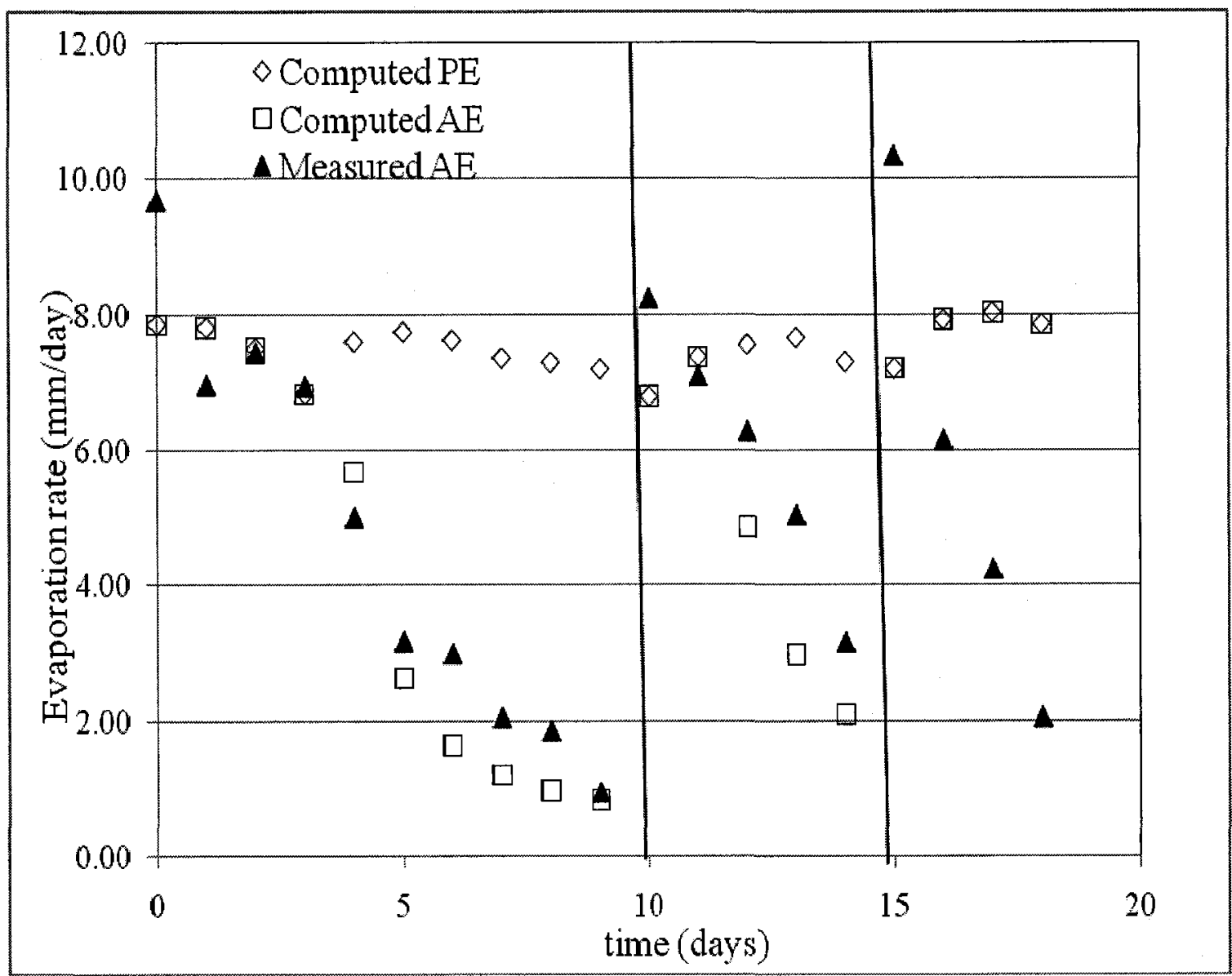

Figure 5.5.8: Computed actual evaporation, computed potential evaporation and measured actual evaporation. 


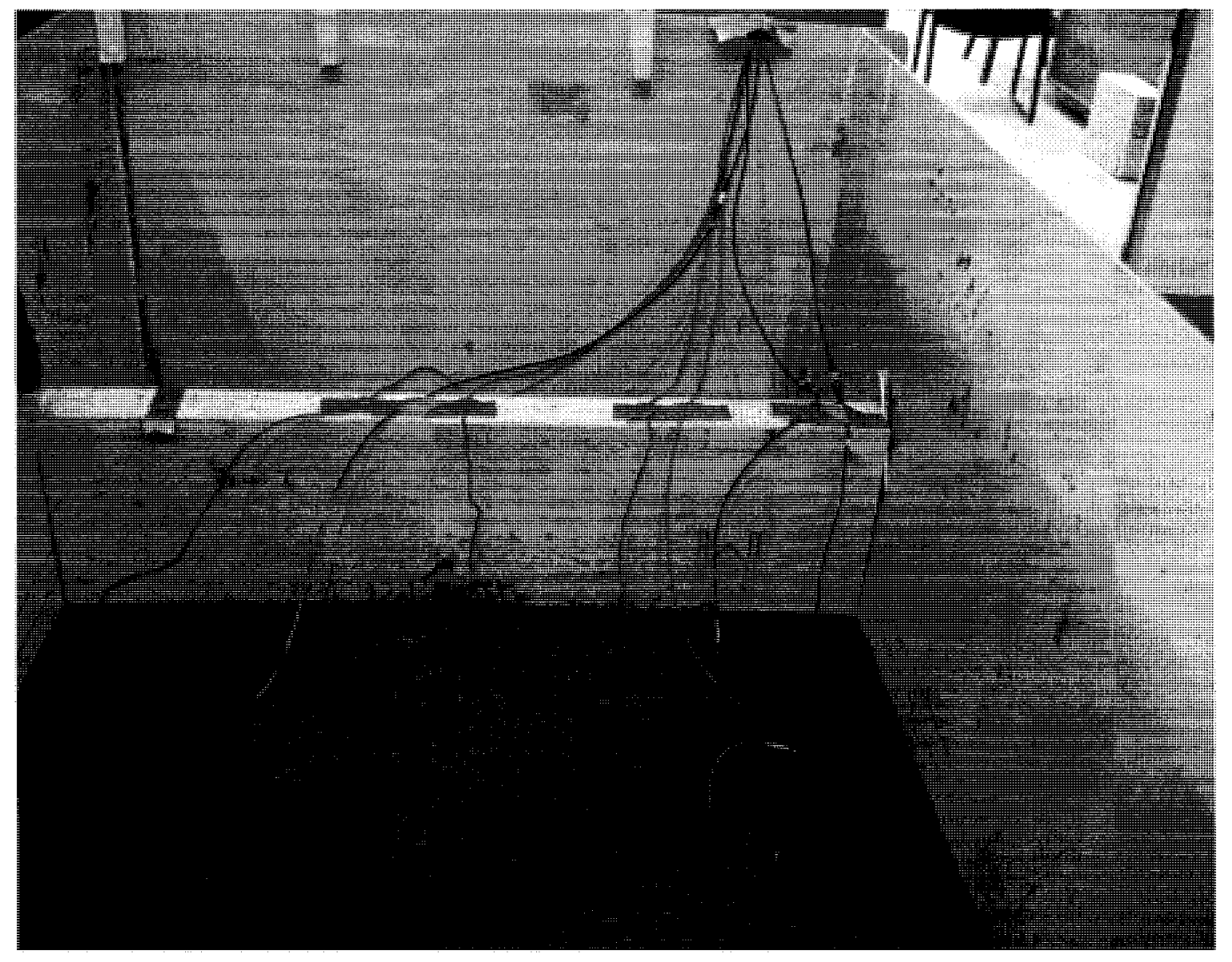

Figure 5.5.9: Day two of first layer drying test. 


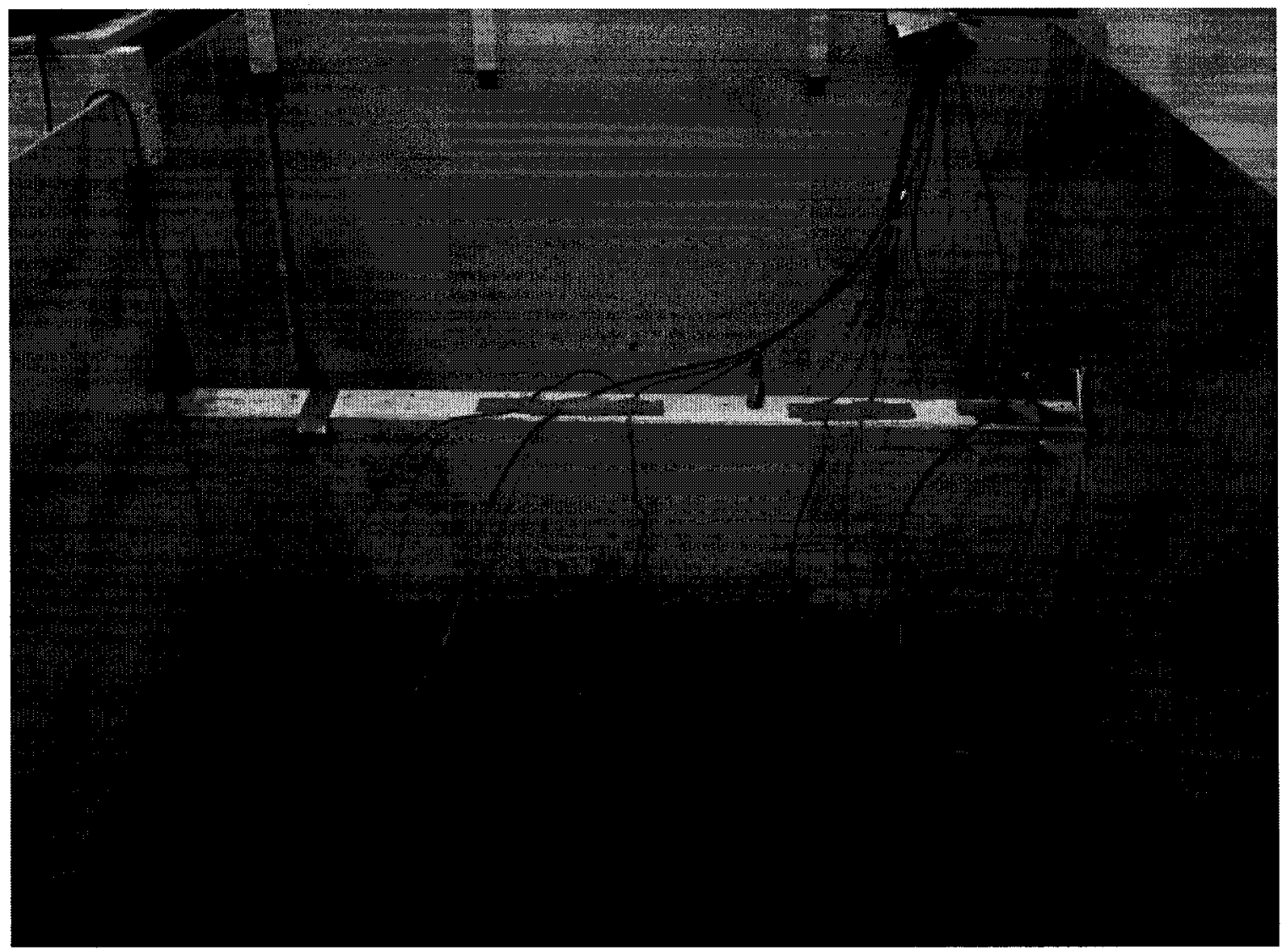

Figure 5.5.10: Day three of first layer drying test. 




Figure 5.5.11: Day four of first layer drying test. 


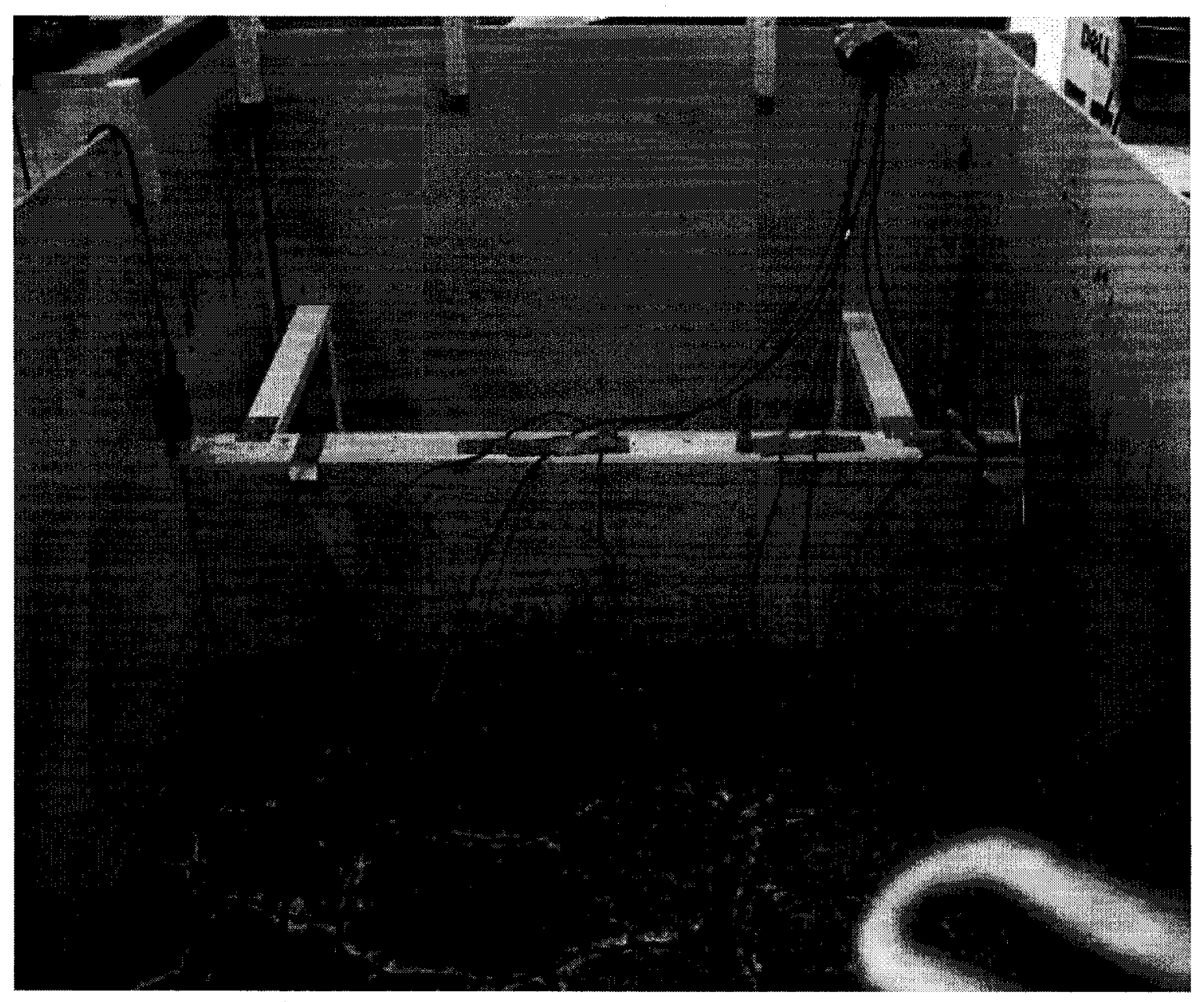

Figure 5.5.12: Day five of first layer drying test.

\subsubsection{Effect of Salt Precipitation}

\subsubsection{Decrease Vapour Pressure}

Precipitation of salts affects the rate of evaporation through different mechanisms. Accumulation of salts near surface decreases the vapour gradient by decreasing vapour pressure at the surface. The decrease in vapour gradient will lead to decrease in rate of evaporation (Fujiyasu and Fahay, 1997). 


\subsubsection{Increase Reflectivity}

Precipitation of salt at the surface increases the reflectivity of the incoming solar radiation. Higher reflectivity (albedo) reduces the rate of evaporation by decreasing the net radiation available to uptake water from its liquid phase to gaseous. However, this was not relevant to this experiment as the effect of radiation is insignificant.

\subsubsection{Hinders Upward Movement of Moisture}

Upward movement of moisture is hindered as a result of salt crust formation at the surface acting as physical barrier. Rate of evaporation will be affected due to the less upward movement of moisture from the bottom position.

Osmotic suction at the surface increases exponentially, as shown in Figure 5.5.13. The exponential increase is due to the accumulation of mass by upward transport of moisture to feed evaporation, and by the decrease in water at the surface and the consequent increase in concentration. This will occur until the solubility of the salts is exceeded. The SoilCover model was able to predict the $\mathrm{AE}$ for the first and second layers, but not after rewetting (see Figure 5.5.7). This is likely due to the influence of salts as indicated by Figure 5.5.15 the effect of salts would be clear. Note the total suction, being the sum of osmotic and matric suction must be over $3000 \mathrm{kPa}$ to induce a decrease in the $\mathrm{AE} / \mathrm{PE}$ ratio. 


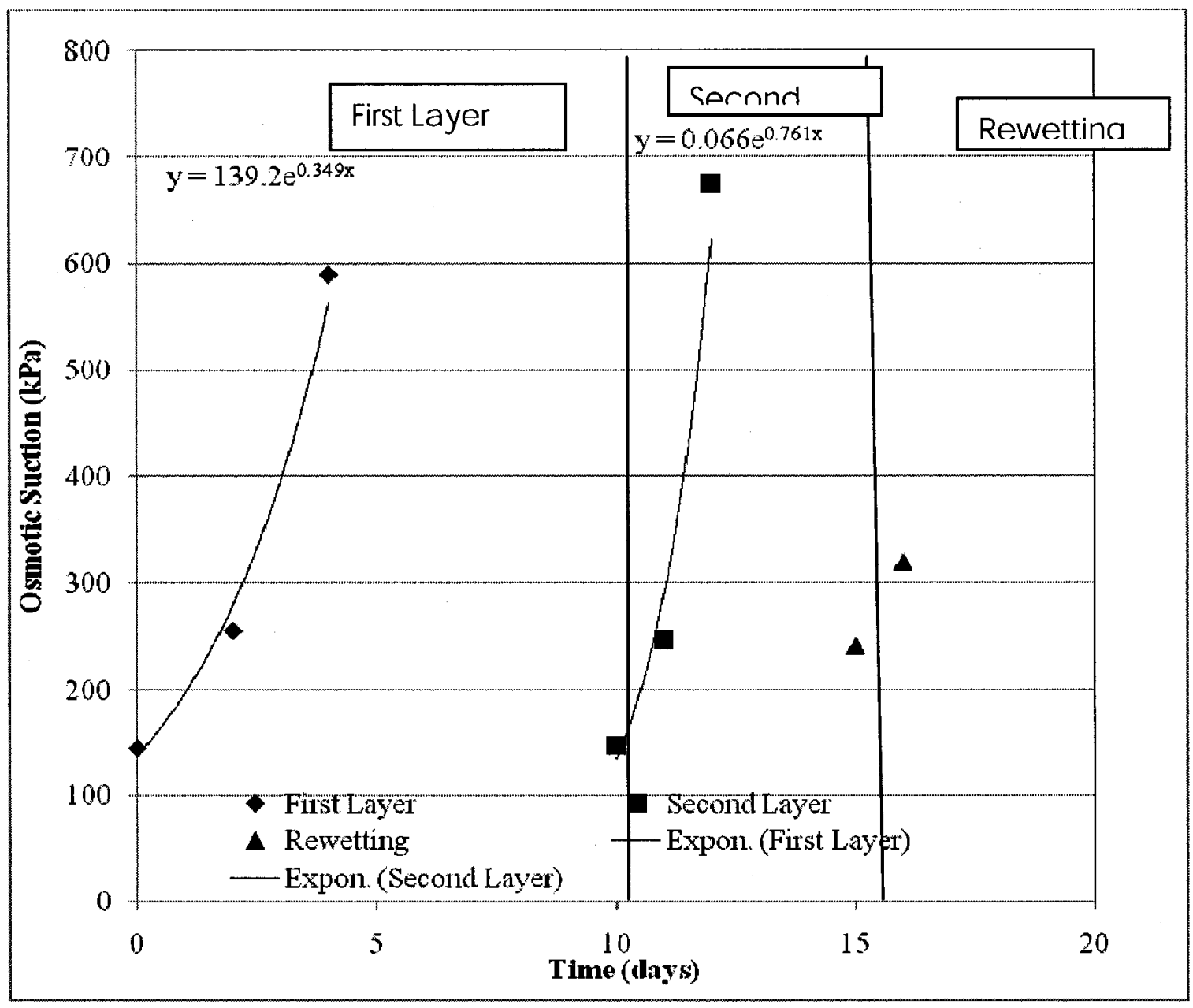

Figure 5.5.13: Osmotic suction versus time for each layer. 


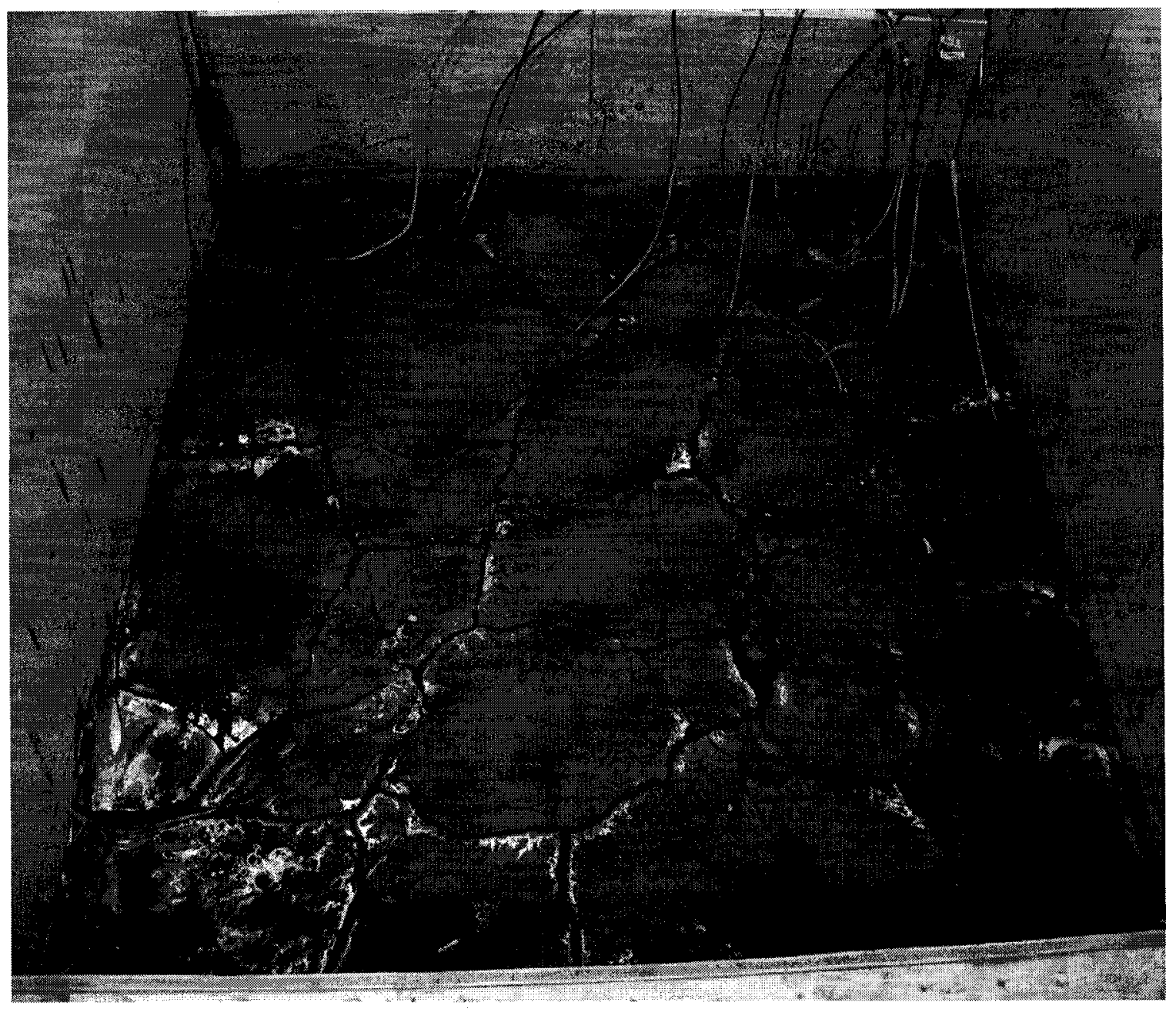

Figure 5.5.14: Large scale, Day 16 and Day one of rewetting. 


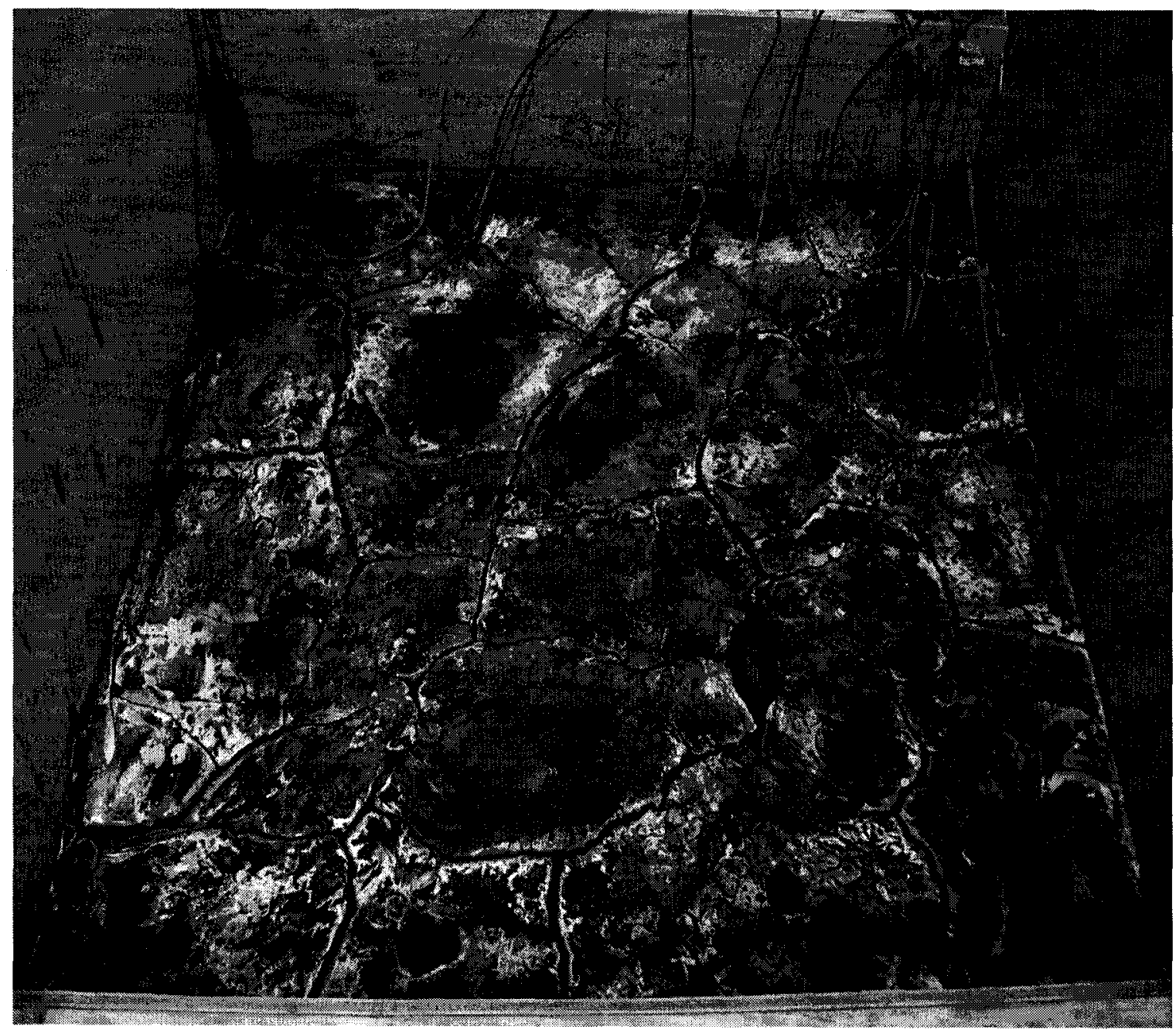

Figure 5.5.15: Large scale, day seventeen for first layer and day two after rewetting.

A small quantity of salt start to precipitate near to the crack edges by day 4 and by day 5 salt precipitated at the surface as it can be seen in the above Figure 5.5.14. Measured actual evaporation was reduced once the precipitation of salts occurred in all large scale and small scale tests. This observation was also reported by different researchers (Fujiyasu, 1997). It is possible that the accumulation of salts is responsible for the lower than predicted evaporation rates after deposition of the second layer in the small-scale test. 


\section{Summary, Conclusion and Recommendations}

\subsection{Summary}

In summary, laboratory multilayer drying tests were conducted using both "large" and "small" scale setups. The large scale test used a metallic box $1.5 \mathrm{~m}$ by $1.5 \mathrm{~m}$ in plan area, while the small scale tests were performed on $\sim 250 \mathrm{~mm}$ diameter columns. The large-scale test was performed using Bulyanulu tailings and the small column tests were performed using both Bulyanhulu and Toromocho tailings. Evaporation was directly measured by monitoring the change in weight using load cells or scales. Relative humidity and air temperature were monitored. Evaporation was primarily driven by fans mounted close to the apparatus, while the contribution to evaporation from net radiation from ambient laboratory lighting was determined to be negligible.

Each layer was deposited after properly remixing the sample to produce uniform moisture content of $40 \%$ GWC, using a paint mixer and by hand. Matric suctions were measured using heat dissipation sensors and tensiometers. Volume change due to self-weight consolidation, vertical shrinkage, lateral shrinkage, and crack formation was measured. Propagation of cracks and their development was measured. Gravimetric moisture content was measured at the surface and profiled with depth at specific times. Conductivity of the pore-water was measured in the large scale test using a pore-water squeezer on samples collected $1 \mathrm{~cm}$ below the surface at two day intervals. Room temperature and relative humidity was measured 
using USB probe from Omega engineering Inc. In some tests, the effect of rewetting to simulate precipitation was also investigated.

Calculations to determine the matric suction, osmotic suction, average degree of saturation, void ratio, average gravimetric moisture content and rate of evaporation were performed for each day of the drying test. The experimental results were compared with a one-dimensional unsaturated flow model (SoilCover). The model parameters were obtained by laboratory tests, with the exception of the $m_{v}$ value, which was calibrated in order to facilitate simulation of water release during self-weight consolidation.

\subsection{Conclusions}

- In the multilayer test, the underlying layer soaks up water from the freshly placed layer and facilitates the rate of drying. This can be seen by the convergence of tensiometer readings in the upper and lower layers.

- SoilCover can reasonably simulate the matric suction profiles developing from interlayer interaction in both small scale and large scale tests

- For the simulated climatic conditions, Bulyanhulu and Toromocho tailings dry uniformly with depth before shrinkage stops.

- The increase in rate of evaporation due to crack formation is no more than $5 \%$ in the laboratory. In the field, it has been observed, that the ratio of plan surface area to crack surface area is a constant, regardless of the deposition depth, this ratio is the 
same as in the large scale laboratory test. Therefore, the effect of cracking on field evaporation rates is not expected to be significant. This is different from the results reported by Fujiyasu (1997), who reported a significant contribution of cracks to evaporation after Stage I drying had stopped at the surface of the tailings. However, Fujiyasu (1997) studied the effect of cracks in a conventional slurried tailings deposit, where both the initial water content (>50\% GWC) and the depth of deposition (>1 m) were much greater than in this study.

- Precipitation of salts was observed at the surface of the Bulyanhulu tailings for both small and large scale tests. Osmotic suctions measured near the surface increased exponentially with time during drying in each layer and measured actual rate of evaporation was decreased once the precipitation of salts visibly blanketed the surface. This is likely due to some combination of vapour pressure depression and the physical barrier created by the salt precipitates.

- The SoilCover model can simulate evaporation rates in both the double layer and single layer tests until development of significant salt crust. The model can therefore be used as a tool to explore other deposition scenarios for these tailings during early deposition, thought the effect of salts must somehow be integrated into any hypothetical analyses.

\subsection{Recommendations}

Many researchers pointed out that accumulation of salts affects the rate of evaporation in different ways, such as decrease vapour gradient, hindered upward transfer of moisture, increased surface reflectivity (Fujiyasu et al, 1997; Malek et al, 1990; Hillel, 1977; Chen 1992). Effect of salts on rate of evaporation deserves closer attention in future studies. 
This could be done using a small column drying test

- Preparing a mixture of known salt compound with soil, such as Sodium chloride, or gypsum. This gives a known property of salt such as its solubility, bond strength on electrical conductivity.

- Consequent sampling of the pore water while it's drying

- Measurement of osmotic suction or total suction using sensors

- Measurement the electrical conductivity of the pore water and compare or correlate with the direct measured osmotic suction

- Develop a generic formula to predict salt concentrations from a given parameter at a given time

- Develop a code which simulate salt precipitation and test the code to validate it

As paste or thickened surface deposition increasingly used as mine impoundment closure, factors affecting process of evaporation has to be studied attentively. Effect of salt precipitation has not been studied yet, however understanding effect of salt will give a better and accurate prediction of evaporation, which is very vital for optimizing the designing process and reduce the risk of environmental contamination to remain in compliance and protect human health. 


\section{References}

Aachib, M., Mbonimpa, M., and Aubertin,M. 2004. Measurement and prediction of the oxygen diffusion coefficient in unsaturated media, with application to soil covers. Water, Air, and Soil pollution, 156:163-193.

Abu-Hejleh, A.N. and Znidarcic, D. 1995. Desiccation theory for soft cohesive soils. Journal of Geotechnical Engineering, ASCE, 121: 493-502.

Adams, J.E., Ritchie, J.T., Burnett, E. and Fryrear, D.W. 1969. Evaporation from a simulated soil shrinkage crack. Soil Sci. Soc. Amer. Proc., 33, pp.609-613.

ASTM D4943-02, 2003, Standard test method for Shrinkage Factors of Soils by the Wax Method, ASTM, West Conshohocken, Pennsylvania, USA.

ASTM D427. Standard Test Method for shrinkage factors of soils. 1992 Annual Book of ASTM Standards, Vol. 04.08, Soil and Rock; Building stones, sect. 4, ASTM Philadelphia, PA.

ASTM D854. Standard Test Method for specific gravity of soils. 1992 Annual Book of ASTM Standards, Vol. 04.08, Soil and Rock; Building stones, sect. 4, ASTM Philadelphia, PA.

ASTM D4318. Standard Test Method for Liquid limit, plastic limit, and plasticity index of soils. 1984 Annual Book of ASTM Standards, Vol. 04.08, Soil and Rock; Building stones, sect. 4, ASTM Philadelphia, PA. 
ASTM D422. Standard Test Method for shrinkage factors of soils. 1963 Annual Book of ASTM

ASTM Standards, Vol. 04.08, Soil and Rock; Building stones, sect. 4, ASTM Philadelphia, PA.

Aubertin, M., Mbonimpa, M., Bussiere, B. and Chapuis, R.P. 2003. A Model to predict water retention curve from basic geotechnical properties. Canadian Geotechnical Journal, 41: 11041122.

Bishop , A.W. and Donald, I.B., 1961. The experimental study of partly saturated soil in the Triaxial Apparatus, in proc. $5^{\text {th }}$ int. conf. soil mech. Found. Engineering, Paris, France, Vol.1, pp.13-21.

Bowen, I. S. (1926). The ratio of heat losses by conduction and by evaporation from any water surface. Physical Rev., 27:779-787.

Brooks, R.H and Corey, A.T. 1964. Hydraulic properties of porous medium. Colorado State University, Hydrology paper 3.

Brutsaert, W. 1968. The permeability of a porous medium determined from certain probability laws for pore size distribution. Water Resources Research, 4: 425-434.

Brutseart, W. 1982. Evaporation into the Atmosphere :Theory, History and Applications, D.Riedel Publishing Company, Dordrecht, Holland.

Buckingham, E.1907. Studies of the movement of soil moisture. USDA, Bur. of soils, Bulletin No.38. 
Childs, E.C., and Collis-George, G.N. 1950. The permeability of porous materials. Proceedings of the Royal Society of London, 201: 392-405.

Chen, X.Y. 1992. Evaporation from a salt-encrusted sediment surface: field and laboratory studies. Aust. J. Soil Res., 30: 429-442.

Choudhury, B.J. and Monteith, J.L. 1988. A four-layer model for the heat budget of homogeneous land surfaces. Quart. J.R. Meteorol. Soc., 114: 373-398.

Couto, R., Grabinsky, M.W., Simms, P.H. 2006. Shrinkage characteristics of surface deposited paste tailings. 2006 Canadian Geotechnical Conference, Vancouver, B.C., Oct. 1st4th 2006 (Electronic proceedings).

Dalton., J. 1802. Experimental essays on the constitution of mixed gases; on the force of stream or vapour from water and other liquids in different temperatures, both in a Torricellian vacuum and in air; on evaporation and on the expansion of gases by heat, Mem. Manchester Lit. and Phil.Soc. 5: 535-602.

De Vries, D.A.1975. Heat transfer in soil. In Heat and mass transfer in the biosphere 1.Tranfer processes in plant environment. Edited by D.A. de Vries and N.H. Afghan. Scripta Book company, Washington, DC pp 5-28.

Edlefsen, N.E. and Anderson A.B.C. 1943. Thermodynamics of soil moisture. Higardia, 15: $31-298$.

ENS- Environmental News Service, "Spanish Mine Spill Fine Contested" August 8", 2002. 
Eptisa, Servicios de Ingenieria S.A. 1998. Investigation of the Failure of the Aznalcóllar Tailings Dam: Summary. Report for Boliden Apirsa, dated November 1998.

Feasby, G., Tremblay, G., and Weatherell, C.J.1997. A decade of improvement to the challenge of acid drainage- A Canadian Perspective, Proceedings of the Fourth International Conference on Acid Rock Drainage, Vancouver, B.C. Canada, June.

Fisseha, B.T. and Simms, P.H., 2007. Methods to predict unsaturated properties of soils from grain size-applicability to silts, $60^{\text {th }}$ Canadian Geotechnical Conference, Ottawa, Canada. Oct $21^{\text {st }}-24^{\text {th }}$.

Fisseha, B.T., Glancy, T., Simms, P.H. 2007. The influence on the initial degree of saturation on the shrinkage curve of silts, $60^{\text {th }}$ Canadian Geotechnical Conference, Ottawa, Canada. Oct $21^{\text {st }}-24^{\text {th }}$.

Flint, A.L., G.S. Campbell, K.M. Ellett, and C. Calissendorff. 2002. Calibration and Temperature correction of Heat Dissipation Matric Potential sensors. Soil sci. soc. Am. J 66: 1439-1445.

Fourie, A. B. 2003. In Search of the Sustainable Tailings Dam: Do High-Density Thickened Tailings Provide the Solution, School of Civil and Environmental Engineering, University of the Witwaterstrand, South Africa: 12.

Fredlund, D.G. and Morgenstern, N.R. 1977. Stress state variables for unsaturated soils. ASCE Journal of Geotechnical Engineering, GT 11: 447-466. 
Fredlund, D. G., and Dakashanamurthy, V. 1982. Prediction of moisture flow and related swelling or shrinking in unsaturated soils. Journal of Geotechnical Engineering 13: 15-49.

Fredlund, D. G. and Rahardjo, H. 1993. Soil Mechanics for Unsaturated soils. John Wiley and Sons, Toronto, Canada.

Fredlund, D.G, Xing, A., Huang, S. 1994. Predicting the permeability function for unsaturated soils using the soil-water characteristic curve. Canadian Geotechnical Journal, 31: 533-546.

Fredlund, D.G. and Xing, A. 1994b. Equations for the soil-water characteristic curve. Canadian Geotechnical Journal, 31: 521-532.

Fredlund, Murray D., Wilson, G. Ward, and Fredlund, Delwyn G. 2002. Use of the grain-size distribution for estimation of soil-water characteristic curve. Canadian Geotechnical Journal, 39: 1103-1117.

Fujiyasu, Y., 1997. Evaporation behavior of tailings. Ph.D. Dissertation. University of Western Australia., Perth, Australia.

Guan, Y. and Fredlund, D.G. 1997. Use of the tensile strength of water for the direct measurements of high soil suction. Canadian Geotechnical Journal. 34: 604-614.

Gardner, W.R.1958. Some steady state solutions of the unsaturated moisture flow equation with application to evaporation from a water table. Soil Science, 85: 228-232.

Gardner, W.R. and Fireman, M. 1958. Laboratory studies of evaporation from soil columns in the presence of a water table. Soil. Sci. 85: 244-249. 
Gibbs, H. J. and Coffey, C.T. 1969b. Techniques for pore pressure Measurements and Shear Testing of soil. In Proc. $7^{\text {th }}$ int. conf. soil mech.Found. Eng. (mexico), vol. 1, 1969, pp. 151157.

Gray, D.M. 1970. Handbook on the principles of Hydrology, Canadian National Committee for the international Hydrological Decade, pp. 631.

Hatano, R., Nakamoto, H., Sakuma, T. and Okajima, H. 1988. Evapotranspiration in cracked clay field soil. Soil sci. Plant Nutr., 34: 547-555.

Hilf, J.W. 1956. An Investigation of pore-water pressure in compacted Cohesive Soils, Ph.D.

Dissertation, Tech. Memo. No. 654, U.S. Dept. of the interior, Bureau of Reclamation,

Design and Construction Div., Denver, CO, 654 pp.,1956.

Hillel, D. 1977. Computer Simulation of soil-water Dynamics. International development Research Centre, Ottawa, Canada.

Hillel, D. 1980. Applications to Soil Physics. Academic press, New York.

Ho, D.Y.F and Fredlund, D.G., 1982a. a multi-stage triaxial test for unsaturated soils, ASTM Geotech. Testing J., 5 (1/2): 18-25, June 1982.

ICOLD and UNEP (2001). Bulletin 121: Tailings Dams - Risk of Dangerous Occurrences, Lessons learnt from practical experiences. Paris.144.

Instructional Manual, L-229. 2006. Campbell Scientific Inc. 
Kimball 1976, B.A, Jackson, R.A., Reginato, R.J.,Nakayama, F.S., and Idso, S.B. 1976. Comparison of field-measured and calculated soil-heat fluxes. Soil society of America proceedings $40(1): 18-25$.

Lai, S., Tiedje, J.M., and Erickson, A.E. 1976. In situ measurement of gas diffusion coefficient in soils. Soil Science Society of America Proceedings, 40(1):3-6.

Laliberte, L.E., Brooks, R.H., Corey, A.T.1968. Permeability calculated from desaturation data. Journal of irrigation and drainage division. Proceedings of the American Society of Civil Engineers, vol. 94(1R1), pp.57-71.

Lindahl, L. 1990. Acid mine drainage . Research and remedial actions in Sweden. Report of the Swedish Environmental protection Agency, Stockholm.

Lee, C.H. 1972. Discussion of evaporation on reclamation projects, Trans. Amer. Soc. Civil Eng., 90: 330-343.

Malek, E.,Bingham,G.E. and McCurdy, G.D. 1990. Evapotranspiration from the margin and moist playa of a closed desert valley. Journal of Hydrology, 120: 15-34.

Martin, V., Aubertin, M. and McMullen, J. 2006. Surface disposal of paste tailings $5^{\text {th }}$ International Congress on Environmental Geotechnics, Cardiff, Wales, UK, $26^{\text {th }}-30^{\text {th }}$ June 2006, H.R Thomas Editor, Thomas Telford Publishing, London, Vol.2., pp.147-1478.

Mualem, Y. 1976. A new model for predicting the hydraulic conductivity of unsaturated porous media. Water Resources Research, Vol 12, pp.513-522. 
Penman, H.L.1948. Natural evapotranspiration from one water, bare soil and grass.

Proceedings of the Royal Society of London, Series A, Vol. 193, pp.120-146.

Philip, J.R. and de Vries, D.A. 1957. Moisture movement in porous materials under temperature gradients. Trans. Amer. Geophys Union, Vol. 38, No. 2, pp. 222-232.

Richard, L.A.1931. Capillary conduction of liquids through porous medium. Physics, 1: 318333.

Ritchie, J.T. and Adams, J.E. 1974. Field measurement of evaporation from soil shrinkage cracks. Soil sci. Soc.Amer. Proc. Vol.38, pp.131-134.

Robertson, A. 1987. Alternative measures for acid mine drainage abatement at Norwegian Mines, Report to Norwegian state pollution Control Authority.

Robinsky, E.I 1999. Thickened tailings disposal in the mining industry. Robinsky Associates, Toronto, Canada.

Selim, H.M. and Kirkham, D. 1970. Soil Temperature and water content changes during drying as influenced by cracks: a laboratory experiment. Soil. Sci. Soc. Amer. Proc. Vol. 34, pp. 565-569.

Shuttleworth, W.J. and Wallace, J.S. 1985. Evaporation from sparse crops -an energy combination theory. Quart. J.R. Meteorol. Soc. 111: 839-855.

Shuttleworth, J.A., Thomson, B.J., and Wates, J.A. 2005. Surface disposal at Bulyanhulu practical lessons learned. $6^{\text {th }}$ International Conference on Paste and Thickened tailings, Santiago, Chile, April 20 $0^{\text {th }}-22^{\text {nd }}$. Editors R.Jewel, S.Barerra, pp. 207-216. 
Simms, P.H., and Grabinisky, M.W. 2004. A simple method for estimating rates of drying and desaturation of paste tailings during surface deposition. Proceedings of the $11^{\text {th }}$ annual conference on Tailings and Mine Waste, October 10-13 ${ }^{\text {th }} 2004$, pp. 287-292.

Simms P., Grabinsky M.W., and Zhan, G. 2007. Modelling evaporation of surface paste tailings from the Bulyanhulu mine. Canadian Geotechnical Journal, 44: 1417-1432.

Sofra and Boger DV. 2002. Environmental rheology for waste minimization in the minerals industry. Chemical engineering Journal, 86 (3): 319-330.

Sudhakar, M.Rao and Shivananda, P. 2005. Role of osmotic suction in swelling of a saltamended clay. Canadian Geotechnical Journal, 42:307-315.

Theriault, J. Frostiak, J. Welch D. 2003. Surface disposal of paste tailings at the Bulyanhulu gold mine, Tanzania. Proceedings of Sudbury 2003, Mining and the Environment, Sudbury, Ontario, Canada, May 26th-28th 2003. Editors G. Spiers, P. Beckett, H. Conroy, pp. 265269.

Thornthwaite, C.W. 1948. An approach toward a rational classification of climate, Geographical Rev., 38: 55-94.

Turk, L.J (1970). Evaporation of brine: a field study on the Bonneville Salt Flats, Utah. Water Resources Research. 6(4):1209-1215.

User Manual-UMS-T5. 2001. Version 1.8, UMS GmbH, Munich.

Van Genutchen, M.T. 1980. A closed form solution for predicting the hydraulic conductivity of unsaturated soils. Soil Science Society of America Journal, 44: 892-898. 
Wilson, G.W.1990. Soil Evaporation fluxes for geotechnical engineering problems. PhD Dissertation. University of Saskatchewan, Saskatoon.

Wilson, G.W., Fredlund,D.G., Barbour, S.L.1994. Coupled soil-atmosphere modeling for soil-evaporation. Canadian Geotechnical Journal, 31: 151-161.

Wilson, G.W. 1997. The effect of soil suction on evaporative fluxes from soil surfaces. Canadian Geotechnical Journal, 34: 145-157.

Yanful, E.1993. Oxygen diffusion through soil covers on sulphidic mine tailings. Journal of Geotechnical Engineering, 119(8): 1207-1228.

Zawislanski, P.T., Tokunaga, T.K. Benson, S.M., Oldfather, J.M. and Narasimhan, T.N. 1992. Bare soil evaporation and solute movement in selenium-contaminated soils of Kesterson Reservoir. J.Environ. Qual., 21: 447-457. 
Appendix A: The influence on the initial degree of saturation on the shrinkage curve of silts 


\title{
THE INFLUENCE ON THE INITIAL DEGREE OF SATURATION ON THE SHRINKAGE CURVE OF SILTS
}

\author{
Bereket Fisseha, Taryn Glancy, Paul Simms \\ Department of Civil and Environmental Engineering - Carleton University, \\ Ottawa, Ontario, Canada
}

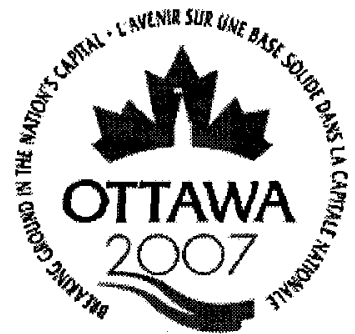

THE DIAMOND SUBLEE LE JUDEC DE DIAMANTS

\section{ABSTRACT}

The final void ratio achieved through drying is an important parameter in several geotechrical applications. It has been recognized for some time that the void ratio achieved by drying is sensitive to the initial degree of saturation. For example, it has been recently obseryed that the void ratio achieved in drying tests on thickened tallings is typlcally larger than the void ratio determined by the ASTM shrinkage test. In an attempt to quantily this phenomenon, silt size glass beads of known grain size distributions (25-50 and 6-8 microns ranges in diameter) were mixed at different water contents above the shrinkage limit, using various mixing methods in order to induce a wide range of initial degree of saturation $(0.7-1.0)$. There appears to be a strong correlation between the initial degree of saturation and the final void ratio.

\section{RESUME}

Le rapport vide final réalisé en séchant est un paramètre important dans plusieurs applications géotechnicues. On l'a identifié pendant un certain temps que le rapport vide réalisé par le séchage est sensible au degré initial de saturation. Par exemple, on la récemment abservé que le rapport vide réalisé dans les essais de séchage sur les remblais miniers est en général plus grand que le rapport vide déterminé par l'essal de rétrécissement d'ASTM Dans la tentative de mesurer ce phẻnomène, des perles de verre de taille de vase des distributions de grandeurs connues de grain (25-50 et 6-8 microns de gammes de diamètre) on été mélangées à différentes teneurs en eau aurdessus de la limite de rétrécissement, en utilisant de diverses méthodes de mélange atin dìnduire un éventall de degré initial de saturation. I semble y a une corrélation forte entre le degré initial de saturation et le rapport vide final.

\section{INTRODUCTION}

It has been recognized for some time that the initial degree of saturation of compacted clayey solis has some impact on the shape of shrinkage curve. This is shown on Figure 1, where decreasing the initial degree of saturation results in a gentler slope of the shrinkage curve and a higher final void ratio (Fredlund and Rahardjo, 1993). Of late this phenomenon is of increasing interest to geotechnical engineers dealing with unsaturated solls. In mine waste management, the stability of tailings and their susceptibility to liquefaction, whether deposited on surface or underground, is a function of the void ratio achieved through environmental drying or drying induced by hydration. For near-surface geotechnical structures such as embankments, or natural slopes, prediction of long-term behaviour and susceptlbility to rainfall induced collapse is a function of their unsaturated properties, which themselves are dependant on the volume change the soils experience due to wet/dry cycles.

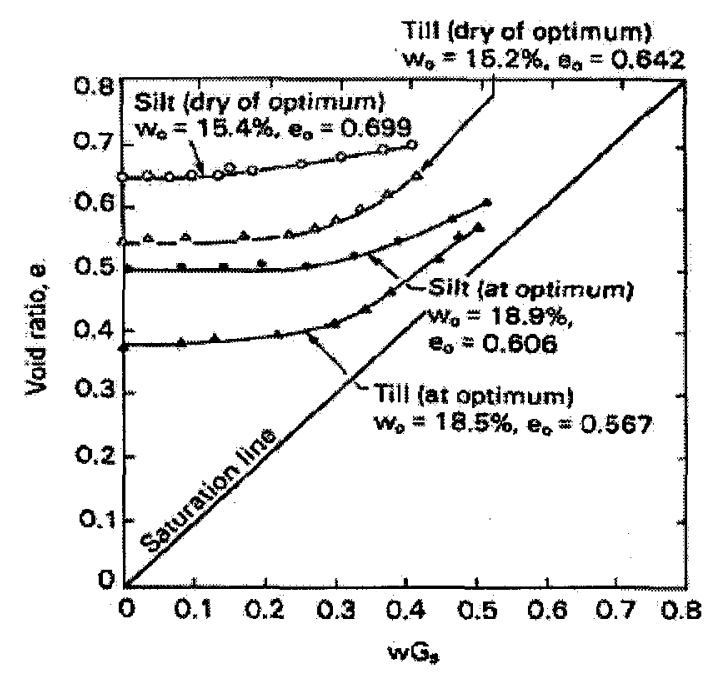

Figure $i$ Shrinkage curves of compacted till and silt (Fredlund and Rahardjo, 1993) 
In particular, it has been noted that the final void ratio achleved through drying in surface deposited silt-sized tailings is often considerably higher than the void ratio predicted from the standard ASTM shrinkage limit test. This has been observed both in laboratory drying tests and well as in the field (Simms et al. 2006, 2005; Theriaull et al. 2003). For example, gold tailngs from the Bulyanhulu mine in Tanzania typically diy to a void ratio of 0.8 rather than the void ratio predicted by the shrinkage limit test, about 0.6 . Couto al (2006) examined the final void ratio achieved through a number of drying tests on different tailings, starting from different initial void ratio's, and found that there was general correlation between the initlal vold ratio and the final void ratio, as shown in Figure 2.

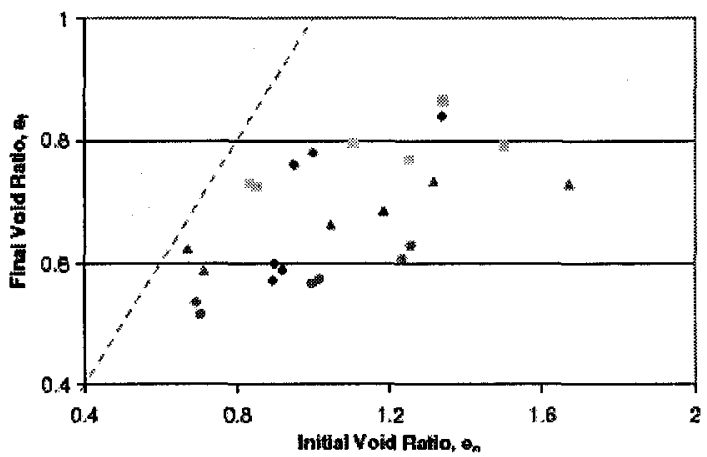

Figure 2 Initial and final void ratios of drying mine tailings (adapted from Couto et al. 2006)

The object of the present study was to examine this phenomenon in more detail, by performing drying tests using two artificial silts. The rationale for employing the artificial silts is that their properties, particle size distribution, and particle shape are known, which provides a more solid footing for understanding the fundamental behaviour of drying of silts. For comparison with a "real" material, the same test was done on samples of gold tailings.

The authors proceeded on the assumption that the initial degree of saturation affects the final void fatio due to the entrainment of air during of mixing. Our hypothesis was that the pockets or bubbles of entrained air will not shrink or collapse during drying, and thus the void ratio at the shrinkage limit of sample with air bubbles will be higher than for a sample with no entrained air.

\section{MATERIALS AND METHODS}

\subsection{Materials}

Two artificial silts, comprised of spherical glass particles, were employed. One silt has an average grain size of 7 microns, the other approximately 25 microns. The artificial silts are manufactured by Potter industries, and are designated by " 7 micon" and "25-50 micron". This designation will be employed for the remainder of the paper. The basic properties of the silts are shown in Table 1.

Table 1: Properties of the materials

\begin{tabular}{l|l|l|l}
\hline Properties & 7 micron & $\begin{array}{l}25-50 \\
\text { micron }\end{array}$ & $\begin{array}{l}\text { Gold } \\
\text { tailings }\end{array}$ \\
\hline $\begin{array}{l}\text { Specific } \\
\text { gravity }\end{array}$ & 2.55 & 2.48 & 3.00 \\
\hline $\begin{array}{l}\mathrm{D}_{10}, \mathrm{D}_{50}, \\
\mathrm{D}_{60} \\
\text { (microns) }\end{array}$ & $1,6,7$ & $1,37,41$ & $2,36,55$ \\
\hline $\begin{array}{l}\mathrm{Cu} \\
\left(\mathrm{D}_{60} \mathrm{D}_{10}\right)\end{array}$ & 7 & 41 & 27.5 \\
\hline $\begin{array}{l}\text { W, Wp, Ws } \\
(\%)\end{array}$ & $26,25,16$ & $19,13,13$ & $21,20,20$ \\
\hline $\mathrm{K}_{\mathrm{sat}}(\mathrm{m} / \mathrm{s})$ & $5.5 \times 10^{-8}$ & $1.7 \times 10^{-5}$ & $1.0 \times 10^{-1}$ \\
\hline
\end{tabular}

These properties were measured by the authors using standard methods. The mydraulic conductivity of each materlal was delermined by a falling head test.

In addition, the samples tend to self-weight consolidate or settle down to gravimetric water contents of $29 \%$ and $25 \%$ for the 7 and $25-50$ samples respectively.

\subsection{Methads}

The authors attempted to control the amount of air initially entrained in the samples by two methods:

Tost 1 - Mixing by blender

The first series of tests were prepared by mixing the samples in a blender. Samples were first mixed by hand with tap water in a bowl to a range of water contents above the shrinkage limit. Then each sample was placed in a blender. A timer was set and the sample was mixed for different amounts of time to vary the amount of air in the sample. The fypical mixing times were $10 \mathrm{~s}, 20 \mathrm{~s}, 30 \mathrm{~s}$, 1 min and 2 min. After each time interval, a small sample (approximately $50 \mathrm{~g}$ ) from the blender was poured into a small aluminum tin. The volume and mass of the sample in the tin was recorded and the tin was set aside to air dry tor a couple days. After such time the volume and weight of the sample in the tin was recorded again to determine water content and final void ratio. Final gravimetric water contents ranged from $2 \%$ to $3 \%$. This test was repeated at initial water contents ranging from $30 \%$ to $50 \%$ gravimetric.

Test 2 - Using manual mixing

A second series of tests were carried out where manual stirring was used instead of a blender. The sample was mixed for 10 minutes by hand with a spatula. Small samples (approximately $50 \mathrm{~g}$ ) were placed in aluminum tins. The volume and weight of the sample in the tin was 
recorded and the tin was set aside to dry for a couple days. After such time the volume and weight of the sample in the tin was recorded again to determine water content and final void ratio. This test was repeated at different initial water contents, fanging from $30 \%$ to $50 \%$ gravimetric. The gold tailings were prepared using this method at a gravmetric water content of $34 \%$.

\subsection{Volume measurement.}

The initial sample volumes were determined using a noncontact displacement sensor from Senix. The sensor operates on the principle of ultrasound wave reflection. The sensor measures the vertical distance from the sensor to the surface of the material. The surtace of the dried silt was visualized by moving each tin horizontally to predetermined points under the sensor. This method was verified on tins flled with water. A sample of the final void ratios determined using this method were checked against the wax mathod (ASTM Standard D4943-02). The difference in void ratio was always less than 0.05 .

The 25-50 micron samples did not exhibit cracking or horizontal shrinkage away from the sides of the tins. The 7 micron sample, however, did exhibit some hailine cracking or some horizontal separation from the sides of the tins. At most, the horizontal defection would account for an error of $4 \%$ in volume measurement. This would roughly change the void ratio by 0.02 . The void ratio's presented here for the 7 micron samples are not corrected for horizontal shrinkage.

\subsection{AESULTS}

3.1 Influence of mixing time on Initial degree of saturation.

Despite achleving a wide range of initial degree of saturation $(0.75$ to 1$)$, there was no consistent trend between initial saturation and mixing time or mixing method. There was a weak correlation between higher water contents and higher void ratios with lower initial degrees of saturation. This is shown for the 25-50 micron silt in Figure 3.

\section{$3.2 " 25-50^{"}$ micron silt}

The final void ratio's measured after air-drying ranged from 0.34 to 0.44 , while the void ratio corresponding to the shrinkage 位it, assuming $S=1$, is 0.32 . As can be seen in Figure 4, there are only weak correlations between initial void ratio and inlital water content with the tinal void ratio. The only trend is that the variability of final void ratios seems to decrease with decreasing initial water content and initial void ratio. A much stronger trend is exhibited with intitial degree of saturation, as shown in Figure 5. As the degree of saturation increases, so does the final void ratio. This relationship seems however only to hold for degrees of saturation greater than 0.8 .
Figure 6 tests our hypothesis that the final void ratio depends on the amount of entrained air. The entrained air is represented as (1-\$) $X$ initial void ratio. Figures 5 and 6 suggest that either of the following relationships can relate the actual void ratio to the ASTM shrinkage limit:

$$
\begin{aligned}
& e_{f}=w_{s} G_{s}+C_{1}(1-s) \\
& e_{f}=w_{s} G_{s}+C_{2}(1-S) e_{i}
\end{aligned}
$$

Where denotes the final vold ratio, $G_{s}$ the specific gravity, $\theta$ the initial void ratio, $w_{s}$ the shrinkage limit, and $C_{1}$ and $C_{2}$ are constants.

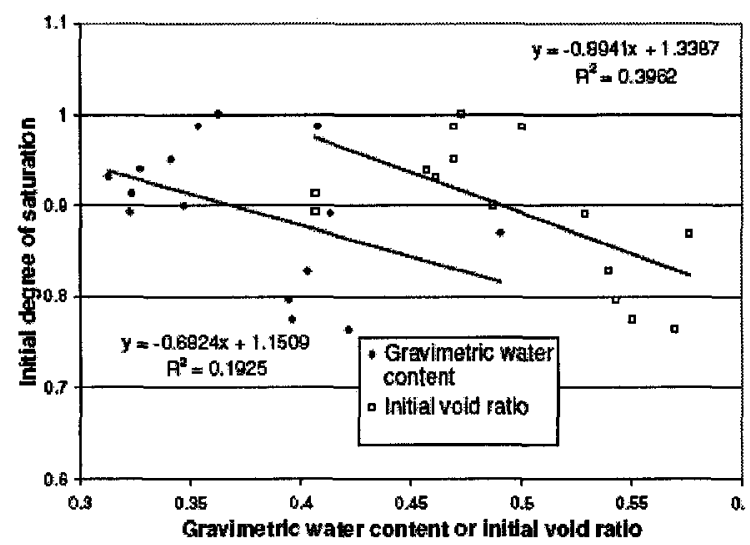

Figure 3 Sensitivity of initial degree of saturation to initial water content and void ratio for the "25-50 micron" silt 


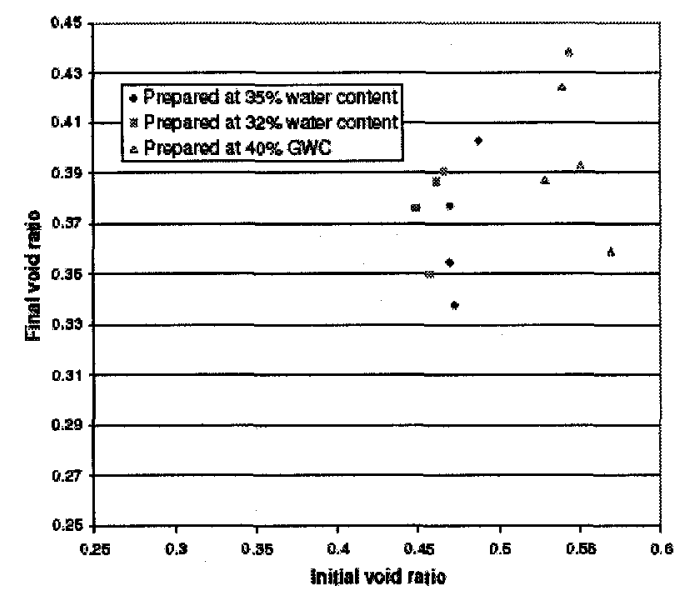

Figure 4 Initial and final void ratios, "25-50" micron silt

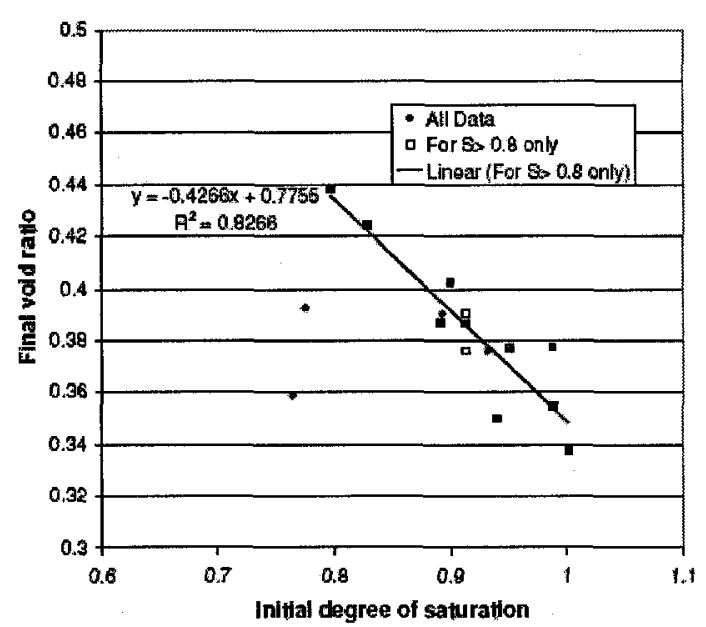

Figure 5 Final void ratio versus initial degree of saturation for the "25-50" micron silt

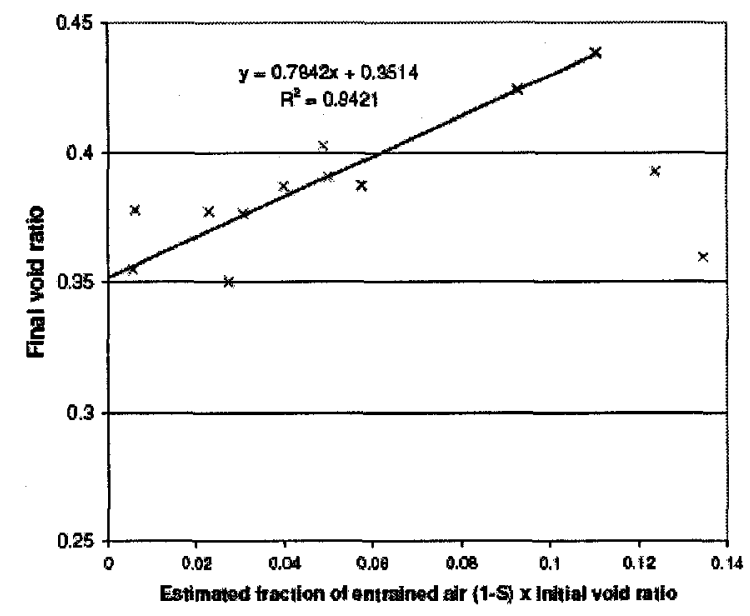

Figure 6 Final vold ratio as a function of initial volume of air filled voids for the "25-50" micron silt

\section{3 " 7 " micron silt}

Final void ratios for the 7 micron silt ranged between 0.39 and 0.50 . The ASTM shrinkage limit was $16 \%$, corresponding to a void ratio of 0.41. As with the 25-50 micron sample, the final void ratio showed poor correlation with initial void ratio or initial water content, and as well showed stronger correlations between the final void ratio and initial degree of saturation or the initial volume of air-filled voids, as shown in Figures 7 and 8 . Either equation 1 or 2 could apply to this material.

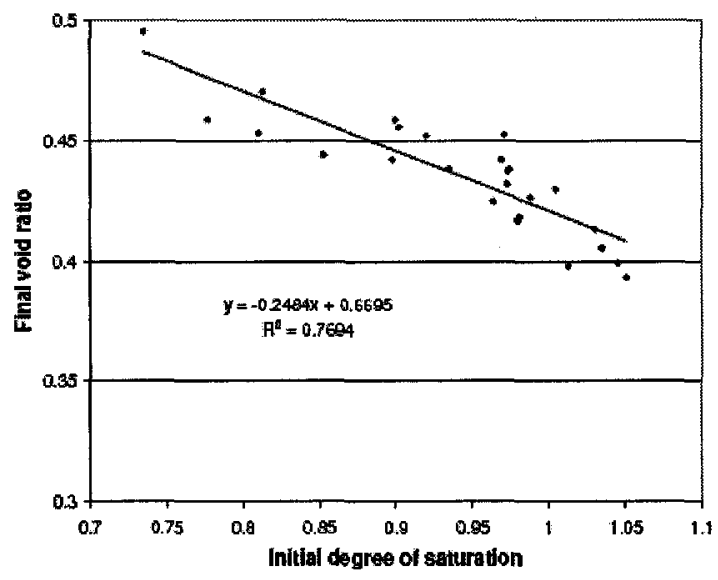

Figure 7 Final void ratio versus initial degree of saturation for the "7" micron silt 


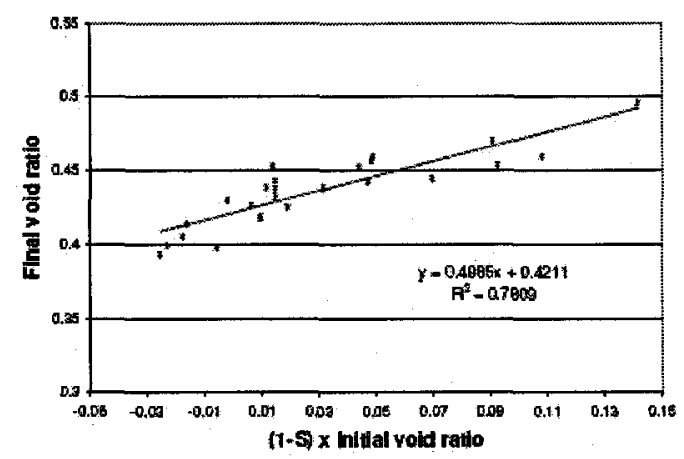

Figure 8 Final void ratio as a function of initial volume of air filled volds for the "7" micron silt

\subsection{Bulyanhulu tailings}

Similar tests were done on predominantly silt sized gold faillngs from the Bulyanhulu mine in Tanzania. The correlation with degree of saturation and the initial volume of entrained air is plotted in Figure 9. Though the dala set is smaller than the tests on the artificial silts, the same frends are evident. The vold ratio equivalent to the shrinkage limit for the gold tallings is 0.60 .

A picture of one of the airndried samples is shown in Figure 10, where cracking is evident. However, even being conservative about the volume of cracks in this sample, the contribution of cracks to the void ratio would be less than 0.02 .

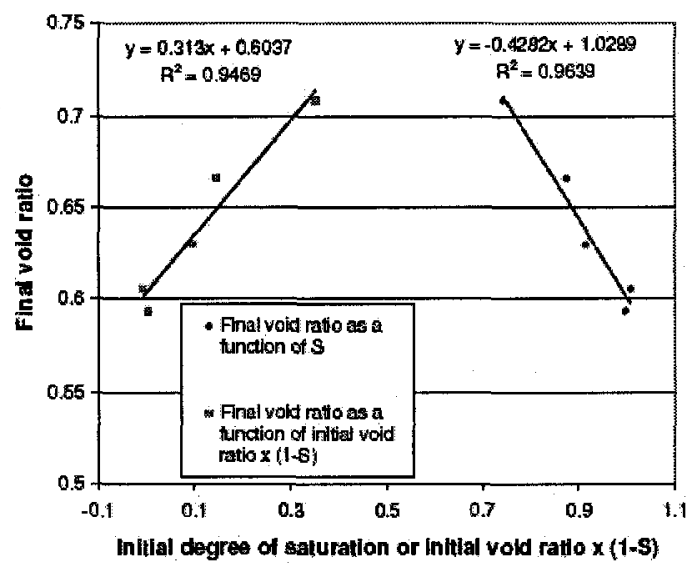

Figure 9 Final vold ratios from goid tailings

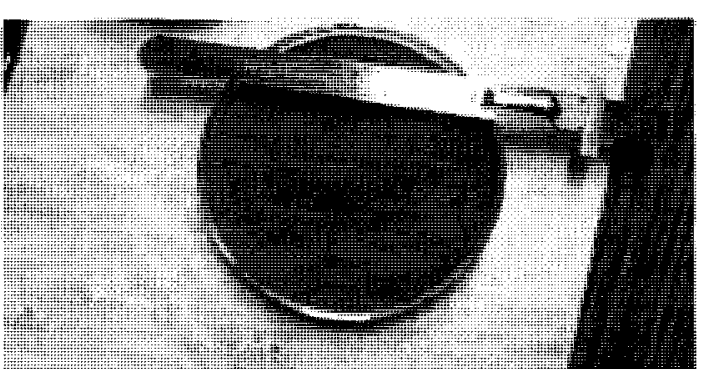

Figure 10 Gold tailings after air drying

\subsection{DISCUSSION}

It is apparent that the intial degree of saturation does influence the tinal void ratio achieved through drying, though not simply due to the persistence of initially entrained air. If this were so, the value of $\mathrm{C}_{2}$ in Equation 2 would be 1 , while in tact the values of $\mathrm{C}_{2}$ are 0.78 and 0.50 for the $25-50$ and 7 micron samples respectively. If is possible that a fraction of the entrained air bubbles are destroyed during shrinkage of the sample. Some of the large pores may link up to form cracks or form open cavities at the surface. From a macroscopic viewpoint, the lower initial degree of saturation implies a lawer average stress induced by a given suction. Most deformation will occur for suctions less than the air-entry value. Assuming a constant air-entry value for a given soll, this would imply that the deformation would decrease as the initial degree of saturation decreases.

The values of $C_{1}$ and $C_{2}$ of the three materials are compared in Table 2 with some properties of the solls

Table 2: Comparison of correlations with basic properties

\begin{tabular}{l|lll}
\hline & 7 micron & $\begin{array}{l}25-50 \\
\text { micron }\end{array}$ & $\begin{array}{l}\text { Gold } \\
\text { Tallings }\end{array}$ \\
\hline $\mathrm{C}_{4}$ & 0.25 & 0.43 & 0.43 \\
$\mathrm{C}_{2}$ & 0.50 & 0.78 & 0.30 \\
$\mathrm{D}_{10}$ & 1 & 1 & 2 \\
$\mathrm{D}_{50}$ & 6 & 37 & 36 \\
$\mathrm{C}_{4}$ & 7 & 41 & 27.5 \\
$\mathrm{PL}$ & 25 & 13 & 20 \\
\hline $\mathrm{LL}$ & 16 & 13 & 20 \\
\hline
\end{tabular}

The vale of $C_{1}$ compares well with the difference in $D_{50}$ between the samples. The only apparent correlation for $\mathrm{C}_{2}$ is with the inverse of the $\mathrm{LL}$. 


\section{CONCLUSION}

The final void ratio of wo artificlal silts and gold tailings achieved by air drying appears to be linearly correlated with the initial degree of saturation and the initial volume of entrained air. The correlation is slightly stronger with the initial degree of saturation. Two simple equations are proposed to calculate the final void ratio as a function of the ASTM shrinkage limit and the initial degree of saturation and the initial void ratio.

These results are important as the void ratio achioved by drying has important consequences for the performance of solls in terms of their unsaturated behaviour and dynamic stability. This is particularly relevant to deposition of thickened or paste tailings, where the degree of stability achieved by drying is an important consideration in tailings impoundment design (Simms of al. 2007).

\section{ACKNOWLEDGENENTS}

This research is princlpaly funded through an NSERC grant to the third author

\section{REFERENCES}

ASTM D4943-02, 2003, Standard test method for Shrinkage Factors of Solls by the Wax Method, ASTM, West Conshohocken, Pennsylvania, USA

Couto, $\mathrm{A}_{x}$, Grabinsky, M.W. Simms, P.H. 2006 . Shrinkage characteristics of sufface deposited paste tailings. 2006 Canadian Geotechnical Conference, Vancouver, B.C., Oct. 18t-4th 2006 (Electronic proceedings).

Fredlund, D. and Rahardjo, L. 1993. Soil Mechanics for Unsaturated Soirs. Wiley, New York, 1993.

Simms $P_{x,}$ Grabinsky MW., and Zhan, G. 2007. Modeling evaporation of surface paste tailings from the Bulyanhulu mine. Canadlan Geotechnical Journal (In Press).

Simms, P.H $H_{x,}$ Grabinsky, M.W ${ }_{x,}$ and Zhan, G. 2006. Field and laboratory investigation of evaporation from Bulyanhulu tallings. Proceedings of the $7^{b}$ International Conference on Paste and Thickened tailings, Limerick, Ireland, April 4-6 2006 , Editors A. Fourie, A. Jewel, S.Lawson, p. 61-68.
Theriault, J. Frostiak, J. Welch D. 2003. Surface disposal of paste tailings at the Bulyanhulu gold mine, Tanzania. Proceedings of Sudbury 2003, Mining and the Environment, Sudbury, Ontario, Canada, May $26^{\text {th }}-28^{\text {th }}$ 2003. Editors G. Spiers, P. Beckett, H. Conroy, p. 265-269 
Appendix B: Methods to predict unsaturated properties of soils from grain size: applicability to silts 


\title{
METHODS TO PREDICT UNSATURATED PROPERTIES OF SOILS FROM GRAIN SIZE: APPLICABILITY TO SILTS
}

\author{
Bereket Fisseha and Paul Simms \\ Department of Civit and Environmental Engineering - Carleton University, Ottawa, \\ Ontario, Canada
}

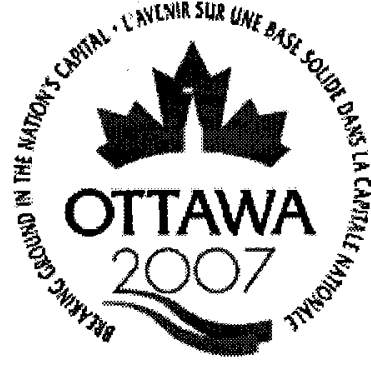

THE DIAMONO JURILEE LE JUDUL DE DIAMANTS

\section{ABSTRACT}

Several methods exist to predict the Sol Water Characteristic Curve (SWCC) from the grain size distribution. However, while these methods are accurate for coarse-grained solls, they are generally less accurate for fine-grained soils. To examine the applicability of these methods for silt-size solls, this research examines measured soil-water characteristic curves (SWCC) of artificial silt sized glass beads of 7 micron and $25-50$ microns using the volumetric pressure plate extractor. The SWCC values of both artificial silts were compared to predictions of the methods proposed by Fredlund et al. (2002) and Aubertin et al. (2003). Both these methods could reasonably fit the predicted data when one free parameter in each case was adjusted, namely the packing factor and a parameter controlling the amount of adsorbed water.

\section{RÉSUME}

Pusieurs méthodes existent pour prévoir la courbe caractéristique de l'eau de sol (SWCC) de la distribution de grandeurs de graín. Cependant, alors que ces méthodes sont précises pour les sols grenus, elles fonctionnent généralement moins bien pour les sols fins. Pour examiner l'applicabilité de ces méthodes pour des sols de vase-taille, cette recherche examine les courbes caractéristiques mesurées de l'sol-eau (SWCC) des perles de verre classées par vase artificielle de 7 microns el de $25-50$ microns a l'aide de l'extracteur volumétrique de plat de pression. Les valeurs de SWCC des deux vases artiticielles ont été comparées aux prévisions des méthodes proposées par Fredlund et autres (2002) et Aubertin et autres (2003). Ces deux méthodes pourraient raisonnablement adapter" les données prévues quand un paramètre libre dans chaque cas a été ajusté, à savoir le facteur d'emballage et un paramètre commandant la quantité de l'eau adsorbée.

\section{INTAODUCTION}

A challenge to the application of unsaturated soil mechanics to conventional geotechnical practice is the extensive work, time and cost needed to measure some unsaturated properties, such as the soil-water characteristic curve (SWCC). This has prompted researchers to develop methods to estimate the SWCC from readily obtainable soil properties such as grain size and the Atterberg Limits. These types of method has been proposed by various investigators, notably such Arya and Paris (1981) and Nimmo (1997), Fredlund at al. (2002), Aubertin ef al. (2003), and Simms and Yantul (2005). Among the recent models, Fredlund at al. (2002) developed a model on how to predict the soll-water characteristic curve of a particular soil from the grain size distribution by relating the pore-size distributions to the particle size. Aubertin of al (2003) also developed a relationship to predict the soil-water characteristics curve of a given soil using their basic soll properties, including grain size and Atterberg limits. Simms and Yanful (2005) developed a method to predict the SWCC, and unsaturated hydraulic conductivity of a clay soll from direct measurements of its pore-size distribution using mercury intrusion porosimetry. Catana et al. (2006) developed a simplified method to predict the full SWCC of clays trom a small set of SWCC measurements.

This paper investigates the applicability of two such methods to estimate the SWCC of slits prepared as a slurry. The paper provides comparisons between measured of soil-water characteristics curve and shrinkage curves of two artificial silts of different grain size using a pressure plate extractor, with values predicted using the grain size distribution and other basic geotechnical properties according to the methods of Fredlund et al (2002) and Aubertin et al. (2003).

\subsection{MATERIALS AND METHODS}

\section{1 Materials}

The following table gives basic geotechnical properties of the artificial silts. The wo silts are labelled "25-50 micron" and "7 micron" by the manufacturer. Even though the grain size does not conform to these limits, the designation has been retained in this paper. The 
laboratory measurements were done according to the ASTM standards of D854 (specific gravily test), D4318 (Atterberg limits), D427 (Shrinkage Limit), and D422-63 (particle size analysis using hydrometer).

Table 1: Properties of the material

\begin{tabular}{|c|c|c|}
\hline Properties & 7 micron & 25-50 micron \\
\hline $\begin{array}{l}\text { Specific } \\
\text { gravily }\end{array}$ & 2.55 & 2.48 \\
\hline $\begin{array}{l}D_{10,} D_{50}, D_{60} \\
(\mathrm{~mm})\end{array}$ & $0.001,0.006,0.007$ & $\begin{array}{l}0.001,0.037 \\
0.041\end{array}$ \\
\hline $\mathrm{Cu}\left(\mathrm{D}_{60} \mathrm{D}_{10}\right)$ & 7 & 41 \\
\hline $\bar{w}_{1}, w_{0}(\%)$ & 26,25 & 19,13 \\
\hline $\mathrm{K}_{\sin }(\mathrm{m} / \mathrm{sec})$ & $5.5 \times 10^{-8}$ & $1.7 \times 10^{-6}$ \\
\hline
\end{tabular}

The grain size data is presented in Figures 1 and 2 below.

2.2 Measurement of the Soil-Water Characteristic Curve, Shrinkage curve, and unsaturated hydraulc conductivity

Direct measurement of the SWCC was done using a volumetric pressure extractor plate with 5 bar capacity for both sizes of artificial silt ranges 25.50 micron and 7 micron). Slurry of the given soll was prepared at $30 \%$ of gravimetric moisture content for the different range of soils and let settle for a little while before any pressure appled to the extractor. Volume change was measured after each pressure increment by removing the cap of the extractor, and measuring the deformation of the surface of the soll at several points using a non-contact displacement sensor. The volume change data was used to calculate the degree of saturation and the vold ratio of the material.

\subsection{Prediction of the SWCC}

1. Aubertin at al (2003) presented the MK (moditied Kovac's) model. The model uses two different formulas, one for plastic soil and the other for coarse-grained solls. Each equation is based on an expression for the capillary rise of water above a water table. As seen in Table 2, a different empirical formula is employed depending on whether which the soils are coarse grained with low plasticity or are soils with high plasticity. Comparison of Aubertin's method with the measured SWCC was done using both formulae, as the 7 micron soil quallites is classitied as 'high plasticity' and the 25-50 micron soil 'low plasticity' for the purpose of the MK model.

The MK model uses $\mathrm{D}_{10}, \mathrm{Cu}$ (Coefficient of uniformity) and vold ratio to predict the SWCC of low plasticity solis, while $W$ (liquid IImit) and void ratio for high plasticity soils. Using the proposed formula the capillary rise, residual suction, and degree of saturation was calculated for the wo types of soils. Table 2 has all the formulas used to calculate the capillary rise for both granular and the solls.

Table 2: Expressions employed in the MK model to fit the SWCC

\begin{tabular}{|c|c|}
\hline Formukas & Description \\
\hline$h_{\mathrm{ra} G}=\frac{\sigma_{\mathrm{r}} \cos \beta}{\mu_{w}} \frac{\alpha}{e D_{h}}$ & $\begin{array}{l}\text { Capillasy rise for } \\
\text { granular soils: ow - } \\
\text { surface tension of } \\
\text { water. Bw. Contact } \\
\text { angle of water. } \\
\text { Specific gravity of } \\
\text { water. void ratio, } \\
\text { DiH equivalent particle } \\
\text { diameter. a- Shape } \\
\text { factor }\end{array}$ \\
\hline$D_{t}=[1+1.17 \log (C u)] D_{0}$ & $\begin{array}{l}\text { DH equivalent particle } \\
\text { diameter } \\
\text { Cur coefficient of } \\
\text { uniformity, D10- } 10 \% \\
\text { passing of cumulative } \\
\text { weight of particle } \\
\text { distribution }\end{array}$ \\
\hline $\begin{array}{l}h c o, P=\frac{\xi}{e} W_{L}^{1.45} \\
\text { Where: } \\
\xi \approx 0.15 \rho\end{array}$ & 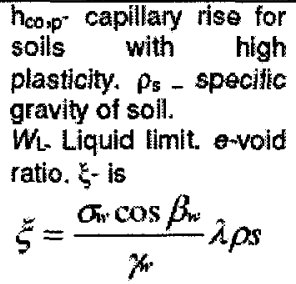 \\
\hline
\end{tabular}

The parameters heo and $\xi$ are then used in equations that give the volumetric water content held due to capillarity and due to adsorption at a given suction. These equations for the capillary water and the adsorbed water have fitting parameters $m$ and $a_{c}$ respectively. Aubertin et al. (2003) reported that empirical investigations have shown that for coarse grained sols the values of $m$ and $a_{c}$ are given by $1 / \mathrm{Cu}$ and 0.01 , and for plastic solis $3 \times 10^{-3}$ and $7 \times 10^{-4}$. As an example, the equation for capllary water is given: 


$$
S_{c}=1-\left[\left(h_{v o} / \psi\right)^{2}+1\right]^{m} \exp \left[-m\left(h_{v o} / \psi\right)^{2}\right][1]
$$

A similar equalion is employed the adsorbed water using the fitting parameter $a_{a}$.

2. Fredlund et al (2002) used a physico-mpirical model method that was introduced by Arya and Parls (1981) to estimate the SWCC of a soil from its grain size distribution. The grain size distribution is divided into a number of smaller divisions of particle size. The volume of the pores associated with each division of particle size is assumed to be proportional to the volume of solids in that division, and the constant proportionality is the packing factor, denoted $P F$ in this paper. The volume of solids is calcukated from the mass of solids associated with each particle size diviston, which in turn can be calculated readily from the grain size distribution curve.

In Fredlund at al. (2002), the volume of pores associated which each division in the grain size curve is then used to generate its own SWCC, the pore volume of each particle size division being distributed over a range of suctions. The summation of each of the individual curves gives the SWCC for the soil. In this paper, we have simplified the method by assuming that the volume of pores associated with each grain size represents uniform pores that will drain at the suction given by the capillary theory for that pore radius $r$ :

$$
\psi=2 T_{2} / \rho_{u g} r
$$

where $T_{s}$ is the surface tension and $\rho_{w}$ is the density of water. We have assumed that $r$, which for the drying curve represents the size of an entrance to a pore, can be calculated from the relationship proposed by Nimmo (1997):

$$
r=r_{\text {grain }} e^{1 / 3} \frac{1}{\beta}
$$

where $\beta$ is 2.2, and accounts for the shape of the pore opening. If we use the final void ratios for the solls measured in this paper $(0.55$ for the 25-50 micron and 0.63 for the 7 micron), this gives us proportional constants of 0.36 and 0.39 between $r$ and $r_{g r a i n}$ respectively.

The packing factor determines the range of particles that actually have pore volume associated with them. The space between large particles may be filled with smaller particles, and so there may be no pore volume associated with them. The method handles this by summing up the pore volumes from each particle size division, from smaller to larger particles, until the initial water content is obtained. The rest of the larger particles are assumed to have no porosity associated with them. The larger the packing factor, the smaller the range of pores, and therefore the larger the air-entry value on the predicted swC..

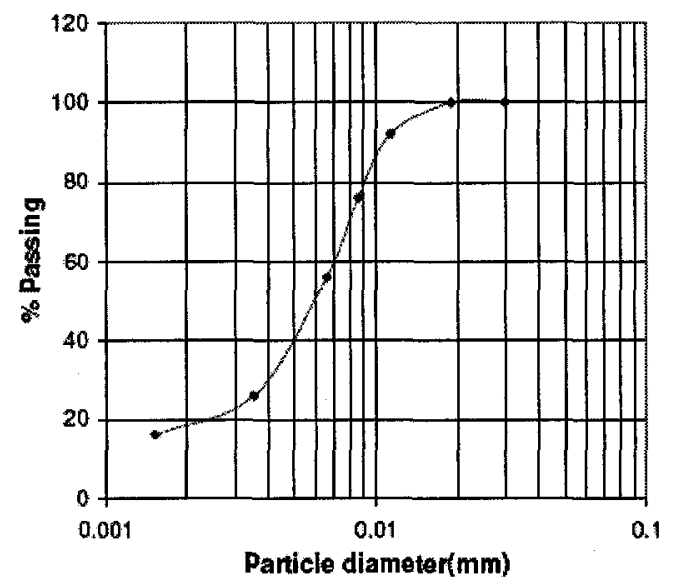

Figure 1 Grain size curve for the 7 micron silt, fitted with theoretical expression for grain size curve proposed by Fredlund et al. (2002).

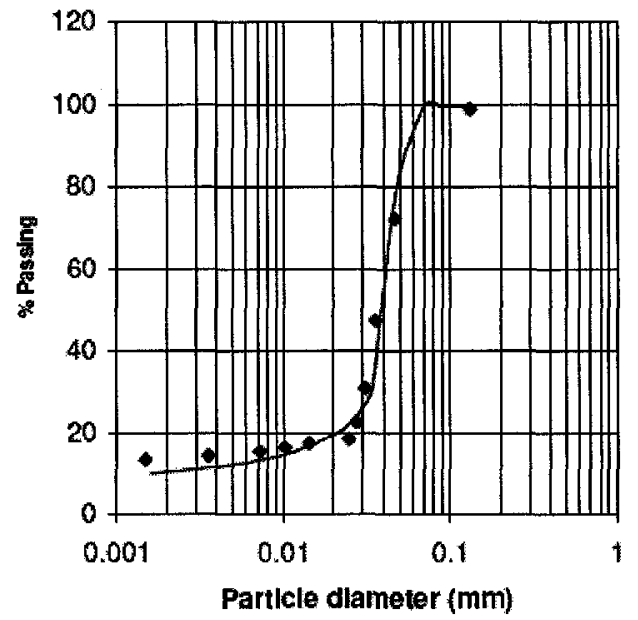

Figure 2 Grain size distribution of $25-50$ micron silt fitted with theoretical expression for grain size proposed by Fredlund et al. (2002) 


\subsection{RESULTS}

\subsection{Experimental results.}

The SWCC of both soils, expressed in terms of gravimetric water content and degree of saturation, are shown in Figures 3 and 4. Both solls start with a degree of saturation significantly below 1, which initially increases as the soll is compressed before the AEV is reached. Most of the volume change occurs before the AEV, and it is evident that most of the volume change is due to compression of the air-flled porosity. The AEV of each soll is approximately 70 and $175 \mathrm{kPa}$.

\subsection{Comparison with the MK model}

Comparisons of the measured SWCC values and predictions of the MK granular model are presented in Figures 5 and 6 . The granular model provided much befter fils to the experimental data than the plastic soils model. It can be seen that the granular model provides reasonable fits to both sols, if the ac parameter is adjusted away from the recommended value of $0.01 \mathrm{As}$ the recommend value is based on a dataset, it is not surprising that adjusting this value provides better fits for individual soils. The slope of the SWCC tor the 7 micron soil is still under predicted, but that may be expected as the sharpness of that soll's grain size distribution may not necessarly be captured by the limited grain size data utilized by the MK model. The model only utilizes the $D_{10}$ and the uniformity coefficient.

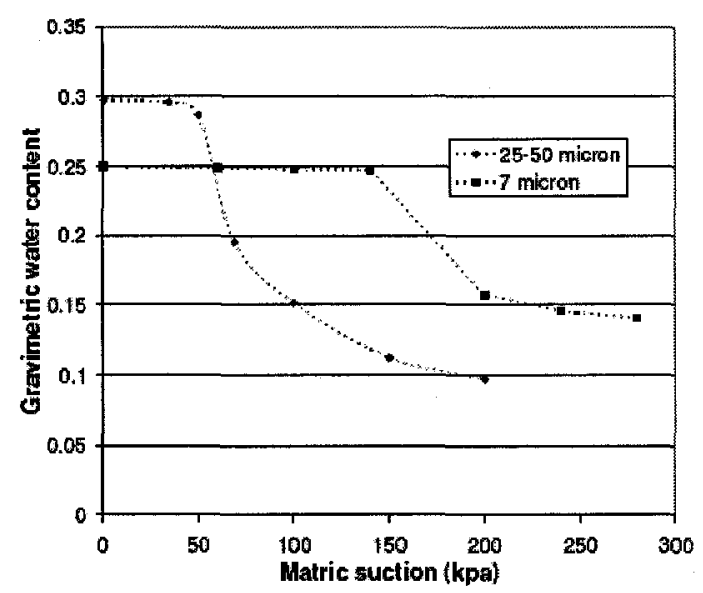

Figure 3. SWCC for 25-50 micron and 7 micron for artificial silt with gravimetric water content

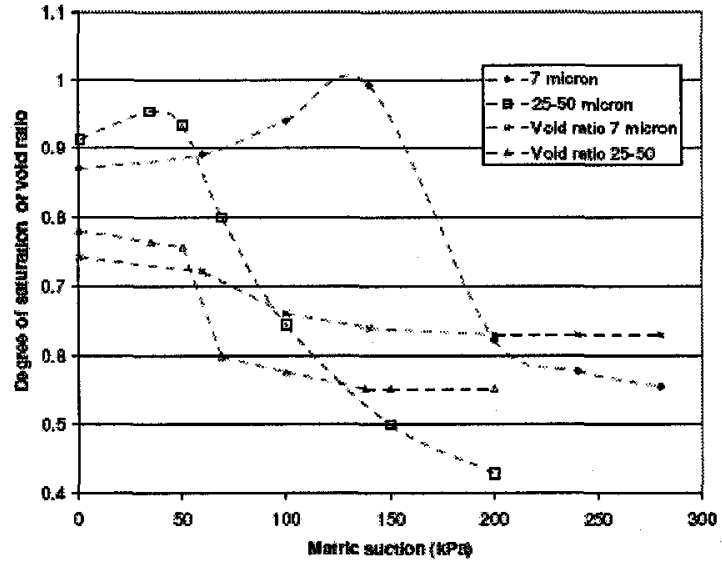

Figure 4 Saturation versus suction and void ratio versus suction curves

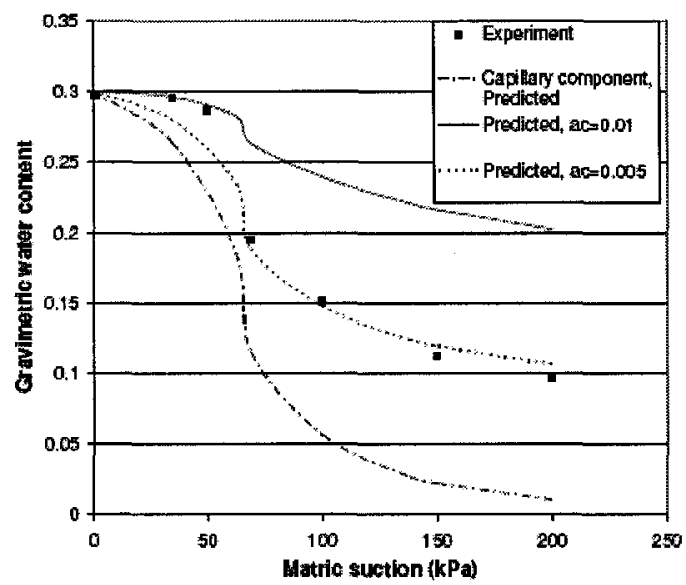

Figure 5. SWCC of $25-50$ micron silt compared with prediction of MK model for granular soils. Note $a_{c}=0.01$ is the standard coefficient. 


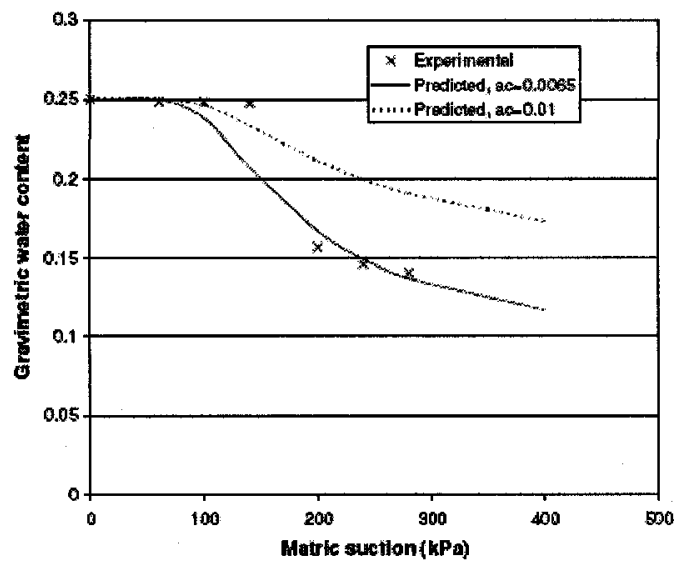

Figure 6 SWCC for 7 micron silt compared with MK model for granular soils

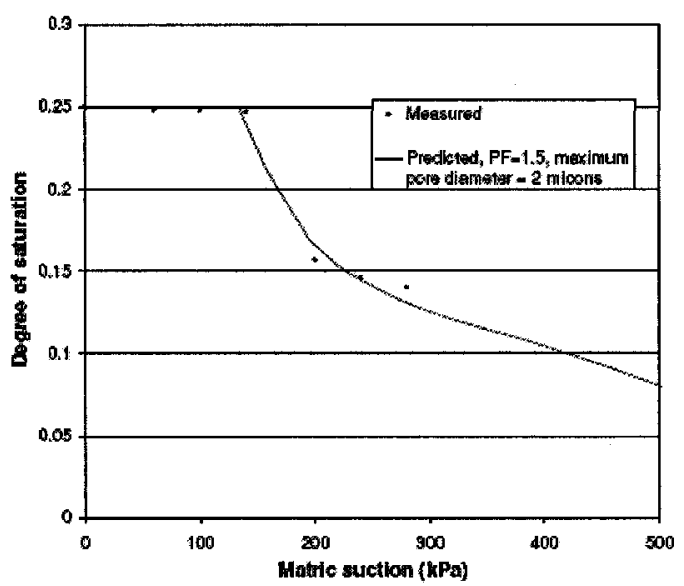

Figure 7 SWCC of 7 micron silt compared with simplified method of Fredlund et al. (2002)

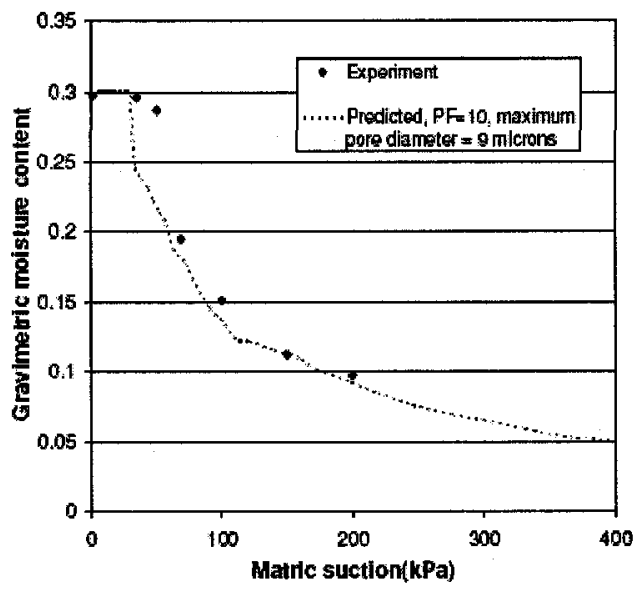

Figure 8 SWCC of 25-50 micron silt compared with prediction of simplifled method of Fredlund et al. (2002)

3.3 Comparison of measured values with predictions of Frodlund et al. (2002)

These comparisons are shown in Figures 7 and 8 . For a suitable PF a good fit can be obtalned. As discussed in the methods section, the physical meaning of the PF is that it sets the range of pore sizes that are assumed to hold water. For the PF values given in the figures, this range is 9 microns and smaler and 2 microns and smaller for the 25-50 micron and 7 micron solls respectively.

\subsection{DISCUSSION}

Though reasonable fits are obtained using the two predictive methods, the accuracy of the prediction depends, in each case, on modification of a parameter that can not be computed from any other property of the

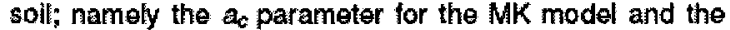
packing factor for the Fredlund et al. (2002) model.

The authors briefly looked at whether simple percolation theory could be used to predict the range of pore sizes that could hold water, in other words whether it could used to determine the packing factor. The authors employed the assumption of Childs and Collis-George (1950), that the geometry of the soil can be described by two adjacent cross-sections of pores. This transformation is a fundamental theoretical assumption of many methods commonly employed to predict the unsaturated hyctraulic conductivity function from the SWCC, for example, the van Genutchen-Mualem method (van Genutchen 1980).

The pore distibution calculated using the Fredlund et al. (2002) mothod was used as a probability function to assign pores in an array of 2 adjacent columns, each 1000 numbers long. Each column represents the distribution of pores in a cross-section, and each row 
represents pores connected across both cross-sections. The assumption of Childs and Collis-George (1950) was that the smaller of the two pores would control the flow. thus transforming the pore-size distribution. Applying this effective pore-size distribution to generate the SWCO gave a good match to the 7 micron (Figure 9). The AEV is relatively well-matched for the $25-50$ micron silt but not the slope of the SWCC (Figure 10).

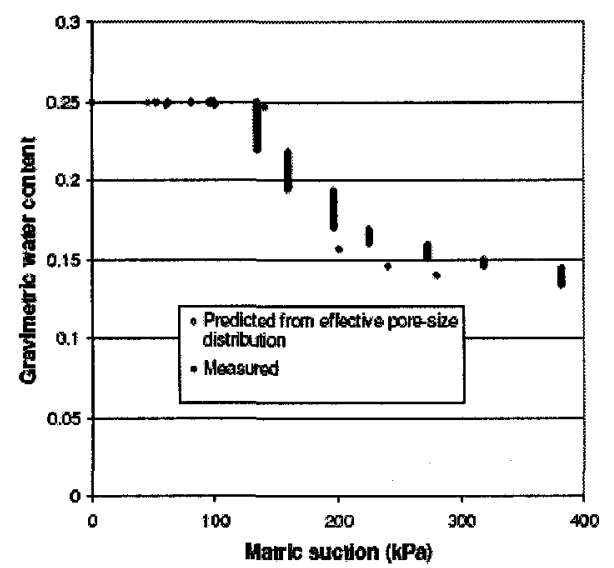

Figure 9 Predictions for 7 micron silt by applying transformation of Chllds and Collss-George (1950) to pore-size distribution from Fredlund et al. (2002)

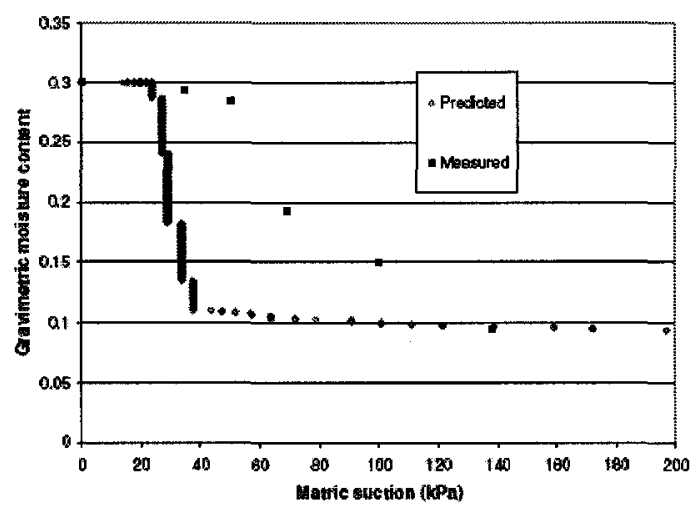

Figure 10 Predictions for 25-50 micron silt by applying transformation of Childs and Colls-George (1950) to pore-size distribution from Fredund et al. (2002)

\subsection{SUMMARY AND CONCLUSIONS}

The measured SWCC of two measured silts were compared to two predictive methods based on grain-size distribution. Whille good matches could be obtained, these were only obtained by varying certain free parameters. These free parameters, namely the packing factor in the Fredlund of al. (2002) model, and a parameter controlling the magnitude of adsorbed water in the MK model, are not at present deducible from basic soil properties. The authors briefly investigated the potential of using percolation theory to interrogate the packing factor parameter for the Fredlund of al. (2002) model.

\section{ACKNOWLEDGEMENTS}

This work is funded by an NSERC grant to the second author.

\section{REFERENCES}

Arya, L.M and Paris, J.F. 1981. Physico-empirical model to predict the soll-moisture characteristic curve from particle-size distribution and bulk density data. Soll Science Society of American Journal, 45: 1023-1030

Aubertin, M., Mbonimpa, M., Bussiere, B. and Chapuis, R.P. 2003. A Model to predict water retention curve from basic geotechnical properties. Canadian Geotechnical Journal, 41: 1104-1122

Catana, C., Vanapall, S.K. and Garga, V.K. 2006. The water retention characteristics of compacted clays. Proceedings of the Fourth International Conference on Unsaturated Soils, Carefree, Arizona, American Society of Civil Engineers Geotechnical Special Publication No. 147, Vol. 2, pp. 1348-1359.

Childs, E.C., and Collis-George, G.N., 1950. The permeability of porous materials. Proceedings of the Royal Sociely of London, 201:392-405.

Fredlund, Murray D., Wilson, G. Ward, and Frediund, Delwyn G. 2002. Use of the grain-size distribution for estimation of soll-water characteristic curve. Canadian Geotechnical Journal, 39:1103-1117

Simms, P.H and Yanful, E. 2005. A pore-network model for hydro-mechanical coupling in unsaturated clayey solls, Canadian Geotechnical Journal, 42:499-514

Nimmo, J.A.1997. Modeling structural influences on soil water retention. Soll Science Society of America Journal, $61: 712-719$.

van Genutchen, M.T. 1980. A closed form solution for predicting the hydraulic conductivity of unsaturated solls. Soll Science Society of America Joumal, 44: 892-898. 


\section{Appendix C: chemical composition of tailings: - Solid Phase}

\begin{tabular}{|c|c|c|c|c|}
\hline \multicolumn{5}{|l|}{ Client: Carleton University } \\
\hline \multicolumn{5}{|l|}{1125 Colonel By Drive } \\
\hline \multicolumn{5}{|l|}{ Ottawa, Ont } \\
\hline \multicolumn{5}{|l|}{ K1S 5B6 } \\
\hline \multicolumn{5}{|l|}{ Attention: Paul Simms } \\
\hline & & LAB ID: & 511941 & \\
\hline & & $\begin{array}{r}\text { Sample } \\
\text { Date: }\end{array}$ & $\begin{array}{c}2006-12- \\
12\end{array}$ & \\
\hline & & $\begin{array}{r}\text { Sample } \\
\text { ID: }\end{array}$ & $\begin{array}{c}\text { Mine } \\
\text { Tailings }\end{array}$ & \\
\hline & & & solid & \\
\hline PARAMETER & UNITS & MDL & & \\
\hline Cyanide (total) & $\mathrm{ug} / \mathrm{g}$ & 0.10 & $<0.10$ & \\
\hline Calcium & $\mathrm{ug} / \mathrm{g}$ & 100 & 17700 & \\
\hline Magnesium & $\mathrm{ug} / \mathrm{g}$ & 100 & 5070 & \\
\hline Potassium & $\mathrm{ug} / \mathrm{g}$ & 100 & 1670 & \\
\hline Sodium & $\mathrm{ug} / \mathrm{g}$ & 100 & 992 & \\
\hline Aluminum & $\mathrm{ug} / \mathrm{g}$ & 1 & 5730 & \\
\hline Antimony & $\mathrm{ug} / \mathrm{g}$ & 1 & 2 & \\
\hline Arsenic & $\mathrm{ug} / \mathrm{g}$ & 1.0 & 240 & \\
\hline Barium & $\mathrm{ug} / \mathrm{g}$ & 1 & 22 & \\
\hline Beryllium & $\mathrm{ug} / \mathrm{g}$ & 1 & $<1$ & \\
\hline Cadmium & $\mathrm{ug} / \mathrm{g}$ & 0.5 & $<0.5$ & \\
\hline Chromium & $\mathrm{ug} / \mathrm{g}$ & 1 & 17 & \\
\hline Cobalt & $\mathrm{ug} / \mathrm{g}$ & 1 & 72 & \\
\hline Copper & $\mathrm{ug} / \mathrm{g}$ & 1 & 317 & \\
\hline Iron & $\mathrm{ug} / \mathrm{g}$ & 1 & 78400 & \\
\hline Lead & $\mathrm{ug} / \mathrm{g}$ & 1 & 116 & \\
\hline Manganese & $\mathrm{ug} / \mathrm{g}$ & 1 & 595 & \\
\hline Mercury & $\mathrm{ug} / \mathrm{g}$ & 0.1 & $<0.1$ & \\
\hline Molybdenum & $\mathrm{ug} / \mathrm{g}$ & 1 & 2 & \\
\hline Nickel & $\mathrm{ug} / \mathrm{g}$ & 1 & 44 & \\
\hline Selenium & $\mathrm{ug} / \mathrm{g}$ & 1 & 3 & \\
\hline Silver & $\mathrm{ug} / \mathrm{g}$ & 0.42 & 2.74 & \\
\hline Strontium & $\mathrm{ug} / \mathrm{g}$ & 1 & 42 & \\
\hline Thallium & $\mathrm{ug} / \mathrm{g}$ & 1 & $<1$ & \\
\hline Vanadium & $\mathrm{ug} / \mathrm{g}$ & 1 & 14 & \\
\hline
\end{tabular}




1

1

\section{Appendix D: Chemical composition of mine tailings: - Liquid}

\section{Phase}

\begin{tabular}{|c|c|c|c|c|c|}
\hline Client: Carleton Univer & & & & & \\
\hline 1125 Colonel By & & & & & \\
\hline Ottawa, Ont & & & & & \\
\hline K1S 5B6 & & & & & \\
\hline Attention: Paul Simms & & & & & \\
\hline $\begin{array}{l}\text { Chain of Custody Numbe } \\
56566\end{array}$ & & & & & \\
\hline & & LAB ID: & 511936 & & \\
\hline & & $\begin{array}{r}\text { Sample } \\
\text { Date: }\end{array}$ & $\begin{array}{c}2006-12- \\
12\end{array}$ & & \\
\hline & & $\begin{array}{l}\text { Sample } \\
\text { ID: }\end{array}$ & $\begin{array}{c}\text { Mine } \\
\text { Tailings }\end{array}$ & & \\
\hline & & & nquid & & \\
\hline PARAMETER & UNITS & MDL & & & \\
\hline Cyanide (total) & $\mathrm{mg} / \mathrm{L}$ & 0.005 & 0.082 & & \\
\hline Calcium & $\mathrm{mg} / \mathrm{L}$ & 1 & 7030 & & \\
\hline Magnesium & $\mathrm{mg} / \mathrm{L}$ & 1 & 2010 & & \\
\hline Potassium & $\mathrm{mg} / \mathrm{L}$ & 1 & 662 & & \\
\hline Sodium & $\mathrm{mg} / \mathrm{L}$ & 2 & 394 & & \\
\hline Aluminum & $\mathrm{mg} / \mathrm{L}$ & 0.1 & 2280 & & \\
\hline Antimony & $\mathrm{mg} / \mathrm{L}$ & 0.01 & 0.97 & & \\
\hline Arsenic & $\mathrm{mg} / \mathrm{L}$ & 0.05 & 95.3 & & \\
\hline Barium & $\mathrm{mg} / \mathrm{L}$ & 0.01 & 8.80 & & \\
\hline Beryllium & $\mathrm{mg} / \mathrm{L}$ & 0.01 & 0.04 & & \\
\hline Cadmium & $\mathrm{mg} / \mathrm{L}$ & 0.01 & 0.02 & & \\
\hline Chromium & $\mathrm{mg} / \mathrm{L}$ & 0.02 & 6.67 & & \\
\hline Cobalt & $\mathrm{mg} / \mathrm{L}$ & 0.005 & 28.6 & & \\
\hline Copper & $\mathrm{mg} / \mathrm{L}$ & 0.01 & 126 & & \\
\hline Iron & $\mathrm{mg} / \mathrm{L}$ & 0.1 & 31100 & & \\
\hline Lead & $\mathrm{mg} / \mathrm{L}$ & 0.01 & 46.2 & & \\
\hline Manganese & $\mathrm{mg} / \mathrm{L}$ & 0.01 & 236 & & \\
\hline Mercury & $\mathrm{mg} / \mathrm{L}$ & 0.05 & $<0.05$ & & \\
\hline Molybdenum & $\mathrm{mg} / \mathrm{L}$ & 0.01 & 0.83 & & \\
\hline Nickel & $\mathrm{mg} / \mathrm{L}$ & 0.01 & 17.4 & & \\
\hline
\end{tabular}




\begin{tabular}{|l|c|c|c|c|c|} 
Selenium & $\mathrm{mg} / \mathrm{L}$ & 0.05 & 1.00 & & \\
\hline Silver & $\mathrm{mg} / \mathrm{L}$ & 0.01 & 1.09 & & \\
\hline Strontium & $\mathrm{mg} / \mathrm{L}$ & 0.05 & 16.4 & & \\
\hline Thallium & $\mathrm{mg} / \mathrm{L}$ & 0.01 & 0.05 & & \\
\hline Vanadium & $\mathrm{mg} / \mathrm{L}$ & 0.05 & 5.56 & & \\
\hline Zinc & $\mathrm{mg} / \mathrm{L}$ & 0.05 & 10.8 & & \\
\hline
\end{tabular}

\section{Appendix E: SoilCover sample pages}

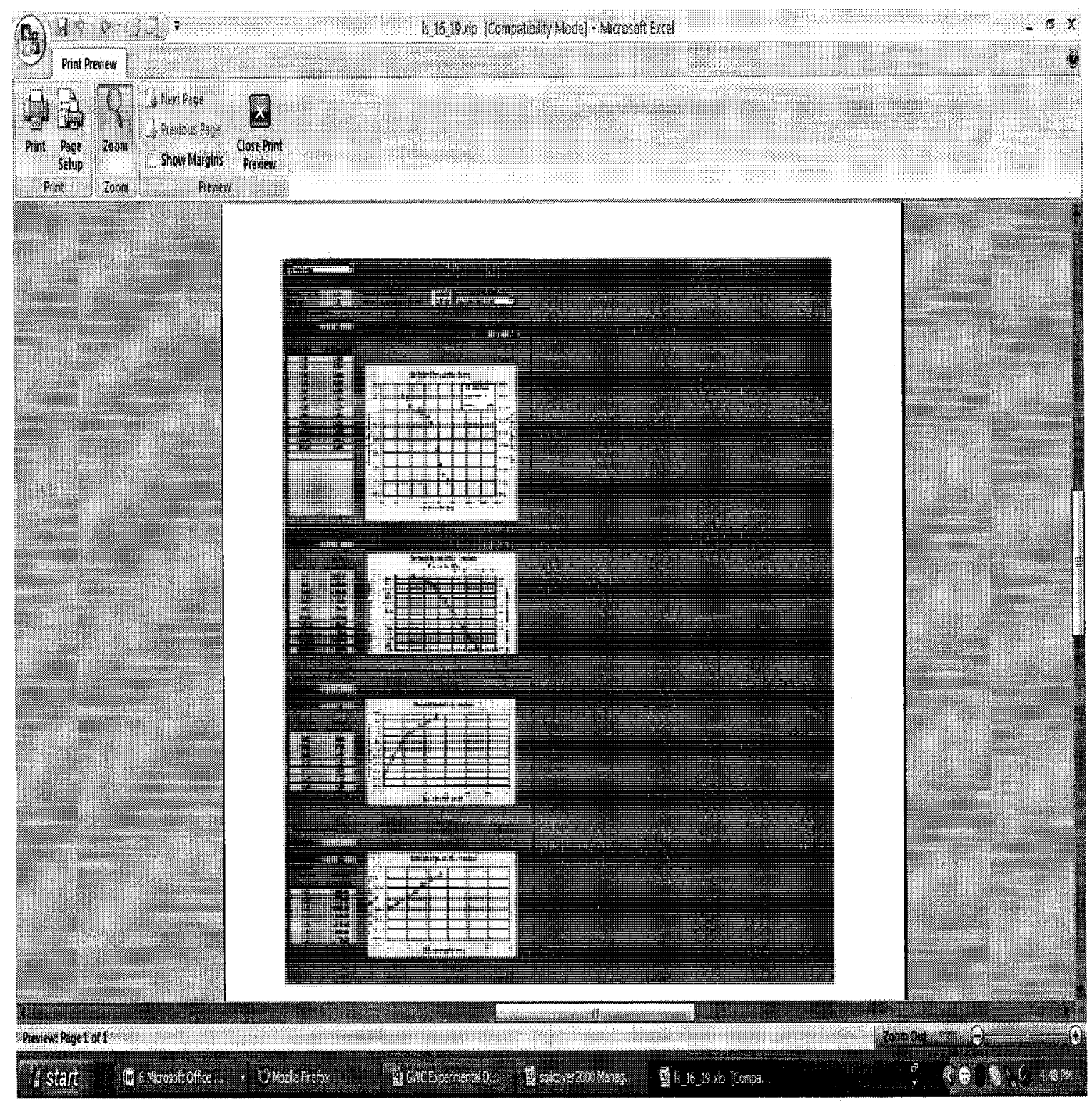

Figure 1: SoilCover Properties interface 


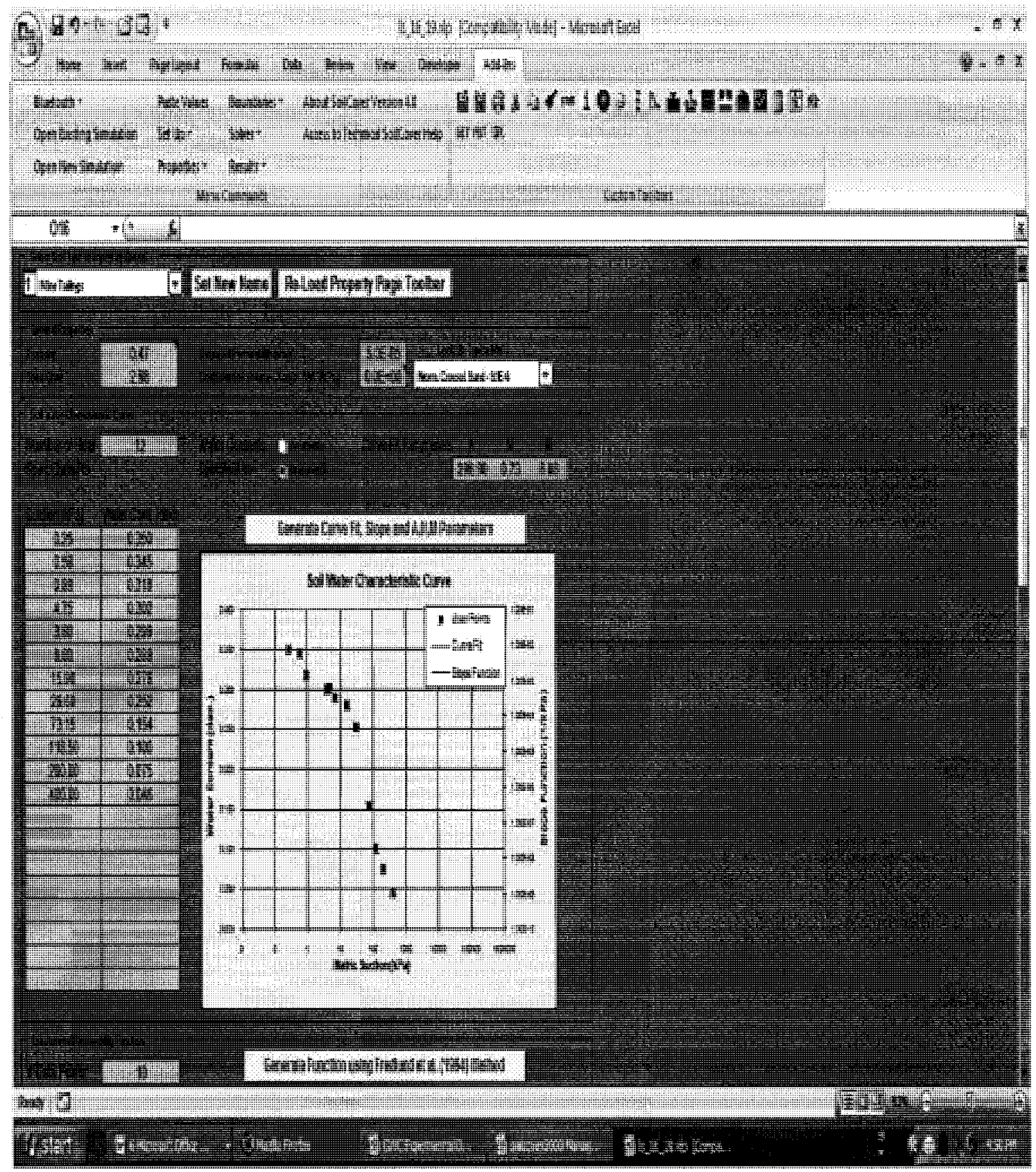

Figure 2: SoilCover Properties interface. User specify SWCC, Porosity, Specific gravity, Saturated Hydraulic conductivity, Coefficient of Volume change, Moisture content. 


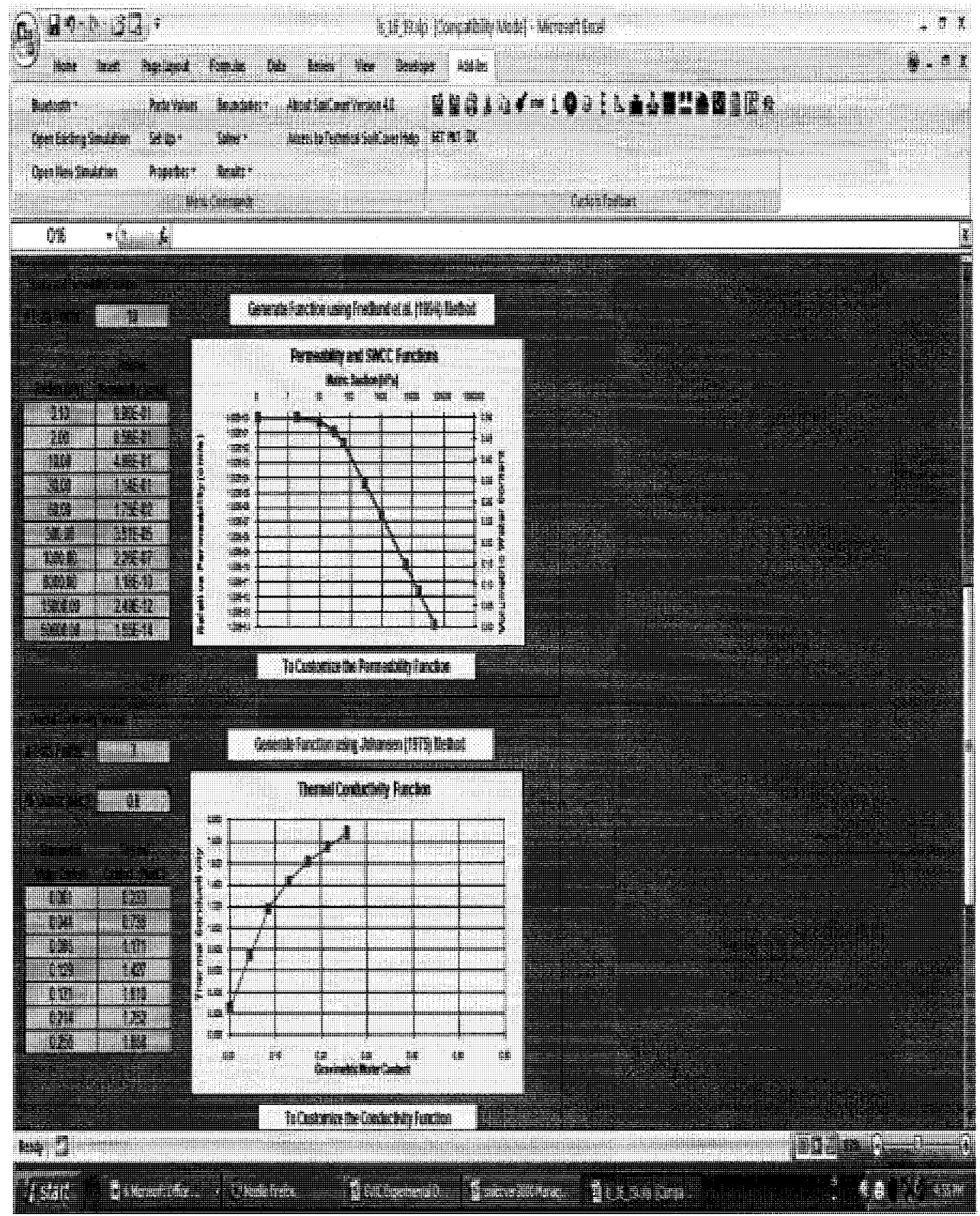

Figure 3: SoilCover Properties interface; unsaturated hydraulic conductivity and thermal conductivity functions. 


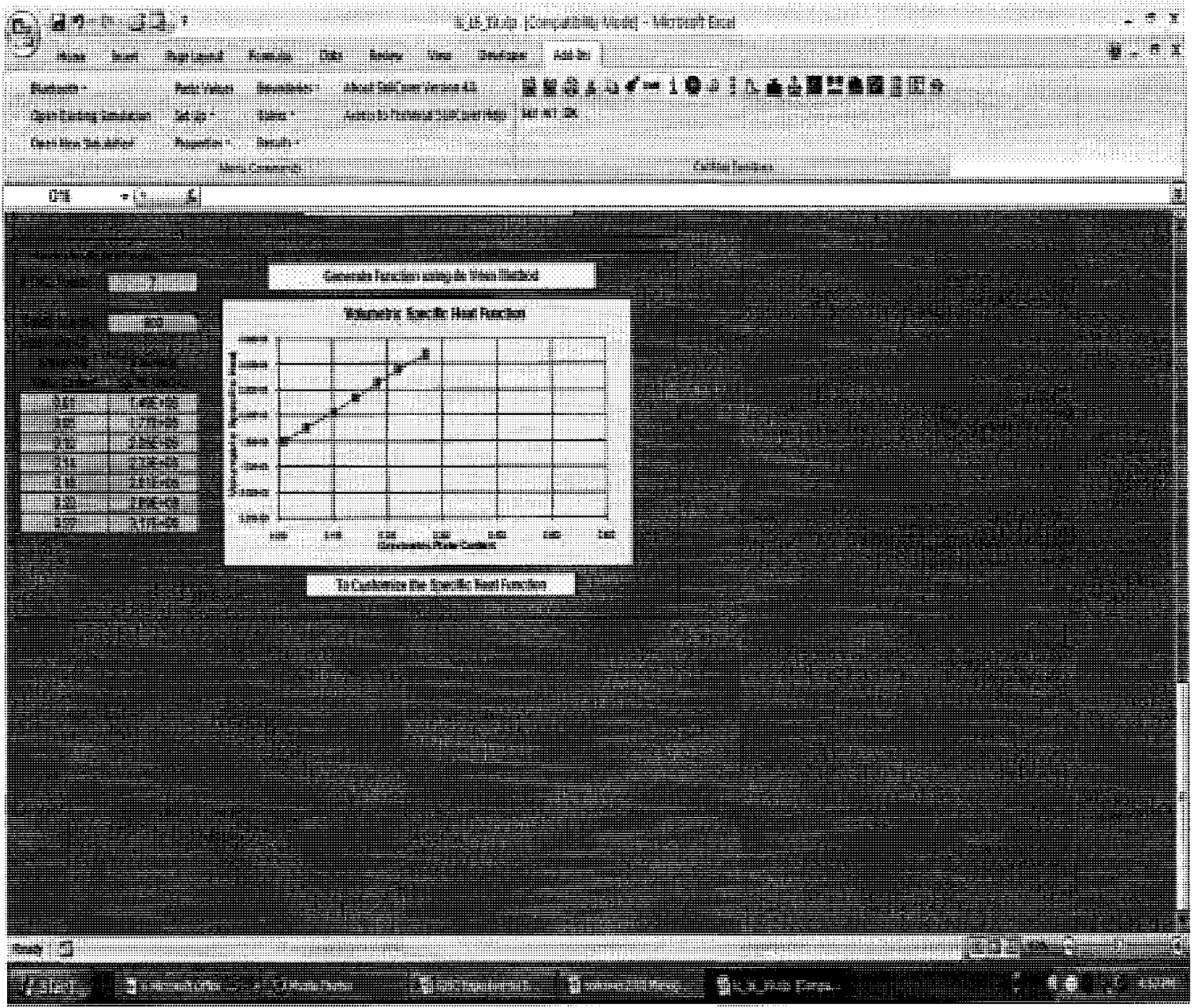

Figure 4: SoilCover properties interface; volumetric specific heat function 


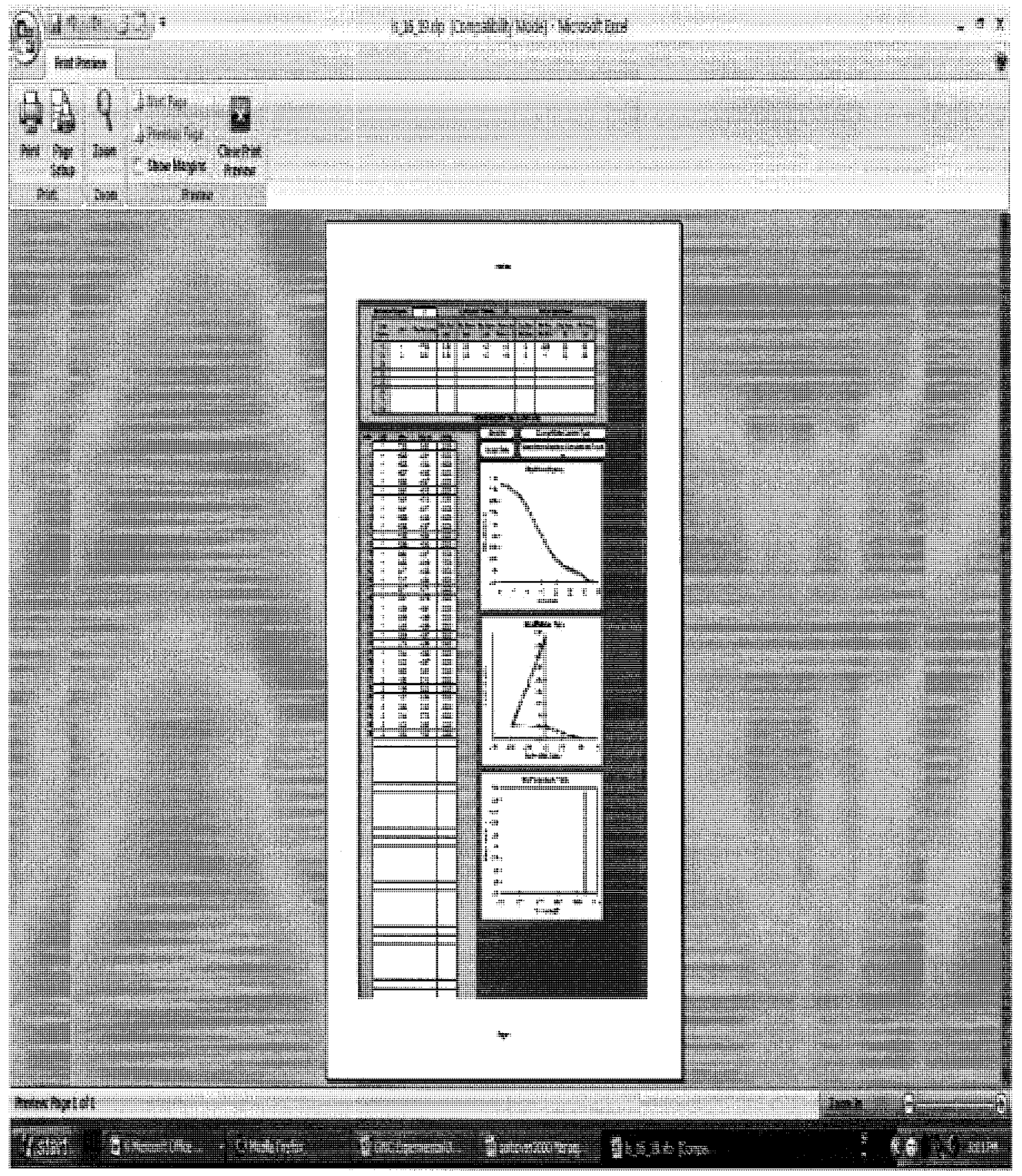

Figure 6: SoilCover, Setup-Mesh interface 


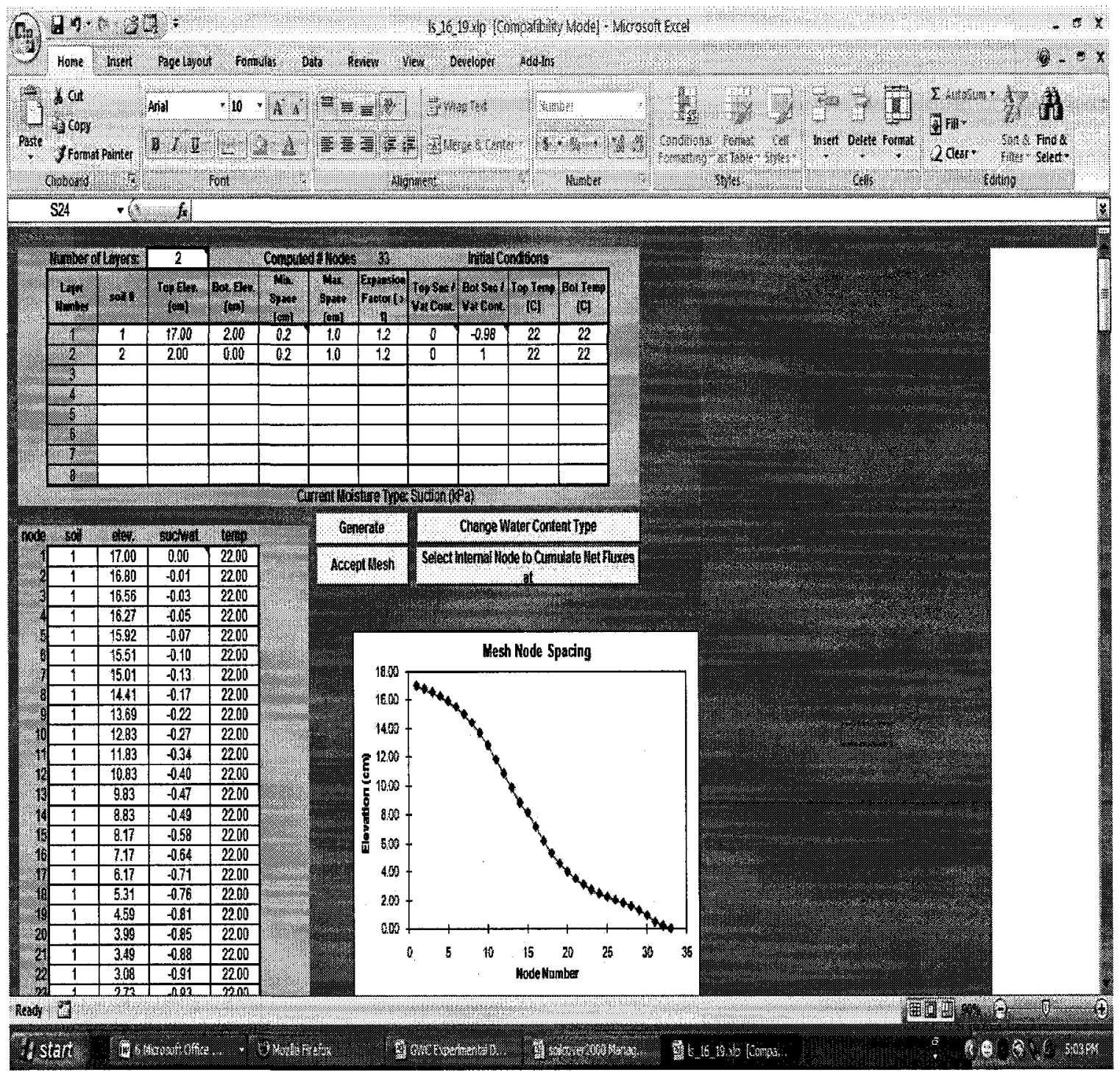

Figure 7: A closer look to SoilCover, Setup-Mesh interface 


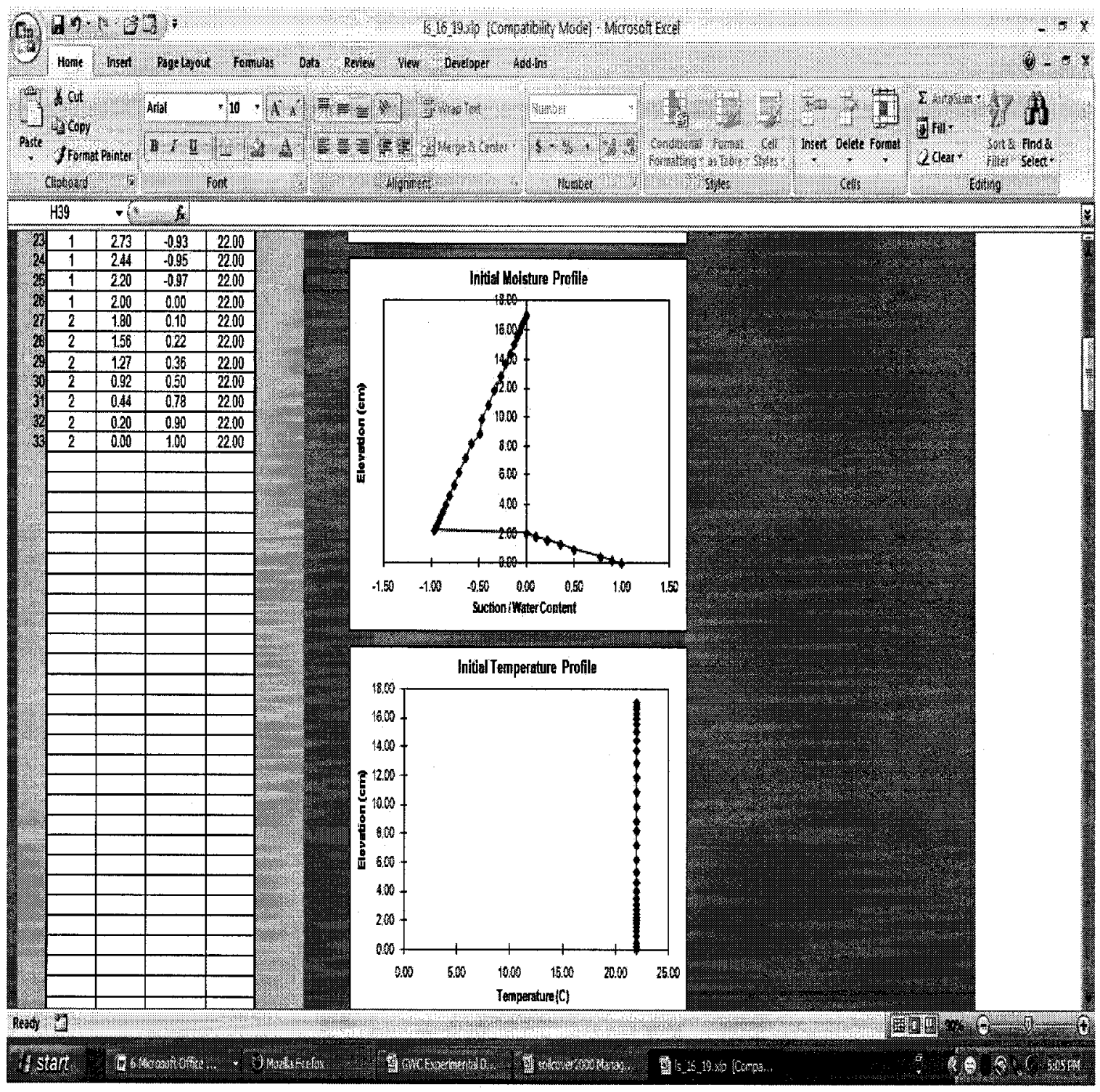

Figure 8: A closer look to SoilCover, Setup -Mesh interface part 2. 


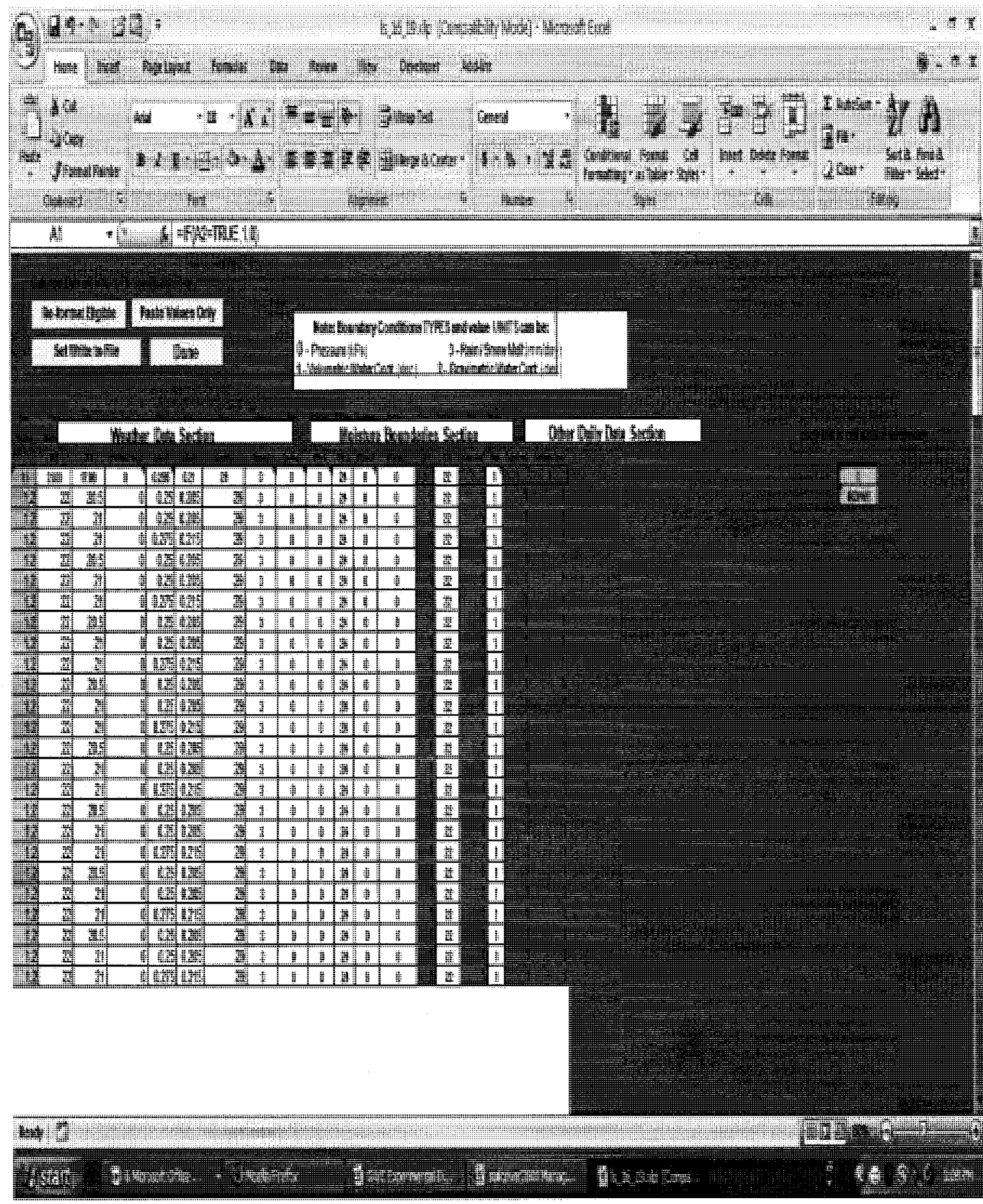

Figure 9: SoilCover, Boundaries interface. daily collected climatic data-relative humidity, temperature, wind speed, rainfall, time of run. 


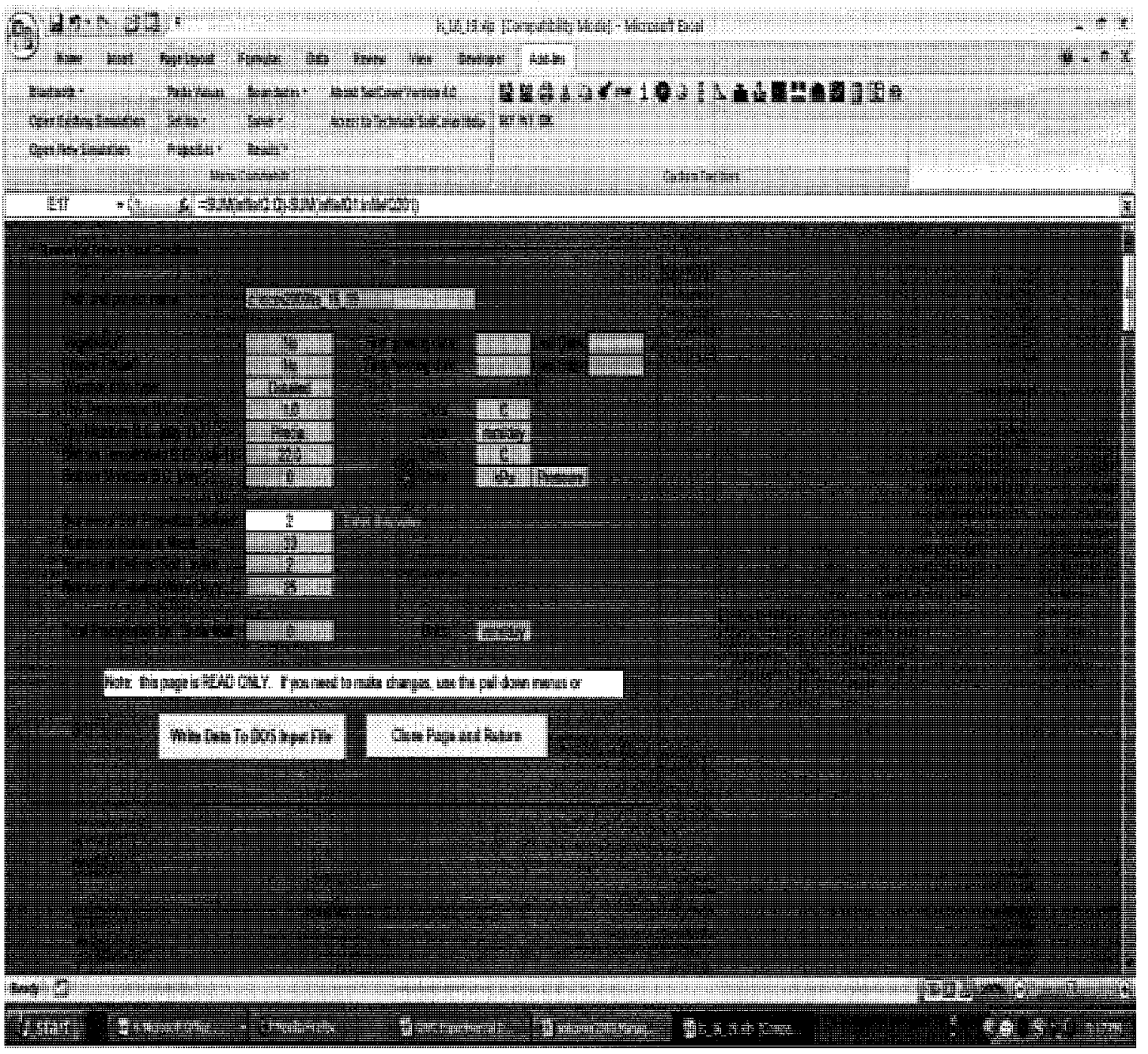

Figure 10: SoilCover, solver interface 


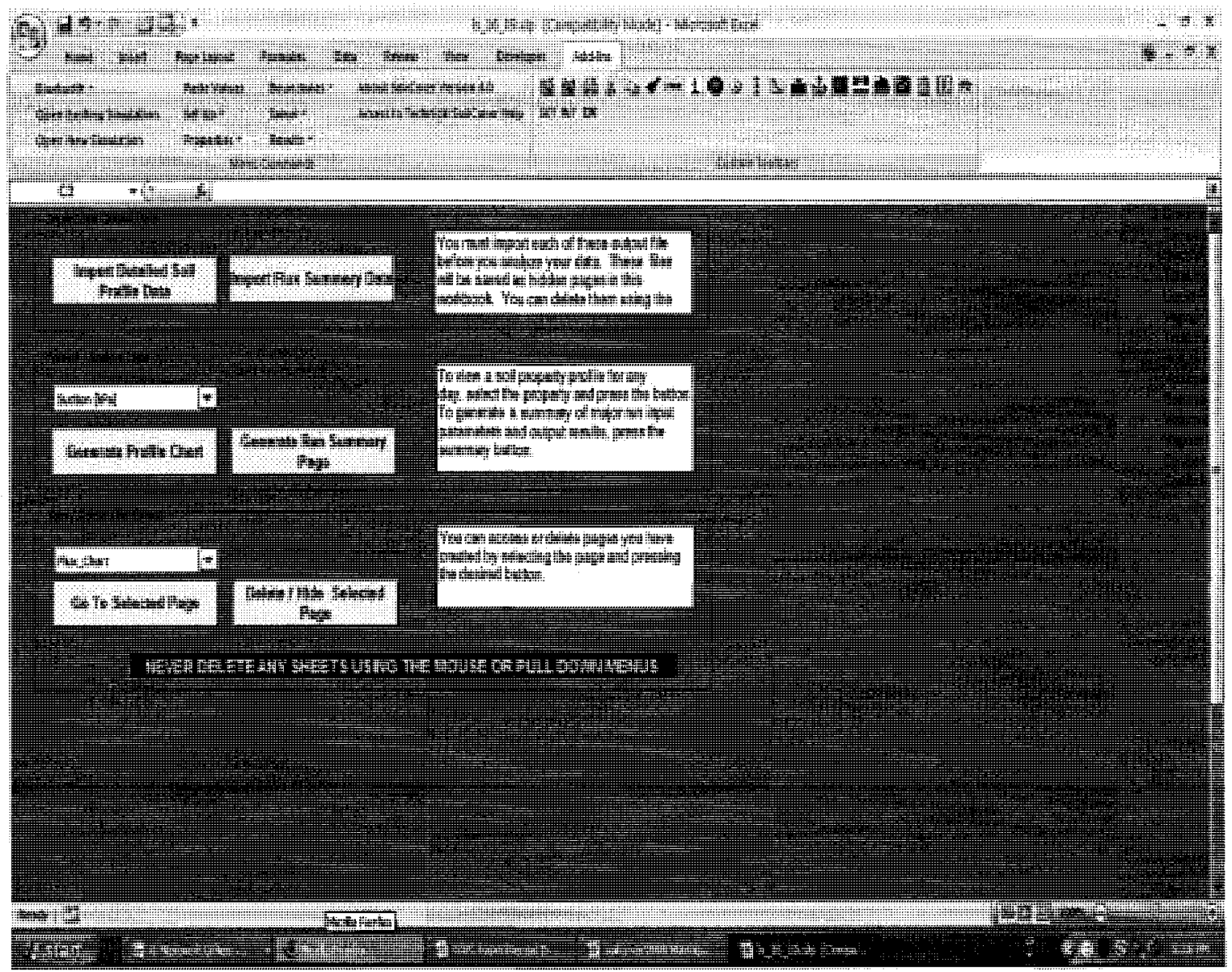

Figure 11: SoilCover: results, output interface 


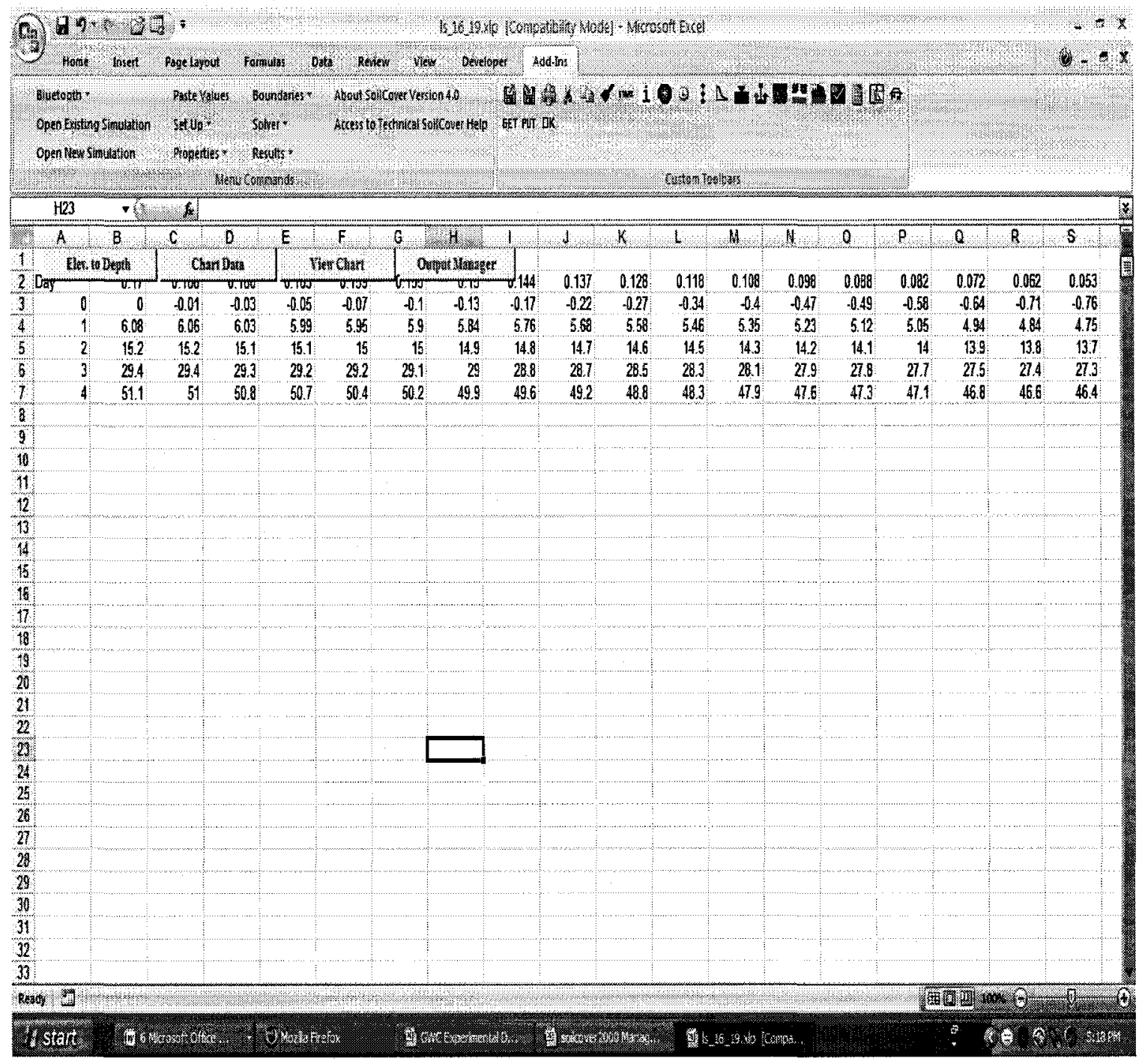

Figure 12: SoilCover, results, output data 


\section{Appendix F: Temperature and Relative Humidity data}

Sample of data collected of temperature and relative humidity for the large scale drying test.

\begin{tabular}{|c|c|c|c|c|c|c|c|}
\hline EasyLog & USB & Time & 30.00 & Time & Celsius $(-C)$ & Humidity(\%rh) & $\begin{array}{l}\text { Dew } \\
\text { point }\end{array}$ \\
\hline & & & minutes & Days & & & \\
\hline 1 & $26 / 01 / 2008$ & $3: 45: 00$ & 0.00 & 0.000000 & 22 & 23 & -0.1 \\
\hline 2 & $26 / 01 / 2008$ & $4: 15: 00$ & 30.00 & 0.020833 & 22 & 23.5 & 0.2 \\
\hline 3 & $26 / 01 / 2008$ & $4: 45: 00$ & 60.00 & 0.041667 & 21.5 & 24.5 & 0.4 \\
\hline 4 & $26 / 01 / 2008$ & $5: 15: 00$ & 90.00 & 0.062500 & 21.5 & 25 & 0.7 \\
\hline 5 & $26 / 01 / 2008$ & $5: 45: 00$ & 120.00 & 0.083333 & 21.5 & 24.5 & 0.4 \\
\hline 6 & $26 / 01 / 2008$ & $6: 15: 00$ & 150.00 & 0.104167 & 21.5 & 24 & 0.1 \\
\hline 7 & $26 / 01 / 2008$ & $6: 45: 00$ & 180.00 & 0.125000 & 21.5 & 24 & 0.1 \\
\hline 8 & $26 / 01 / 2008$ & $7: 15: 00$ & 210.00 & 0.145833 & 21.5 & 24 & 0.1 \\
\hline 9 & $26 / 01 / 2008$ & $7: 45: 00$ & 240.00 & 0.166667 & 21.5 & 24 & 0.1 \\
\hline 10 & $26 / 01 / 2008$ & $8: 15: 00$ & 270.00 & 0.187500 & 21 & 24 & -0.3 \\
\hline 11 & $26 / 01 / 2008$ & $8: 45: 00$ & 300.00 & 0.208333 & 21 & 24 & -0.3 \\
\hline 12 & $26 / 01 / 2008$ & $9: 15: 00$ & 330.00 & 0.229167 & 21 & 24 & -0.3 \\
\hline 13 & $26 / 01 / 2008$ & 9:45:00 & 360.00 & 0.250000 & 21 & 24 & -0.3 \\
\hline 14 & $26 / 01 / 2008$ & $10: 15: 00$ & 390.00 & 0.270833 & 21 & 24 & -0.3 \\
\hline 15 & $26 / 01 / 2008$ & $10: 45: 00$ & 420.00 & 0.291667 & 21.5 & 24 & 0.1 \\
\hline 16 & $26 / 01 / 2008$ & $11: 15: 00$ & 450.00 & 0.312500 & 21.5 & 23.5 & -0.2 \\
\hline 17 & $26 / 01 / 2008$ & $11: 45: 00$ & 480.00 & 0.333333 & 21.5 & 23.5 & -0.2 \\
\hline 18 & $26 / 01 / 2008$ & $12: 15: 00$ & 510.00 & 0.354167 & 21 & 24 & -0.3 \\
\hline 19 & $26 / 01 / 2008$ & $12: 45: 00$ & 540.00 & 0.375000 & 21 & 24 & -0.3 \\
\hline 20 & $26 / 01 / 2008$ & $13: 15: 00$ & 570.00 & 0.395833 & 21 & 24 & -0.3 \\
\hline 21 & $26 / 01 / 2008$ & $13: 45: 00$ & 600.00 & 0.416667 & 21 & 24 & -0.3 \\
\hline 22 & $26 / 01 / 2008$ & 14:15:00 & 630.00 & 0.437500 & 21 & 24 & -0.3 \\
\hline 23 & $26 / 01 / 2008$ & $14: 45: 00$ & 660.00 & 0.458333 & 21.5 & 23.5 & -0.2 \\
\hline 24 & $26 / 01 / 2008$ & $15: 15: 00$ & 690.00 & 0.479167 & 21 & 23.5 & -0.6 \\
\hline 25 & $26 / 01 / 2008$ & $15: 45: 00$ & 720.00 & 0.500000 & 21.5 & 23 & -0.5 \\
\hline 26 & $26 / 01 / 2008$ & $16: 15: 00$ & 750.00 & 0.520833 & 21.5 & 23 & -0.5 \\
\hline 27 & $26 / 01 / 2008$ & $16: 45: 00$ & 780.00 & 0.541667 & 21 & 24 & -0.3 \\
\hline 28 & $26 / 01 / 2008$ & $17: 15: 00$ & 810.00 & 0.562500 & 21 & 24 & -0.3 \\
\hline 29 & $26 / 01 / 2008$ & $17: 45: 00$ & 840.00 & 0.583333 & 21 & 24 & -0.3 \\
\hline 30 & $26 / 01 / 2008$ & $18: 15: 00$ & 870.00 & 0.604167 & 21 & 24 & -0.3 \\
\hline 31 & $26 / 01 / 2008$ & 18:45:00 & 900.00 & 0.625000 & 21 & 24 & -0.3 \\
\hline 32 & $26 / 01 / 2008$ & 19:15:00 & 930.00 & 0.645833 & 21 & 24 & -0.3 \\
\hline 33 & $26 / 01 / 2008$ & $19: 45: 00$ & 960.00 & 0.666667 & 21 & 24 & -0.3 \\
\hline 34 & $26 / 01 / 2008$ & $20: 15: 00$ & 990.00 & 0.687500 & 21 & 24 & -0.3 \\
\hline 35 & $26 / 01 / 2008$ & $20: 45: 00$ & 1020.00 & 0.708333 & 21.5 & 24 & 0.1 \\
\hline 36 & $26 / 01 / 2008$ & $21: 15: 00$ & 1050.00 & 0.729167 & 21.5 & 24 & 0.1 \\
\hline
\end{tabular}




\begin{tabular}{|r|r|r|r|r|r|r|r|}
37 & $26 / 01 / 2008$ & $21: 45: 00$ & 1080.00 & 0.750000 & 21 & 24 & -0.3 \\
\hline 38 & $26 / 01 / 2008$ & $22: 15: 00$ & 1110.00 & 0.770833 & 21 & 24 & -0.3 \\
\hline 39 & $26 / 01 / 2008$ & $22: 45: 00$ & 1140.00 & 0.791667 & 21.5 & 24.5 & 0.4 \\
\hline 40 & $26 / 01 / 2008$ & $23: 15: 00$ & 1170.00 & 0.812500 & 21.5 & 24.5 & 0.4 \\
\hline
\end{tabular}

Samples of data collected of temperature and relative humidity for small scale drying test

\begin{tabular}{|c|c|c|c|c|c|c|c|}
\hline EasyLog & USB & Time & 30.00 & time & Celsius $(-C)$ & Humidity(\%rh) & $\begin{array}{l}\text { Dew } \\
\text { point }\end{array}$ \\
\hline & & & time & days & Celsius $(-C)$ & Humidity(\%rh) & \\
\hline 1 & $26 / 08 / 2007$ & $16: 19: 51$ & 0.00 & 0.000000 & 25 & 49.5 & 13.7 \\
\hline 2 & $26 / 08 / 2007$ & $16: 49: 51$ & 30.00 & 0.020833 & 23.5 & 52 & 13.1 \\
\hline 3 & $26 / 08 / 2007$ & $17: 19: 51$ & 60.00 & 0.041667 & 23.5 & 52.5 & 13.2 \\
\hline 4 & $26 / 08 / 2007$ & $17: 49: 51$ & 90.00 & 0.062500 & 23.5 & 52.5 & 13.2 \\
\hline 5 & $26 / 08 / 2007$ & 18:19:51 & 120.00 & 0.083333 & 23.5 & 52.5 & 13.2 \\
\hline 6 & $26 / 08 / 2007$ & $18: 49: 51$ & 150.00 & 0.104167 & 23.5 & 52.5 & 13.2 \\
\hline 7 & $26 / 08 / 2007$ & 19:19:51 & 180.00 & 0.125000 & 23 & 53 & 12.9 \\
\hline 8 & $26 / 08 / 2007$ & $19: 49: 51$ & 210.00 & 0.145833 & 23 & 53 & 12.9 \\
\hline 9 & $26 / 08 / 2007$ & $20: 19: 51$ & 240.00 & 0.166667 & 23.5 & 53 & 13.4 \\
\hline 10 & $26 / 08 / 2007$ & $20: 49: 51$ & 270.00 & 0.187500 & 24 & 53 & 13.8 \\
\hline 11 & $26 / 08 / 2007$ & $21: 19: 51$ & 300.00 & 0.208333 & 24 & 52.5 & 13.7 \\
\hline 12 & $26 / 08 / 2007$ & $21: 49: 51$ & 330.00 & 0.229167 & 24 & 52.5 & 13.7 \\
\hline 13 & $26 / 08 / 2007$ & $22: 19: 51$ & 360.00 & 0.250000 & 24 & 52 & 13.5 \\
\hline 14 & $26 / 08 / 2007$ & $22: 49: 51$ & 390.00 & 0.270833 & 24.5 & 51.5 & 13.9 \\
\hline 15 & $26 / 08 / 2007$ & $23: 19: 51$ & 420.00 & 0.291667 & 24.5 & 51 & 13.7 \\
\hline 16 & $26 / 08 / 2007$ & $23: 49: 51$ & 450.00 & 0.312500 & 24.5 & 51 & 13.7 \\
\hline 17 & $27 / 08 / 2007$ & $0: 19: 51$ & 480.00 & 0.333333 & 24.5 & 50.5 & 13.6 \\
\hline 18 & $27 / 08 / 2007$ & $0: 49: 51$ & 510.00 & 0.354167 & 24.5 & 50.5 & 13.6 \\
\hline 19 & $27 / 08 / 2007$ & $1: 19: 51$ & 540.00 & 0.375000 & 24.5 & 50.5 & 13.6 \\
\hline 20 & $27 / 08 / 2007$ & $1: 49: 51$ & 570.00 & 0.395833 & 24.5 & 50.5 & 13.6 \\
\hline 21 & $27 / 08 / 2007$ & $2: 19: 51$ & 600.00 & 0.416667 & 24.5 & 50.5 & 13.6 \\
\hline 22 & $27 / 08 / 2007$ & $2: 49: 51$ & 630.00 & 0.437500 & 24.5 & 50.5 & 13.6 \\
\hline 23 & $27 / 08 / 2007$ & $3: 19: 51$ & 660.00 & 0.458333 & 24.5 & 50.5 & 13.6 \\
\hline 24 & $27 / 08 / 2007$ & 3:49:51 & 690.00 & 0.479167 & 24.5 & 50.5 & 13.6 \\
\hline 25 & $27 / 08 / 2007$ & $4: 19: 51$ & 720.00 & 0.500000 & 24.5 & 50.5 & 13.6 \\
\hline 26 & $27 / 08 / 2007$ & $4: 49: 51$ & 750.00 & 0.520833 & 24.5 & 50.5 & 13.6 \\
\hline 27 & $27 / 08 / 2007$ & $5: 19: 51$ & 780.00 & 0.541667 & 24.5 & 50.5 & 13.6 \\
\hline 28 & $27 / 08 / 2007$ & $5: 49: 51$ & 810.00 & 0.562500 & 24.5 & 50 & 13.4 \\
\hline 29 & $27 / 08 / 2007$ & $6: 19: 51$ & 840.00 & 0.583333 & 24.5 & 49.5 & 13.2 \\
\hline 30 & $27 / 08 / 2007$ & $6: 49: 51$ & 870.00 & 0.604167 & 24.5 & 49 & 13.1 \\
\hline 31 & $27 / 08 / 2007$ & $7: 19: 51$ & 900.00 & 0.625000 & 23.5 & 49 & 12.2 \\
\hline 32 & $27 / 08 / 2007$ & $7: 49: 51$ & 930.00 & 0.645833 & 23 & 51 & 12.3 \\
\hline 33 & $27 / 08 / 2007$ & $8: 19: 51$ & 960.00 & 0.666667 & 23 & 51.5 & 12.5 \\
\hline
\end{tabular}




\begin{tabular}{|r|r|r|r|r|r|r|r|}
34 & $27 / 08 / 2007$ & $8: 49: 51$ & 990.00 & 0.687500 & 23 & 51 & 12.3 \\
\hline 35 & $27 / 08 / 2007$ & $9: 19: 51$ & 1020.00 & 0.708333 & 23 & 51 & 12.3 \\
\hline 36 & $27 / 08 / 2007$ & $9: 49: 51$ & 1050.00 & 0.729167 & 23 & 50.5 & 12.2 \\
\hline 37 & $27 / 08 / 2007$ & $10: 19: 51$ & 1080.00 & 0.750000 & 23 & 51 & 12.3 \\
\hline 38 & $27 / 08 / 2007$ & $10: 49: 51$ & 1110.00 & 0.770833 & 23 & 51 & 12.3 \\
\hline 39 & $27 / 08 / 2007$ & $11: 19: 51$ & 1140.00 & 0.791667 & 23 & 51.5 & 12.5 \\
\hline
\end{tabular}

Appendix G: Sample of height measurements for large scale

\section{drying test}

\begin{tabular}{|c|c|c|c|c|c|c|c|c|}
\hline \multicolumn{3}{|c|}{ Empty } & \multicolumn{3}{|c|}{ Jan-26 } & \multicolumn{3}{|c|}{ Jan-28 } \\
\hline $\begin{array}{l}\text { Width } \\
(10- \\
140)\end{array}$ & $\begin{array}{l}\text { Length } \\
\text { (A-K) }\end{array}$ & Height & $\begin{array}{l}\text { Width } \\
(10- \\
140)\end{array}$ & $\begin{array}{l}\text { Length } \\
\text { (A-K) }\end{array}$ & Height & $\begin{array}{l}\text { Width } \\
(10- \\
140) \\
\end{array}$ & $\begin{array}{l}\text { Length } \\
\text { (A-K) }\end{array}$ & Height \\
\hline 10 & 1 & 106.2 & 10 & 1 & 96.5 & 15 & 1 & 96.2 \\
\hline 20 & 1 & 106.0 & 25 & 1 & 96.5 & 25 & 1 & 97.8 \\
\hline 40 & 1 & 105.8 & 45 & 1 & 96 & 35 & $\overline{1}$ & 97.8 \\
\hline 50 & 1 & 105.8 & 55 & 1 & 95.2 & 45 & 1 & 97.4 \\
\hline 60 & 1 & 105.6 & 75 & 1 & 96.5 & 55 & 1 & 97.5 \\
\hline 70 & 1 & 105.6 & 85 & 1 & 96.5 & 75 & 1 & 97.5 \\
\hline 85 & 1 & 105.8 & 115 & 1 & 97.3 & 85 & 1 & 97.3 \\
\hline 90 & 1 & 105.8 & 135 & 1 & 97 & 105 & 1 & 98 \\
\hline 105 & 1 & 106.0 & 10 & 45 & 95.5 & 115 & 1 & 98 \\
\hline 115 & 1 & 106.1 & 25 & 45 & 96 & 135 & 1 & 98.5 \\
\hline 135 & 1 & 106.4 & 45 & 45 & 95.5 & 15 & 45 & 97.5 \\
\hline 10 & 15 & 106.2 & 55 & 45 & 95.5 & 25 & 45 & 97.2 \\
\hline 20 & 15 & 106.0 & 75 & 45 & 95.5 & 35 & 45 & 97.2 \\
\hline 40 & 15 & 105.7 & 85 & 45 & 95.5 & 45 & 45 & 96.7 \\
\hline 50 & 15 & 105.8 & 115 & 45 & 96.3 & 55 & 45 & 97.1 \\
\hline 60 & 15 & 105.6 & 135 & 45 & 97 & 75 & 45 & 96.5 \\
\hline 70 & 15 & 105.6 & 10 & 90 & 95.5 & 85 & 45 & 96.5 \\
\hline 85 & 15 & 105.7 & 25 & 90 & 95.5 & 105 & 45 & 97 \\
\hline 90 & 15 & 105.7 & 45 & 90 & 95.5 & 115 & 45 & 97.5 \\
\hline 105 & 15 & 106.0 & 55 & 90 & 95.5 & 135 & 45 & 98 \\
\hline 115 & 15 & 106.0 & 75 & 90 & 95.5 & 15 & 90 & 97.3 \\
\hline 135 & 15 & 106.4 & 85 & 90 & 95.5 & 25 & 90 & 97.4 \\
\hline 10 & 30 & 106.2 & 115 & 90 & 96.5 & 35 & 90 & 97.3 \\
\hline 20 & 30 & 106.1 & 135 & 90 & 97.2 & 45 & 90 & 97.2 \\
\hline 40 & 30 & 105.8 & 10 & 135 & 97.5 & 55 & 90 & 97 \\
\hline 50 & 30 & 105.8 & 25 & 135 & 97.5 & 75 & 90 & 97 \\
\hline 60 & 30 & 105.6 & 45 & 135 & 96.5 & 85 & 90 & 97.1 \\
\hline
\end{tabular}




\begin{tabular}{|c|c|c|c|c|c|c|c|c|}
\hline 70 & 30 & 105.6 & 55 & 135 & 9 & 105 & 90 & 97.3 \\
\hline 85 & 30 & 105.8 & 75 & 135 & 9 & 115 & 90 & 97.8 \\
\hline 90 & 30 & 105.7 & 85 & 135 & 9 & 135 & 90 & 98.4 \\
\hline 105 & 30 & 105.9 & 115 & 135 & 9 & 15 & 135 & 99 \\
\hline 115 & 30 & 106.1 & & & & 25 & 135 & 99 \\
\hline 135 & 30 & 106.4 & & & & 35 & 135 & 98.5 \\
\hline 10 & 45 & 106.3 & & & & 45 & 135 & 98.2 \\
\hline 20 & 45 & 106.1 & & & & 55 & 135 & 97.7 \\
\hline 40 & 45 & 105.8 & & & & 75 & 135 & 97.5 \\
\hline 50 & 45 & 105.8 & & & & 85 & 135 & 97.3 \\
\hline & & & & & & & & \\
\hline \multicolumn{3}{|c|}{ Jan-29 } & \multicolumn{3}{|c|}{ Jan-30 } & \multicolumn{3}{|c|}{ Jan-31 } \\
\hline $\begin{array}{l}\text { Width } \\
\text { (10- } \\
140)\end{array}$ & $\begin{array}{l}\text { Length } \\
\text { (A-K) }\end{array}$ & Height & $\begin{array}{l}\text { Width } \\
(10- \\
140)\end{array}$ & $\begin{array}{l}\text { Length } \\
\text { (A-K) }\end{array}$ & Height & $\begin{array}{l}\text { Width } \\
(10- \\
140)\end{array}$ & $\begin{array}{l}\text { Length } \\
\text { (A-K) }\end{array}$ & Height \\
\hline 10 & 1 & 98.2 & 10 & 1 & 98.2 & 10 & 1 & 98.2 \\
\hline 20 & 1 & 98 & 25 & 1 & 97.9 & 25 & 1 & 97.8 \\
\hline 35 & 1 & 97.9 & 35 & 1 & 98 & 35 & 1 & 97.8 \\
\hline 45 & 1 & 97.9 & 45 & 1 & 97.7 & 45 & 1 & 97.8 \\
\hline 55 & 1 & 97.8 & 55 & 1 & $\begin{array}{l}97.8 \\
\end{array}$ & 55 & 1 & $\begin{array}{l}97.8 \\
\end{array}$ \\
\hline 75 & 1 & 98.2 & 75 & 1 & 97.9 & 75 & 1 & 98.3 \\
\hline 85 & 1 & 98.3 & 85 & 1 & 98.1 & 85 & 1 & 98.3 \\
\hline 105 & 1 & 98.3 & 105 & 1 & 98.3 & 105 & 1 & 98.3 \\
\hline 115 & 1 & 98.4 & 115 & 1 & 98.5 & 115 & 1 & 98.5 \\
\hline 135 & 1 & 99.1 & 135 & 1 & 99.1 & 135 & 1 & 99 \\
\hline 10 & 45 & 97.8 & 10 & 15 & 98.7 & 10 & 15 & 98.7 \\
\hline 20 & 45 & 97.5 & 25 & 15 & 98.3 & 25 & 15 & 98.2 \\
\hline 35 & 45 & 97.3 & 35 & 15 & 98.3 & 35 & 15 & 98.1 \\
\hline 45 & 45 & 97.3 & 45 & 15 & 98.2 & 45 & 15 & 98.2 \\
\hline 55 & 45 & 97.1 & 55 & 15 & 98.1 & 55 & 15 & 98.2 \\
\hline 75 & 45 & 96.8 & 75 & 15 & 97.7 & 75 & 15 & 98 \\
\hline 85 & 45 & 97.2 & 85 & 15 & 98 & 85 & 15 & 97.9 \\
\hline 105 & 45 & 97.6 & 105 & 15 & 97.7 & 105 & 15 & 98 \\
\hline 115 & 45 & 97.7 & 115 & 15 & 98.7 & 115 & 15 & 98.6 \\
\hline 135 & 45 & 98.4 & 135 & 15 & 99.2 & 135 & 15 & 99.4 \\
\hline 10 & 90 & 97.9 & 10 & 30 & 98.3 & 10 & 30 & 98.3 \\
\hline 20 & 90 & 97.5 & 25 & 30 & 97.9 & 25 & 30 & 97.9 \\
\hline 35 & 90 & 97.4 & 35 & 30 & 97.6 & 35 & 30 & 97.8 \\
\hline 45 & 90 & 97.4 & 45 & 30 & 97.5 & 45 & 30 & 97.6 \\
\hline 55 & 90 & 97.4 & 55 & 30 & 97.6 & 55 & 30 & 97.7 \\
\hline 75 & 90 & 97.4 & 75 & 30 & 97.2 & 75 & 30 & 97.3 \\
\hline 85 & 90 & 97.5 & 85 & 30 & 97.3 & 85 & 30 & 97.4 \\
\hline 105 & 90 & 97.9 & 105 & 30 & 97.4 & 105 & 30 & 97.4 \\
\hline 115 & 90 & 98.1 & 115 & 30 & 97.8 & 115 & 30 & 97.9 \\
\hline
\end{tabular}




\begin{tabular}{|r|r|r|r|r|r|r|r|r|}
\hline 135 & 90 & 98.2 & 135 & 30 & 98.5 & 135 & 30 & 98.6 \\
\hline 10 & 135 & 99.5 & 10 & 45 & 97.7 & 10 & 45 & 97.8 \\
\hline 20 & 135 & 99.3 & 25 & 45 & 97.4 & 25 & 45 & 97.6 \\
\hline 35 & 135 & 98.7 & 35 & 45 & 97.5 & 35 & 45 & 97.5 \\
\hline 45 & 135 & 98.8 & 45 & 45 & 97.2 & 45 & 45 & 97.4 \\
\hline 55 & 135 & 98.3 & 55 & 45 & 97.3 & 55 & 45 & 97.2 \\
\hline 75 & 135 & 97.7 & 75 & 45 & 97.1 & 75 & 45 & 97 \\
\hline 85 & 135 & 97.7 & 85 & 45 & 97.2 & 85 & 45 & 97.3 \\
\hline 105 & 135 & 97.9 & 105 & 45 & 97.4 & 105 & 45 & 97.4 \\
\hline 115 & 135 & 98.2 & 115 & 45 & 97.6 & 115 & 45 & 97.7 \\
\hline 135 & 135 & 99.3 & 135 & 45 & 98.4 & 135 & 45 & 98.4 \\
\hline & & & 10 & 60 & 97.5 & 10 & 60 & 97.6 \\
\hline
\end{tabular}

